\title{
Governance and malnutrition: exploring the contribution of "good governance" to malnutrition reduction in developing countries
}

Citation for published version (APA):

Rokx, C. (2006). Governance and malnutrition: exploring the contribution of "good governance" to malnutrition reduction in developing countries. [Doctoral Thesis, Maastricht University]. Febodruk N.V. https://doi.org/10.26481/dis.20060412cr

Document status and date:

Published: 01/01/2006

DOI:

10.26481/dis.20060412cr

Document Version:

Publisher's PDF, also known as Version of record

Please check the document version of this publication:

- A submitted manuscript is the version of the article upon submission and before peer-review. There can be important differences between the submitted version and the official published version of record.

People interested in the research are advised to contact the author for the final version of the publication, or visit the DOI to the publisher's website.

- The final author version and the galley proof are versions of the publication after peer review.

- The final published version features the final layout of the paper including the volume, issue and page numbers.

Link to publication

\footnotetext{
General rights rights.

- You may freely distribute the URL identifying the publication in the public portal. please follow below link for the End User Agreement:

www.umlib.nl/taverne-license

Take down policy

If you believe that this document breaches copyright please contact us at:

repository@maastrichtuniversity.nl

providing details and we will investigate your claim.
}

Copyright and moral rights for the publications made accessible in the public portal are retained by the authors and/or other copyright owners and it is a condition of accessing publications that users recognise and abide by the legal requirements associated with these

- Users may download and print one copy of any publication from the public portal for the purpose of private study or research.

- You may not further distribute the material or use it for any profit-making activity or commercial gain

If the publication is distributed under the terms of Article $25 \mathrm{fa}$ of the Dutch Copyright Act, indicated by the "Taverne" license above, 


\title{
Governance and Malnutrition
}

\author{
Exploring the Contribution of \\ 'Good Governance' to Malnutrition \\ Reduction in Developing Countries
}

Proefschrift

ter verkrijging van

de graad van doctor aan de Universiteit Maastricht, op gezag van de Rector Magnificus, prof.mr. G.P.M.F. Mols,

volgens besluit van het College van Decanen

in het openbaar te verdedigen

op woensdag 12 aprill 2006 om 14.00 uur

door

Claudia J.M.C. Rokx

geboren op 30 april 1964

te Bosschenhoofd 
promotor:

prof. dr. A.F.A. Korsten, Open Universiteit Nederland co-promotor:

prof. dr. J.A. Kusin, Universiteit van Amsterdam

Leden van de beoordelings-commissie:

prof.dr. F.A.M. Stroink, voorzitter,

prof.dr. I Beghin, Institute of Tropical Medicine te Antwerpen, Belgiè

prof.dr. P. Glasbergen, Universiteit Utrecht / Open Universiteit Nederland

prof.dr. J.W. Foppen

prof.dr.J.G.A. van Mierlo 

ISBN-10: 90-9020512-8

ISBN-13: 978-90-9020512-0

Printed by FEBODRUK B.V. Enschede, The Netherlands www.febodruk.nl 


\section{Contents}

Contents

Foreword

Abbreviations

i

Chapter 1: Why Malnutrition is a Problem and How "Good

Governance' Matters

1.1. Introduction

1.2. Problem Statement

1.3. Exploring the Contribution of "Good Governance' to

Malnutrition Reduction

1.4. Justification for this study

1.4.1. Research area

1.4.2. Justification

vii

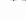

1

1

1

1.5. Outline

1.6. Summary and next chapters

Chapter 2: Framework, Hypothesis and Methodology $\quad 15$

2.1. Introduction

2.2. Conceptual Framework

2.3. Hypothesis and Main Research Questions 18

2.4. Methodology and Data-sources 20

2.4.1. Methodology 20

2.4.2. Data-sources 22

2.4.2.1. Governance Indices 22

2.4.2.2. Underweight Malnutrition; WHO-Global Database

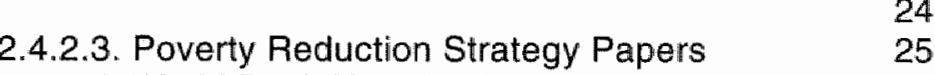

2.4.2.4. World Bank Nutrition Lending Data-base 26

2.5. Summary and Conclusion 27

Chapter 3: Malnutrition; a Heavy Tax on Development 29

3.1. Introduction 29

3.2. Malnutrition 29

3.3. Malnutrition is a Development Problem 30

3.4. Causes and Determinants of Malnutrition 32

3.5. Measuring Malnutrition 37

3.6. The Global Magnitude of Malnutrition 39

3.7. Preventing and Reducing Malnutrition 40

3.8. World Bank supported Nutrition Projects and Programs 42

3.9. Summary and Conclusion $\quad 45$

Chapter 4: Development Assistance and Malnutrition $\quad 47$

4.1. Introduction 47

4.2. The 1950s and 1960s: Economic Growth and Malnutrition as

a Metabolic Disease 48

4.2.1. Economic Growth $\quad 48$

4.2.2. Malnutrition as a Metabolic Disease 51 
4.3. The 1970s: Including the Poor and Malnutrition as a

Development Problem

4.3.1. Including the Poor

4.3.2. Malnutrition as a Development Problem

4.4. The 1980s: The Washington Consensus, Structural

Adjustment and where is Malnutrition?

4.4.1. 1980s: The Washington Consensus and the Era of Structural Adjustment

4.5. The 1990s: Poverty Reduction linked to Governance, Malnutrition linked to Poverty

4.5.1. Poverty reduction, Governance and Human Rights 60

4.5.2. Malnutrition reduction better understood and recognized

4.6. 2000: "Good Governance" and Millennium Development Goals (MDGs)

4.6.1. Development Assistance and Malnutrition 66

4.7. Summary and Conclusion

Chapter 5: 'Good Governance'

5.1. Introduction

5.2. Good Governance

5.2.1. Good Governance Defined

5.2.2. The Rise of Governance in Development Assistance

5.2.3. Underlying Evidence

5.3. The World Bank and Good Governance

5.3.1. World Bank Definition of Good Governance and Underlying Theories

5.3.2. Evolution of World Bank interpretation of Good Governance

Bank Operationalization of Good Governance 87

5.4.1. Enhanced Highly Indebted Poor Countries Initiative (E-HIPC)

5.4.2. Poverty Reduction Strategies

5.4.3. Lending for Good Go

5.5. Summary and Conclusion

Chapter 6: Governance and Malnutrition 94

6.1. Introduction

6.2. Malnutrition Reduction and the Role of

Role of the State

Responsibility

6.2.1. Governance is Important to Malnutition Malnutrition Reduction 97 in Several Ways

6.3.1. Good Governance may contribute to Accountability 
6.3.1.1. Broad-based Participation

6.3.1.2. Result-oriented Strategies and Pro-poor focus

6.3.1.3. Country-driven Processes

6.3.2. Good Governance may contribute to Malnutrition

Reduction through Government Effectiveness

6.3.3. Good Governance may contribute indirectly to

Malnutrition Reduction through Anti-corruption and Legal reforms

105

6.4. A Measurement for Public Accountability for Nutrition 109

6.4.1. Data-sources $\quad 110$

6.5. Measuring Governance Key-elements 111

6.6. Summary and Conclusions 111

Chapter 7: Governance Indices and Malnutrition Outcomes 113

7.1. Introduction 113

7.2. Measuring Governance

113

7.3. Changes over Time in Governance Indices between 1996 and 2004

7.3.1. Status and Changes Over time in Governance Indices in Selected Countries

7.4. Correlations between Governance and Underweight Malnutrition

7.4.1. Voice and Accountability Index

7.4.2. Political Stability Index

7.4.3. Government Effectiveness Index $\quad 124$

7.4.4. Regulatory Quality Index 125

7.4.5. Rule of Law Index

7.4.6. Control of Corruption Index

7.4. Correlations conditioned on Income and Regional

Differences

7.5. Summary and Conclusion

Chapter 8: Governance and Public Accountability for Nutrition

8.1. Introduction

8.2. Description of the data

8.2.1. Public Accountability for Nutrition

8.2.2. Governance

8.3. Results Governance and PA-Nutrition

8.3.1. Route 1

8.3.2. Houte 2

8.3.3. Route 3

8.4. Governance and Investment in Nutrition $\quad 144$

8.5. Summary and Conclusion 151

Chapter 9: Governance and Malnutrition in Madagascar, 155

A Case-study

9.1. Introduction 
9.2. Background

9.2.1 Geography and Brief Historic overview of Madagascar

9.2.2 Madagascar Economic Growth, Decline and Poverty

9.3. Governance in Madagascar between 1990 and $2004 \quad 159$

9.3.1. Early 1990s - 1997

9.3.2. Changes in governance between 1996 - $2004 \quad 163$

9.3.3. Decentralization

165

9.4. Malnutrition in Madagascar: Government Response and PANutrition between 1990 and 2004

9.4.1. Early 1990 s to 1997

167

9.4.2. 1997-2002

172

9.4.3. 2002-2004

175

9.5. Investment in Nutrition between 1994 and 2004

179

9.6. Malnutrition in Madagascar Improved

181

9.7. Discussion and Conclusion

Chapter 10: Conclusions and Discussion

10.1. Introduction

10.2. Theoretical considerations 187

10.3. Empirical Findings 190

10.4. Discussion 195

$\begin{array}{ll}\text { Executive Summary (English) } & 199\end{array}$

Executive Summary (Samenvatting in het Nederlands) 213

References

229

Annex l: World Bank Basic Facts $\quad 241$

I.1. Introduction

1.2. Purposes of the World Bank

1.3. Bank Resources and Lending

1.4. The World Bank Project Cycle

1.5. Policy Influence Instruments

1.5.1. Policy Instruments

1.6. Lending Instruments

1.7. Resource Allocation

Annex II: Additional tables and graphs

Annex III. The Millennium Development Goals, Targets, and Indicators 
Tables:

2. I Kaufmann et al Governance Indices

3.1 Malnutrition prewalence among different age groups in Burkina Faso $1998 / 9$

3.2 Malnutrition rates among the poorest $20 \%$ of the population and the population average for selected countries

3.3 Selected terms for describing anthropometry in children

3.4 WHO classification for assessing severity of malnutrition by prevalence ranges among children under five years of age

3.5 Estimated prevalence and number of stunted children, 1980-2005

6.1 Variables making up the proxy measurement of PA-Nutrition

7.1 Significant changes in governance between 1996 and 2004 in selected countries

8.1 Data-description of variables for PA-Nutrition

8.2 Country-Scores on PA-Nutrition in PRSP

8.3 Classification of country-performance on key-principles of governance

8.4 Average governance scores research populations

8.5 Country-scores on 'voice and accountability' index and PA-nutrition

8.6 Country-scores on 'government effectiveness' index and PA-nutrition

8.7 Country-scores on 'rule of law" and 'control of corruption' indices and PA-nutrition

8.8 Per capita investment for nutrition interventions between 1993 and 2000 in US-dollars

8.9 Nutrition investment per capita and trends in governance indices between 1993 and 2004

8.10 Average per capita investment in nutrition in the $1990 \mathrm{~s}$ and performance scores on 'government effectiveness' index

8.11 Averagle per capita investment in nutrition in the 1990 s and performance scores on voice and accountability, rule of law and control of corruption 'indices

9.1 Kaufmann and Kraay Governance Indices between 1996 and 2004 in Madagasciar

Graphs:

3.1 Trends in Percentage of Stunted Children under five years of age

7.1 to Scores and Trends in Governance Indices (Kaufmann) between 1996

7.6 and 2004 by number of countries

7.7 Scores and Trend in Vaice and Accoumtability Index in Latin America between 1996 and 2004

7.8 Underweight Malmutrition (2000) and Voice and Accountability Index (1996)

7.9 Underweight Malnutrition (2000) and Political Stability Iridex (1996)

7.10 Underweight Malinutrition (2000) and Government Effectiveness Index (1996)

7.11 Underweight Malnutrition (2000) and Regullatory Quality Index (1996)

7.12 Underweight Malnutrition (2000) and Rule of Law Index (1996)

7.13 Underweight Malnutrition (2000) and Control of Corruption Index (1996)

7.14 Underweight Malnutrition in 2000 and Voice and Accountability Index in 1996, controlled for GDP per capita and regional differences

7.15 Underweight Malnutrition in 2000 and Pollitical Stability Undex in 1996, controlled for GDP per capita and regional differences

7.16 Underweight Malnutrition in 2000 and Government Effectiveness Index in 1996, controlled for GDP per capita and regional differences

7.17 Underweight Malnutrition in 2000 and Pegulatory Quality Index in 1996, controlled for GDP per capita and regional differences

7.18 Underweight Malnutrition in 2000 and Rule of Law Index in 1996 , controlled for GDP per capita and regional differences 
7.19 Underweight Malnutrition in 2000 and Controi of Corruption Index in 1996, controlled ior GDP per capita and regional differences

9.1 Kaufmann and Kraay Governance Indices between 1996 and 2004 in Madagasicar

9.2 Investment in nutrition with World Bank support between 1994 and 2006 in millions of dollars

Figures:

Adapted UNICEF Conceptual Model on the Causes and Determinants of Malnutrition

2.2 Conceptual Framework: Potential Relation between Good Governance and Malnutrition Reduction

$3.1 \quad$ Nutrition throughout the Lifecycle

5.1 WDR 2004 Accountabillty Framework

6.1 Adapted Conceptual Framework: Relation between Good Governance and Malnutrition Reduction

7. 1 Conceptual Framework: Relation between Good Governance and Malnutrition Reduction

7.2 Framework: Relation between Good Governance and Malnutrition Reduction

8.1 Conceptual Framework: Relation between Good Governance and Malnutrition Reduction

8.2 Conceptual Framework: Relation between Good Governance and Investment in Malnutrition Reduction Interventions

10.1 Conceptual Framework: Relation between Good Governance and Malnutrition Reduction

10.2 Adapled Conceptual Framework: Relation between Good Gavernance and Malnutrition Reduction

\section{Boxes:}

4.1 The Order of Magnitude of Official Development Assistance

4.2 Structural Adjustment and Malnutrition

4.3 Millennium Development Goals - List of goals and targets

4.4 World Development Indicators Trends

5.1 Definitions of the Good Governance

5.2 Empirical exidence of Good Governance with regards to Human

Development

5.3 Criticism on the Interpretation, Operationalization and Implementation of Good Governance

6.1 Applying Good Governance to Sustainable Development

6.2 Implementation of National Plans of Action for Nutrition

6.3 Poverty Reduction Strategy Papers from a Nutrition Perspective

7.1 Kaufmann and Kraay Aggregate Indices

9.1 Definition and Modalities of Decentralization

9.2 Seecaline Community Nutrition Program

9.3 Poverty Reduction Strategy Paper Madagascar and Nutrition

9.4 Millennitum Development Goals - Trend on Nutrition and Estimaled

Progress with increased Investments 


\section{Foreword}

Although writing a dissertation and at the same time have a full-time job is a challenge, it also brings with it advantages such as: combining of theory and practical experience; discussing various subjects with experts who at the same time are colleagues; access to a world of information as well as an excellent library service. However, that was not the reason for doing this; rather it started out of a long felt frustration. I have been trying for the past 10 years to make malnutrition among young children a serious issue on the political agenda of decision-makers in developing countries. And as all those who will read this study will see, it often failed.

During the past decade I have worked in different capacities in local NGOs, international NGOs, the UN and finally at the World Bank in a variety of developing countries. This has provided me with numerous opportunities to experience how and where governance plays a role in making malnutrition a development issue. Therefore I was interested in learning more about 'good governance' and its potential contribution in the area of improving nutrition. Instead of just reading and learning about it, I decided to add discipline to the interest by systematically document my new knowledge and turning it into my dissertation subject.

The effort has paid off. I learned a lot, I got involved in new areas and have obtained new insights. Although this has become my dissertation, it involved many people continuously or at different stages of the process. I want to pay tribute to all these people but in particular Arno Korsten and Jane Kusin, my promoters. They have been the most stimulating and encouraging advisors I could have wished for. They have provided me with excellent and constructive advice and guidance throughout. What I have also much appreciated is that we never started a review of the work without first discussing family, and Dutch and world politics.

Of course, I cannot thank sufficiently my friends and colleagues who have read, commented and re-read the various versions of this study. First and foremost Rae Galloway, who read everything from the first to the last version and whose inputs I have highly valued; Menno Mulder-Sibanda who provided me with many new insights and challenges; Emanuela Galasso and Alessandra Marini without whom I would not have been able to do the statistical analysis. The chapter on Madagascar I have discussed in detail with my friend Anne Bossuyt whose insights after many years of living in Madagascar I highly appreciate. Other readers and commentators to whom I 
am grateful are Judith McGuire, Jim Levinson, Richard Heaver and Stefan Rokx. Joost Tennekes, April Harding and Navin Girishankar have provided excellent ideas on the governance chapters. I thank Willyanne de Cormier-Plosky for doing a fantastic job editing this work.

I am grateful to my husband Søren Nellemann for his dedicated support during these five years. He took care of the kids, read my many versions and put up with my stress and different moods. And thanks to the 'para-nimfen' my brother Stefan Rokx and my long-time friend Linda Aten who both also helped in correcting my by now rather poor Dutch for the summary. I would like to thank my brother Coen Rokx for his older-brother pride and support while writing this. I dedicate this book to my parents, and in particular to my father who sadly passed away just a few years ago. He would have been very proud seeing it finished.

Last, I would like to thank my Malagasy colleagues and counterparts who, although largely unknowingly, have contributed to this study. In particular Blanchard Andriamparany, Valencia Ranarivelo, Malalanirina Ratomaharo, Bruno Bearivo and Jean Rakotosalama. I have learned on-site what governance and politics can do for the successful implementation of nutrition policies and programs and how success can be subsequently harmed by poor governance. I have benefited from the many discussions we have had to better understand the complexity of Malagasy society and how decisions are taken in Madagascar. 


\section{Abbreviations}

\begin{tabular}{|c|c|}
\hline $\begin{array}{l}\text { AAA } \\
\text { ACC/SCN }\end{array}$ & $\begin{array}{l}\text { Analysils - Adaptation - Adoption } \\
\text { Administrative Committee on Coordination, Sub-Committee on } \\
\text { Nutrition }\end{array}$ \\
\hline$A C N$ & Agent Communautaire de Nutrition \\
\hline AED & Academy for Educational Development \\
\hline AIN & Atención Integral a la Niñez \\
\hline APL & Adaptablle Program Lending \\
\hline BERI & Business Environment Risk Intelligence \\
\hline BIANCO & Bureau Indépendante Anti-Corruption \\
\hline BMI & Body-Mass index \\
\hline CAS & Country-Assistance Strategy \\
\hline CDF & Comprehensive Development Framework \\
\hline CIDA & Canadian International Development Agency \\
\hline CNN & Conseil National de Nutrition \\
\hline CPIA & Country Policy and Institutional Assessment \\
\hline CPP & Country Program Paper \\
\hline DAC & Development Assistance Committee \\
\hline DFID & Department For International Development \\
\hline DGIS & Dutch International Cooperation \\
\hline DHS & Demographic and Health Surveys \\
\hline E-HIPC & Enhanced Highly Indebted Poor Countries Initiative \\
\hline EMSAP & Economic Management \& Social Assistance Project \\
\hline ERL & Economic Recovery Loan \\
\hline ESW & Economic and Sector Work \\
\hline FAO & Food and Agriculture Organization \\
\hline FDl & Foreign Domestic Investment \\
\hline FMG & Franc Malagasy (Malagasy Franc) \\
\hline FS & Food Security \\
\hline GAIN & Groupe d'Action Interagencial de Nutrition \\
\hline GDP & Gross Domestic Product \\
\hline GNP & Gross National Product \\
\hline GOBI & $\begin{array}{l}\text { Growth Monitoring Oral Rehydration Breastfeeding and } \\
\text { Immunization }\end{array}$ \\
\hline GOM & Government of Madagascair \\
\hline $\mathrm{HAZ}$ & Height for Age Z-score \\
\hline HNP & Health, Nutrition and Population \\
\hline HIPC & Highly Indebted Poor Countries \\
\hline IBRD & International Bank for Reconstruction and Development \\
\hline$I C N$ & International Conference on Nutrition \\
\hline ICRG & International Country Risk Guide \\
\hline ICSID & International Center for Settlement of International Disputes \\
\hline IDA & International Development Agency \\
\hline IDA & Iron Deficiency Anemia \\
\hline IDD & Iodine Deficiency Disarder \\
\hline IEC & Intormation, Education, Communication \\
\hline $\mathrm{FC}$ & International Finance Corporation \\
\hline IFPRI & International Food Policy and Research Institute \\
\hline $\mathrm{MCl}$ & Integrated Management of Childhood lliness \\
\hline IMF & International Monetary Fund \\
\hline KK & Kaufmann and Kraay \\
\hline LBW & Low Birth Weight \\
\hline LIL & Learning and Innovation Loan \\
\hline
\end{tabular}




\begin{tabular}{|c|c|}
\hline$M D G$ & Millennilum Developnent Goals \\
\hline MICS & Mulli-Indiciator Cluster Survey \\
\hline MOA & Muttinational Investmeni Guarantee Agency \\
\hline MIT & Massachusets institute for Technology \\
\hline $\mathrm{MOH}$ & Ministry of Health \\
\hline MOR & Ministry of hesearich \\
\hline MUAO & Mid Upper Arm Circumference \\
\hline NGO & Non-Govemmental Organization \\
\hline NMP: & Nathonal Nutrition Policy \\
\hline NPAN & National Plan of Action for Nutrition \\
\hline NPM & New Public Management \\
\hline Q101 & Oversees Development Institute \\
\hline ODA & Official Development Assistance \\
\hline OECD & Organization for Economic Cooperation and Development \\
\hline OED & Operations Evaluation Department \\
\hline ONN & Office Nationalle de Nutrition \\
\hline PA & Publlic Accountability \\
\hline PAHO & Par American Health Organization \\
\hline PAl & Programme Activités Intégrées \\
\hline$P A N$ & Programma de Alimentacion y Nutrition \\
\hline PEM & Protein Energy Malnutrition \\
\hline PEA & Public Expenditure Review \\
\hline PHCS & Programme Intégrée Cyclone el Sécheresse \\
\hline PNG & Programme de Nutrition Communautaire \\
\hline PNS & Progiamme de Nutrition Scolaire \\
\hline PPP & Public Private Partnership \\
\hline PAS & Political Fisk Services \\
\hline PRSP & Poverty Feduction Strategy Paper \\
\hline PRSC & Poverty Reduction Strategy Credit \\
\hline$S A L$ & Struchural Adlustment Loan \\
\hline SAP & Structural Adjustment Program \\
\hline SECAL & Sector Adjustment Loan \\
\hline S\|L & Sector investment Loan \\
\hline SIM & Sector Investment and Maintenance Loam \\
\hline SSA & Sub-Saharan Atrica \\
\hline SWAP & Sector Wide Approach project \\
\hline S.D. & Standard Deviation \\
\hline TAL & Technical Assistance Loan \\
\hline TINP & Tamil Nadu Integrated Nutrition Program \\
\hline UNDP & United Nattions Development Program \\
\hline UNESCO & United Nations Education, Science and Cultural Organization \\
\hline UNEP & United National Envitonment Program \\
\hline UNICEF & Unted Nations Children's Fund \\
\hline USAID & United States Agency for International Development \\
\hline VAD & Vitamin A Dafilciency \\
\hline WAZ & Weight for Age Z-score \\
\hline WB & World Bank \\
\hline $\mathrm{MB}$ & World Bank Institute \\
\hline WOR & World Development Report \\
\hline WFP & World Food Program \\
\hline WHO & $\begin{array}{l}\text { World Healtt Organization } \\
\text { Weight for Height } Z \text {-score }\end{array}$ \\
\hline WHZ & $\begin{array}{l}\text { Weight for Height Z-score } \\
\text { Wetenschappelike Raad voor het Beneringcholoid }\end{array}$ \\
\hline WAR & $\begin{array}{l}\text { Wetenschappelijke Raad voor het Regeringsbeleid - Scientific } \\
\text { Council for Government Policy }\end{array}$ \\
\hline & World Trade Organization \\
\hline
\end{tabular}




\section{Chapter 1: Why Malnutrition is a Problem and How 'Good Governance' Matters}

\subsection{Introduction}

Why is malnutrition reduction not higher on the development agenda? This question is particularly salient in countries where malnutrition rates affect more than 20 percent of children under five. Governments of developing countries and nations, as well as international development partners seem to be little aware of the problem or its serious negative consequences for the health of the population and the entire economy. They also appear largely unaware of the cost-effective solutions that exist to address, and even prevent, malnutrition. Poor governance is assumed to play an important role in this lack of action and in turn good governance may contribute to improving

In this first chapter, the problem statement underlying this study is described and an argument is made that malnutrition reduction is a public sector responsibility. Governance is assumed to play an important role through providing an enabling environment in which accountability for malnutrition can be built. Why this is a challenge for a multisectoral development problem such as malnutrition is also described in detail in this introductory chapter. The justification for conducting this study is provided and the last section of this first chapter contains a short overview of the contents and purpose of this book's remaining chapters.

\subsection{Problem Statement}

Despite the cost of malnutrition in social, human and economic terms, the prevalence of malnutrition is decreasing only slowly in developing countries.

Malnutrition in early life has a long-term negative impact on health, cognitive development and productivity and is therefore costly in human, social and economic terms. Malnourished children tend to have more severe illnesses. There is a strong association between underweight (malnourished children) and child mortality (Pelletier 1993). Malnutrition affects all age-groups, and the consequences of malnutrition in one generation affect future generations. Girls who were malnourished as children themselves are more likely to give birth to low birth weight babies. Low birth weight is associated with a greater risk of chronic disease in adult life (Barker 1998). Malnourished children have reduced $\mathrm{IQ}$ and impaired cognitive 
skills and ability to learn. In addition, malnourished children may receive less schooling because of their lower height, which often is used as an indicator by parents for readiness for school (Alderman et al 2002). Late enrollment leads to lower expected lifetime earnings (Glewwe and Jacoby 1995). Adults suffering from iron-deficiency anemia, or who are of small stature, or who are thin, have lower work outputs than better-nourished adults (Strauss 1998; Behrman 1993; Levin 1986). Improving nutrition has both short and long term benefits of enormous economic and social significance, and contributes to improving development outcomes.

But, after more than 50 years of development assistance, malnutrition among young children remains a massive development problem. Although progress was made in reducing chronic malnutrition world-wide, from $47 \%$ in 1980 to $32.5 \%$ in 2000 , it is too slow at merely $0.7 \%$-points per year (WHO Global Data-base ). Progress is also uneven among regions. While Latin America has made good progress, Sub-Saharan Africa has not. Within regions, there is also uneven progress. In East-Asia the reduction in malnutrition is due mainly to China's improvement in nutrition. The other countries in that region have made very little progress.

\section{Much is known about what to do to reduce and prevent
malnutrition.}

Experience over the years has led to better understanding of what interventions and programs are effective in improving the nutritional status of populations. Economic growth by itself, for example, reduces malnutrition by reducing poverty at an estimated rate of $0.5 \%$ points per year (Alderman et al 2002). However, this estimate assumes stable economic growth of at least $5 \%$ annually. This is not always the rate of growth developing countries attain, and the rate in any one year is rarely one that is achieved for an extended period of time. Addressing the underlying determinants of malnutrition through formal education, health, and sanitation programs can help reduce malnutrition. But targeted nutrition interventions will reduce malnutrition more rapidly. Nutrition programs in Thailand and Costa Rica, and most recently Madagascar, show that the reduction in malnutrition can be accelerated beyond the reductions due to economic growth and improved education levels. One of the most impressive examples is Thailland, where malnutrition rates diminished at a rate of $1.1 \%$ points per year

\footnotetext{
"http://www. who int/nutgrowthab
} 
between 1986 and 1995 (Heaver and Kachondam 2002:47), about $0.6 \%$ faster than expected with annual economic growth of $5 \%$.

The rationale for investing public resources in reducing malnutrition is based on both human and economic grounds malnutrition reduction is a public sector concern and responsibility.

Improving young child nutritional status is a long-term investment. It positively impacts on learning capacity and productivity in later life. Public investment in nutrition is needed because there are no private markets to finance nutrition, since there is no collateral, demand is low, and investments by the poor in nutrition are likely to be very limited (Musgrove 1996). Also, many households are ignorant about the benefits of good nutrition and do not recognize when children are faltering in growth and suffer from chronic malnutrition. Feeding children is not intuitive and parents and caregivers often are not equipped with skills to adequately feed children. Besides late recognition of symptoms, moderate chronic malnutrition or stunting is so widespread it has become an accepted part of daily life. When action is finally taken, often irreversible damage has already been done. The Copenhagen consensus ${ }^{2}$ recognized malnutrition interventions as among the most cost-effective and demonstrative of positive results (Behrman et al 2004:363-4).

Malnutrition reduction is a public sector responsibility and can be justified by public goods, human rights, and welfare arguments. These arguments, which are elaborated on in chapter six, call for a role of the state in reducing malnutrition and the provision of a mandate to govern the issue at the political level.

Why then, is more not invested to reduce malnutrition?

Despite high malnutrition rates and the knowledge that nutrition programs accelerate malnutrition reduction, nutrition programs, if implemented at all, remain often at the pilot stage and program coverage is too small to have significant impact at the national level. Notwithstanding the serious ramifications for

\footnotetext{
${ }^{2}$ In 2004 a panel of well-known development thinkers and Nobel prize wimers was asked to answer the question: What would be the best ways of advancing global welfare, and particularly the wellare of deweloping countries, supposing that an additional US $\$ 50$ billion were at government's disposal? Pollicies to attach hunger and malnutrition were ranked second (out of ten) (Lomborg 2004:606).
} 
having a malnourished population, few countries have coreinstitutions mandated with the responsibility to develop policies and implement nutrition programs to reduce malnutrition. Only a few countries have nutrition policies, and even fewer invest longterm in nation-wide nutrition programs and reduce malnutrition with success. The literature on implementing nutrition policies and programs attributes inaction or failures to a variety of causes. These range from unclear institutional responsibility, limited capacity ${ }^{3}$ to develop policies and implement nutrition programs, insufficient interest, and lack of commitment from political and administrative government levels, to inadequate investments (Heaver 2002; Levinson 2002; McLachlan 1997; Gillespie and Mason 1996; Heaver and Israel 1987; Berg 1987 and Berg 1973).

Colombia is an example where a new government eliminated a well-functioning nutrition program, largely because there was no commitment to it (Levinson 1995). The Food and Nutrition Planning Division in Sri Lanka was dismantled and its mandate given to another, possibly less appropriate, institution with the result that the nutrition program suffered set-backs. And in Bangladesh, the national nutrition program functioned well despite governance problems, which can in part be explained by working closer to the communities and through NGOs. In many other countries lack of funding, too narrow targeting, and capacity are major constraints. Also in Colombia in the 1970s the food and nutrition program (PAN) looked very strong, but with changes in government, the program was changed and resulted in being eliminated, despite positive initial results. A case-study in a book edited by Pinstrup Andersen (1993) identifies the primary problem to be that the program had insufficiently built up public awareness and commitment to withstand changes by new governments. While a sister-program had managed to insulate itself from changes thanks to strong public local commitment, which had protested and prevented the changes effectively (Mosquera 1993).

So, even though there are strong arguments that reducing malnutrition is a public sector responsibility, not many countries give it sufficient attention to make it a priority on the development agenda and allocate resources for nutrition. The lack of responsibility and subsequently sustained commitment appears in almost every evaluation report that explains the failure of nutrition program implementation. Commitment to

\footnotetext{
${ }^{9}$ Capacity can be defined as the ability of a person, community, or organization iterative process of assessment, manage and direct its development through an
} 
malnutrition prevention and reduction, or public accountability in this study, can be defined as the will to take action and invest public resources to reduce malnutrition by those holding power ${ }^{4}$ and building institutions to sustain the commitment ${ }^{5}$.

\subsection{Exploring the Contribution of 'Good Governance' to Malnutrition Reduction}

It is argued in this study that malnutrition is a public sector concern and responsibility, and therefore governance may be an important determinant to reducing malnutrition.

States have a wide variety of governing functions, including addressing the provision of public goods, merit goods and, the case can be made, for externalities (Fukuyama 2004:8). It is argued that the reduction of malnutrition and the provision of nutrition services should be among those functions ${ }^{6}$. Governments are the institutions that carry out these functions, and good governance has to do with how well and appropriate these functions are carried out. Good governance stands for political, social and economic policy-priorities that are based on a broad consensus in society that includes the voices of the poor and vulnerable in decision-making processes about the allocation of development resources. In this broad definition, good governance may contribute to the enabling environment in which malnutrition can be addressed as a development problem and receive attention and allocation of resources, a government that is accountable to nutrition.

However Hoogerwerf argues: "for a government to respond to a problem, a problem needs to be raised. Theoretically, or in an ideal situation, the public elects its representatives on the basis of expectations that its rights and priorities will be taken into account in the policy making process ${ }^{7}$. But these expectations need to be voiced. A public policy is a

\footnotetext{
"Decision-takers and policy-makers, as well as implementers at both central and decentralized levels are meant here.

${ }^{5}$ Definition combines definitions of commitment from Heaver (2005:2) 'the will to act and keep acting to get the job done' and the United Nations Millennium Project (2003-draft) 'the desire to act on the part of those holding power and building institutions or strengthening them:

${ }^{5}$ There is a large body of literature on the functions of the State and there are ongoing debates on what the function should be, including philosophical debates on bigness and smallness of state, all of which are beyond the scope of this study. Fukuyama's book on State-building (2005) draws attention to what is still lacking in the current knowledge on nation-building.

7 This is in practice not always the case, in fact there are ample examples of where people elect on the basis of religion (Haiti) or fear for worse (Liberia). But the statement is made to show the principle and therefore need for accountability.
} 
response of government to a perceived problem by society (Hoogerwerf 2003:21:67). For public accountability ${ }^{8}$, public awareness is crucial and Leeuw, Van Gils and Kreft (1999) show in their evaluation of anti-corruption initiatives that increased awareness does not automatically lead to taking action.

\section{Building Public Accountability for Malnutrition Reduction meets Challenges}

Taking these insights or "conditions" into account, there are at least four important challenges ${ }^{3}$ to building public accountability for nutrition (PA-Nutrition). First, there is a lack of awareness of the problem itself, both at the political ${ }^{10}$ and household level, resulting in little demand for nutrition. Chronic malnutrition is largely an invisible problem. Until it becomes severe, even parents often do not see their children's gradual growth failure as malnutrition. Apart from catastrophic events such as droughts, cyclones and other natural disasters leading to famine, chronic malnutrition has no place on the political agenda. Second, the malnourished, women and young children, in the poorest areas, do not have a voice to demand political attention for their concerns. Third, there is little incentive for accountability ${ }^{11}$. Addressing malnutrition is not only complex, it is also a long term process before results are visible. This is not attractive for politicians who are more likely to support interventions that demonstrate success between two elections, normally a period of 4 to 5 years, in order to improve their chances of re-election. Instead, preventing malnutrition is difficult to show, difficult to measure, and difficult to make visible to the public to win their votes. Fourth, it is multisectoral. Defining

\footnotetext{
accountability in this context is political or public accountability, being responsive to key-actors outside of an administrator's office or agency and for a Siervice supplied to consumers (Romzek in Perry 1996:102).

For a more comprehensive review of the challenges of building commitment for
nutrition see Heaver (2005) Strengthening Development. agencies. ${ }^{11}$ The most simple definition of accountability is that is describes a relationship
between two parties, where $A$ is accountable to $B$ if $A$ is obliged to explain and
justify its actions to $B$. In this case, it will be argued the reduction a public sector responsibility $A$ ccountability argued that reducing malnutrition is and explaining why and what is to the population for being responsive, taking action particular. For a more comprehensive population at llarge and the poorest in and the different meanings used in the review of the definitions of accountability and $\mathbb{R}$. Jenkins (2002) Voice, Accountabilopment literature see Goetz A.M. Emergence of a new agenda. This is ability and Human Development: the Development Report 2002 2 .
} 
institutional arrangements for malnutrition policy-making and program implementation is difficult because it is a multi-solutions problem and does not have a natural organizational identity. In fact, malnutrition can be described as an ill-structured problem which encounters difficulties getting attention in an often highly structured government (Parsons 1996). It can require coordinated action and several structures. These challenges lead to little demand for nutrition services and governments often do not respond because there is not demand.

\section{A fifth challenge; Building Ownership}

A fifth challenge can be added to the above four: the lack of national ownership for the nutrition agenda which has left much of the policy making and implementation of programs up to the international nutrition community. The latter recognized the importance of reducing malnutrition for overall development in the 1970s, and in response started investing in malnutrition policy advice and programs in a large number of developing countries. Although in some countries that has led to successes, there are as many, maybe even more, failures. In general the development partners have failed to invest sufficient resources for long term to have significant impact. And, high transaction costs incurred by governments to comply with different donor requirements and reporting systems can be substantial in addition to dealing with donor-set priorities. In the 1970s, the international nutrition community created institutional homes to address the multiple causality of malnutrition and build commitment and high level awareness of the problem. These institutions were supposed to coordinate among the sectors for the purpose of addressing malnutrition. Therefore, these multisectoral national nutrition planning commissions, often housed in the Ministry of Planning (Levinson 2002), were established in about 26 countries at that time. While there is not much doubt about the need for a 'home' for nutrition or the need to build commitment or take multisectoral action, the operationalization of the commissions at the time was heavily criticized (Field 1987; Levinson 2002). In practice, the scope of these commissions was very limited and most failed to accomplish their goals. In hindsight it appears that the commissions focused too much on planning and too little on doing (Field 1987). They were imposed as blueprint models, 
rather than home grown institutions ${ }^{\$ 2}$, and failed to build much local capacity.

An important aspect that may have contributed to the failure is the overall development environment at that time. The international community believed that economic growth would reduce malnutrition. There was much less attention to involving communities and building ownership than there is currently. This study argues that the environment to building public accountability for nutrition (Public Accountability for Nutrition = PA-nutrition) is better in the latter part of the 1990s and the new millennium than it was in the 1970 s when the national nutrition commissions were created (chapter four).

There has been too little attention from the development partners to increase country commitment to nutrition alongside too much focus on short term and vertical programs, and far too little attention to implementation processes and capacity building (Field 1987; Berg 1987; Gillespie 2003; and Heaver 2005). Because national governments pay so little attention to malnutrition reduction, in a large number of developing countries, donors or development partners in nutrition tend to be in the socalled driver's seat and not the government. Not only do they provide the major share of the financing, they also determine the agenda and set priorities in nutrition. Also, international agencies tend to change policies more often than developing countries, a propensity which runs contrary to productively assisting the intended beneficiaries. As a result, the developing countries may become even more dependent and less interested in addressing the issue.

The large share of external funding for nutrition exacerbates the ownership problems. Externally funded programs tend to use time-limited resources to focus on problems that may not be prioritized by the community itself, but rather by the external agency providing the funding. Nutrition interventions that follow the objectives of donors rather than governments are unlikely to foster ownership. In order to reduce malnutrition, long term assistance and investment is needed, as has been very recently re-confirmed in the 2005 Gleneagles summit on development aid. Next to long term commitment and investment, making national governments take the responsibility for development and nutrition by building ownership and accountability, is crucial for sustainability. For example, countries such as Thailand took more than 10 years to reduce malnutrition

\footnotetext{
Winikoff found a mix of success and failures in 1978, brief reviews of these experiences from Chile, Colombia, Ghana, Nigeria, the Philippines and others
} 
rates from 25 to 15 percent, and it was a largely country-owned and financed process. Thailand's success is considered to be among the fastest and most impressive.

The principles of good governance include promotion of broad-based participation in decision-making processes, sharing information, anti-poverty programs, improved public sector management and anti-corruption programs and a strong antipoverty focus. As such, good governance offers a variety of ways in which it can contribute to building PA-nutrition because it helps to address the challenges. It broadens governance to include civil society and private sector actors, in addition to traditional governance actors. It also helps to address problems related to high transaction costs for national governments who have to deal with a variety of donors. Good governance strongly promotes national ownership and budget-aid, instead of project directed aid.

\subsection{Justification for this study}

\subsubsection{Research area}

Three areas of research can evolve from the challenges in building public accountability for malnutrition reduction. First, at the household level, questions regarding incentives for behavior change are highly relevant. What will make mothers change behavior regarding the nutrition of their children? A growing body of literature is becoming available on this: from negotiation techniques, to active involvement in promoting the growth of children. Also in other areas of health promotion, such as anti-tobacco campaigns, HIV/AIDS prevention campaigns, and family planning offer a large body of research on this question. Cognitive psychology theory is used to understand the mechanisms better.

The second area would be research to gain a better understanding of creating incentives at the political decisionmaking level for malnutrition reduction. Malnutrition is a serious development problem, and slows down the poverty reduction agenda in developing countries. Although this is widely recognized, including among some decision-makers, the step of committing to take action and invest funds to prevent and reduce the problem is not often made. Lack of attention to malnutrition reduction and investments in nutrition programs are often linked to poor governance and lack of commitment. A key-question is whether the renewed attention of the development agencies to governance had an effect on malnutrition? A large number of developing countries that have high malnutrition rates do not 
even have a strategic govermment policy or vision to address malnutrition problems. Good governance addresses in theory several of the key-challenges to building public accountability for malnutrition reduction.

A third area is the development partner influence and ownership of the nutrition agenda. It is becoming more evident among development partners that there is a great need for better understanding as to how malnutrition can be addressed. This study focuses mostly on the second research area about the relationship between governance and malnutrition ${ }^{13}$, and to a lesser extent on the third area.

\subsubsection{Justification}

The question of why decreases in malnutrition lag behind other social indicators continues, and this study is but one contribution to the search for answers to that question. A variety of underlying explanations have been put forward in the literature. Some explanations are biological, while others are linked to poor national governance (Wagstaff and Claeson 2004; Dollar and Pritchett 1998) and/or governance of the nutrition system in specific (Levinson 2002; Field 1987; Berg 1987). For decades there has been a debate on how best to institutionalize the responsibility for malnutrition reduction, or, PA-nutrition. But the nutrition community has hardly made use of insights from the fields of public administration, organizational change, institutional economics, public policy, social development economics, etc, all of which offer important insights regarding this question. This study therefore makes an attempt to explain the paradox, by making use of the perspectives of institutional economics and public sector theories.

The need to better understand why so many countries with high malnutrition rates under-invest in effective nutrition programs is made more acute with global development emphasis on good governance as a determining factor in aid-allocation. This may influence the willingness of governments to address mainutrition and increase investments, or may have the opposite effect and leave malnutrition out of the development agenda altogether because of lack of popular pressure. It is important to understand how these influences may work and the interface between context and programs.

\footnotetext{
Although the agenda-selting literature offers many insights and theories in this
regard, the focus in this study has been governance and malnutrition and been kept or the relation between good literature where relevant.
} 
As a result of the attention to governance, new data are now available on a series of governance indicators, making it possible to analyze the relationship between governance and malnutrition and provide a basis for further research. Over 25 data-sets track changes and compare governance indicators among countries. Although there is a large debate over the value of the indicators, which will be explained in more detail in subsequent chapters, there are data-sets on which the international community agrees, such those of Transparency International (TI) and Political Risk Services (PRS), and the Kaufmann et al dataset used in this study (Knack and Manning 2000). The availability of these data-sets allows one to assess the progress and its assumed link to malnutrition reduction.

Finally, there is an opportunity to take a closer look at ten years of macro-level support for good governance on malnutrition reduction, programs and outcomes. Donor policies and priorities tend to change frequently and influence national governments' policies in nutrition. The latest such policy change is the focus on good governance. The World Bank intensified its attention on strengthening governance in its client countries around 1992. Between 1992 and 2004 a number of new lending programs with the objective of reducing malnutrition were started. These provide an opportunity to assess how enhanced attention to improving country's institutional arrangements (governance) influenced implementation of these projects. More broadly, one can also assess the influence of external donor policies on countries' national nutrition agenda. In those countries where the leadership for malnutrition reduction is weak, the influence of donor-assistance is often dominant.

\subsection{Outline}

This study sets out to gain a better understanding of a heretofore under-researched area: the relationship between good governance and malnutrition. It seeks to link macro-level governance with the sectoral level policies and implementation of programs for malnutrition reduction. The study consists of three main parts. The first is the background to the two issues (governance and malnutrition) reviewed, and the theoretical considerations regarding the potential contribution of 'good governance' to malnutrition reduction. The second part of this book analyses the correlation between aggregate outcome indicators of governance and underweight malnutrition. It also analyzes the relationship between the aggregate governance indices and proxies of the assumed routes by which governance affects malnutrition reduction. The latter analysis is to gain more 
understanding about the factors that help explain the relationship between the aggregate indicators. Existing data-bases such as the Kaufmann and Kraay data-set, the WHO Global Malnutrition database, and the new data-base compiled from national Poverty Reduction Strategy Papers (PRSP) that were produced by lowincome develloping countries between 1999 and 2004, are used. The third and last part of the book is a case-study on a country where governance and malnutrition reduction are analyzed to show how the assumed theoretical links play out in a real case. Case-studies are a preferred strategy when questions as how and why are asked (Yin 1994). As the subject of this study has been little explored to date, the inclusion of a case-study in which more in-depth how and what questions are addressed, will add depth to the discussion. It will also bridge the divide between the theoretical and the practical.

\subsection{Summary and next chapters}

The purpose of this first chapter is to introduce the problem and the justification for the study. The international literature on malnutrition identifies the lack of commitment and accountability as major constraints in the efforts to reduce malnutrition. There are a number of challenges to building public accountability at the country-level for malnutrition reduction, such as: a low level of recognition of the problem, low demand for public action, the multisectoral nature of malnutrition, and dominant development partner influence. Good governance, the current development priority, may contribute to addressing these challenges and therefore contribute to improving the problem of high malnutrition levels in developing countries.

This study is focused on the World Bank. This is because the World Bank is not only one of the largest development agencles, but is also the largest external investor in malnutrition reduction programs since the 1970s. And, it is the agency that put good governance on the agenda of development assistance. An overview of World Bank Basic Facts is provided in Annex 1.

Chapter two provides the framework, the hypotheses and how the research questions will be addressed. A review of the data-sources used for the empirical analysis is included. Chapter three is a background chapter on malnutrition and explains why it is a development problem. The chapter also discusses the nature of malnutrition, its causes and determinants, the magnitude of the underweight-malnutrition problem world-wide, its solutions and the type of programs the World Bank implements. The chapter ends with a description how malnutrition can be measured and how the World Bank supported nutrition since the 
1970s. Chapter four reviews the evolution of development assistance policy and dominant development strategies during the last 50 years: from economic growth to good governance. In parallel, the chapter reviews the thinking about malnutrition in order to show when and where overall development became more conducive to including malnutrition reduction as a priority. Chapter five discusses in detail the good governance theory and the interpretation used by the World Bank, and identifies keyelements of governance that may influence malnutrition reduction. Chapter six describes the three routes through which it is assumed governance may contribute to addressing malnutrition by building public accountability: increasing budget allocations and improving expenditure levels. Chapter seven provides an empirical analysis of the correlation between the aggregate governance indicators and underweight malnutrition rates in Sub-Saharan Africa, Asia and Latin America. Chapter eight tests the three routes through which governance may contribute to malnutrition reduction and discusses the explanatory value. Chapter nine is an in-depth case-study on Madagascar. The purpose of this case is to explore how the three identified routes through which good governance influences malnutrition reduction and whether statistical relationships are borne out by reality. Madagascar has very high malnutrition rates and had long standing financial support from the World Bank for reducing malnutrition, which has produced many reports and data to be analyzed. It aiso received a decade of support for improving governance. During that same decade, the country suffered major natural disasters and a political crisis. In the area of malnutrition, Madagascar addressed the challenges mentioned in section 1.3 and made the change from project-level financing to programmatic financing ${ }^{14}$. It has made important judicial and administrative changes to improve its governance and addresses corruption openly. Much can be learned from the ownership aspects, capacity building, strong enabling environment and political support to scale up needed to make malnutrition programs sustainable in Madagascar. Chapter ten is the final discussion and overall conclusion.

14. Budgetary support means financing is provided from the national budget instead of through a special account for project activities often provided either by external donors or external budgetary accounts, such as Presidential special funds for example. The latter are considered less sustainable. 


\section{Chapter 2: Framework, Hypothesis and Methodology}

\subsection{Introduction}

The problem of slow progress with reducing malnutrition rates in developing countries and the potential contribution of good governance to accelerating progress was laid out in chapter one. This second chapter develops the conceptual framework, the hypotheses and research questions, as well as the methodology to test whether in fact there is a correlation. It will start with a conceptual framework which is based on a widely accepted model on the causes and determinants of malnutrition. After the framework, the hypotheses are proposed as well as the main research questions that will be explored in the next chapters. Finally the methodology, including the data-sources regarding how the questions will be addressed and the hypotheses tested are provided in this chapter.

\subsection{Conceptual Framework}

Figure 2.1 shows the widely accepted UNICEF-model on the causes and determinants of malnutrition, which are explained in detail in chapter three. The upper part of the model represents the immediate and underlying causes to malnutrition. Those are relatively well understood, and empirical data regarding the causal links exists. The lower part of the model represents the basic, or societal, determinants to malnutrition. Those are less well understood, and only a very limited research base about the links exists. This study therefore concentrates on the lower part of the model and the links between the two. More precisely, it is situated in the interface between context and programs (figure 2.2)

Following the framework proposed in figure 2.2, a well governed country (good governance) is expected to be accountable to reducing malnutrition and to mobilize resources to invest in nutrition programs. Effectively implemented large-scale malnutrition reduction programs would lead to accelerated decreases in malnutrition. Alternatively, poor governance contributes to no action for malnutrition, and creates the opportunity for international donors to define national policies and control resources, which is more likely to lead to poor implementation because of lack of ownership. In the positive framework, donors would be expected to support governmentowned policies and national nutrition programs. 


\section{Figure 2:1: Adlapted UNICEF Conceptual Model on the Causes and Determinants of Malnutrition}

A: Empirical evidence, large research base:

\section{Outcomes}

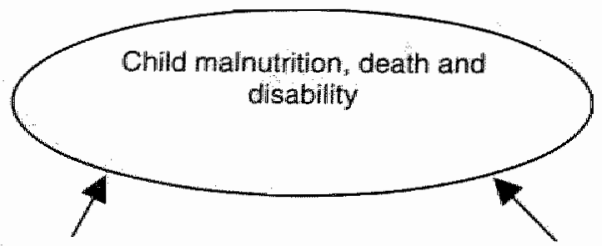

\section{Immediate}

Causes

Inadequate
Dietary
Intake

Disease

Underlying

causes at household level

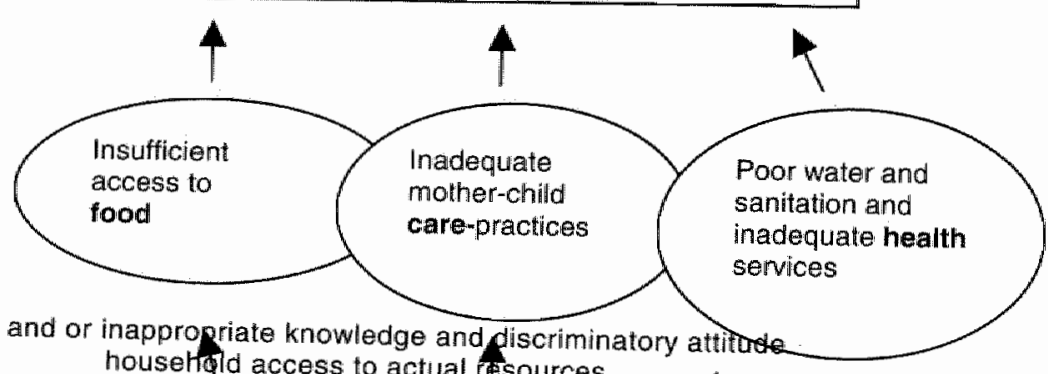

Inadequate and or inappropriate knowledge and discriminatory attitude

B: No empirical evidence, smal research base:

houserifd access to actual fysources

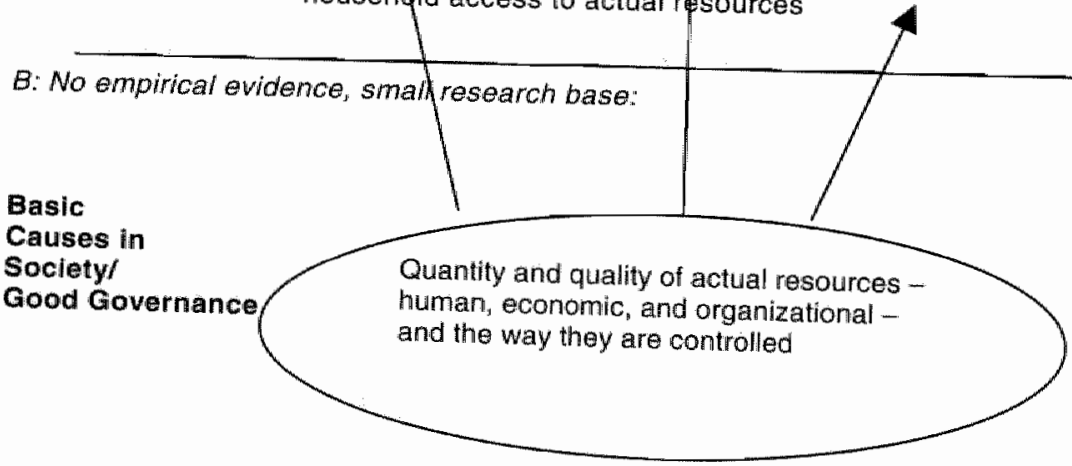

Political, cultural, religious, economic, and so al systems, including status of women, limit the use of potential resources

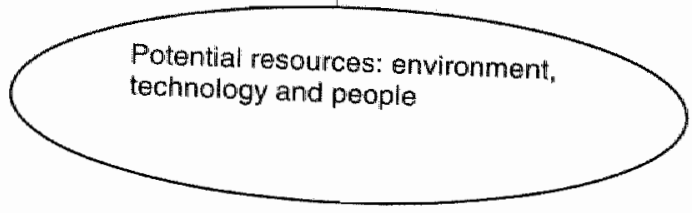

Source: UNICEF (1998) The State of the World's Children 1998. Oxford
University Press 
Figure 2.2: Conceptual Framework: Potential Relation between Good Governance and Malnutrition Reduction

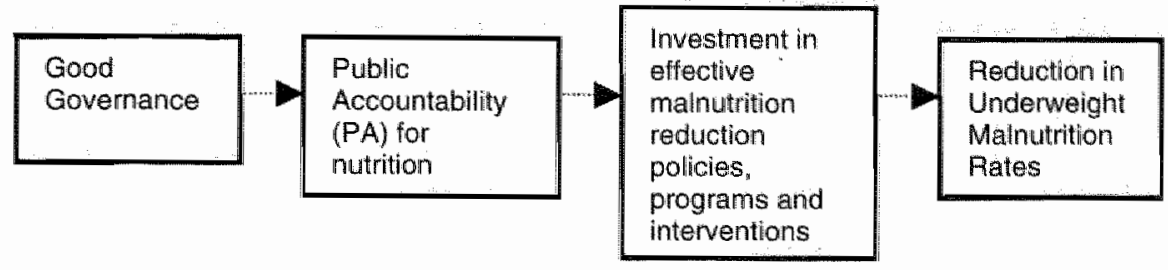

Definitions:

Good governance: Governance is defined as the manner in which power is exercised in the management of a country's economic and social resources (World Bank 1997). Good governance stands for, among other things, participatory, transparent and accountable policies. It promotes rule of law, it ensures that political, social and economic priorities are based on broad consensus in society and that the voices of the poorest and most vuinerable are heard in decision making over the allocation of resources (UNDP 1997). This is the definition used in this study.

Public Accountability for Nutrition (PA-nutrition) is defined as: the public sector being responsive to malnutrition problems by not only raising awareness to create knowledge and public demand, but also taking action to address the problem and providing information on how, why, what, and for whom, to the population at large, and the poorest in particular. In this study PA-nutrition is considered as good when a country has made (mal)nutrition a priority in their overall development program and has allocated resources to implement interventions and programs.

This study will not go into detail on the correlation between investment in nutrition programs and interventions and malnutrition outcomes, the far right arrow in the framework. A large body of literature is available on what works in malnutrition reduction, what type of interventions is most cost-effective and efficient. Although this is dependent on how these programs are implemented, there is evidence in the mutrition literature that targeted nutrition programs that have large-scale coverage reduce malnutrition. Countries as Thailand, Costa Rica and more recently Madagascar, have implemented large scale nutrition programs with positive impact on underweight malnutrition. An overview of these different interventions is provided in chapter three. 
This study instead focuses on the lower part of the UNICEF model, and within that on accountability to make and implement the policy, rather than what the policy is or should be. Investment in malnutrition and signals of accountability for malnutrition reduction are used as proxy-process outputs of periormance for the lower part of the UNICEF causal model. The relation between aggregate governance indicators and malnutrition outcomes at the national level, as well as the differences in PA-nutrition are analyzed. Investment in malnutrition reduction interventions and programs will be measured using lending for investment in malnutrition interventions with World Bank support. How governance indices influence the levels of investments in nutrition will also be analyzed.

\subsection{Hypothesis and Main Research Questions}

The goal is to gain insights into how governance may facilitate malnutrition reduction. It is hypothesized that good governance improves the enabling environment in which malnutrition reduction will be addressed as a development problem and countries with better governance are more likely to be accountable to and invest in malnutrition reduction programs. The central research questions of this study include an exploratory theoretical and an empirical part.

Theoretical What are the key-elements through which governance contributes to malnutrition reduction? in order to address this general question, several sub-questions are posed:

1. What is malnutrition, why is it a development problem, and why is it a public sector responsibility to which the principles of governance apply? - chapter 3

2. How did development assistance theory evolve, and when does the environment become more enabling to malnutrition reduction in developing countries? - chapter 4

3. What is 'good governance', and when and why did it become a dominant development policy? - chapter 5

4. What are the key-elements of governance that in theory may contribute to malnutrition reduction in developing countries? - chapter 6

5. How do these key-elements contribute to malnutrition reduction, and through which processes? - chapter 6

Empirical Although there are data-limitations, as is explained in detail in the respective chapters, empirical crosscountry analysis helps to test the underlying assumptions to the 
link between governance and malnutrition reduction. Existing databases and new data-collection from various Poverty Reduction Strategy Papers (PRSPS) and investment in nutrition interventions are used as data-sources. These are described in detail in section four of this chapter.

6. Has governance improved in developing countries since the mid-nineties? - chapter 7

7. Is there a correlation between aggregate governance indices and underweight malnutrition rates in developing countries in Africa, Asia and Latin America? - chapter 7

8. Do developing countries that display better scores on aggregate governance indicators also demonstrate PAnutrition? - chapter 8

9. Did developing countries with better scores on governance invest more in malnutrition reduction interventions? - chapter 8

Finally, in addition to the theoretical assumptions and the empirical tests, a case-study is included. - Chapter 9 .

The research question concerning to what extent the World Bank"s focus on good governance contributed to the improvement of governance in developing countries is certainly of empirical interest. However, a causal analysis of this type is beyond the scope of this study. The effect of development assistance on governance and development has been addressed in Assessing Aid; What Works, What Doesn't and Why? a World Bank publication by Dollar and Pritchett in 1998, and is discussed in a large number of studies since ${ }^{15}$. Dollar and Pritchett conclude that foreign aid has a positive influence on development and is most effective in those countries with good policies.

However, a number of studies in very recent years, Rajan and Subramanian (2005), Easterly, Levine and Roodman (2004) Roodman (2004) and Easterly (2003) all suggest that there is no robust statistical association between aid and growth, even in countries with good policies (Rajan and Subramanian 2005:4). One of the possible explanations mentioned for the lack of long term positive effects of aid on growth is that the process of giving aid may miss important inputs. For example in education, construction of classrooms may spur economic activity in the short-run, but without well trained teachers in the cllassroom the long term effect may be minimal or even zero. The same argument can be used for providing food to malnourished

${ }^{15}$ A gaod overvilew of the literature on aid effectiveness is surveyed in Clemens et al 2004. 
children, an intervention that may have a positive short-term effect, but without changing behavior for better feeding practices, long-term effects are unlikely. It is also important to take equitable spending in the equation. For example, in the health sector the majority of public spending is on tertiary care (hospital-based), while most gains on health outcomes come from less costly efforts to improve primary care. Other explanations for the lack of effect of aid on growth mentioned are the risk that aid resources initially provide more budgets, but may at the same time make receiving countries more lax about collecting tax revenues, which has negative effects long term. And finally, aid may in fact weaken institutions instead of strengthening them because countries feel less inclination to explain actions to citizens when using aid-money and instead may be more accountable to the donor.

The debate on the effectiveness of aid continues. Rajan and Subramanian suggest moving beyond the inconclusive debate and emphasizing the need to spend aid effectively. Productivity improvements from increased public investments can offset any dampening effects from a fall in competitiveness. Competitiveness was found to be a significant explanatory variable in the analysis of aid-effectiveness on growth (Rajan and Subramanian 2005:22).

Meanwhile the general consensus remains that aid is more effective in countries with good policies, and that more attention is needed as to the quality of the policies themselves so that there are trained teachers in the newly built classrooms. The 2005 Global Monitoring Report, a report endorsed by the World Bank and the IMF, states clearly that economic growth accelerates with stronger institutions and better policies (World Bank and IMF 2005).

\subsection{Methodology and Data-sources}

\subsubsection{Methodology}

The theoretical part of the research includes an extensive literature review on the subjects of governance and good governance, in particular nutrition and malnutrition, public World Bank published documents were incl. A large number of in chapter five on the World Bank and good governane overview number of project orid Bank and good governance. A large evaluations were used for additional supervision reports and the case-study. 
The empirical part of the research questions is addressed using two complementary methodologies. First, a quantitative analysis of cross-sectional data at the country level and second, a more qualitative analysis of one country, Madagascar

Quantitative analysis: A cross-country analysis is carried out to determine whether, and where, governance improved since 1996. A cross-country multivariate analysis ${ }^{16}$ of macrolevel governance indices and malnutrition outcomes is carried out to test whether governance is correlated with lower underweight malnutrition rates. The units of analysis are individual countries. The dependent variable is underweight malnutrition outcomes.

As a second stage analysis, the relationship between the governance indices and PA-nutrition and investment in nutrition interventions is evaluated. A proxy for PA-nutrition is developed using scores on signals of PA-nutrition. The data are collected from Poverty Reduction Strategy Papers (PRSPs) that were developed between 1999 and 2004 in low income countries. Nutrition investment data are calculated using the World Bank Nutrition Lending database.

There are two questions that cannot be evaluated quantitatively due to data-limitations. First, whether PA-nutrition has a positive direct influence on malnutrition outcomes, and second whether investment in nutrition programs has a direct effect on nutrition outcomes. However, the latter is shown in a variety of existing studies of large-scale programs in individual countries as well as in the Madagascar case-study. The reason a cross-country analysis cannot be conducted with the data in this study is a time-issue. The proxy for PA-nutrition is collected from PRSPs that were developed between 1999 and 2004, while nutrition outcome data is available only up till the year 2000 for most countries. This study in fact could be seen as a base-line for further research to test the direct link between PA-nutrition and malnutrition outcomes.

Analyzing the links between PA-nutrition and the influence of governance is feasible because there is a causal link and time-lag that can be introduced. PA-nutrition data from 1999 and beyond and governance indices are available from 1996 onward. Links between governance and investment levels for nutrition can also be made, as can investment and malnutrition

\footnotetext{
16 A multivariate cross-country analysis assesses the importance of several different variables - in this care governance indicators - to explain differences in the dependent variable - in this case malnutrition - between countries.
} 
outcomes, given that investment data are available for the same period as malnutrition (including time-lag).

Qualitative analysis: With the objective of being true to the explanatory nature of this study, an in-depth case-study of governance and nutrition policies and programs is included. Madagascar offers an example of a country where malnutrition became a national priority, and where investments were increased to address it at large scale. The theoretical links between good governance and malnutrition reduction, and how the former contributed to the improvement of the latter, is addressed in detail in this case-study. Madagascar had very high malnutrition rates and had long standing financial support from the World Bank for reducing malnutrition, as well as for improving governance. The case adds value to the analysis regarding the building up of public accountability, as well as the political support to scale up and make national malnutrition programs sustainable. There is no other country used as a counterfactual, because Madagascar itself shows how governance played both positive and negative roles in different periods.

\subsubsection{Data-sources}

\subsubsection{Governance Indices}

A review of available data-sources on governance indicators was carried out to identify the most appropriate source for this study. Over the last several decades, there has been a large increase in number and type of governance indicators that measure various aspects of governance, but there is little consensus on their use. Knack and Manning, discuss the differences in the various data-sources in Towards a Consensus on Governance Indicators. They followed criteria that are agreed upon in the Development Assistance Committee (DAC).

For the measurement of governance, this study uses the 2005 Kaufmann et al data-set. This set provides data on six aggregate governance indices and data are available for the period between 1996 and 2004 . The six indices and what they
measure are described in table 2.1. 
Table 2.1: Kaufmann et all Governance Indices

\begin{tabular}{|l|l|}
\hline $\begin{array}{l}\text { Index } \\
\text { Governance }\end{array}$ & Measuresi \\
\hline $\begin{array}{l}\text { Accoice and } \\
\text { Accountability }\end{array}$ & political will, civil and human rights \\
\hline 2. Political Stability & $\begin{array}{l}\text { the likelihood of violent threats to or changes in } \\
\text { government }\end{array}$ \\
\hline $\begin{array}{l}\text { 3. Government } \\
\text { Effectiveness }\end{array}$ & $\begin{array}{l}\text { the competence of the bureaucracy and the quality of } \\
\text { public service delivery }\end{array}$ \\
\hline $\begin{array}{l}\text { 4. Regulatory } \\
\text { Quality }\end{array}$ & $\begin{array}{l}\text { the incidence of market-unfriendly policies } \\
\text { court as well as the likelihood of crime and viollence }\end{array}$ \\
\hline $\begin{array}{l}\text { 5. Rule of Law } \\
\text { the exercise of public power for private gain, including } \\
\text { both petty and grand corruption. }\end{array}$ \\
\hline $\begin{array}{l}\text { 6. Control of } \\
\text { Corruption }\end{array}$
\end{tabular}

Source: Kaufmann D. and A Kraay, Governance Matters III and IV, 2004, 2005.

The use of other data-sources such as Transparency International (TI), the International Country Risk Guide (ICRG), Business Environmental Risk Intelligence (BERI) 17, and Freedom House, were considered but not used for a variety of reasons. Although these data-sets are considered good following the DAC criteria for indicators, they are limited in the type of data they collect. For example, Freedom House focuses on the political rights and democracy while ICAG primarily collects data on business environments ${ }^{18}$. The Kaufmann et al data-set integrates many of the data collected from these sources, and using the principle that more information is preferable to less, the Kaufmann et al data-set provides currently the most comprehensive set.

In addition to being an internationally recognized valuable data-set, the Kaufmann et al data-set operationalizes the World Bank definition of good governance in six aggregate indices: voice and accountability, political stability, quality regulatory framework, government effectiveness, control of corruption, and rule of law (table 2.1). These aggregates were constructed from indicators from 25 different sources, produced by 18 different organizations, including the often used ICAG ${ }^{19}$ " the BERI, and Freedom House indicators. The indices cover hundreds of variables measuring perceptions of governance.

\footnotetext{
${ }^{17}$ BERI indicators have been available since 1972 , but for onlly 50 countries, if developing countries, then the larger middle income ones.

${ }^{18}$ For a more extensive overview of the different governance indicators and data-sources, see Governance and Public Sector Pewiew overwiew of indicators of governance and institutional quality see:

www. worldbank.org/prem/prmps/publicsector/indicators. htm

19 The data-set is produced by the Political Risik Services (PRS) Group of Syracuse in New York, covers over 130 countries since 1982 , ratings are subjective assessments produced monthly by local experts and averaged on a annual basis.
} 
Even though it is the most comprehensive set, there are caveats with the Kaufmann et al data that should be kept in mind. For example, it is not possible to say with absolute certainty that changes in governance are due to real changes over time in the indicators, or due to changes in coverage in the countries in the data-base. If in one year Luxembourg and Iceland are included, this could pull all other countries down, because ratings are in relation to other countries in the database. In addition, for specific countries, some survey-years may, for example, include ICRG-data (or other surveys) and other survey-years not. This may introduce a bias in the outcome, in particular regarding the change between years in one country. Despite these caveats, the Kaufmann et al data-set is the best available to determine whether governance is improving and where and for use in this study. It incorporates many different sources and variables for a large number of countries, which reduces the bias more so than in other data-bases.

Also the World Bank's internal governance data-set, the Country Policy and Institutional Assessment (CPIA), was considered for use. It is an annual assessment of four categories of policies and institutions making up process indicators of governance. The CPIA is rated by World Bank staff that work on the respective country, and it is sometimes asserted the rating is biased upward because the rating contributes to the allocation of funds. It is assumed though, that all staff would be inclined to round off to a higher rating because of that link. Therefore this bias, if it exists, is considered to be introduced across the board. There is also a control function in place that should prevent significant over and under-rating. Although it would provide very interesting data and would allow more detailed analysis of governance factors, for example scores on poverty monitoring and equitable use of public resources, the data was not publicly available before 2004. In 2004, the Board of Directors of the World Bank passed a disclosure policy, but the disclosure does not work retrospectively. For this study, data before 2004 would be needed.

\subsubsection{Underweight Malnutrition; WHO-Global Database}

Malnutrition reduction is most often defined as the change in prevalence in underweight (weight for age < - 2 S.D.) among children under five. The Millennium Development Goals (MDG) target for reducing malnutrition also uses underweight as 
the indicator. Although stunting ${ }^{20}$ would be a more appropriate indicator of nutritional status and the changes over time in population groups, it is not used because there are fewer observations than for underweight.

The World Health Organization (WHO) Global dataset on Malnutrition is the most comprehensive data-set for malnutrition, and is the source for the data on underweight malnutrition rates in this study. For the three regions used as the research population in this study, Sub-Saharan Africa, Asia and Latin America, data on underweight malnutrition rates and governance indicators is available for a total of 82 countries. For 40 of the total of 82 countries, data on changes in both governance indicators and underweight malnutrition are available.

\subsubsection{Poverty Reduction Strategy Papers}

Poverty Reduction Strategy Papers (PRSPs) provide a valuable source of information to obtain proxies for public accountability for nutrition. At the Annual Meetings of the World Bank and the IMF in September 1999, it was agreed that PRSPS should provide the basis for all World Bank and IMF concessional lending and for debt relief under the Heavily Indebted Poor Countries (HIPC) initiative. Governments are expected to treat PRSPs with care, i.e. adhering to the principles, because their preparation and implementation are tied to funding from cooperating partners through debt relief and budget support.

As of January 2004, 55 countries have developed PASPs. They describe a country's macroeconomic, structural and sociall policies and programs to promote growth and reduce poverty, as well as associated external financing needs. Underlying principles for PRSPS include broad participation ${ }^{21}$ from both civil society and private sector in developing the strategy and fostering strong ownership ${ }^{22}$. PRSPS contain policies and programs, identify sector priorities, and sometimes include actual plans and budgets.

The fact that there are guidelines for the process developed by the international development community raises questions about the true national ownership of the documents.

\footnotetext{
20 Details on the different indicators stunting "wasting and underweight are explained in chapter three, section 5: Measuring Malnutrition.

21 The PRSP guidebook suggests this at minimum consultations with all stakeholders should be held, and the process should be open and participative.

${ }_{22}$ Ownership can be an ambiguous concept. In the PRSP process it refers to the state as a political entity and not to the nation, with a more cultural dimension (Piron and A. Evans 2004:5).
} 
Also, evaluation reports on the processes of development of PRSP are not entirely convincing about the success of the participatory approach or the leadership by the national governments. However, more recent reports show a positive trend with regard to the application of the guiding principles. More discussion on the validity of the PRSPs is included in chapter six. For this study, PRSPs are considered good datasources to observe whether or not malnutrition is a priority area in the overall development strategy of a given country.

The National Plans of Action for Nutrition were considered as an alternative data-source to obtain this information. These are the Plans that were developed as a follow-up to promises made by representatives of heads of state, at the International Conference on Nutrition (ICN) in 1992, to eliminate malnutrition in their respective nations. There is, however, little information on the progress made on the development and implementation of these plans, or the financing of the plans for that matter. Therefore they were rejected as good data-sources for the public accountability for malnutrition reduction proxies for this study ${ }^{23}$.

\subsubsection{World Bank Nutrition Lending Data-base}

The Nutrition Lending Database is a data-base on all nutrition interventions to which the World Bank has provided financial and technical support since 1976. The data-base is updated on a regular basis by the World Bank nutrition department/group. Other sources of nutrition investment were considered, such as using national finance law data. However, besides the data being difficult to obtain for a large number of countries and retro-actively, most countries do not include specific nutrition expenditures. They are often embedded in other types of expenditures or included in other sector interventions.

Other important development partners in the nutrition domain, such as UNICEF, WHO, FAO, WFP, USAID and other bi-laterals, do provide financing for nutrition. However, most of it is in the form of grants and technical assistance, forms of financing which are not usually listed in countries' expenditure reviews. The World Bank is the largest financier of nutrition interventions in developing countries. National governments use World Bank lending to close finance gaps in their national budgets and to borrow resources for those areas in which they want to increase investments. Therefore, this data is considered

\footnotetext{
23 A review of the existing progress reports was carried out though, for this
study, of which results are reported in chapter 6 .
} 
to a certain extent reflective of a trend in investment in nutrition interventions in developing countries. Data on investment for malnutrition reduction programs and interventions is available for only 32 of the 40 countries in the three regions included in this study.

\subsection{Summary and Conclusion}

This chapter laid out the conceptual framework, the hypothesis, research questions and methodology. The section on the methodology also introduced the data-sources and the justification for the use of these, and not, other sources. There is a qualitative and quantitative analysis of cross-country data.

It is hypothesized that good governance improves the enabling environment in which malnutrition reduction will be addressed as a development problem and countries with better governance are more likely to be accountable to and invest in malnutrition reduction programs. The central research questions include a theoretical part to identify the key-elements through which governance contributes to malnutrition reduction; and an empirical part to test the assumptions.

Existing databases are used for governance indicators and national poverty reduction strategy papers are used to collect data to create a score for public accountability for nutrition. Although there are data-limitations cross-country statistical analysis can be carried out using a data-set of 82 countries for the aggregate governance indices and malnutrition outcomes and data from 40 countries for the analysis on aggregate governance indices and public accountability for nutrition. The qualitative analysis is based on a country case, Madagascar.

The next chapter is a background chapter about malnutrition as a development problem. 


\section{Chapter 3: Malnutrition; a Heavy Tax on Development}

\subsection{Introduction}

The purpose of this chapter is primarily to provide a background on malnutrition, which due to its serious negative lifelong consequences on a person's health, learning ability, and productivity imposes a heavy tax on development that could largely be prevented. In this chapter, a review of what malnutrition is and why it is a development problem is described. It goes into details on the causes of malnutrition, including the immediate, underlying and basic causes, using the UNICEF causal model as the conceptual framework. It is highlighted that malnutrition is not a one-time or a one-cause event, but a gradual process of interlinked causes. A review of how malnutrition is measured and a discussion on the magnitude of malnutrition rates worldwide is also provided. References to further reading are made for those that would be interested in more details. The last part of this chapter is an overview of the type of programs that the World Bank supports as a background to the investment data that is used to analyze effects of improved governance and Public Accountability for nutrition.

\subsection{Malnutrition}

There is a very close relation between nutrition ${ }^{24}$, what one eats, and physical and mental welfare. Physical growth, maintenance of the body's functions, reproductive capacity and capacity to work reflect a balance between consumption of energy and nutrients on the one hand and physiological requirements and extra needs to cover exposure to (illness) on the other hand (Davidson 1983:255). This relationship becomes very clear due to acute nutritional imbalances in times of crises such as wars, droughts and economic recessions. However, it exists chronically among poor populations, due to chronic marginal food insecurity and poor environmental hygiene. As a result, people, and particularly young children, become gradually and chronically malnourished. At present, over 180 million children under five worldwide suffer from chronic malnutrition,

24 The World Health Organization (WHO) definition of nutrition is as follows: the process whereby living arganisms take in and transform solid and liquid substances necessary for maintenance of life, growth and the normal functioning of organs and the production of energy". 
the vast majority in developing countries (WHO Global Database 2004).

Among children under five years of age, protein-energy malnutrition (PEM) is the most often used term to describe a range of clinical disorders. Marasmus, the clinical term for severe malnutrition, is due to a continued restriction of dietary energy and protein, as well as other nutrients. Kwashiorkor is due to a quantitative and qualitative deficiency of protein, but in which energy intake may be sufficient. These are two extremes, but there exist many varying combinations of deficiencies of protein and energy, which are usually accompanied by micronutrient deficiencies (minerals and vitamins). Deficiencies of the latter also exist in combination with sufficient protein and energy. The most important for public health are vitamin A deficiency (VAD), anemia due to dietary iron deficiency (IDA), and iodine deficiency disorders (IDD). PEM and anemia are the most important public health problems in terms of magnitude in the developing world today. Malnutrition diminishes the ability of all systems of the body, in particular the immune-system, to perform properly with grave consequences in young children. PEM contributes significantly to mortality of under-fives in developing countries.

PEM occurs characteristically in children under 5 years, and peaks during the period when children are gradually taken off breast-milk and introduced to other nutrients. This is usually between 12 and 24 months, primarily due to a diet inadequate in energy and micronutrients that result from poor feeding practices and the coinciding increases in the occurrence of infectious disease. Malnutrition is a process that occurs over time, and thus preventing malnutrition requires time. Making sure a child is wellnourished requires attention many times per day. It is not a onetime intervention, but a continuous and time-intensive task, especially when children are ill.

Among adults, chronic energy deficiency is common, but pure protein deficiency seldom occurs. From a health perspective, the negative consequences of common energy deficiency in adults are most obvious among women, notably during pregnancy and lactation. Maternal under-nutrition is a major cause of low birth weight in their offspring (WHO 1995; Krasovec 1991).

\subsection{Malnutrition is a Development Problem}

Malnutrition in early life has a long-term negative impact. Malnourished children tend to have more severe illnesses, including diarrhea and pneumonia. There is a very strong association between underweight and child mortality. It has been 
estimated that out of 11.6 million deaths that occurred in 1995 among children under 5 in developing countries, 6.3 million $(54 \%)$ were associated with low weight-for-age (Pelletier 1993:1130). This is mostly due to moderate malnutrition, and not the more commonly monitored forms of severe malnutrition like marasmus and kwashiorkor. Also, micronutrient deficiencies are clearly linked with increased morbidity and mortality. Iron deficiency is associated with cognitive deficits in children (Seshadri and Gopaldas 1989), and severe anemia with maternal death (Galloway et al 2002).

The capacity to learn is negatively affected by malnutrition, as both chronic malnutrition and short term hunger can lead to paying less attention in class (Del Rosso 1996; Pollitt 1993; Grantham-McGregor 1993;). Also, malnourished children may receive less schooling because of their height, which often is used as an indicator by parents for readiness for school (Alderman et al 2002). Late enrollment leads to lower expected lifetime earnings. Glewwe and Jacoby illustrate that for each year of delay in entry to primary school in Ghana, a child loses 3 percent of lifetime wealth (Glewwe 1995:167). Besides the obvious human costs, there is an economic cost to government. Higher repetition rates among malnourished children reduce the effectiveness of public resources spent on education.

Malnutrition undermines development and poverty reduction. Child malnutrition is a manifestation of poverty. To the poor, 'not being worried about where the next meal is coming from' is seen as a sign of well-being. Malnutrition is also strongly related to income-poverty. Low incomes constrain the accessibility to adequate nutritional intake (Strauss and Thomas 1998; Behrman 1993). Low incomes also are associated with higher incidence of diarrheal infections. These infections reduce the absorption of nutrients, which can be very detrimental among low-income populations that have increased nutrient needs due to the necessity of performing hard physical labor (McGuire 1990). Higher fertility rates place an additional burden on the mother's physical well-being and demands for adequate food intake.

But, while malnutrition is an outcome of poverty, it is also important to understand the role of malnutrition in contributing to poverty. Adults suffering from iron-deficiency anemia, who are of small stature and underweight, have lower work outputs than better-nourished adults (Behrman 1993; Levin 1986). Horton aggregated the literature on the costs of low birth weight, malnutrition in young childhood, late school enrollment, reduced cognitive ability due to malnutrition or iron deficiency anemia, and the negative effect on adult productive life. She found that 
the loss in economic terms of foregone gross domestic product (GDP) can be as high as 3 percent of national income (Horton 1999:251). And this cost estimate may even underestimate of the true cost. It does not include the cost of vitamin A deficiency or diet-related chronic disease costs, which in China for example, have been estimated at 2.4 percent of GDP $^{25}$ (Haddad 2003:2). In addition, the costs of malnutrition in one generation can affect many generations to come (figure 3.1). Malnourished girls are more likely to be short, anemic and underweight (Allen and Gillespie 2001; Scholl and Hediger 1994). Girls who were malnourished as children themselves are more likely to give birth to low birth weight babies. Low birth is associated with a greater risk of chronic disease in adult life (Barker 1998). Figure 3.1 provides an overview of the causal links between malnutrition and consequences throughout life.

Figure 3.1: Nutrition throughout the Lifecycle.

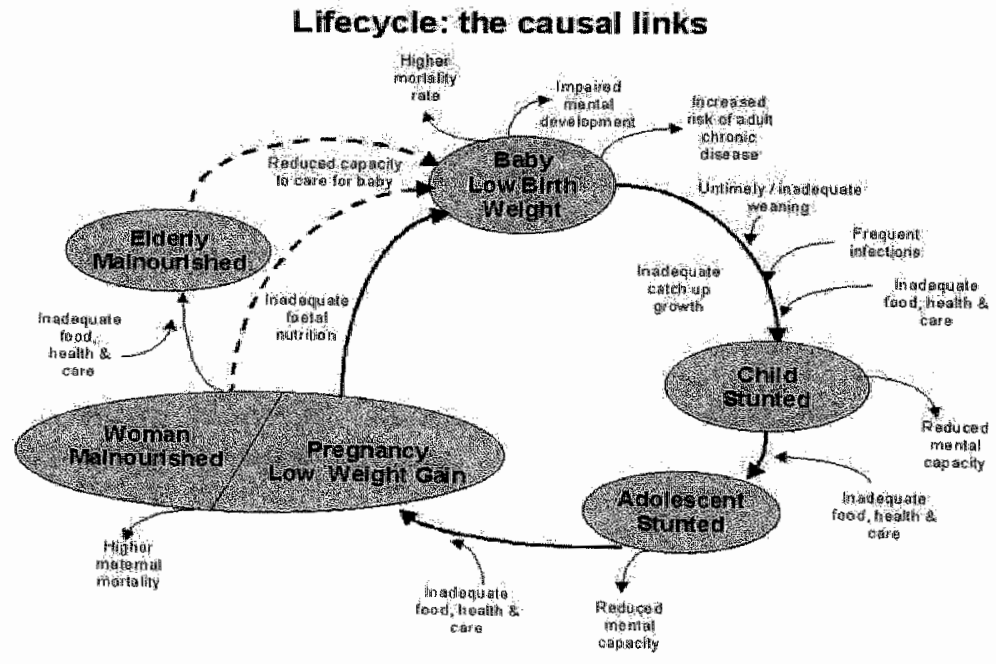

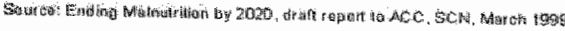

\subsection{Causes and Determinants of Malnutrition}

To explain the causes of malnutrition, one will need to look at three different levels. This is visualized in the widely accepted conceptual model of malnutrition of UNICEF in figure

\footnotetext{
25 And even this figure is a largely underestimated because it does not incllude
the loss of work due to illness, only death.
} 
2.1 in chapter two. The causes are classified at the immediate level (the individual child), the underlying level (household level), and the basic level (societal/community level).

The immediate determinants of malnutrition manifest themselves in the individual human being. They are dietary intake and health status. Malnutrition is a direct result of deficiency in intake of energy and protein, as well as other nutrients, such as micronutrients. Infectious disease adversely affect nutritional status and adequate growth by reducing appetite and thus food intake, decreasing nutrient absorption, increasing energy and nutrient requirements and they can even cause acute nutrient loss (Davidson 1983). Of all infectious diseases, diarrhea has the most marked effect on nutritional status, and can reduce a child's adequate growth and result in chronic malnutrition (Tompkins 1989). It is often seen among the poor that a child with diarrhea, with no access to basic health care, falls into a worsening spiral of malnutrition and illness.

The immediate determinants of malnutrition are in turn influenced by the underlying determinants manifesting themselves at the household level: food security, care, and healthy environment and access to basic services. Year-round food security is achieved when every person has access to enough food of the right kind to lead an active and healthy life. At the household level, it refers to the ability of the household to secure, either from its own production or through purchases, adequate food for meeting the dietary requirements of its members. The term food insecurity does not only mean lack of food, for it includes lack of availability (linked to food production and agriculture), lack of accessibility to food (which relates to the income and poverty pillar of food insecurity and distributional problems), and finally to intra-household distribution of foods and the gender issues.

Sound agricultural policies and a good food distribution system are crucial to provide food security at the population level. But even good agricultural policies and a good distribution system may fail to provide adequate nutrition if there is not a proper selection and preparation of food and subsequently equitable intra-household distribution at the household levell. Intra-household food security includes the latter distribution aspect of food security (van Liere 2001:7). Gender aspects play a large role in food security. Women play a key-role in the production and preparation of food. Women themselves often put

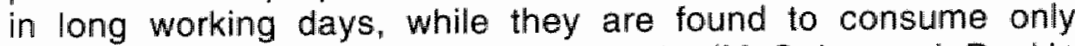
about two-thirds of their energy needs (McGuire and Popkin 1989). Programs that aim at improving food security through increased production often fail to take into account that a 
disproportionate burden of extra inputs is shouldered by women. The higher workload, combined with low energy-intake, may be detrimental to women's health and nutritional status.

Lack of food is often thought to be the only cause of child malnutrition. However, UNICEF estimates that inappropriate feeding practices are the cause of about at least 50 percent of chronic malnutrition among children under the age of three. Proper and appropriate child care, stimulation, and appropriate feeding practices during infancy and early childhood (up to two years) are fundamental to the child's development. And it is exactly this period that longitudinal studies have shown to be the peak age for growth faltering, deficiencies of micronutrients and diarrhea. After a child has reached two years of age, it is difficult to reverse stunting that has occurred earlier (Martorell 1994).

Ignorance about nutrition and inappropriate feeding practices in this period can lead to benign neglect with serious consequences. For example, the recommendation to exclusively breastfeed an infant during the first six months of life may not be followed due to lack of knowledge and/or pressure from family and society. Exclusive breastfeeding for the first six months of life provides infants not only with the most appropriate nutrition, but also protection against illness. This is because it requires no preparation, and so remains the cleanest source of food, and provides the anti-bodies that help prevent disease. Thus, early and abrupt cessation of breastfeeding may be the primary cause of the onset of malnutrition.

Ignorance about feeding during and after illness, such as using starvation treatment (offering the child only water, ricewater or other non-nutritious liquids for a period longer than 24 hours) during periods of diarrhea exacerbates the problem further. Malnourished children are at higher risk of becoming sick, and while sick they can become more malnourished, and thus they end up in the vicious circle of malnutrition and illness.

Evidence of the importance of feeding practices can be illustrated with data from Burkina Faso on the period when children's malnutrition peaks. Based on the evolution and type of malnutrition, one can reasonably assume that complementary feeding practices are inadequate (table 3.1). More than 90 percent of children are born and remain well nourished up to six months of age (adequate breastfeeding). By six months, when children need complementary foods in addition to continued breastfeeding, acute malnutrition (wasting) doubles and reaches over $25 \%$ by $12-23$ months. Stunting rates increase by almost 10 -fold between the ages of six months and two years old. This is most likely attributable to the lack of variety in the diet (often due to beliefs and myths about which foods children can 
tolerate), and the lack of sufficient amounts of complementary foods required as the child grows older.

Table 3.1" Malnutrition prevalence among different age groups in Burkina Faso 1998/9

\begin{tabular}{||l|c|c|c|}
\hline Age group & Stunting & Wasting & Underweight \\
\hline $6-11$ months & 5.0 & 6.9 & 4.1 \\
\hline $12-23$ months & 14.8 & 24.5 & 34.5 \\
\hline $24-35$ months & 45.1 & 25.4 & 51.9 \\
\hline $36-47$ months & 46.4 & 12.5 & 44.9 \\
\hline $48-60$ months & 50.8 & 5.0 & 33.4 \\
\hline
\end{tabular}

Source: Demographic Health Survey (DHS) Burkina Faso 1998/9, MacroInternational

The third underlying determinant of child nutritional status is the healthy environment and access to basic services. The healthy environment or nutrition conditions include the availability of safe water, hygiene, and sanitary conditions and access to health care and environmental safety, such as shelter.

Poverty affects all underlying determinants of malnutrition. Poverty ${ }^{26}$ can lead to low levels of parental education, poor water supply and sanitation, scarce resources to buy food, poor food availability and inadequate health care, all of which as shown above lead to increased risk for disease and poor energy and nutrient intake. Cultural factors, and influences by social and economic background, also play very important roles. Behavior is grounded in culture and social structures, manifesting through habits, values, perceptions, beliefs, attitudes and ideas. That malnutrition is higher among the poorer population groups is demonstrated with data available for a growing number of countries. However, the contribution of poverty to malnutrition is relative if people are homogenously poor, as illustrated by the examples in table 3.2 .

20 A person is considered poor when he or she is unable to satisfy his or her basic needs - food, shelter, water, primary education and community participation. 
Chapter 3: Malnutrition: a Heavy Tax on Development

Table 3.2: Malnutrition rates among the poorest $20 \%$ of the population and the population average for selected countries

\begin{tabular}{|c|c|c|}
\hline Country & $\begin{array}{l}\text { Wnderweight among } \\
\text { poorest } 20 \%\end{array}$ & $\begin{array}{l}\text { Uinderwelght } \\
\text { population average }\end{array}$ \\
\hline Bangladesh (1996) & 59.5 & 47.6 \\
\hline Yemen $(1997)$ & 55.6 & 46.1 \\
\hline Mozambigue (1997) & 36.9 & 26.2 \\
\hline $\operatorname{Tanzania}(1996)$ & 32.2 & 28.8 \\
\hline Uzbekistan (1996) & 25.1 & 18.8 \\
\hline Nicaragua (1997) & 16,0 & 9.7 \\
\hline Nepal $(1996)$ & 56.8 & 48.4 \\
\hline Cambodia (2000) & 52.0 & 45.0 \\
\hline Ghana (1993) & 32.6 & 24.8 \\
\hline Kenya $(1998)$ & 31.6 & 22.1 \\
\hline Morocco (1992) & 77.3 & 9.5 \\
\hline
\end{tabular}

Source: Macro-International, World Bank tabulation of various Demographic and Health Surveys

The underlying determinants of malnutrition are in turn influenced by basic determinants, the societal conditions as to the availlability of and equitable distribution of resources, and the cultural patterns of a society. In order to prevent and reduce malnutrition it is important to understand not only the nutritional status of a population or sub-group of a population, but also have knowledge of nutrition behavior of the different groups. Nutrition behavior can be defined as the manner in which one uses available food influenced by the economic, social and cultural pressure of the society one lives in. Thus, what is served and consumed depends on the price of food and income, the pressure of marketing, knowledge and education about food and nutritional behavior, and the cultural patterns of the society. The nutritional status of an individual is determined by the interaction with his or her direct environment and the circumstances of the family to which he or she belongs. For example, one of the explanations that malnutrition rates are higher in South-Asia than in Sub-Saharan Africa, despite the latter having higher incomes, may be due to the status of women (Smith and Haddad 2000).

Finally, the interface between the underlying determinants and the direct causes of malnutrition is important, and better understanding of this interface is the subject of this study. The interface is formed by formal and informal institutions and organizations. Included are organizational structures within line ministries for food safety and control, basic health services, education, community development, agriculture and sanitation. Consideration should also be given to institutions and laws to protect breastfeeding rights in the work place, iodization of salt enforcement, and oversight committees for agriculture policies that may affect nutrition. in most countries, nutrition suffers from the lack of clear government policy. This is attributable to the fact 
that decisions affecting nutrition are made in several different ministries.

\subsection{Measuring Malnutrition}

Growth faltering, an early warning sign of malnutrition risk, can be recognized by monitoring of a child"s growth: weighing and measuring the child on a regular basis and comparing these values with reference charts and tables ${ }^{27}$. Growth in children and body dimensions at all ages reflect the overall health and welfare of individuals and populations, as they reflect inadequate or excess food intake, lethargy, insufficient physical activity, and disease. Measured height and weight is compared with sex-specific values of healthy, well nourished age mates. Anthropometric indicators include: low Birth Weight (LBW<2500 grams) for newborns, stunting or low height-for-age $(\mathrm{HAZ})^{28}$, wasting or low weight-for-height (WHZ), and underweight, low weight-for-age (WAZ). Body Mass Index (BMI) is used for adults. Low height and weight relative to reference data have been used as classic indicators of under-nutrition in individuals and population groups (WHO 1995).

Data for malnutrition is presented as means and standard deviations or as distributions: the proportion of the population falling below a specific centile or below a standard deviation or Z-score. The Z-score is the difference between the value for an individual and the median value of the reference population, divided by the standard deviation for the reference population. Z-scores are the preferred reporting system because it normalizes the age- and sex-specific variances of different indicators at different ages. Table 3.3 summarizes the most useful terms for describing anthropometry in children.

\footnotetext{
${ }^{27}$ For developing countries the international reference, published by the WHO is used.

${ }^{28}$ Height for age reflects achieved linear growth and low height for age indicates long term (chronic) curmulative inadequacies of health and mutrition. This is also commonly called stunting.

Weight for height reflects body weight relative to height and reflects a vecent and significant weight loss usuaily a consequence of acute starvation oit severe disease.

Weight for age reflects body mass relative to chronological age.

Body Mass index = weight (in $\mathrm{Kg}$ ) / height $\left(\mathrm{m}^{2}\right)$.
} 
Table 3.3. Selected terms for describing anthropometry in children

\begin{tabular}{|c|c|c|c|}
\hline Indicators & Dutcomes & Process & Explanation \\
\hline $\begin{array}{l}\text { Low } \\
\text { Weight-for- } \\
\text { Age }\end{array}$ & $\begin{array}{l}\text { Under } \\
\text { weight }\end{array}$ & $\begin{array}{l}\text { gaining insufficient } \\
\text { weight relative to age or } \\
\text { loosing weight }\end{array}$ & $\begin{array}{l}\text { implies stunting or } \\
\text { wasting }\end{array}$ \\
\hline $\begin{array}{l}\text { High } \\
\text { Welght-for- } \\
\text { Age }\end{array}$ & $\begin{array}{l}\text { Over- } \\
\text { weight }\end{array}$ & $\begin{array}{l}\text { gaining excess weight } \\
\text { relative to age }\end{array}$ & implies obesity \\
\hline $\begin{array}{l}\text { Low Height- } \\
\text { for-Age }\end{array}$ & Stunted & $\begin{array}{l}\text { gaining insufficient } \\
\text { height relative to age }\end{array}$ & $\begin{array}{l}\text { implies long-term } \\
\text { malinutrition and } \\
\text { poor health }\end{array}$ \\
\hline $\begin{array}{l}\text { Low } \\
\text { Weight-for- } \\
\text { Helght }\end{array}$ & Wasted & $\begin{array}{l}\text { gaining insufficient } \\
\text { weight relative to height } \\
\text { or losing weight }\end{array}$ & $\begin{array}{l}\text { implies recent or } \\
\text { continuing current } \\
\text { severe weight loss }\end{array}$ \\
\hline $\begin{array}{l}\text { Hligh } \\
\text { Welght-for- } \\
\text { Height }\end{array}$ & $\begin{array}{l}\text { Over- } \\
\text { weight }\end{array}$ & $\begin{array}{l}\text { glaining excess weight } \\
\text { relative to height or } \\
\text { gaining insufficient } \\
\text { height relative to weight }\end{array}$ & implies obesity \\
\hline LOW MUAC:* & Thinness & Idem weight-for-age & $\begin{array}{l}\text { Idem Weight-for- } \\
\text { Height }\end{array}$ \\
\hline High MUAC & Fatness & Idem weight-for-height & $\begin{array}{l}\text { lidem Weight-for- } \\
\text { Height }\end{array}$ \\
\hline
\end{tabular}

Source: J. Kusin - adapted from WHO report (1995): Use and Interpretation of Anthropometry

Apart from weight for age or underweight measurements as shown above, stunting and wasting are being more often used as indicators of malnutrition because underweight does not differentiate a current or past insult. Stunting is a better measurement of long-term nutritional status, and wasting of recent illness, seasonal changes and food availability. However, underweight is the indicator used to monitor the Millennium Development Goals (MDG) because it is available for a larger number of countries than the other two indicators. Weight-for-age is more often collected because weight is easier to measure in young children than height and is more susceptible to change over a shorter period of time and therefore used in growth promotion programs. The MDGs are listed in annex 3 . They are a set of internationally agreed goals to which countries and institutions have committed themselves to reaching by 2015. The goals were formulated at the United Nations Millennium Summit in September of 2000, where 191 nations reaffirmed their commitment to eradicating poverty and attaining sustainable
development.

In order to determine whether malnutrition rates are of public health concern at the national or country level, the following classification in table 3.4 defined by the World Health 
Table 3.4: WHO classification for assessing severity of malnutrition by prevallence ranges among chilldren under five years of age

\begin{tabular}{|l|c|c|c|c|}
\hline & \multicolumn{4}{c|}{ Severity of malnuitrition by prevalence ranges (\%) } \\
\cline { 2 - 5 } Indicator & Low & Medium & High & Very high \\
\hline Stunting & $<20$ & $20-29$ & $30-29$ & $>40$ \\
\hline Underweight & $<10$ & $10-19$ & $20-29$ & $>30$ \\
\hline Wasting & $<5$ & $5-9$ & $10-14$ & $>15$ \\
\hline
\end{tabular}

Source: WHO 1995

\subsection{The Global Magnitude of Malnutrition}

Malnutrition is not a phenomenon that is equally spread among a population. It affects certain groups at certain times. For example malnutrition is highly prevalent in small farmer's families during the rainy season when food availability is scarce. physical needs for harvesting high, and infectious disease such as malaria and diarrhea are endemic. Among cash crop worker families who do not own land, malnutrition coincides with world market food prices of the produce. In the Caribbean, malnutrition is predominant in children of mainly female headed households (Kusin 1986).

The WHO Global database, which uses data from national surveys, Demographic Health Surveys (DHS), and compatible Multi-Indicator Cluster Surveys (MICS), covers about $87 \%$ of the world's developing populations. Although there has been improvement in reducing malnutrition since 1980, as illustrated in graph 3.1 and detailed in table 3.5, malnutrition remains among the most important development problems with almost one in every three children under five stunted. Graph 3.1 shows the trends in percentage of stunted children under five in developing countries and by region between 1980 and 2000.

\section{Graph 3.1.: Trends in Percentage of Stunted Children under flve years of} age

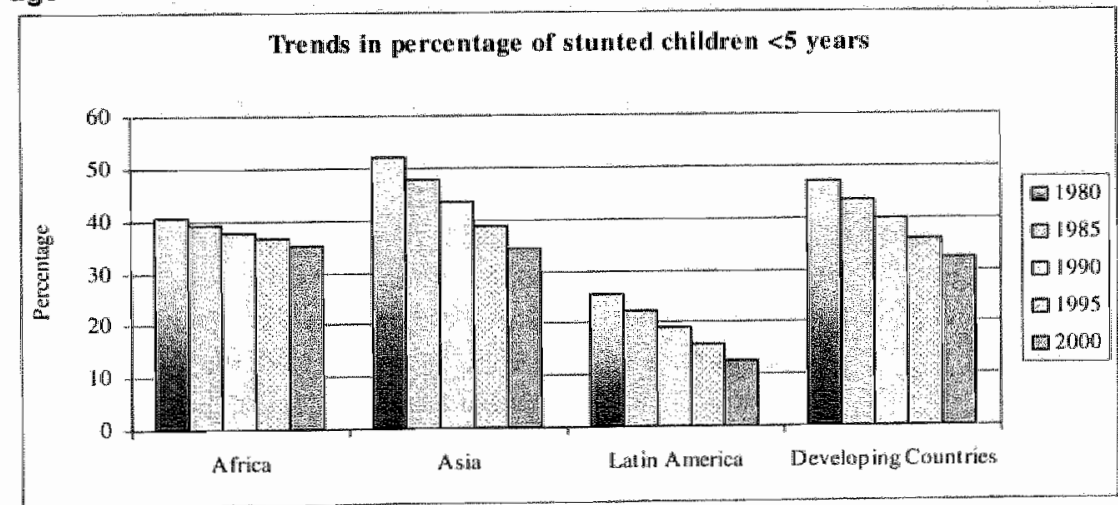

Source: WHO Global Database 
As shown in table 3.5, the highest number, in absolute terms, of stunted children live in Asia, of which $61 \%$ in South Central Asia alone ${ }^{29}$. Sub-Saharan Africa houses $24 \%$ of all stunted children. The highest percentage of stunting is found in the Eastern African region. For example, in Ethiopia $64.2 \%$ of children under the age of five are stunted. Malnutrition rates have increased over time in this region. Half of the countries in the region for which data are available show increasing rates of mainutrition. The Western African region has a much lower stunting prevalence, but its progress has been almost stagnant over the last 20 years. As a result of increasing population numbers, the absolute number of malnourished children increased from nine million to over 14 million.

Although South Central Asia has the highest number of malnourished children, there is a strong decreasing trend, especially in South-East Asia, but this is largely driven by the decline in China. The prevalence for Latin America and the Caribbean continues to decline, although there remain countries in the region with unacceptably high prevalence, such as Guatemala.

Table 3.5: Estimated prevallence and number of stunted children $1980-2005$

\begin{tabular}{|l|c|c|c|c|c|c|c|c|}
\hline & \multicolumn{3}{|c|}{ Prevalence of Stunting (\%) } & \multicolumn{3}{|c|}{$\begin{array}{c}\text { Number Stunted (million } \\
\text { rounded) }\end{array}$} \\
\hline Regions & 1980 & 1990 & 2000 & 2005 & 1980 & 1990 & 2000 & 2005 \\
\hline Africa & 41 & 38 & 35 & 34 & 35 & 42 & 47 & 49 \\
\hline Eastern & 47 & 47 & 48 & 49 & 13 & 17 & 22 & 24 \\
\hline Northern & 33 & 27 & 20 & 17 & 6 & 5.6 & 4.4 & 3.9 \\
\hline Western & 36 & 36 & 35 & 35 & 9 & 12 & 15 & 16 \\
\hline Asia & 52 & 43 & 34 & 30 & 173 & 168 & 128 & 110 \\
\hline South-Central & 61 & 52 & 44 & 39 & 89 & 93 & 79 & 72 \\
\hline $\begin{array}{l}\text { South-East } \\
\text { Latin America \& }\end{array}$ & 26 & 19 & 13 & 9 & 13 & 10 & 6.8 & 5.1 \\
\hline $\begin{array}{l}\text { Caribbean } \\
\text { Caribbean }\end{array}$ & 27 & 22 & 46 & 14 & 0.9 & 0.8 & 0.6 & 0.5 \\
\hline Central America & 26 & 25 & 24 & 24 & 3.9 & 3.9 & 3.9 & 3.8 \\
\hline South America & 25 & 17 & 9 & 5 & 8.4 & 6.1 & 3.2 & 1.8 \\
\hline $\begin{array}{l}\text { All developing } \\
\text { countries }\end{array}$ & 47 & 40 & 33 & 29 & 221 & 220 & 182 & 165 \\
\hline
\end{tabular}

Source: ACC/SCN Fourth Report on the World Nutrition Situation, January 2000

\subsection{Preventing and Reducing Malnutrition}

Although to date only few evaluations have been carried out in a rigorous manner, so that reduction in underweight can be attributed to the programs interventions, there is reasonable evidence that improvements of at least $1-2$ percentage points per

29 South Central Asia includes Afghanistan, Bangladesh, India and Pakistan. 
year can be achieved with large scale nutrition programs (Gillespie, Mason and Martorell 1996:59).

There are several types of nutrition programs that have reduced malnutrition effectively, and overviews of those programs have been documented ${ }^{30}$. A definition of what success in nutrition means is defined in the World Bank publication Combating Malnutrition as follows: Success in nutrition requires more than just achieving desirable outcomes such as reduced child malnutrition. Good outcomes require good processes. In Development as Freedom, Amartya Sen uses 'culmination outcomes' to explain that to achieve the outcome, the process of achieving it is also important (Sen 1999). Combating Malnutrition continues: Increasingly a 'good process' is defined as one in which participation, local ownership, and empowerment, are the driving forces. Focusing on process aligns with the human rights rationale for action wherein beneficiaries are active participants of their own growth and development rather than passive recipients of welfare transfers (Gillespie et al 2003:26).

Transfer programs, such as food stamps and emergency or relief food distribution programs, show modest impact on malnutrition reduction. The Mexican program PROGRESA combines income transfers with supplemental feeding and health care delivery and reduced malnutrition (Skoufias et al 2002). Community based child growth promotion programs have demonstrated encouraging results and are more in line with the process and participation factors of successful programs. For example, the Tamil Nadu Integrated Nutrition Project (Berg 1987), the Tanzania Iringa Nutrition Project (Levinson 2003), Thailand's National Nutrition program (Heaver and Kachondam 2002), recent experiences with the Community Nutrition projects in Seneglal and Madagascar (Seecaline), the Bidani program in the Philippines, and the Integrated Nutrition Practices (AIN) program in Honduras (van Roekel 2002) all show positive impact on the nutritional status of the targeted beneficlaries of the programs.

In addition, beneficiary assessments of some of these programs indicate some level of ownership over the programs at the local community level. The growth promotion programs (Bidani, AIN and Seecalline) cover simillar nutrition activities: child growth monitoring; promotion of breastfeeding, nutrition education and inter-personal counseling, promotion of adequate

${ }^{30}$ See for example: the ACCISCN reports Nutrition-Relevant Actions (1991) and How Nutrition Improves (1996); Feeding Latin. Amevica's Children by Musgrove (1991) and What Works? A Review of the Efficacy and Effectiveness of Nutrition interventions by Allen and Gillespie (2001) 
complementary feeding, in some cases provision of weaning foods, and micronutrient supplementation programs.

But, many of those large-scale successful programs encounter sustainability problems. A majority are financed by external funds and donors, and when donors pull out, it is not always the case that the national government takes over the responsibility to manage and finance the activities. In addition, many other nutrition programs remain small-scale pilots, and encounter serious scaling up problems.

\subsection{World Bank supported Nutrition Projects and Programs}

The World Bank ${ }^{31}$ invests in a considerable number of different projects and interventions that have nutrition improvements as objectives. They follow several key-strategies ranging from targeted food transfer programs, provision of essential nutrition services to vulnerable populations (children under five, school-aged children and pregnant and lactating women), supplying critical micronutrients, and building capacity for nutrition programming. The following overview of the projects and programs supported by the World Bank is far from complete. It is not meant to provide an exhaustive background of what works in reducing malnutrition ${ }^{32}$.

Many countries provide costly consumer food subsidies, or other types of food transfer programs (such as school feeding), with the general objective to improve the nutrition situation of the general population or a particular target group such as school children. The World Bank has supported countries make the shift from financing general food subsidies to identifying mechanisms to reorient and target these programs to make them more costmeffective, thereby reaching the poorest and most vulnerable populations to increase the impact on malnutrition. Examples ${ }^{33}$ of this type of World Bank support can be found in Tunisia and Mexico. In Mexico, means testing ${ }^{34}$ was used as the targeting mechanism for a food-coupon program that was redesigned under an agriculture adjusiment project (Selowsky 1991). In Tunisia a subsidy on milk was redesigned to target the poorest rather than the then main users of the subsidy,

\footnotetext{
"Annex 1 provides details on World Bank Basic Facts; its purposes, resources, pollicy dialogue instruments and lending instruments.

books those interested in more details on the latter, the following papers and ACC/SCN no.19 What Works? A review of thew Nutrition Improves (1996); Nutrition Interventions (2001); and Anemia Prevention and and Effectiveness of (Gailloway 2003)

33 Several more examples can be found in Selowsky (1991).

${ }^{34}$ Using peoples purchase power as a criterion for inclusion in the program.
} 
the better off (Tuck and Lindert 1996). The program discontinued the high-cost subsidies on milk; discontinued expensive packaging used by the well-off, and subsidized only the inexpensive packaged milk used by low-income consumers. In the Dominican Republic, Venezuela and Honduras, geographic targeting was used to reach the poorest populations with specific nutrition interventions.

One of the potentially most cost-effective tools for identifying and targeting nutrition and health interventions is monitoring of a child's weight, which permits early detection of growth faltering, often not visible to the eye, making it possible to counsel the care-giver to prevent malnutrition from occurring: Preventing malnutrition through early detection is far more costeffective than treating children who are malnourished. However, growth monitoring is often used as the only intervention, and is not effective alone in preventing malnutrition. Growth promotion through active counseling of caretakers, nutrition education in general, medical referral, and basic health services provision at the community level (Community-based Integrated Management Childhood IIIness- IMCI) are necessary interventions. The World Bank supported nutrition program that implemented all of the above actions is the Tamil Nadu Integrated Nutrition project in India. Zimbabwe, Bolivia, Bangladesh, Ethiopia, Uganda, Madagascar, Senegal, Mauritania and Iran, all have similar projects and countries such as Benin. Honduras, El Salvador, Nicaragua and Guatemala are preparing them.

Food supplementation, although far from being the main component in nutrition projects, was the main component in terms of costs, and was provided in earlier years indiscriminately to all children under five. Currently, growth monitoring is used to target nutrition counseling to all children and to complement food supplementation, which is given mainly therapeutically to those malnourished. Activities such as food fortification are also ongoing to improve the nutritional quality of food. These components are included in projects in Tanzania, Burkina Faso, Madagascar and Senegal in collaboration with the World Food Program.

Even in the absence of supplemental food, changing behavior has a substantial impact on improving nutritional status and reducing malnutrition. Exclusively breastfeeding infants under 6 months of age reduce the risk of serious illness and even death. Additional gains in giving adequate energy and micronutrients to young children starting at six months can be achieved through active feeding and improved hygiene practices and reduces the risk of infection and diarrhea. Behavior change through counseling and nutrition education is essential to growth 
promotion activities. All growth promotion projects the World Bank supports include these interventions.

Supplying micronutrients to address iodine, iron and vitamin $A$ deficiencies can have significant impact on the targeted population. The costs of micronutrient supplementation are low, and combined with nutrition education, the benefits are considerable (Galloway 2003; World Bank 1993; Lancet articles $2003^{35}$ ). There are many examples of projects the World Bank supports that include micronutrient supplementation. Not only nutrition projects, but many health sector projects include the provision of vitamin A supplements through for example national immunization days. Through education projects, school-aged children receive iron supplementation, nutrition education and deworming medication, also an intervention to improve overall nutritional status. In addition, in Madagascar, school children check every 6 months whether the salt used in their household contains iodine. lodized salt is the most effective fortification strategy to prevent serious mental retardation caused by iodine deficiency.

Also through agricultural loans, nutrition interventions are implemented. For example, agricultural inputs are accompanied by nutrition education: promoting small gardening to improve the quantity and quality of the diet, providing key inputs to women's organizations that support household food production, and providing labor saving devices such as small mills that help reduce the energy expenditure of women and help to reduce the risk of malnutrition during pregnancy.

Last, but not least, to build the capacity for nutrition programming, World Bank projects commonly include resources for financing surveys, operational research, and for local capacity building through organizing study tours and training of personnel. Training in implementation and supervision is a large part of nutrition projects, because of the intensity of the interventions and the numbers to reach (in most programs all children under the age of three in a certain area). This requires intensive supervision. Monitoring of the interventions and eventually evaluation also form large parts of the investment and provide many opportunities for capacity building. And not to forget,

\footnotetext{
The Lancet Articles on Child Survival published in the Lancet Volume 361 and
362 (2003) including Black R.E.. S.S. Morris and J. Bryce Where and Why are
10 Milion Children Dying Every Year? 10 Million Children Dying Every Year? Jones G., R. W. Steketee, R. Black, A. $J$ J, $S$ el Arifeen, $G$ Pariyo, Many Child Deaths can we Prevent this Year? Bryce Mortality: can Public Health Deliver?. V. Gwatkin, J.P. Habicht. Reducing Child Schellenberg. D. Gwatkin. M Deliver?; Victora C., A. Wagstaff, J. Armstrong Child Health and Mortality: More of the S. Habicht Applying an Equity Lens to Study Group on Child Survival Knowledge into is not Enough; and the Bellagio
} 
advocacy, creating awareness of nutritional deficiencies and the consequences, is an important component. Usually it targets a large group, ranging from the beneficiaries in the communities to high level politicians to foster support for the programs.

Beyond lending for nutrition, the World Bank provides policy advice and sectoral analysis. It helps governments assess nutrition situations and analyze trends. It helps governments design, implement and evaluate projects. Not only is this done for countries, also regional analysis and strategies are developed by the World Bank. These strategies are based on the needs in the particular region, lessons learned from earlier experiences and are carried out in collaboration with the WB partners as UNICEF, WHO, WFP, FAO and agencies as international Food Policy and Research Institute (IFPRI), Micronutrient Initiative, the Manoff Group, and Academy for Educational Development (AED) among others.

\subsection{Summary and Conclusion}

The purpose of this chapter was to provide a general background on malnutrition and its importance as a development problem. In addition, information on how it can be measured was provided as background to the empirical data-sources for this study. This chapter also was meant to provide the reader with the understanding of what constitutes a good nutrition program. Good in the sense of having impact, but also implementing processes that are conducive to malnutrition reduction and costeffective. Malnutrition is not an end-point but rather a process. Eating is a daily activity, multiple times per day, that has been over-medicalized by the health sector, to a disease, and oversimplified by the agriculture sector, as a lack of sufficient food. Behavior change, from eating healthy during pregnancy, exclusive breastfeeding and appropriate weaning practices, are complex, but necessary interventions.

The malnutrition reduction interventions and programs that are included in this book as programs that reduce malnutrition are those that focus on behavior change, and to a much lesser extent on food-inputs. As shown in this chapter, more efforts are put in place to move away from food-subsidies and food distribution. It is widely accepted that in order to improve the nutritional status of small children and infants, changing behavior of care takers towards better practices is more effective than providing food. The latter is also less sustainable and more costly. It should be clear from chapter one that building commitment and accountability for such nutrition programs, i.e. which focus on behavior change, are more difficult 
than finding support for food-distribution programs. Even though the latter are less effective, they are more visible which makes them politically more attractive. The last section focused entirely on the World Bank's nutrition programs, and was meant to provide insight in the type of interventions the World Bank supports, because those are used in chapter seven to collect data from for analyzing investment trends. The next chapter aims at putting malnutrition reduction in the context of development policy and development assistance. 


\section{Chapter 4: Development Assistance and Malnutrition}

\subsection{Introduction}

The purpose of this chapter is two-fold. First, it shows how development assistance evolved from believing that overall economic growth would induce development to the understanding of the importance of governance and good policies and institutions. And second, it puts malnutrition reduction in the context of the evolvement of overall development assistance and how this may have influenced thinking about malnutrition. Although the main focus of this study is on the last fifteen years, the overview here covers the last five decades. It starts with the establishment of the Bretton Woods institutions in 1944 and the United Nations in 1945, and includes changes over the next five decades of development assistance. The fact that development is complex is demonstrated by the many turns and changes in development policies and the widely varied success and failure rates experienced around the world over the last half century. Box 4.1 is included to give an idea of the importance of development assistance showing the magnitude of resources provided in aid to developing countries ${ }^{36}$.

This chapter does not provide a comprehensive review of the history of development assistance policy. It also does not pretend to describe the complete evolution of thinking in reducing malnutrition. It merely summarizes what was deemed relevant for the topic discussed in this study. Since much of this study is focused on World Bank development assistance from the both malnutrition and a governance perspective, specific references to the agency are made, as in all of this book's chapters. Although governance is addressed in this chapter as part of the development policy dominating current theories, it is described in greater detail in chapter five. In the conclusion, a discussion is included on the degree of facilitation general development theory provided to malnutrition reduction over the decades.

36i For a more comprehensive overview of development aid, Degnbol and Engberg-Pedersen provide a comprehensive review in Aid, understanding International Development Cooperation (2003) published by Zed Books Lid, London ${ }^{36}$. 
Box 4,1: Orficial Development Assistance (ODA)

The order of magnitude of ODA

In the 1960 s the UN General Assembly approved a declaration to make 1 percent of GDP of the industrial countries avallable to developing countries. This included all transfers and private investments. Most countries have never come close to that figure in the last decades. Between 1970 and 1992 it averaged $0.35 \%$, between 1990 and $2000,0.25-0.30 \%$ (Degnbol 2003:607. sources OECDIDAC) An example of the order of nagnitude. In 1998 about US\$56 billion dollars were transterred from donor countries to $\mathrm{DAC}^{38}$ developing countries. of this amount about one third was provided through the World Bank under the terms of so-called soft loans? As an example of regional distribution of Oversees Development Asisistance (ODA), Sub-Saharan Africa recelved the bulk of ODA in 1998, almost $30 \%$ sectoral allocations to the social sectors health and eductition, increased trom about $20 \%$ in the 1970 s and 1980 s, 10 about $30 \%$ In the 1990s. The significance of loreign aid as a proportion of total GDP differs per region and is most important for Sub-Saharan Arrica, with 11.5\% of ODA of total SSA GDP, For individual countries the contribution can be even more significant, For example, Mozambique recaived $28.2 \%$ of GDP in ODA in 1998 . Burkina Faso $15.5 \%$, and Boliva recelved US879 per capita in ODA (representing $7.5 \%$ of total GDP)

\section{To put this into context:}

The calculation of ODA dollar amounts should be interpreted with caution. The amount in dollars of ODA is defined on the basis of stated goals, not actual effects (Degnbol 2003,57 ). Nor is there an official figure for how large a share of aid is actually used in donor countries themselves (for refugees for example) Also, the definition of reciplent countries of ODA is not the same as the definition of developing countries. in the 1960 s several econemists tried to calculate how much ODA would be needed to achieve the then development gaals of economic growth. Besides the thuctuations in these figures, the donor community never accepted this demand driven approach. Bather, they assessed how much could and would donors contribute (Degnbol 2003.58 ). Last, although the flow of ODA may seem large with around US\$ $50-60$ billion, it is quite small in terms of incomes of rich countries, namely only 2 cents for every US\$10 earned Ritzen 2005.11 )

\subsection{The 1950s and 1960s: Economic Growth and Malnutrition as a Metabolic Disease}

\subsubsection{Economic Growth}

After World War II, the Bretton Woods institutions - the World Bank (WB) and the International Monetary Fund (IMF) and the United Nations (UN) were established. Each had their specific objectives. While the UN's function was to promote international cooperation to achieve world-wide peace and

\footnotetext{
${ }^{37}$ See for more details on per country aid and comparisons with donor countries wealth and growth Degnbol 2003, chapter 5.

${ }^{38}$ Development Assistance Committee

39 World Bank IDA loans, so-called soft loans, are prowided at a lower than 1 percent interest rate, payback requirements start only after 20-40 years.
} 
security, the WB was established for reconstruction and economic growth in then war-torn Europe. The goal of its sister organization, the IMF, was to maintain financial stability and prevent economic disasters, silmilar to what happened in the 1930 s, in part due to the 'beggar thy neighbor" politics. Between 1958 and 1962, with the recognition of the phenomenon of poverty, further burgeoning in the establishment of both biand multi-lateral development assistance agencies took place, with among others the European Investment Bank, CIDA, IDA, and DAC. This second group was established primarily to assist the poor, while the earlier agencies drifted towards this goal over time.

The attention to development in the 1950 s focused on rebuilding war-torn Europe and promoting economic growth in the developing world. Much of the assistance was supply-driven, based on perceived needs by the Western World, and with an emphasis on the interests of former colonizer"s own interests; "i.e. special attention given to former colonies or where economic benefits appeared most beneficial to the donors instead of the developing countries. The dominant development theory in the 1950 s focused on the need of developing countries to invest in capital and modern technology to close gaps in their economies and boost development. In accordance, the international agencies developed strategies to reach that goal by focusing on building infrastructure, mainly physical (roads, ports, telecommunications, etc.), and modernizing technologies. It was expected that modern technology would trickle down and modernize the traditional society (Degnbol 2003:44).

The Marshall Plan was developed to support the rebuilding of the European economy through the provision of large-scale international income-transfers. Its success facilitated progress towards trade liberalization and collaboration between donors and recipients. Because of this success, the development activists in the UN were hopeful for large-scale, multi-annual Marshall Plan-type aid for developing countries. However, the success in Europe did not translate to the developing world (Singer 2001). Among the various reasons for thils failure ${ }^{41}$ was the delay in establishing the World Trade Organization ${ }^{42}$, which

\footnotetext{
40 Countries relled heavily on equilibrating market mechanisms and got themselves deeper and deeper into competitive devaluations, heavy deflation, rising unemployment and protectionism with terrible social and political consequences.

41 For a detailed account see Singer 2001.

4:2 The WTO arganization. as envisioned by Keynes, was not established until 1995.
} 
was to accompany financial and technical assistance provided by the Bretton Woods and UN-agencies ${ }^{43}$.

The early 1960 s were optimistic regarding development. There was steady economic growth in Latin America and Africa. Medical breakthroughs decreased mortality and food was available, even in surpluses. However, by the mid-60s, food deficits and social collapse occurred in many developing countries. The so-called 'white elephants'44 began to emerge. Dissatisfaction with the development theory began to spread. Earlier optimism waned quickly and assistance strategies needed rethinking. The Harrod-Domar formula of 'more savings and investment leads to more growth ${ }^{45}$, gave way to the understanding that development is more complex, and that it involved human factors to succeed as well as physical capital (Singer 2001:50). In the late 1960s, there was a shift towards more emphasis and investment in human capital, measured by school enrollment rates as a proxy for education and life expectancy as a proxy for health.

The World Bank was largely absent from the debate on development assistance in the first decade of its existence, despite the fact that it was already one of the largest financers of development. In the early days, it was primarily pre-occupied with gaining triple AAA status ${ }^{46}$. It had to establish itself first and foremost, according to its Board of Directors, as a worthy investment and sell its bonds (Kapur 1997). In fact, the WB in the $1950 \mathrm{~s}$ was considered more a financial institution than a development agency.

However, by 1969 , the Bank had become a Bank of the poor, increasing its lending to the poorest countries, while reducing lending to middle-income countries. What helped educate the Bank on poverty was its close collaboration after 1961 with the UN-organizations (Kapur 1997). They assisted the Bank in preparing education and agricultural loans. At that time

\footnotetext{
${ }^{43}$ When Keynes was asked by the Minister of Information of Britain in 1940 to develop a counteract to the New Order as proposed by Walter Funk. Hitler"s Finance Minister, Keynes vision foresaw tour pillars: global economic management (Later IMF), a development finance mechanism (later WB) an international trading organization (ITO), and an aide program (UN). See Singer 2001 pages $35-40$ and $95-97$ for details.

14 Development projects that are obvious fiascos, flagships of modern technology not adapted to the local circumstances or surrounding infrastructure are so-called white elephants.

45 Development models in the 1950 s and 1960 s focused on constraints that resulted from limited capital accumulation and inefficient resource aliacation. the objective in those decades.

46 Tripl AAA status is decades. Wall Street.
} 
UNESCO, FAO and WHO (for water and sanitation projects) were the major donors (currently also ILO, UNICEF, WFP, UNAIDS, and UNEP are among the main players assisting the Bank's project preparation). They were involved in preparing the Bank for its poverty orientation in the 1970s. The United Nations in the first two decades of its existence and in contrast to the WB, focused largely on the human rights issues. In the 1980s; the UN became the biggest critic of the WB structural adjustment policies in the 1980s with its publication of Adjustment with a Human Face (Cornia 1987).

\subsubsection{Malnutrition as a Metabolic Disease}

While development assistance in general progressed from pure economic growth to include the importance of human capital, malnutrition went from being a metabolic disease to a chronic multi-dimensional problem. In the 1950s, the scientific understanding of protein-energy malnutrition and micronutrient deficiencies was rather limited to their clinical forms, kwashiorkor and marasmus for energy deficiency, and physical signs of vitamin and mineral deficiencies (scurvy, nutritional blindness, pellagra, goiter, etc). The international nutrition community in the early years of development assistance was therefore primarily interested in the metabolic consequences and treatment of severe protein deficiency. Research focused on technological solutions, such as the development of protein concentrates and high lysine ${ }^{47}$ varieties of certain crops. In 1955, a United Nations Protein Advisory Group was established with the mandate to focus on the 'protein gap'. At the time, the theory that protein was the key nutrition problem fit well into the then conventional wisdom of development theory and legitimized the donor agency philosophy that 'they lack something we have, so let's give it to them' (Jonsson in Pinstrup-Andersen 1993:202).

In the 1960 s, new data from national surveys highlighted not only the magnitude of the malnutrition problem, but also that is was predominantly among the poor and in particular in rural areas. Analysis of household food consumption patterns showed that if diets were adequate in energy, then protein too would be adequate. This led to changes in the understanding of the problems of malnutrition. Protein-deficiency was not the main problem. In response to the new understandings that energy as a whole was a problem, and especially among the poor, nutrition interventions started to focus on food distribution and the establishment of malnutrition recuperation centers in hospitals

${ }^{47}$ Lysine is an amino-acid, a building block of proteins. 
for children with severe malnutrition symptoms (Levinson and McLachilan 1999). The focus was now on hunger, rather than chronic malnutrition, and food production and provision of food was seen as the solution. The importance of child-feeding practices was not yet recognized. At the same time, farm subsidies led to overproduction in the West and produced large food surpluses. These were used to be sent to developing countries to meet their food deficits. This food aid may in fact have further depressed developing countries' own food production and distorted their economies, although this is still being debated.

Through the 1960s, nutrition advocates attempted to apply the human capital theory to nutrition by promoting the plausible theory that improved nutrition status increases physical capacity, time spent on the job, and may boost productivity ${ }^{48}$. The theory has since been empirically underpinned, but it has never attracted major public resource commitment (Field and Levinson 1975). It was only at the end of the 1960s that malnutrition was recognized as a multi-sectoral issue. The relationship between malnutrition and infection became clear and environmental and socio-cultural causes of malnutrition were highlighted (Pacey and Payne 1985). Community-based applied nutrition programs were launched in the 1960s in about 65 countries, but they did not apply the knowledge that malnutrition is multi-sectoral, so that action was not multisectoral in nature. These programs remained highly supply-driven, and later it was generally found they were unsuccessful in meeting their goals of reducing malnutrition.

\subsection{The 1970s: Including the Poor and Malnutrition as a Development Problem}

\subsubsection{Including the Poor}

The expected trickle-down effect of economic growth leading to improved welfare for all did not transpire as quickly as expected, and in some countries this did not happen at all.

Although the expectations of growth had been exceeded in the 1950 s and $60 \mathrm{~s}$, this was in the aggregate. The economic gap among countries and regions was widening rapidly, not to mention the gap within countries. It is estimated that the ratio of per capita income between the richest and the poorest countries

\footnotetext{
48 The promotion for this theory came primarily from Theodore Schultz who postulated that capital stock has a human as well as a physical component,
published in 1961 .
} 
increased six fold between 1870 and 1985 (World Bank 1997). Also within countries, the distribution of the increases in income as a result of growth was unequal. The latter was not recognized as a problem until later, when more detailed household survey data became available.

The development strategists in the 1970 s reacted to these concerns. The response by most of the development agencies was to embrace a strategy that was concerned with addressing issues pertaining to the poor, such as unemployment and more equal income distribution, a focus on social sectors, and assistance to basic human needs (Lewis 1988:5). Also in the 1970 s, women's status and gender issues were increasingly addressed.

Aid strategies in the 1970 s changed significantly, by focusing on poor people because they were recognized as a productive force. The WB's publication Redistribution with Growth (1974) was one of the central background works to the above, together with the United Nation's ILO work on Employment, Growth and Basic Needs (1976). In those publications, the accent was put on improving economic growth, while focusing on reducing poverty in rural areas by assisting the poor to produce more food on their own behalf (Lewis 1988). The idea was to do more for the poor directly, instead of through macro-economic policies that would lead to improved well being for the poor.

The 1970's can in fact be regarded as a breaking point in development thinking: from supply-driven, charity-induced vertical programs to more comprehensive and integrated approaches. The latter were more sustainable because of the focus on building capacity and emphasis on the poor. There was also a shift to emphasize employment because of the increasing unemployment problems in both urban and rural areas (Singer 2001). The overall dominant aid strategy at that time was integrated rural development projects (Degnbol 2003).

The poverty focused strategy was largely led by the World Bank, which by then had evolved in its thinking in development matters. The 1970s for the WB were also clearly marked by its then president, Robert McNamara. He started integrated rural development with the landmark speech in Nairobi in 1973, stating the Bank would support small-scale farmers, a new idea at that time. From then on, each project was supposed to be presented to the Board of Directors for approval with clear statements about how it would contribute to reducing poverty. Although it is said that McNamara took the Bank from a financial institution to a development bank, he is also criticized for pushing large amounts of lending, which contributed to the enormous 
debt burdens of poor countries in the 1980 s (George and Sabelli 1994). In imitation of the World Bank, most of the bilateral donors, including the United States Agency for International

Development (USAID), followed to revise their strategies and include programs along much of the same lines as described above. In 1973 for example, the USAID Foreign Assistance Act codified a new directional approach to foreign economic assistance as follows: Development Assistance is, by statute, now to be focused on several major sectors including, food and nutrition, population planning and health, and education and human resources development (USAID History of Foreign Assistance $)^{49}$.

\subsubsection{Malnutrition as a Development Problem}

Several events in the 1970 s led to an increased interest in the consequences of malnutrition. In 1971, a conference was held at Massachusetts institute of Technology (MIT) on Nutrition and Development, with the objective to study the relationship of nutrition to economic development. The 1973 publication of The Nutrition Factor by Alan Berg further advanced the focus on nutrition as an input to development. At the same time, the notion that nutrition should be considered a measure of the success of development programs was proposed (Rogers 2003). The world food crisis at the time, due to adverse weather conditions and policy changes resulting in food shortages and high prices, was the focus of the 1974 World Food Conference held at FAO in Rome. More research became available after the crisis, and demonstrated that distribution and access to food at the household level, rather than aggregate global food supply was at the root of the food crisis. Better computers and analytic techniques made possible the widespread use of household surveys to analyze the determinants of nutrition problems and the outcomes of nutrition related policies and programs (Rogers 2003). The 1975 conference on 'Women in Development' gave prominence to the importance of intra-household dynamics as a determinant of nutritional outcomes.

Radical changes in viewpoints regarding nutrition determinants were summarized by Pacey and Payne in their publication on Agricultural and Development and Nutrition (Pacey and Payne 1985:18-9). They gave three reasons underlying the changes in viewpoints: 1) malnutrition became regarded as a multiple cause issue and not a single factor problem; 2) there has been progress in the nutrition community's

\footnotetext{
49. WWw usaid gov
} 
understanding of psychological and biological processes underlying malnutrition, such as the adaptation processes to stress situations and the consequences; and 3) there was growing awareness that many of the conventional nutrition programs have not achieved what was hoped, such as promotion of high-protein crops.

In line with the new developments in thinking about mainutrition, the UN Advisory group that had started in 1955 saw its mandate broadened to concentrate on improvement of breastfeeding, maternal and child nutrition, and complementary feeding in 1977 (Mason in Gillespie et al 2003). Information about households and their nutritional status also became important in national agricultural planning. For example, the "green revolution' in Asia demonstrated that increases in food output can in fact have negative influences on the nutritional status of some groups (Pacey and Payne 1985:128). Brown in Africa's Choices, Thirty Years After the World Bank states that the green revolution experiments failed miserably and left small peasants to fend for themselves (Brown 1995:66). In contrast, Smith and Haddad (2000:43) state that the green revolution did reduce malnutrition in Asia, but acknowledge that there was little impact in Africa. The Green revolution was critical in equalizing food production so that hunger famine of large populations was mitigated. But it may have also increased rates in malnutrition in children, severely malnourished, but whose deaths were prevented. Although the latter is only assumed, there is no clear evidence.

Also in the 1970s, the introduction of multisectoral nutrition planning cells marked the institutionalization of nutrition. The main objective of the introduction of these cells was to stimulate countries to develop and initiate programs and policies adapted to their needs, but the establishment of the planning cells was supply-driven. Field criticized the developers of the planning cells of applying 'machine theory', or taking implementation for granted once policies are developed (Field 1985:149). By late 1970s, these cells were largely dysfunctional. With the unsuccessful experiences of multi-national planning, the nutrition community started concentrating on more vertical programs, such as micronutrient distribution and breastfeeding promotion. Although these interventions are important, this led to a reduction in the attention given to reducing malnutrition on the overall development agenda (Levinson and McLachlan 1999).

It was not until the 1970s that the World Bank became involved in lending for malnutrition reduction. Following the overall development assistance theory that economic growth would largely take care of reducing the malnutrition problem, the 
World Bank did not explore how it might contribute to the efforts to reduce malnutrition until the $1970 \mathrm{~s}^{50}$. Then, in 1973 the Board of Directors approved a policy guideline paper on nutrition and four freestanding nutrition investments. The first WB freestanding nutrition project, approved by the Board of Directors in 1976, was for a nutrition loan to Brazill for US\$19 million. The Bank got involved in improving nutrition because the argument that malnutrition is a development problem, supported by evidence that addressing malnutrition reduces child deaths and improves quality of life, was successfully made. The WB nutrition policy had two clear objectives from the beginning: (i) help sensitize national leaders to the importance of nutrition for economic and social development; and (ii) influence, participate and invest in programs with nutritional aims. The aims of the investment programs, as stated in the policy, were to increase resources devoted to mutrition, limit the negative impact of macro-economic, agriculture and pricing policies and improve institutional capacity.

\subsection{The 1980s: The Washington Consensus, Structural Adjustment and where is Malnutrition?}

A great number of lessons were learned during the 1970 s. Lewis summarized several main ones in his publication Strengthening the Poor; What Have We learned? (Lewis 1988:7): (i) individual projects are confined to small geographic areas and pose the problem of replication; (ii) those projects tend to be multi-faceted and multidisciplinary and therefore difficult to operate; (iii) the projects involve heavy commitments of expatriates and personnel not from the area, thereby creating strong dependencies on external expertise; (iv) often projects dealt with local organizational weaknesses by establishing special project authorities, thereby weakening what existed even further. However, there was little time and attention to focus on the lessons learned. The developing world became instead preoccupied with structural adjustment to deal with the enormous debts countries had accrued and the negative consequences of
structural adjustment.

\footnotetext{
50 This is true also for other sectors, including for example health. The first
health project came only years after the first nutrition projects.
} 


\subsubsection{0s: The Washington Consensus and the Era of Structural Adjustment}

The 1980s are the period in which free market thinking became the dominant development theory. Economic growth was urgently needed in developing countries in order for them to repay their debts on the enormous number of loans made in the 1970s. The 1980s are characterized by the economic problems in the developed world as well, which was focusing more on their own budget deficits and bringing inflation down than on providing international assistance to the developing world (Ritzen 2005). In this climate, the 'Washington Consensus' was born. The basic premises of the Washington Consensus were to avoid levels of government deficit and avoid high levels of inflation, and its aim was to rely on the free market forces to reduce poverty and reduce the gap between the rich and the poor. It was the development paradigm of the World Bank and the IMF in the 1980 s and beginning 1990s. In hindsight, as Ritzen discusses in his book $A$ Chance for the World Bank, the Washington Consensus has helped rich countries become and remain rich, and has done more harm than good when applied without context or nuance in developing nations. He asserts there was too little attention to the preconditions of governance needed to make free market forces work (Ritzen 2005:45 and 116).

The 1980s was the era of structural adjustment and Structural Adjustment Programs (SAP). The SAPs were the center piece of the Washington Consensus, and remain to date the most heavily criticized policy of the World Bank. Structural adjustment is a package of reform measures taken by a country in order to reduce economic imbalances and bring long-term, sustainable growth. Structural adjustment and the re-focusing on financial stability was a result of the oil-crises in 1974 and late 1970 s, and the resulting debt crises (e.g. Mexico). It was also a reflection of the swing to the political right of important donor countries: Kohl in Germany, Thatcher in Britain, and Reagan in the US (Degnbol 2003).

Macro-economic balances needed to be stabilized, while removing much of state control. In order to achieve this, the WB and IMF developed structural adjustment programs in which Bank/IMF support was made conditional on fiscal rigor and measures to reduce public provision of consumption goods. Structural adjustment involves broad-based economic and sector policy reforms. They typically reduce public expenditures, change trade and exchange policies, create trade companies, and promote a strong focus on private sector development. These developments led to privatization of state-owned 
enterprises and trade companies and a strong focus on private sector development.

The notion that governments were too large, inefficient, and too costly led to project design using implementation mechanisms outside of the central government. In many countries separate implementation agencies and financing and procurement agencies were established. Many of the international donors involved civil society and worked through NGOs. As a result, governments remained weak and in some cases even worsened, exacerbating the problems.

\subsubsection{Where is Malnutrition?}

Part of the title of this section "where is malnutrition?" reflects what was perceived by the nutrition community at the World Bank in this era of structural adjustment. None of the social sector indicators, including malnutrition, got much attention, during the first half of the 1980s. World Bank lending in nutrition, which had been expected to increase after the successful start of four projects in the 1970s, was minimal. Between 1980 and 1990, the WB approved new lending for an average of only US $\$ 16$ million annually, while, between 1990 and 2000 , this was US $\$ 210$ annually (World Bank 1997). At the same time, structural adjustment had a real potential negative impact on nutritional status (box 4.2).

Outside of the World Bank and its attention on structural adjustment, vertical programs to address malnutrition became fashionable in the 1980s. For example, UNICEF promoted the GOBI (growth monitoring, oral re-hydration, breastfeeding and immunization) strategy, and vertical vitamin and mineral pilotprojects proliferated (Marchione 1999:53). Also in this era, evidence became available that nutrition actions can be effective components of health programs without the need for broadbased planning for national development (Underwood 1983). The 1980 s however, was also the era in which the now well-known Iringa project, supported by UNICEF in Tanzania, became known for its success. It employed a more flexible and communitycontrolled approach to design, implement and manage nutrition programs, then called adaptive programming (Jonsson 1993), and from which later the triple AAA approach ${ }^{51}$ was
conceptualized.

\footnotetext{
5it The approach called triple AAA by UNICEF starts with an Assessment of the level on which Action to be taken is betermine causes of malnutrition at the local
} 
Box 4.2: Structural Adjustment and Malnutrition

The influence of Structural adjustment on malnutrition:

Structural reform programs do increase prices of food, not only due to inflation, but also because in many cases, food exponts were encouraged and general lood subsidies removed. All this can negatively affect real household income, and thus the ability of familles to acquire sutficient food and nutrition services of good quality But, it can also be used to benefit the poor population by redirecting expensive general subsidies benefiting the entire population to the poorer segments of society. The World Bank conducted the analysis and worked with national governments on redirecting castly subsidles to benefit poorer populations and make the subsidies more cost-effective in Tunisia (Tuck and Lindert, 1996). There is increasing evidence that amounts equal to 1 percent of GDP of a typical Latín American economy (per capita above US\$1,000 - 1991 ciollar) could finance a targeted food program (Musgrove, 1991). The Venezuela Structural Adjustment Loan In 1989 applied this advice. In another example, the World Bank supported tax reforms in Jamaica to establish a general tax system that would exclude giving food (Selowsky 199/19), Yet changes of programs of this type take time, and meanwhile the poor will suffer because these costly programs do not reach them. In addition, they require not only time, but also take political will, Removing general tood subsidies is difficult because of the potential political implications While targeting them to the poor is the goal, targeting can be difficult and the poor are net the maln constituency.

In 1986 a symposium on 'Economic Recession, Adjustment and Nutrition" was held in Tokyo. There, the United Nation's $\mathrm{SCN}^{52}$ issued a statement that adjustment policies had compounded the negative effects on malnutrition. The poor were most affected. It was recommended that nutrition objectives form an explicit part of adjustment programs and policies, including compensatory measures for the poor.

As time progressed, the negative consequences of structural adjustment emerged. The book Adjustment with a Human Face by Cornia and Jolly (1987) and published by UNICEF, criticized structural adjustment for its damaging effects on welfare and exacerbating poverty instead of improving the economy. The criticism put pressure on the World Bank to rethink its policies and incorporate policies to address the social dimensions of adjustment. The World Bank responded with giving more emphasis to so-called safety net operations in parallel with structural adjustment. Safety net operations provide targeted social assistance to the poorest populations.

${ }^{52}$ The United Nations Standing Committee on Nutrition 


\subsection{The 1990s: Poverty Reduction linked to Governance, Malnutrition linked to Poverty}

\subsubsection{Poverty reduction, Governance and Human Rights}

During the 1990s; the focus was on getting poverty reduction firmly back on the development agenda and dealing with an entirely new challenge, the Eastern European Region, after the fall of the Berlin Wall. In the mid-1990s there was widespread pessimism about development assistance in general. Financial contributions to aid were declining, the literature on aid effectiveness showed aid was highly fungible, ${ }^{53}$ and aid was considered to have had very little effect on economic growth (Collier and Dollar 2001 reporting on Boone's work in 1995 ${ }^{54}$ ).

Despite the pessimism, or perhaps partly in response to it, the 1990s have also been the decade in which technology, human rights, gender, and globalization became themes on the development agenda. Governance became recognized as one of the main constraints to development. Addressing corruption, the importance of institutions, and participation ${ }^{55}$, factors needed for Good Governance, all became major pillars to human development and equitable economic growth. The publication by Dollar and Pritchett Assessing Aid, What Works, What Doesn't and Why (1998) on the contribution of development agencies' actions to development, shed light on the fact that in order for financial assistance to have impact, the recipient-country should have sound management. This strengthened the governance argument. It was World Bank President J.D. Wolfensohn who made corruption a central issue in one of his first speeches in 1996. As development experience accumulated, it became obvious that policies and institutions mattered much more than public investment alone. Institutional economics, which provides insights in the importance of institutions for development, was invited to join development economics (Williamson 1985; Piccioto 1995).

Democratization, though not new, became more in focus after the Cold War ended. Concerns regarding the political situation in countries were brought forward, since the specific affiliation with the West or East was no longer an issue. Before

\footnotetext{
53. Allocation of resources to health from foreign aid may replace public funds that would have been allocated to health if no foreign aid was obtained. Those funds now can be used for other activities, including milltary spending. This example explains 'money is tungible'.

Boone's work from 1995 was in 2001 demonstrating aid was eff was in 2001 completely reversed by Hansen en Tarp

${ }_{55}$ Participation as in civil society participating continues, see also chapter six.
} 
the Cold War, development agencies eagerly held on to their prohibiting political involvement rules, but after 1989 this changed and most started actively promoting political development goals (Degnbol 2003).

The increased attention from international development partners for the private sector and NGO sector can be seen as an outgrowth of the criticism of the state in the 1980s, while private-public partnerships of the 1990s are somewhat the result of the recognition that the state does have a role to play. NGOs and private sector became more important because of the failure of the state to deliver services. In practice though, many of the NGO efforts, while innovative, remained small and led to the realization that public services could have the greatest coverage but needed to be improved. Private-Public Partnership (PPP) then could deliver services where the public sector alone could not. For example, in Bolivia and Honduras, governments contracted NGOs to deliver health services to the poorest areas. In Madagascar and Senegal, government contracted NGOs to deliver nutrition services to the poor and in Bangladesh; NGOs continue to play a major role in delivering health and nutrition services to the poor.

Development agencies also started making explicit demands regarding democratization of nations in the form of fair elections, observance of human rights, and good governance of the public sector. Including civil society in decision making, open and transparent administrative systems, accountability of the system to citizens and a strong focus on reducing corruption were the result. Women became more recognized as an active group, not as the vulnerable passive group as portrayed in the earlier decades.

Decentralization of power to local authorities, and more attention to particular vulnerable groups, became part of the development agenda. All this required new development strategies (Degnbol 2003:49). Aid to comprehensive sector programs rather than self-standing project support is one example of changes in strategies (e.g. Sector-Wide Approach or SWAps). Much more attention was given to the policy dialogue and putting the government in the so-called driver seat. Although several critics of the practice of this approach jokingly call it rather a taxi-driver seat in which the donor directs the driver where to go. 


\subsubsection{Malnutrition Reduction better Understood and Recognized}

Important events regarding malnutrition happened in the 1990s:

a) International attention turned to nutrition when Nobel Prizes were awarded to two economists whose work has focused on nutrition. In 1993, Robert Fogel suggested that malnutrition was a binding constraint on economic development in Europe dating back to the sixteenth century, and in 1999 Amartya Sen emphasized poverty alleviation could be measured in terms of positive nutritional outcomes;

b) New data became available. Country analysis revealed that some countries with low GNP per capita had achieved greater improvement in nutrition than in a number of those with higher GNP per capita. Survey results showed that micronutrient malnutrition was far worse than previously estimated. At the end of the $1990 \mathrm{~s}$ data on quintile distribution regarding service delivery became available, and with it, the understanding that public expenditures on are as like health did not necessarily mean improvement of health for poor people (Gwatkin 2000). This knowledge may have had a positive spin for malnutrition reduction, since malnutrition rates are in general higher among the poor.

c) New research and analysis of previous studies showed malnutrition, including moderate and sub-clinical, had more severe functional consequences than had been realized: mild protein-energy malnutrition doubles the risk of mortality while moderate malnutrition increases it nearly five times; vitamin A deficiency increases mortality by more than 20 times, and giving vitamin $A$ capsules reduces mortality by almost one fourth; and iodine deficiency is the most common cause of mental retardation (Jonsson, Pelletier and Shrimpton 1998:2)

d) The determinants for malnutrition and its multisectorality became better known, and the UNICEF conceptual model (figure 2.1) of the causes and determinants of malnutrition is to date the model used to analyze the nutrition situation in developing countries. Also, there was a shift in thinking from a basic needs approach to a human rights development paradigm, which brought in the concepts of governance, empowerment and political capital (SCN 2004).

e) The International Conference on Nutrition (ICN) took place in 1992 in Rome, and started the push for the developing National Plan of Action for Nutrition (NPAN) in developing countries with the goals of keeping nutrition at the forefront 
of the development agenda. The WB got back into the poverty reduction business with the 1990 World Development Report on Poverty. The Comprehensive Development Framework (CDF) in 1999 represents a commitment on the part of the Bank to human development, a concept that incorporates health, education, and other interventions that improve human capabilities. Despite the importance of nutrition for health, education and development, nutrition itself is not explicitly mentioned in the CDF. Yet, the CDF does provide an opportunity for advocates to make the case for investment in nutritional improvement (Rogers 2003).

Perhaps the biggest influence from 1990s for the nutrition community has been the development of the conceptual framework of the causes and determinants of malnutrition by UNICEF and the triple AAA approach ${ }^{56}$ to programming interventions (Jonsson 1990:17). The model, together with work by Pelletier (Infant Mortality and Malnutrition Association) and Griffiths (Designing by Dialogue) among others on the consequences of malnutrition on child mortality, served to gain a better understanding about child growth, prevention of malnutrition, and methods for improving nutritional outcomes through counseling and empowering mothers to address the needs of their children with their own means.

In part, as a result of new data and the above mentioned events, community-based nutrition programs, combined with or integrated into, micronutrient programs became the focus of the international nutrition community in 1990s. Publications such as: Malnutrition, What Can Be Done (Berg 1987), Nutrition Relevant Action (ACC/SCN 1991) and How Nutrition improves (ACC/SCN 1996) all focused on what could be done, and how to apply lessons learned in one setting to the other. The UNICEF supported Iringa project in Tanzania and the World Bank supported Tamil Nadu Nutrition project in India, for example, continue to serve as best practice projects of how nutrition can be addressed effectively. World Bank support to investment in reducing malnutrition increased sharply in the $1990 \mathrm{~s}^{57}$.

\footnotetext{
${ }^{56}$ The triple AAA approach begins with an Assessment of the nutrition situation, followed by an Analysis to determine locall causes and determinants and subsequent programming of Actions are based on the first two AA.

57 The division among regions is relatively stable and equally divided between Africa, Asia and Latin America, but less in Northern Africa, Middle East and Eastern Europe. In terms of resources or dollar amounts, Latin America and South Asia are the largest borrowers. Atrica has most projects, but a much smaller amount of resiources. Between 1991 and 1995, nutrition loans to Latin America totaled US $\$ 256$ million for 36 projects. Between 1996 and 2000 , a total of nine new loans were made for a total of US\$ 440 million. In South Asia, nine
} 


\subsection{0: "Good Governance" and Millennium Development Goals (MDGs)}

The new century continues the development that started in the 1990 s of a more comprehensive and hollstic approach to development assistance. Fifty years of development experience have yielded four critical lessons according to the 2001 World Development Report, a leading publication in the development assistance community. First, macroeconomic stabillty is an essential, but not sufficient prerequisite for achieving the growth needed for development. Second, growth does not trickle down, the hard lesson learned trom the 1980 s and one of the main reasons the 1980 s is considered a lost decade for development. It was very clear that development must address human needs directly. Third, because not one policy alone will trigger development, an integrated approach is needed. And fourth, institutions matter; sustained development must be embedded in participatory processes, involve a number of partners and be responsive to changing environments (World Bank 2001:1).

Development strategies have evolved over the years and goals have been added, rather than replacing old goals and objectives. In the 1970s, socio-economic development was added to economic development, the focus on the poor and equitable distribution came next, and themes such as environment, gender and HIV/AIDS all are part of the current goals (box 4.3). At the same time, assistance to infrastructure, maintenance and private sector investments all continue. Foreign aid also involves many more players than it used to do. Nongovernmental and civil-society organizations have been included, and their numbers have grown a great deal.

In addition, all development assistance agencies focus now more than ever on a common goal: reaching the Millennium Development Goals (MDGs ${ }^{58}$ ). The MDGs are a set of internationally agreed upon goals to which countries and institutions have committed themselves to reaching by 2015 . The goals were formulated at the Millennium Summit in September 2000, where 191 nations reaffirmed their commitment to eradicating poverty and attaining sustainable development. As a

projects for US\$330 million were approved between 1991 and 1995 . The Africa region approved 119 projects, but about 70 percent of those were very small in dollar amounts. which reduced the likelihood of obtaining sufficient resources to do proper supervision and monitoring of these small projects.

s:B UNICEF was the first to mobilize donors and get attention to social indicators in the $1990 \mathrm{~s}$ with the world wide acceptance of the so-called super-goals, the and of the decade goals. The MDGs are a more broad-based tool for all UNagencies, including the Bretton Woods institutions, and giwe the goals more weight to shape development pollicy. 
framework, eight broadly stated Millennium Goals with 18 specific targets were accepted for measuring development progress. The framework is intended to help refocus strategies on outcomes, connect actions to outcomes, enable development of informed policymaking and programming, strengthen the institutions involved, and build national capacity for monitoring development. Box 4.4 provides an idea of the progress made in development indicators over the last decades and the challenge that remains.

Box 4.3: Millennium Development Goals - List of Goals and Targets

\section{Millennilum Development Goals and Targets}

Goal 1 Eradicate extreme poverty and hunger

Target 1. Halve, between 1990 and 2015, the proportion of people whose live on less than one dollar a day.

Target 2 Halve, between 1990 and 2015 , the proportion of peciple who suffer from hunger.

Goal 2. Achieve universal primary education

Target 3 . Ensure that, by 2015 , children everywhere, boys and gills alike, will be able to complete a full course of primary schooling.

Goal 3. Promote gender equality and empower women

Target 4. Eliminate gender disperity in primary and secondiary education, preferably by 2005 , and to all levels of education no later than 2015

Goal 4. Reduce chil d mortality

Target 5. Reduce by two thirds, between 1990 and 2015 , the under-five mortality rate

Goal 5 . Improve matemal health

Target 6. Reduce by three quarters ${ }_{\|}$between 1990 and 2015 , the materna mortality ratio.

Goal 6. Combat HIVIAIDS, malaria and other diseases

Target 7. Have halted by 2015 and begun to reverse the spread of HIV/AIDS

Target 8 . Have halted by 2015 and begun to reverse the incidence of malaria and other najor diseases.

Goal 7. Ensure environmental sustainability

Target 9 . Integrate the principles of sustainable developmerit into country policies and programs and reverse the losses of environmental resources.

Target 10 . Halve by 2015 the proportion of people without sustairiable access to safe drinking water.

Target 11 By 2020 to have achieved a significant improvement in the lives of at least 100 million sium dwellers.

Goal 8 . Develop a Global Partnership for Development

Target 12. Develop further an open, rule-based, predictable, nori-discriminatory trading and financial system

Target 13. Address the special needs of the least developed countries

Target 14. Address the special needs of landlocked countries and small island developing States.

Target 15. Deal comprehensively with the debt problems of developing countries through national and international measures in order to make debt sustainable in the long term.

The complete list including the indlicators is included as Annex 4 
Box 4.4: World Development Indicators Trends

\section{Trends In Development Indicators World-wide}

Average per capila income growth has increased, but this growth has been very unequally distributed between regions, between countries, and within countries. The absolute number of poor people ${ }^{59}$ in fact has increased worldwide. In some regions, the proportion of poor also increased. In Latin America, the proportion of poor people increased from $22 \%$ in 1987 10 $23.5 \%$ in 1996, and in Sub-Saharan Africa the proportion ncreased from $38.5 \%$ in 1987 to $39.1 \%$ in 1993 . Worldwide the total rose from 1.2 billion in 1987 to 1.5 billian in 1993, If this trend continues there will be 1.9 billion poor people in 2015 (WDR 2001,25 ), while the Millentim Development Goals actually prescribes a halwing of the 1990 number Only in Asia has the percentage of poor declined from $45.4 \%$ in 1987 io $431 \%$ in 1993 in South Asia, and from $28.8 \%$ in 1987 lo $26 \%$ In 1993 in East Asia and Pacific. An informal rule of thumb is that a per capita growh of 3 percent is needed to leduce poverty rapidly. Belween 1995 and 1997, onily 21 developing countiles met this minimum requirement.

By and large, indicators of human well-being suggest improvements over the last decades. infant montality rates have daclined among the lowincome countries from 104 per 1,000 life biths in 1970-1975 to 59 in 1996. Life expectancy has inereased by about tour months each year since 1970 . Primary school enrol ment has much improved and literacy rates have risen from 46 to 70 percent world wide. There is however a very wide disparity between reglons and between countries. In addition many of the indicators are deteriorating due to the HIVIAIDS epidemic, nost notably in Sub-Saharan Africa. In several countries ${ }^{6}$. life-expectancy has declined back to pre-1980 levels in all regions except Sub-Saharan Africa, malnutrition rates declined, but only very slowly.

Progress on reducing infeetlous disease has been enormous over the last 50 years. Smallpox has been eradicated, and many diseases are on the decline thanks to improved sanitation, nutrition and of course medical technology, drugs and vaceines, However despite an ongoing polio-eradication program, polio is stil prevalent in some areas in Africa, Improvements in malnutrition rates, shelter and basic sanitation access have been unacceptably small and slow. Further, diseases as malaria, tuberculosis and HIVIAIDS pose enomous challenges in the poorest countries. For example in 1995, an estimated 9 million children under the age of five died of preventable diseases and conditions in developing countries.

Source: World Bank - World Devalopment Report 2001

\subsubsection{Development Assistance and Malnutrition}

So, what have fifty years of development assistance for malnutrition, including three decades of World Bank involvement, accomplished? To answer these questions, an assessment of the impact of the two largest contributors to nutrition in developing countries ${ }^{61}$, the World Bank and UNICEF, was carried out between 2000 and 2003. The main findings confirm that malnutrition is often sidelined in poverty agendas despite its potential to improve health, mental development, and

\footnotetext{
${ }^{59}$ Living under 1 USS a day.

${ }^{60}$ For example Zambia, Uganda, Rwanda.

67 World Bank and UNICEF are currently largest contributors; earlier WHO and FAO were the major players.
} 
productivity. Nutrition professionals broadly agree on key interventions and on success factors for implementation, but these are not reflected in more programs and interventions. Few large-scale programs are implemented and fewer still are rigorously monitored and evaluated. Inadequate capacity at the country level, both in terms of human resources, technical training and financial resources, to tackle malnutrition is a major factor limiting progress toward poverty reduction. And per capita spending on nutrition is generally low and poorly targeted (Gillespie, McLachlan and Shrimpton 2003).

Current new millennium development assistance provides new opportunities with its focus on building and supporting good governance and national government ownership over their development agendas. This new thinking is expected to ensure malnutrition reduction, which is one of the indicators to monitor the achievement of the first MDG goal, and is inclluded in national development programs. However, despite the commitment to MDGs in public speeches, it appears sometimes to be only rhetoric and no action. The new commitments from the rich countries to development assistance remain small in comparison to the needs and current assessments of progress on the achievements of the MDGs are not positive on most of the indicators.

It is now also recognized that without national commitment to development from broad participation "any aid efforts made are doomed to fail. This is also very much the case for malnutrition reduction. In the 1990s, a large number of new initiatives and approaches were developed and piloted. It is in the new millennium that those can be implemented at large scale in order to make impact on larger population groups. Scaling-up successful approaches that demonstrate results at the community-level fits squarely in the latest development policy thinking. However, action upon malnutrition needs strong advocacy and continued commitment because of its characteristics, which make it challenging to build accountability for malnutrition reduction for reasons previously detailed.

It should be noted, that in some countries, the World Bank-supported nutrition projects have affected development plans and programs, and have demonstrated what can be achieved in countries that have at least a commitment to reducing malnutrition (Berg 1987:101). The preparation of World Bank-supported nutrition projects can help shape a government's development agenda for nutrition. The WB's independent evaluation department, OED, which carries out evaluations on a regular basis for all the WB operations, concluded that the WB had impact on nutrition interventions where it had been able to 
(a) introduce nutrition into policy dialogue (Zimbabwe); (b) promote better targeting of nutrition interventions (India, Tamil Nadu, Tunisia food subsidies); and (c) strengthen the surveillance system in government-supported programs (Indonesia).

The debate that evolved in the last decades around the question on where the responsibility for malnutrition should be housed was renewed in the late 1990s. Frustration with the lack of attention surfaced again, and sparked new hope with the renewed attention to reducing malnutrition thanks to the Millennium Development Goals (Levinson $2003^{62}$ ). However, the ownership issue remains very important. Donors continue changing policies too often and too quickly without giving programs a change to be implemented, let alone evaluated. And donor-harmonization of nutrition policies is, although making some progress, not high on the attention of donors. Donorharmonization around policies and programs in nutrition is the responsibility of local governments. The catch is that in many countries it is the donor-community that dominates the nutrition agenda. So governments have two challenges: first, gaining back the nutrition agenda and second, harmonizing the donors around their agenda.

According to World Bank publication Combating Malnutrition (Gillespie et al 2003) there is currently a new opportunity for mutrition provided by the relatively recent consensus among development strategists that a shift in thinking is necessary towards intersectoral strategies and programs. The shift in thinking should be going towards accomplishment of agreed upon goals and outcomes by the development community as a whole. This may offer nutrition another chance to become part of the development process internationally. Nationally, this opportunity is possibly provided by the PRSPS, the monitoring of the MDGs and other intersectoral development initiatives. But, this time the national government should be in the driver's seat, and this should not in the taxi driver's seat.

\subsection{Summary and Conclusion}

This chapter provided a chronological overview of the evolution in thinking about development assistance in general and malnutrition reduction in particular and how the emergence of governance in development assistance theory is positive for malnutrition.

\footnotetext{
62 In Gillespie el al (2003) Combating Malnutrition Lewinson, Institutionalization of Nutrition World Bank HNP series
} 
Before the 1970s malnutrition was seen as a metabolic disease, and recognized and addressed only in very severe cases and mainly in the hospital setting. In the 1970s, the development assistance climate lends itself much better to recognize malnutrition as a development problem. First of all the focus of general development assistance was on the poor and basic human needs. Adequate nutrition is one of those basic needs. Malnutrition reduction was by the 1970 s recognized as a development problem and no longer a metabolic disease. The link between poverty and malnutrition became clearer and the multidimensional nature of malnutrition was recognized: However, it was only the beginning. Development assistance was still supply-driven and did not allow much in-country capacity-building. The National Nutrition Commissions that were established in the 1970s were premature and have largely failed. Part of the failure may have been the inability of the planners to have a place at the table when development decisions were made. There was very little attention to building local leadership and ownership of the nutrition policies. As a result, nutrition plans were made but resources to implement them never obtained.

In addition, in the 1970s, far less was known about what works to reduce malnutrition through large-scale nutrition programs. Much of the now available data on direct relations between child mortality, education attainment, and malnutrition were not available then. It should be recognized that nutritionists had a weaker case to make for getting malnutrition on the development agenda and obtaining adequate funding, than for example in the 1990s. In the 1980s, there was even less convergence in thinking about macro-level development assistance and micro-level implementation of malnutrition reduction interventions. The focus regarding malnutrition was on vertical nutrition interventions, mainly through the health sector. Macro-level structural adjustment was the dominant development strategy. As a result, there was little opportunity for malnutrition to be addressed as a multisectoral development problem.

In contrast, in the 1990 s and especially at the start of the new millennium, general development assistance theory appears to have focused more on building an enabling environment, within which malnutrition could be addressed as a development problem. At the same time, malnutrition theory started looking more at enabling environments, instead of only implementation of verticall programs. Broad participation, meaning inclusion of civil society, non-governmental organizations, and the private sector in the public sector debates on poverty reduction are 
strategic directions were promoted by international development agencles and nutritionists alike.

Already in the 1970 s the general development policy environment was thought to be advantageous for malnutrition reduction. In their 1975 article in Food Pollicy, Field and Levinson asserted there was a growing momentum and awareness about malnutrition as a development problem (Field and Levinson 1975:54-6). The authors also identified the challenges to building commitment to malnutrition reduction, the awareness problem and the political illiteracy of those suffering from it. However, at that time, there was little attention to broad-based participation, building ownership or room for multisectoral issues, all keyelements of governance which are now widely recognized as essential to general development. The review in this chapter shows that the 1970 s and more so the 1990 s offer most opportunities for nutrition to be included on the development agenda. In the 1970s, however, understanding of the solutions and processes of malnutrition reduction were less clear and understood. In the 1990s, the understanding of malnutrition was better, as was the enabling environment in which nutrition could become a development issue.

Now that governance, good policies, and the importance of institutions has emerged as the new development policies the nutrition community should be ready to adapt to this, or malnutrition will again risk falling through the cracks. As discussed earlier, national ownership of nutrition programs is very important in countries with high rates of malnutrition. Malnutrition reduction is a public sector responsibility and it is time countries recognize and accept this. With the emergence of 'good governance' and the manner in which it is interpreted by the main donors, such as the World Bank, national governments will be in charge of decision-making regarding their development programs. If there is no strong voice for malnutrition reduction at the highest levels, it is likely it will continue to be not recognized and no significant financing will be allocated to it.

However, it should be kept in mind that although the environment may be more positive for building accountability for malnutrition reduction and subsequently more resource allocation, the overall situation and commitment to development is important. As mentioned earlier, despite the strong commitment in public speeches to the MDGs, true resources commitment to development has been less convincing. Regarding good governance, Ritzen in his recent book $A$ Chance for the World Bank is critical on the window of opportunity that was created by the fall of the Berlin Wall. With that came the opportunity to change the old system of providing development 
aid resources following lines of allies or 'political friends'. However, Ritzen fears the window may have been too short since there is a high risk it is replaced by a system allocating resources following a new divide; the war on terrorism (Ritzen 2005:186). Finally, the United Nations reports that inequality has in fact worsened, and the gap between the rich and poor nations has grown, despite development efforts and the focus on equality, over the past decades.

So far, we are not yet back to the positive era of the 1970s, which the United Nations has named the Development Era. We are also no longer in the era of Structural Adjustment, considered to be the lost era for Development. The Washington Consensus has been replaced by the Monterrey Consensus, and the MDGs have given new hope, but much more is needed and in particular in terms of donor harmonization and building countyownership and responsibility. There are many books that are much more comprehensive on the evolvement of development assistance and new opportunities. This chapter discussed only briefly those most relevant to the topic here, malnutrition and governance. 


\section{Chapter 5: 'Good Governance’}

\subsection{Introduction}

As demonstrated in chapter four, general development assistance may provide a more supportive environment for malnutrition reduction. Comprehensive poverty reduction strategies promote broad participation and ownership, which are key governance elements of that environment. Governance may influence the process whereby malnutrition is made a priority issue on the development agenda by addressing the constraints underlying the lack of commitment to malnutrition reduction.

In the next two chapters, the analysis will focus on identifying the key elements of governance that are expected to positively influence the constraints underlying mainutrition reduction. The purpose is to gain better understanding of how governance contributes to malnutrition reduction, and which processes appear most important. This chapter will firstly provide more detail regarding underlying theories to governance, and the history of how good governance became a development priority is discussed. After this, a more general overview the World Bank's interpretation and operationalization of governance is given and the concept of good governance is described following these questions: (i) What is the World Bank good governance policy? (ii) How did it evolve over time? and (iii) What are the key-elements of good governance upon which the World Bank focused? Chapter six addresses the links between the keyelements of governance and malnutrition reduction.

This chapter is based on an extensive literature review of the underlying basis of "good governance', and its interpretation by development assistance agencies. It starts with an overview of the definitions and interpretations of good governance as a concept. The overview is limited to the definitions and interpretation of progress on governance as a development policy condition. At the same time, it is recognized that this is a limitation and the review does not do justice to the very rich literature that exists on the subject, but it is beyond the scope of this study to provide a more comprehensive review. In her recent book Governance, Anne Mette Kjaer more richly illustrates the subject, and gives sense to the concept of governance by introducing the many ways in which it is used as well as by sketching the underlying theoretical debates ${ }^{63}$.

\footnotetext{
63 A comprehensive guide to Governance is provided by Anne Mette Kjaer in Governance Polity Press, UK, 2004. The book offers an easy to read introduction to Governance and the theoretical debates around the concept.
} 


\subsection{Good Governance}

\subsubsection{Good Governance Defined}

Although the statement 'good governance is essential for successful development" has become a truism (Fukuda-Parr et al 2002:2), there is no one definition or single concept that defines 'good governance'. Instead, there are many different interpretations. One of the most comprehensive definitions of it in the context of development assistance is provided by the United Nations. In box 5.1, the different definitions used by several development assistance agencies are listed as an illustration of the variety. These definitions of governance are typical of international organizations in the development community, which through good governance wish to support reforms that will strengthen the recipient governments' capacity to decide their own future (Kjaer 2004:11).

\section{Box: 5.1: Definitions of the Good Governance}

\section{A Compilation of Definitions of Good Development Agencies and Institutions}

World Bank Group. Governance is defined as the manner in which power is exercised in the management of a country's economic and social resources. The World Bank identifies three distinct aspects of governance, (1) The form of political regime; (ii) the process by which authority is exercised in the management of a country's economic and social resources for development, (iii) the capacity of governments to design, formulate and implement policles and discharge functions (World Bank 1997).

United Nations Development Program (UNDP): A general conceptualization of governance is as the UNDP defines it: governance is the exerolse of economic, political and administrative authority to manage a country's alfairs at all levels. It comprises the mechanisms, processes and institutions through which citizens and groups articulate their interests, exercise their legal rights, meet their obligations and mediate their differences, Good governance is then among other things, participatory, transparent and accountable. It promotes rule of law, it ensures that political, social and economic priorities aire based on broad consensus in society and that the voices of the poorest and most vulnerable are heard in decision making over the allocation of resources. UNDP's primary interest lies in how effectively the state serves the needs of its people.

Organization for Economic Coordination and Development (OECD): The concept of governance denotes the use of political authority and exercise of control in a society in relation to the management of its resouices for social and economic development. This broad definition encompasses the role of public authorities in establishing the environment in which economic operators function and in determining the distribution of benefits as well as the nature of the relationstip between the ruller and the ruled (OECD DAC, 1995). OECD's Development Assistance Committee (DAC) thus defines governance as paiticipatory development, human rights and democratization. 
Box 51 contimued: institutions, process

Institute on Governance, Ottawa, Governance comprises the

ses and conventions in a society that determine how power is exercised, how important decisions affecting society are made, and how various interests are accorded a place in such decisions.

Commission on Good Governance. Governance is the sum of the many ways individuals and institutions, public and private, manage their common affairs it is a continuling process through which conflicting or diverse interests may be accommodated and co-operative action may be taken it includes formal institutions and regimes empowered to enforce compliance, as well as informal arrangements that people and institutions either have agreed to or perceive to be in their interest.

Although there are differences in the definitions, there are many common characteristics. Almost all include capacity to execute public programs effectively, transparency and accountability, and rule of law. First, the differences in the definitions reflect the programmatic interests of the development agencies rather than major differences of interpretation. For example, the World Bank focuses its definition on sound economic development, while the United Nations leans more towards human development and human rights. Second, differences reflect how the concept is seen, in the narrow or broad sense. Good governance in the narrow sense ${ }^{64}$ is a functional concept and focuses on administrative features conducive to development. The World Bank definition primarily follows the narrow sense. Good governance in the broad sense not only focuses on administrative aspects, but also includes human rights, democracy and rule of law (WRR 2001:17). The United Nations definition follows the broad sense.

\subsubsection{The Rise of Governance in Development Assistance}

A number of global events (WRR 2001: $12^{55}$ ), globalization, and the questions raised in development assistance regarding the failures of development programs in a

\footnotetext{
${ }^{34}$ Leftwich (1993) differentiates between three strands to Good governance: (i) systemic; (ii) political; and (iii) administrative. The systemic use of governance is broader than government covering the distribution of both internal and external political and economic power. The political use of governance refers to a state enjoying both legitimate and authority, derived from a democratic mandate. The administrative refers to en efficient, open, accountable, and audited public: service which has the bureaucratic competence to help design and implement appropriate policies and manage whatever public sector there is (Leftwich 1993:611). Good governance as interpreted by the World Bank focuses on the administrative and systematic strands, since it is limited by its Articles in focusing an the politicall strand.

65 This report is concerned with the relationship between development policy and good governance and more specifically with the possibilities at bi-laterall level.
} 
large number of countries, all contributed to the rise of the importance of governance in development policy.

Since the Universal Declaration of Human Rights in 1948, there has been improvement in the way states treat their citizens. United Nations observers regularly accompany elections to ensure a fair process, and countries violating human rights and rigging elections find themselves more often facing sanctions. In addition, international war tribunals (Rwanda and Yugoslavia) have been established. With the fall of the Berlin Wall, Communism disappeared as the anti-thesis to Democracy, and a new world order was needed. Before the end of the Cold War, aid was primarily funneled to political allies of major Western powers (World Bank 1998a:7).

An increased awareness of globalization made international treaties a necessity, with the protection of the environment and labor laws among the most important ones. Over time, private investments in developing countries have increased many-fold, bringing new needs in terms of governance to build trust. Those countries saw the benefits of those investments, and many more countries became willing to improve their governance in order to maintain and attract more foreign investment. The debates on the role of the state (World Bank 1997) and the attention to non-governance organizations all have led to increased need for good policies and institutions, good governance, and for more effective administrations (WRR $2001: 12$ ). However, the high expectations of globalization in the 1980 s and 1990 s with respect to reducing poverty had not materiallized. The Washington Consensus goals had been far from reached, given that there was an increase in the gap between the poor and the rich instead of a closing of the gap. The acknowledgement of the failure of the Washington Consensus led to a new consensus, which was the Monterrey Consensus in 2002. The Monterrey Consensus linked aid effectiveness with developing ownership of good policies.

When the 1980 s macroeconomic reform programs started to mature in the 1990s, more attention was spent on the questions of why the proposed reforms were not better implemented, and why they were not more effective. For example, the problems the World Bank experienced with its adjustment lending portfolio ${ }^{66}$ in Sub-Saharan Africa were the starting point for recognizing weak institutional capacity, lack of llegal frameworks for investors (of major importance to economic growth), weak administrations, and widespread corruption as underlying factors for the failure. Calls for more openness and

Low disbursement of funds and very little improvement in indicators 
transparency were heard from citizens and leaders, as well as international donors. As a result governance rose to the forefront of development agendas.

\subsubsection{Underlying Evidence}

Development assistance agencies focus on improving the impact of their programs and effectiveness of assistance in general. In that context, the recognition of the importance of governance is not a surprise, but at the same time there was little evidence to support the many assumptions underlying the concept. That evidence has become available over the years. First, data to support or justify the focus on governance, i.e. channeling relatively more aid-resources to countries with good policies "became available in 1998 with the publication of Assessing Aid, What Works, What Doesn't and Why? (Dollar and Pritchett 1998). The report demonstrates that aid accelerates growth in developing countries with sound institutions and good policies, i.e. those with better scores on governance indicators.

Since this first report, a growing body of literature has demonstrated that aid, or development assistance in general, improves with good policies and less corruption. There is also more literature which links good policies to human development and well-being, and makes the case that institutions also matter for human development, not only economic development. For example, Rajkumar and Swaroop found evidence that as the level of corruption goes down, public health spending becomes more effective in lowering both child and infant mortalities (Rajkumar 2002:23). A more detailed overview of the most recent research on this is provided in box $5.2^{67}$ below.

Box 5.2.: Empirical evidence of Good Governance with regards to Human Development ${ }^{\text {ts }}$

Empirical research confirms the theoretleal arguments underlying good governance theory:

Mauro (1995) shows corruption is negatively linked to economie growth. He carried out cross country regressions to assess corruption, the amount of red tape, the efficiency of the judicial system and political stability.

\footnotetext{
${ }^{67}$ A good overview of the successes and failures of contributions of development assistance to development can be found in Assessing Aid, What Works, What Doesn't and Why (1998).

68 More comprehensive reviews of the empirical evidence of the rale of institutions for economic growth, financial development, inequality and poverty are provided in: WDR 2001 report Development Policy and Good Governance; World Bank Policy paper 1998: Beyond the Washington Consensus: Institutions Matter.
} 
Knack and Keefer (1995) also did cross country analysis using indices of institutional development ${ }^{59}$ and show that institutions that protect property rights are orucial for economic growth. Foreign direct investment is an important factor tor economic growh in

smal aconomies, many of them developing countries. Alesina et al (2000) found That toreign direct investment was reduced by host-country corruption levels when they explored aid, foreign direct investment, and corruption in a eross: country analysis.

Amartya Sen (1999) argues that democracy can make a positive contribution to development by creating political incentives for rulers to respond positively 10 the needs and demands of their citizens. Dreze and Sen (1989) assert that the openness and accountablity of democratic societies explain why Indla, and not China, has managed to avoid large-scale tamines. And Kaufmann, Kraay, and Zoido Lobaton (1999) ind that an index of "volce and accountability" Is associated with lower infant mortality. There is also some evidence that participating in local and national decisions helps improve the quality of projects (Isham, Kaufmann, and Pritchett 1997 ) and the welfare of vulneirable groups such as women and their children (Narayar, 2000).

There is evidence that a state with transparent and effective institutions is aissochated with higher income growth and social achievements. A large body of omplitical literature on the relationship between good governance and human development outcomes shows positive impact, Higher per caplita incomes are linked to improved health and education outcomes (Filmer and pritchett 1999 a and 1999b: Pritchett and Summers 1996), Gupla et al (2002) find that countries with high corruption have high child and infant mortalify rates.

Burnside, Graig and Dollar did panel regressions in order to explain the Impact of aid on economic growith in developing countries. They found that in developing countries with weak economic management, there is no relation between aid and change in intant mortality, Where economic management is stronger, there is a irelation between aid and changes in intant mortality. Strong economic management is part of governance, Later in 2002, Riajkumar and Swaroop conclude the following from their recent inwestigation as the level of corruption goes down, public spending on health becomes more effective in lowering child and infant mortality rates (Rajkumar 2002:33), The same results were found for public spending on education. Whether this would also hold for nutrition outcomes is not clear, but there is indication it does. For example,

Frongillo et al found in 1997 in their research that the association of health expenditures and stunting ${ }^{70}$ differs between regions (Frongillo, Onis and Hanson 1997). Equitable allocation of resources and antl-corruption progiams are part of the World Bank package to promote better governance.

However, the evidence has been repeatedly criticized, of which an overview is provided in box 5.3 . Some critics believe that aid is never positive and should be eliminated altogether. Others find positive effects everywhere and accordingly aid should be given everywhere instead of only there where policies are deemed better. The truth lays somewhere in between. Excessive concern on aid effectiveness could be carried to the

\footnotetext{
29. ICRG index (International Country Risk Guide) produced by the Political Risk Service (PRS) group of Syracuse in New York. BERl index (Business Environmental Risk intelligence).

${ }^{70}$ Stunting is low height for age, minus 2 S.D. from the median, serious growth retardation.
} 
extreme and result in "abandonment" of countries whose performance is weak but who need it most.

\section{Box 5.3: Criticism on the Interpretation Operationalization and Implementation of Good Governance ${ }^{7 t}$}

\section{Despite the growing evidence base there remains skeptlicism}

An extensive review of the empirical evidence of good governance on human development indicators was carried out for the Dutch Government in 2001 , and is critical of those who claim a relationship. It concludes that the good governance thesis is only partiaily supported by empirical evidence. Only 3 out of 33 studies used human development indicators next to economic growth as the dependent variable in the reviewed research on the relation between institutions and development. However, although limited to throe studies all show positive results of political regime on human development, whereas only one third of the 33 studies in total show positive result of political regime on economic growth as development variable (Hout in WRR 2001). Glahe and Vorhies (1989) used an index composed of GDP/capita, life expectancy, illiteracy rate and infant and under-five mortality. They found a positive rellation and Pourgerami (1992) finds positive results of human rights index on the dependent variable.

Hyden (2001) critiques the World Bank interpretation of good governance as limited to political economy. He distinguishes between two levels of politics: the distributive "who gets what, when and how", and the constitutive "who sets the rules, when and how". While the first deals more with political economy and how public resources get allocated in society, the second gluides political choice and action. It is generally the latter that is understood as governance, but the World Bank's interpretation of governance addressed the first, since political interference is prohibited by its Articles (Hyden 2001118).

Pincus and others find certain aspects of the operationalization of the concept not convincing. In "Reinventing the World Bank", Pincus states that giving poor countries more voice in the World Bank's internal accountability, as an aspect of its improving governance is unlikely to tesult in better assessments. Poor countries are more likely to resist NGO involvement in decision-making for example (Pincus, 2002 p.20).

Severe criticism comes from George and Sabelli (1994), Abrahamsen (2000) and Doornbos (2003).

George and Sabelli (1994) focus on the World Bank"s past fallures with adjustment lending, and sees good governance as the Bank's last refuge to defend structural adjustment. If adjustment did not improve the macro-economic environment, it was because of poor governance in the country. For example, in 1994 they argued that the World Bank's new focus on good governance is tied to: (i) continuing and refurbishing the 'blame the victim' defense for the structural adjustment enterprise; (ii) gaining time for the institution; and (iii) positioning the World Bank for the 21 century (George 1994:160-161).

Abrahamsen (2000), in her book Disciplining Democracy critiques the good governance concept of the World Bank harshly as being the latest in a series of new development theories - 'fads' - all promising to reduce poverty (Abrahamsen 2000:47). Her analysis of the good governance agenda cancludes that it appears to go in circles and always leads to one factor: economic liberalization. Empowerment of the people is reduced to cost-sharing. Also, she concludes the discourse on good governance is used to legitimize the

7 Much of the criticism regarding 'good governance' is directed at the interpretation and implementation of the World Bank, but not exclusively so. 
continuation of structural adjustment and to give it a more democralic face (Abrahamsen 2000:65)

Doormbos (2003) agrees to a certain extent with Abrahamsen that good govennance was merely a necessary vehicle to launch a new generation of political canditionalities. He asks whether it is right that by imposing conditions on structures of governance, as the World Bank and other donors do, changes in govemments may become, in part, externally drven. Doombos coneludes that although in the 1990 s the notion of good governance was high on the radar screen of international development agencles, it has evolved into a general and often used figure of speech without much practical meaning or consequence (Doontios 2003417 ).

The data used in Assessing Aid were revisited in 2004 and show that in the 1990 s development aid was effectively targeted to countries with better scores on governance. Those that scored one standard deviation higher on the indices of rule of law and democracy corresponded to $28 \%$ more overall aid and $50 \%$ more financing from World Bank IDA facility ${ }^{72}$ (Burnside and Dollar 2004:7). The evidence does not answer the question whether this shift was caused or could be attributed to the focus on strengthening governance ${ }^{73}$. This question, whether aid influences the quality of governance, was explored by Steve Knack in $2000^{74}$. Knack found from cross-country analysis that higher aid levels appear to erode the quality of governance. Governance in that study was measured as indices of bureaucratic quality, corruption, and rule of law.

Following these findings, Knack identified policy implications for bi- and multi lateral donors to circumvent the problems contributing to weakening governance when aid increases. Several of those policy implications have since been adopted by the World Bank. For example, direct budgetary support instead of project support; increased participation of civil society; and increased efforts to reduce corruption. More details on these policy implication and how the World Bank integrates them is provided in the next sections on the World Bank operationalization of the good governance concept.

In 2001, at an expert's seminar organized by the Development Assistance Committee (DAC) in 2001, it was agreed that aid works better when government performance is

\footnotetext{
7.2 See for explanation of IDA facility Annex 1 World Bank basic facts.

${ }^{73}$ For literature that explains donor allocations in terms of economic and politica variables see Alesina and Dollar (2000).

74 There appears a debate between economists and political scientists, the former focusing in on providing aid to impirove equitable growth through which governamce improves - better salaries solicit less bribery and corruption among public employees, police and the justice system for example. The latter, however argue that aid weakens governmental accountability, by delaying the development of a "healthy' civil society underpinning demociracy and the rule of law (Knack 2000:4; Brautigam 2000).
} 
better. The relative measure of performance includes economic and other anti-poverty policies, as well as the quality of governance and institutional capacity. In conclusion, there is agreement among the donors on the importance of performance in aid effectiveness, but not on the weight and subsequent policy implications, in particular regarding the allocation of resources decision-making processes (OECD/DAC 2001:2-4 ${ }^{75}$ ). Several questions continue to be studied, and may have important policyimplications when more empirical evidence becomes available. In the meantime the international development community continues the efforts to improve governance and the use of governance indicators to allocate resources to developing countries (Korsten and Rokx 2005).

\subsection{The World Bank and Good Governance}

The World Bank and several other development agencies included good governance as a priority in their development policy in the 1990s. For example, the United Nations Development Program (UNDP) promotes good governance as a key factor in development and as the basis for decisions about allocation of funds, and included it in its index rating of countries. In its $58^{\text {th }}$ report, Development Policy and Good Governance, the Scientific Council for Government Policy of the Netherlands endorsed the good governance focus of the Dutch international Cooperation (DGIS) on the subject (WRR 2001:56-58).

The World Bank was the first to publicly address the governance concern in its 1989 Long Term Perspective Study Sub-Saharan Africa: From Crisis to Sustainable Growth: Underlying Africa's Development Problems is a Crisis of Governance (World Bank 1989: 60) ${ }^{76}$. This publication linked development to issues of leadership authority and legitimacy. It addressed the absence of balance of power, the lack of official accountability, the control of information, and a failure to respect rule of law. It spoke in favor of independence of the judiciary, respect for law and human rights at all levels of government, transparent accountability of public funds, and independent public auditors responsible to the legislative, not to the executive

75 OECD-DAC (2001) Experts Seminar on Aid Effectiveness, Selectivity and Poor Performers Summary of main points of the discussions, mimeo.

${ }_{76}$ Also in other regions of the WB there were shifts in governance that brought the issue to attention. For example in the Latin America region authoritarian regimes became democratic regimes. In Asia the most prominent example is China where first an opening with economic liberalization was reversed with the suppression of political change; Tiananmen Square (Kapur 1997). And the Soviet Union's Glasnost focused attention on openness as a critical element of governance (Brautigam 1991). 
branch, of government (World Bank 1989:192). It is generally recognized, in addition, that the World Bank's strategic discourse regarding good governance structures, informs to a large degree, the international discussion (Tennekes 2005).

After this first publication, good governance and corruption became more openly and extensively discussed and criticized. Most importantly the issue was put squarely on the agenda. The publication Assessing Aid in 1998 provided the empirical evidence that good policies are important to development. In its policy recommendations, it highlighted that development agencies, in order to create incentives, should focus on developing countries with good policies. In those countries with poor policies, the development agencies should "be patient", i.e. not tolerating poor governance but allowing governments time to build better governance (World Bank 1998a:117). The World Bank should help build better governance in those countries.

Although there is much debate regarding definitions, as mentioned earlier in this chapter, good policies or sound management are defined as policies that will lead to rapid development and poverty reduction in a particular country (World Bank 1998a:12). They include such good economic policies as low inflation, small fiscal imbalances and open trade regimes. Uganda in the mid-1990s is often mentioned as a good example of such a country because it kept inflation low and implemented good fiscal policy, while opening up for trade. An example of a poor economic policy country at that time is Nicaragua in the 1980s (World Bank 1998a:12), where inflation was high and fiscal imbalance large. A second measure to define good policies is institutional quality, which inciudes an assessment of the strength of rule of law, the quality of public bureaucracy, and the pervasiveness of corruption.

\subsubsection{World Bank Definition of Good Governance and Underlying Theories}

The World Bank definition changes over time and depends on the documents consulted. For example, in the 2000 World Development Report on Poverty, the definition was as follows: "governance is the institutional capability of public organizations to provide the public and other goods demanded by a country's citizens, or their representatives in an effective, transparent, impartial, and accountable manner, subject to resource constraints' (World Bank 2000/1:48). Despite the use of different definitions over the years in different reports, reducing corruption and rule of law are among the two core-features at 
any time and in any report (Kjaer 2004:173). Tennekes concluded that the good governance policy-discourse of the World Bank started out focusing on economic and functional Governance $^{77}$, and in the late 1990 s participatory governance was given emphasis ${ }^{78}$.

Institutional economics, public sector management, and New Public Management (NPM) theories, and development management and public choice theories inspired the World Bank good governance definition NPM includes the introduction of private sector management styles, explicit performance management standards and measures, management by result, value for money, and closeness to the client, among others. It promotes competition between service and providers, and with that promotes empowering citizens by giving them choice. Control is pushed from the bureaucracy to the community. Governments that adhere to NPM principles measure performance and goals rather than inputs should be driven by their objectives, not by rules and regulations. They prevent problems, rather than offer solutions after problems occur. They decentralize decision-making. They focus not only on providing public services but catalyzing all sectors, public, private, and voluntary into action to solve their community's problems

Following new political economy theory, traditional public sector management issues such as civil service reform were broadened in the World Bank's good governance concept. Key elements of the good governance agenda and reforms include: rule of law, (such as enforcement of property rights), eliminating corruption and rent-seeking activities ${ }^{p}$, transparency, ownership and commitment to the development agenda, and efficiency in public service delivery. These aspects are all influenced by the writings of the new political economy of the 1970s and 1980s, which emphasize political rationality of policy makers as a variation on economic rationality from classical economics. New

\footnotetext{
${ }^{77}$ In the early 1990s, the World Bank defined good governance as the manner in which power is exercised in the management of a country's economic and sociall resources. It identifies three distinct aspects of governance; (i) the form of political regime; (ii) the process by which authority is exercised in the management of a country's economic and social resources for development; (iii) the capacity of governments to design, formulate and implement policies and discharge functions (World Bank 1994:xiv). Because it's Articles prohibit the World Bank from political interventions, the focus in the early 1990s was on the latter two aspects. During the 1990s, the World Bank introduced more political considerations in its interpretation (Kapur: 1997).

78 See for a good analysis of the policy-discourse and changes Tennekes (2005) chapter 5 .

${ }^{79}$ Seeking opporfunities and abuse of power, usually in situation where saliaries are very low; for example providing contracts to friends and receiving kickbacks, attending workshops and receiving per diem in appropriately.
} 
insights to challenge the earlier thinking about rational selfinterested politicians, bureaucrats and interest-groups came from new institutional economics, public choice theory, transaction cost economics, and rent seeking behavior among others (Findlay 1991:13).

Public sector management explores the operational side of governance. It seeks to improve the efficiency in the allocation of resources and broader participation in decision-making. Much of the development management writers have been influenced by networks of management institutions in developing countries, in particular those in Latin America, India and Egypt (Brautigam 1991:11). Participation and institutional pluralism (a diversity of organizations: non-governmental organizations, unions, women's groups and other intermediate organizations) is of interest particularly to programs that implement multidimensional or multisectoral issues, such as nutrition, HIV/AIDS and enviromment.

Good governance, as in public institutions and policies that enforce property rights and contracts while restraining corruption is, despite ongoing debates, in general accepted to be a necessary condition for long-term economic growth. Starting in 1990 with Douglass North's work, and many others after him, a growing number of theories, including transaction cost economics ${ }^{80}$, rational choice theory, information and institutional economics, game theory, and organization theory became available. Douglas North made the argument that economic performance is not easily explained by the logic of economic theory alone. Governments are not neutral; they are more frequently political than economic and rational. According to North, the contrast between the logical implications of neoclassical theory and the performance of economies is startling (North 1990:11).

New institutional economics introduces incentive structures into public service provision through contracting out and consumer choice. Institutional economics provides useful insights and ideas for exploring questions on the type of institution that should deliver basic services because it adds transaction costs and information asymmetry to neoclassical economic theory (Coase 1988; Eggertsson 1990). In the health sector, institutional economics provides insights in the roles of the public and private sector, a question many governments are facing in countries around the world (Preker 2000). Transaction

\footnotetext{
7ransaction cost economics is part of the new institutional economics research tradition and is an interdiscipinary undertaking drawing on law, institutions and economics (Ohvier E. Williamson 1985: 16).
} 
costs are associated with the cost of acquiring information, which in neoclassical economics was assumed fully available to every individual. Transaction costs can be high enough to decrease welfare (Eggertsson 1990). Transaction costs in nutrition consist largely of costs to users of using the service, and could also include costs for business of dealing with red tape, i.e. arranging contracts to deliver services and monitoring their execution.

Efficient public service delivery is another one of the major elements in governance. Albert Hirschman's model on incentives (Exit, Voice and Loyalty) has played an important role in determining delivery mechanisms for public services (Preker 2000; World Bank 1997). Hirschman's trilogy was originally developed based on the private sector, but can very well be applied to the public sector as well. in Hirschman"s Trilogy of incentives, exit is the preferred mechanism to ensure accountability when there is a market, because different alternatives are available to the consumer and the consumer can choose a new product when the old product does not suffice (exit). The consumer has a choice in services and goods.

Accountability is assured through the possibility for customers to change brand or providers if dissatisfied with the quality of the service or product. Providers, in order to keep their customers, will have to offer good quality products or services. Voice is the preferred mechanism when there is no, or only a very weak, market. In that case, customers make known they are dissatisfied with the product or service, with the objective to flag management to do something about it. In this accountabilitymechanism, participation is crucial. Loyalty, which is the third incentive, intervenes when voice and exit co-exist. Customers loyal to a product or service will continue out of loyalty to brandname or provider, even if they have a broader choice (Hirschman 1970:33-9). Applying this to the public sector in developing countries, and for example to malnutrition, often leaves only voice as the principal accountability mechanism. If malnutrition reduction services are offered at all, there is often no choice in provider. All these theories contributed to and inspired the World Bank's definition and operationalization of good governance.

\subsubsection{Evolution of World Bank interpretation of Good Governance}

The objective of the World Bank's focus on good governance is twofold: first, to assist client countries in creating and sustaining an enabling environment for development; and second, to improve the efficient use of development resources to reduce poverty and increase sustainable growth. In the first half 
of the 1990 s the World Bank good governance focus was primarily on what is called the narrow focus, the administrative aspect, since it is limited by the World Bank's Articles in focusing on the political aspect. In those earlier years, it reacted to the state-dominated economic and social development of the previous decades, and called primarily for reducing the size and importance of central government. In the first half of the 1990s, a country with a functioning justice system, financial discipline, and an efficient public sector was considered to be well governed (World Bank 1994). World Bank financed projects then aimed at achieving public service delivery efficiency, supported strengthening of competition and markets, approved privatization of public enterprises, endorsed civil service reforms, promoted budgetary discipline, advanced decentralized administration, and encouraged greater use of non-governmental organizations.

However, the interpretation of good governance evolved over time. It was in the later half of the 1990s that rule of law, democracy and anti-corruption became more prominent attention points in the World Bank good governance agenda, adapting to the more broad governance focus. Equitable economic growth, with a focus on the poor benefiting more proportionately than the richer quintiles of the population from the development aid, became an outcome of development policy good governance (WRR 2001:18). Today the debate is centered on improving and reforming institutions, strengthening accountability, and exploring active roles for non-state actors.

The evolution of the good governance theory and its interpretation at the World Bank culminated in the 2004 World Development Report: Making Services Work for the Poor. It introduced an accountability framework in seeking answers to the problems related to service delivery for the poor ${ }^{81}$, heavily influenced by Hirschman's trilogy of exit, voice, and loyalty. The WDR-2004 framework adds a power relations dimension to the accountability structures: voice/politics, compact ${ }^{82} /$ policies, and client power. It emphasizes people's behavior in the chain of interactions between demand and service delivery ${ }^{83}$ (figure 5.1)

\footnotetext{
${ }^{91}$ Critics of the WDR suggest that its emphasis on the compact simply defines away the central problem in service delivery. It is precisely because performance cannot be specified and measured, that its delivery is in the public sector and that messy implementation mechanisms become necessary.

"Compact can be explained as a sort of agresment, ${ }^{\text {contract }}$, between policymakers and providers. The provider agrees to deliver a service and in turn is rewarded depending on performance. The compact can be with providers as private organizations, civil servants and NGOs. The compact idea was developed following the problems encountered with incentives for civil servant service delivery.

3ublic, private and non-governmental organizations
} 
(World Bank 2003b). For children to learn they will have to go to school for example, a teacher is needed, and children need to attend school and have materials to learn from. Teachers should be paid for their service, trained, supervised and motivated. Behind this chain of interactions, a ministry of education usually is responsible for ensuring the chain is not interrupted. All those decisions are, or should be, influenced by local governments and communities (World Bank 2003b:46-52).

Figure 5.1: WDR 2004 Accountability Framework:

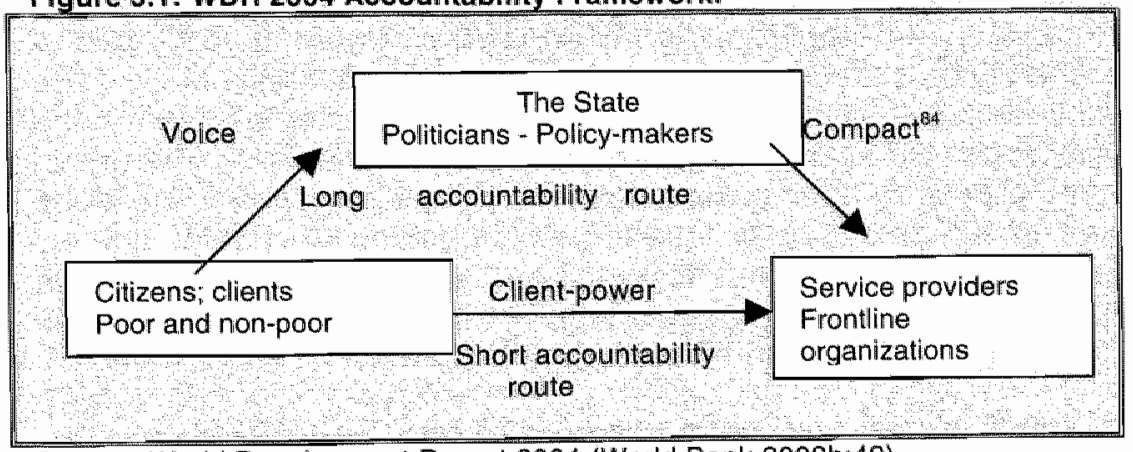

Source: World Development Report 2004 (World Bank 2003b:49).

\subsection{World Bank Operationalization of Good Governance}

Probably the most influential application of good governance by the World Bank is its decision to allocate funds based on countries' progress towards good governance ${ }^{85}$. With that decision the World Bank gave a clear sign to governments of its client countries in the developing world, to take serious action to improve their governance. In order to determine whether countries are making progress on improving governance and to guide the allocation of IDA $^{86}$-resources, the World Bank assesses countries' performance and the quality of institutions in the areas of economic growth and poverty reduction through the annual country performance assessment; CPIA. The World Bank conditions its lending-allocations on these CPIA-scores, and a number of other assessments in the areas of financial

The broad, long-term relationship of accountability connects policy-makers to organizational providers. This is usually not as specific or legally enforceable as a contract, but an explicit, werifiable contract can be one form of compact (World Bank 2003:48).

85 The Bank initiated country assessments to help guide allocation decision already in 1970s, but governance as a determining factor became more prominent in the ratings in the 1990 s.

${ }_{66}$ International Development Agency (IDA) - see annex 1 for details 
management and procurement, as well as the quality of implementation of the entire lending-portfolio in a country.

The second influential decision was made in the late 1990 s, in part as follow up to the publication of Assessing Aid. This is because of its conclusion that financial aid, which is the World Bank's main assistance vehicle, has a more positive impact in those countries with sound management based on good policies and institutions ${ }^{87}$. As a result, specific investment lending (or project lending) was no longer the preferred lending instrument, except for countries with very poor governance. Programmatic lending, to finance the entire public sector development program, and not only specific sectors, is now the main modality. Coordination of donors and systems would make development assistance more efficient. In addition, money is fungible, so financing the health sector via project lending does not ansure the money is well used, or used on health and by supporting the entire development program and measuring progress on a variety of development indicators, the incentive is to use resources more efficiently.

\subsubsection{Enhanced Highly Indebted Poor Countries Initiative (E- HIPC)}

In concrete terms, the good governance concept contributed to the decision regarding the so-called Enhanced Highly Indebted Poor Countries (E-HIPC) initiative, towards the late 1990s. The World-Bank/IMF E-HIPC initiative was started in $1996^{\circ 8}$ and was designed to relieve the high burdens of external debt of some of the poorest nations. The purpose of HIPC was to reduce the external debt as part of a strategy to achieve sustainable debt load, thereby promoting economic growth. In 1999, the E-HIPC reflects the Good Governance debate, as well as the influence from NGOs, to create a direct link between debt rellef and poverty reduction. The E-HIPC targeted the anticipated debt service savings to increase spending on social sectors.

The E-HIPC initiative has been successful in reaching its original objective, reducing external debt in the poorest nations, according to a recent independent evaluation (World Bank

\footnotetext{
A country with sound economic policy would typically have low inflation, small fiscal imbalance and an open trade-regime (Sachs and Warner 1995). Institutional quality is measured as the strength of the rule of law, the quality of Dollar, 2004). In fact, much earlier than first envisioned. A draft of the working paper was laaked to the press in 1995 and pressure was put on to launch the initiative in Brady-plan provided debt-relief.
} 
2003a). In addition to effectively reduce debt service, OED found that the targeted countries increased spending in the agreedupon sectors. However, the evaluation concludes that the $E$ HIPC initiative, although good, plays only a small part in addressing broader development problems. One-time debt relief does not ensure that debt will remain at sustainable levels, and fungibility of resources is onlly very marginally addressed. A key criticism on the E-HIPC approach is that the primary determinant of whether a country's external debt is sustainable concerns its ratio of debt to exports, as this narrow measure does not take a country's human development indicators into account ${ }^{89}$.

An additional successful outcome of the E-HIPC initiative was the increased collaboration on development policy among donors. In 1998, the donors became united around the need for a common approach to the development of a country (Ritzen 2005). The Poverty Reduction Strategy Papers are one of the outcomes of this unison.

\subsubsection{Poverty Reduction Strategies}

The E-HIPC initiative did serve as a catalyst to changes in development policy, reflecting the evolution of governance thinking about transparency, participation and ownership of the development strategy. As a condition for debt relief, an eligible country should establish broad-based ownership over its development agenda and develop a strategy in the process to reduce poverty: the Poverty Reduction Strategy Paper (PRSP ${ }^{90}$ ). The World Bank may provide financing for the national public budget in support of the PRSP, through a so-called poverty reduction credit (PRSC). PRSPS are primarily done in lowincome countries eligible for debt-relief.

It was not only the E-HIPC though that led to PRSPS. Twenty years of development thinking and learning about conditions for effective poverty reduction led to the PRSP approach. However, the ideas of PRSP were formulated during 1999 in the course of discussing the conditionality of E-HIPC. PRSPs describe a country's macroeconomic, structural and social policies and programs to promote growth and reduce poverty, as well as associated external financing needs. Process guidelines for PRSPs include broad participation - including civil society and private sector - in developing the strategy in order to foster strong ownership at all levels. They are guided by the

89 This may change now with the commitment to the Millennium Development Goals.

${ }_{90}$ The PRSP replaced the Policy Framework Paper, formally the tri-partite document of the national government, the IMF and the World Bank. 
following principles: (i) country-driven, involving broad-based participation, (ii) results-oriented and focused on outcomes that benefit the poor; (iii) comprehensive in recognizing the multidimensional nature of poverty; (iv) partnership oriented involving coordinated participation of development partners; $(v)$ based on a long-term perspective for poverty reduction. The application of the principles and the variation between countries has been the subject of a number of studies to date. Especially in the beginning years, 1999 and 2000, the first PRSPs were far cries from the participatory process; they were often written by a small group of local and external consultants without the required broader discussions (Ritzen 2005:50). But the application of the principles has much improved since.

Piron and Evans identify two contrasting views critical as background to PRSPs and important for beiter understanding in the context of evolving development assistance. On the one hand, it is thought, the PRSP approach offers an agenda for propoor reform and opportunities for national governments to become more committed to pro-poor policy-making and for donors to work more in line with country-owned processed and priorities. However, on the other hand, the very fact that the PRSP approach is led by the donors is seen as a factor that could negatively influence national policy development (Piron 2004:1). Both sides though agree that an incremental process if possible through PRSP approach, but that there are major challenges.

Earlier work by Booth showed that for the PRSP approach to work it has to work through political systems and processes (Booth 2003). Besides the importance of historic "political capital" of poverty reduction and the relevance of the formal political structures, Piron highlights how political timing and elections influence the development of the PRSP (Piron 2004:13). In Bolivia and Georgia, governments changed in the process of development and it remains unclear how the new governments will adopt them. In Madagascar, the PRSP development started in 2000, a political stand-off stopped all discussions in 2001 and the PRSP was finalized with the new government in 2002. The PRSP reflects the political agenda of the new government, but was informed by a wide variety of constituency groups from both governments.

\footnotetext{
P1 Refers to how powerty reduction is perceived and what importance it has. For example in Georgia, one of the cases studies by Piron, poverty reduction is a reduction has long been seen as political agenda, whereas in Uganda poverty to reduce sectarian divisions (Piron 2004:11).
} 
The most variation in PRSPs is seen in the consultation process with civil society organizations, which depends heavily on different patterns of state-society relations. Piron studied four countries $^{92}$, and concluded that governments such as Bolivia which need civil society for their ruling party survival need to consult with all groups, whereas governments such as Uganda and Vietnam were able to select whom they consulted because they had no need of the more contentious groups for political survival (Piron 2004:17).

An OED evaluation found that the PRSP initiative added most value in those countries where government leadership and aid management processes were already strong (OED 2004). The report allso found less positive effects, for example, the tension between donor-driven initiatives versus country-driven processes. More attention was spent on developing the documents that give countries access to resources than on improving country processes (OED 2004). However, most countries did hold extensive consultations while developing the strategy, which has brought new stakeholders into the dialogue and increased transparency. While this is a measure of success, civil society in many countries, the evaluation found, felt this process had only limited impact on the actual design of the poverty strategy. The NGOs in particular criticized this aspect of the process (box 5.3). This raises questions about the effects of participation (i.e. only buy-in - or actual ownership) and the type of participation that is used during the implementation, and subsequently the sustainability of the strategy. The evaluation found that, in fact, national governments were most positive about the initiative being country-driven, while the international NGOs were least positive (OED 2003:14). Piron concludes that the PRSP requirement of participation is the one most open to different interpretations (Piron 2004:18).

In 2002, a PRSP-implementation assessment revealed that governance issues feature in a large number of PRSPS, capacity constraints are openly discussed, and public expenditure reviews are in the majority of the documents included in the study. Parliaments though are not adequately involved, and governance indicators to measure progress on this last feature of PRSPs are largely absent (World Bank 2002:10). In all, it is probably too early to make any definite conclusions about the value of the PRSP initiative. Although most reports and evaluations tend to lean towards the more positive impacts, there remain many areas for strengthening, several of which fall in fact

${ }^{2}$ Bolivia, Georgia, Uganda and Vietnam 
in the good governance domain, such as civil society involvement in decision-making ${ }^{93}$.

An independent evaluation ${ }^{94}$ presented to the World Bank in October 2003 agreed with that finding and added that the quality of PRSPs is uneven. They seem to be prepared at the initiative of WB/IMF, are often prepared under pressure, and are sometimes donor oriented. Yet, that during the process ownership has been increasing. Participation of civil society was found insufficient according to the report. But other evaluations indicate that PRSPs are more and more owned by national governments, and that parliaments have become more involved in the formulation and a continued role is foreseen during implementation. Dialogue between PRSP teams and sector ministries is becoming more common, and the PRSP process has survived transitions in national governments in some countries (IMF/IDA PRSP progress report, Sept. 2003:2).

By July 2004, a total of 54 PRSPs were developed, but the quality and the experiences regarding the process vary widely across countries. Despite the variation, it is in general agreed that the process of developing a PRSP has helped policymakers link specific sectors to poverty reduction. For example, sector plans are linked to poverty indicators, and resource allocation should be proportionally increased for the poorest segments of the population. Analytical work in countries has demonstrated that the largest shares of health and education budgets for example, went primarily to the richer segments of the population (WDR 2004). In the poverty strategies, actions are proposed that would reverse this trend by making more resources available to those interventions that would benefit the poorer population the most. The PRSPs are considered to provide a valuable source of information, and are used in chapter eight for data collection on public accountability for nutrition.

\subsubsection{Lending for Good Governance}

Taken as an article of faith that good governance is essential for effective aid, the World Bank committed itself to assisting countries in improving their governance. Institutional assessments help the Bank identify the areas for capacity building. In addition, a large number of projects and others types

\footnotetext{
93 DFIF is among those partners that monitor the PRSP processes in countries and produces critical reports regarding progress on the guiding principles. Several of those reports have been reviewed for this chapter.

Findings of the German PRSP-Evaluation, Washington DC, October 20, 2003. Countries studied: Bolivia, Honduras, Mauritania, Tanzania, Zambia and
Vietnam
} 
of loans finance capacity building activities. According to the World Bank Strategy Reforming Public institutions and Strengthening Governance (1997), the public sector management action has had rather limited impact. Also, the World Bank's independent evaluation department (OED) often rated public sector projects lower in success factors than other sector projects. According to the report, the Bank has had a relatively poor track record in its work on reform of public institutions and strengthening of governance. Evaluations, both internal and external, often indicate weak performance in the Bank-supported projects and programs.

A decade after the first introduction of good governance in the Bank's operation work, reports are more positive. For example, the 2002 implementation update of the 1997 Strengthening Governance Strategy reports that all Country Assistance Strategies (CASs) now address corruption issues, and diagnose governance conditions and risks of corruption. In addition, practically all CASs use governance-related triggers to determine the strategy for the country (World Bank 2002:35). Since it was openly recognized that corruption and rent-seeking are among the most important constraints to good governance, anti-corruption policy discussions are an increasingly-addressed agenda issue in the country-dialogue. A large number of projects that were developed during the 1990 s and to date include financing actions to strengthen the justice system, development of anti-corruption policies, and implementation and public sector reform.

There are limitations to what the World Bank can do in the area of governance, and there is severe criticism on what it does do as mentioned earlier. The World Bank's Articles prohibit it from addressing political accountability, although gradually the World Bank has begun to address these issues more directly. It can advise and support governments, but it cannot substitute for a government. Unless a government is committed to reform, changes will not be sustainable.

Grindle, in a recent article (2004), asserts correctly that the good governance agenda has become too long. Getting good governance calis for improvements in virtually all aspects of public sector, from institutions that set the rules of the game, to decision-making structures that determine priorities among public problems and allocate resources "to the interface of officials and citizens in the political arenas (Grindle 2004:526). In 1997, the World Development Report The State in a Changing World

95 World Bank (2002) Reforming Public Institutions and Strengthening Governance: a World Bank Strategy Implementation Updale - April 2002. 
included a list of what was needed for good governance, with 45 items. By 2002, this list included more than 115 items. In addition to being too long, there is very little guidance on prioritization and phasing and what is achievable in what time-frame. Grindle's proposal is to recast the so-called good governance agenda as a 'good enough governance' agenda. Good enough governance includes better understanding of the evolution of institutions, learning and allowing trade-offs, and setting priorities. 'Good enough governance' is a concept that is proposed to be considered by development agencies, as the World Bank who targets the poorest countries with the weakest administrations for good governance. Instead good enough governance should be their aim (Grindle 2004:526) ${ }^{96}$.

\subsection{Summary and Conclusion}

The purpose of this chapter was to provide the background to good governance as a concept, and how it is interpreted and operationalized by the World Bank. As shown in this chapter, there are a number of different definitions and interpretations of good governance, and they have changed overtime as they were adapted to changes in context. The remainder of this book will use the World Bank's narrow definition of good governance. Although the broader interpretation of good governance is of interest for malnutrition reduction, it is belleved in this study that the narrow interpretation offers a workable definition from which proxies can be derived for the analysis needed to test the hypotheses. It is primarily the operationalization of good governance that will be analyzed regarding its influence on malnutrition reduction. The links between good governance and malnutrition reduction, in specific the support to improving accountability and public sector reform, are analyzed in the next chapter. An extensive review of PRSPs was included as background because they are used to collect data on PA-nutrition from.

\footnotetext{
96 One could argule that to a certain extend "Good Enough Governance" is applied by the World Bank when it discusses countries' progress towards the triggers that are set to decide whether or not a country has made sufficient progress to move to a next PRSC. Usually these discussions are about whether the progress is sufficient to show the reform is going in the right direction.
} 


\section{Chapter 6: Governance and Malnutrition}

\subsection{Introduction}

The UNICEF model of causes and determinants of malnutrition states that the availability and equitable distribution of financial and human resources and the cultural patterns of society are basic determinants of malnutrition. Availability and equitable distribution of resources is linked to good governance. Chapter one discussed the challenges the nutrition problem faces in building commitment or public accountability (PA) in order to create awareness and obtain adequate resources for nutrition malnutrition reduction interventions. The purpose of this chapter now is to explore which and how key-elements of governance may contribute to addressing these challenges. The objective is to start explaining the relation between good governance and malnutrition reduction. Following the theoretical exploration, variables and proxies to measure the key-elements of governance and PA for nutrition are proposed and subsequently tested in the following chapters. As in chapter five, the focus is on the World Bank and the data-sources for the variables are taken from World Bank data-bases.

The following research questions are addressed: (1) What are the key-elements of good governance on which the World Bank focused? (2) How could these key-elements contribute to malnutrition reduction? (3) How can public accountability (PA) for nutrition be measured? (4) How is governance measured? But before discussing the links between good governance and malnutrition, the case is made that malnutrition reduction is a public sector responsibility, and therefore governance may be an important determinant of malnutrition outcomes.

\subsection{Malnutrition Reduction and the Role of the State}

\subsubsection{Malnutrition Reduction is a Public Sector Responsibility}

That malnutrition is a public sector responsibility can be justified on equity and efficiency grounds. Economic theory provides valuable guidance on whether malnutrition reduction is a role for the state, and what would be the appropriate rolle of the state to play. Fukuyama for example, shows that in the current era of industrial policy and the need for wealth re-distribution, not only addressing market failure, but also improving equity can be considered a basic argument for state-intervention (Fukuyama 
2004:8 and World Bank 1997). Market failure and distributional equity are the two frequent reasons used to argue for government financing. Investing in nutrition fulfills both these efficiency and equity arguments as follows:

- From a welfare and production-function point of view. First of all, nutrition is often incorporated in the welfare functions of individuals in developing countries; i.e. good nutrition leads to higher welfare. From this perspective, ensuring good nutritional status may lead to a higher utility level. There are also productivity reasons for governments to invest in nutrition. According to Ray (1998:500-4), a significant fraction of the population in developing countries might be caught in a poverty trap. This fraction cannot afford an adequate amount of quality-nutrition. This decreases the capacity of the body to perform tasks that generate income that can be used to provide nutrition (Behrman 1993).

- From an investment benefit point of view. Behrman, Alderman, and Hoddinott (2004) distinguish direct and indirect effects of malnutrition. Direct effects are the extra costs incurred due to problems and illnesses related to malnutrition, and indirect effects are the loss in (future) praductivity. Government spending on malnutrition reduction reduces these costs. There is a strong link between income and mainutrition. Policies aimed are reducing malnutrition are therefore likely to be pro-poor (Behrman et al 2004).

- From a public good point if view. Although most interventions that reduce malnutrition are not considered a pure private good, there are some examples where they are considered a public good ge $^{97}$ De-worming ${ }^{98}$ is a good example of such an intervention. By de-worming school-aged children, the overall parasite infection-rate in the community is reduced ${ }^{99}$. Nutrition education campaigns which create knowledge on better nutrition for better health are another example. Mass nutrition education campaigns are non-excludable and non-

\footnotetext{
Public good are goods or services such that one person's consumption does not reduce the amount available for others to consume. Typically these are goads from which consumers cannot be excluded: if they are made available they are made available to all, at least locally or temporarily. Since people can consume these goods without payling for them, no one will produce them for sale to individuals. Therefare they will be produced only if government pays for their
production.

De-worming is malnutrition reduction interventions. It improved the absorption of food and it reduces anemia through the reduction of blood loss caused by
worm infections.

99 School-aged children are the most significant spreaders of the parasite. As a result of the de-worming of that age-group, the entire community benefits, creating externalities beyond the direct beneficiary.
} 
rival, two characteristics of a public good. It is generally accepted that even in a minimalist state, protecting the poor and most vulnerable is a responsibility of the state. Malnutrition is proportionally higher among the poor. If one adheres to a broader role of the state, the intermediate functions, those malnutrition interventions that provide externalities are considered the role of the state ${ }^{100}$.

- From a human rights and equity point of view. UNICEF's human rights arguments for good nutritional status as a basic human right also would make investment in malnutrition reduction a role of the State. Nutrition services that aim at preventing and reducing malnutrition are by definition propoor, because malnutrition is disproportionately higher among the lower income quintiles. In many cases, equity reasons lead governments to provide private goods--those that are disproportionately consumed by the poor--as a means of transferring resources to the needy in a targeted manner.

The above argues for public financing of malnutrition reduction interventions. The question as to what the appropriate role for the state is in implementing interventions that contribute to reducing malnutrition has been explored in earlier work using institutional economics theory ${ }^{101}$. Based on the characteristics of mainutrition interventions, the role of the State would be to implement those interventions that are difficult to monitor and for which effectiveness is difficult to measure, for which there are few providers, and that are information -asymmetric (see table 2 Annex 2 for more specific examples).

\subsubsection{Governance is Important to Malnutrition Reduction}

Together, the comprehensive definition of good governance by the United Nations and the World Bank's definition provide the answer (see chapter 5 for definitions). Improving governance as a means for malnutrition reduction implies listening to poor people and responding to demand for services that contribute to reducing malnutrition. Good governance could make public officials accountable for their

\footnotetext{
${ }^{100}$ Malnutrition reduction interventions share similar characteristics with other health promotion interventions that focus on behavior change, such as promotion of bed-net use to reduce the risk of malaria and anti-smoking campaigns. Usually governments take charge of those interventions because they have large positive externalities (public good argument), but low demand.

${ }_{101}$ For more details see Rokx (2000). Who Should Implement Nutrition Interventions; The application of institutional economics to nutrition.
} 
action, and inaction, regarding government programs. It could ensure a capable government which would design, and implement policies effectively. In other words; a well governed country could be more likely to ensure that the malnourished are taken into account in public policy making, that resources are provided to address the problem, and that government is capable of designing and implementing malnutrition reduction interventions and programs. Building accountability is the actual attribute of good governance for addressing malnutrition, as described in chapter one.

\subsection{Good Governance may contribute to Reducing Malnutrition in Several Ways}

Malnutrition reduction is a public responsibility. The state has a role to play. But how can it be ensured that the state will play its role? in chapter one the lack of action and commitment public accountability - to nutrition was identified as a major constraint to the implementation of nutrition programs. Analyzing governance can provide insights into this question. Good governance as defined earlier implies that political, social and economic priorities are based on broad consensus in society and that the voices of the poor and vulnerable are heard in decision making over the allocation of development resources. In other words, governments are accountable for malnutrition reduction. PA-nutrition is defined as the public sector being responsive to mainutrition problems by not only raising awareness to create knowledge and public demand, but also taking action to address the problem and providing information on how, why and what and for whom, to the population at large, and the poorest in particular. in this study, PA-nutrition is considered as good when a country has made nutrition a priority in their overall development program, and has allocated resources to implement interventions and programs. An example of how good governance can be operationalized to a specific development problem is Hyden's work (Box 6.1). 


\section{Box 6.1: Applying Good Governance to Sustainable Development}

\section{Hyden's Application of Good Governance to Sustainable Development}

Goran Hyden (2001) operationalized the principles of good governance to sustainable development by defining changes in power relations necessary to reach an accountability level. His operationalization focuses on the interface between micro and macro levels, which is of particular impontant in societies with weak states (cieveloping countries), and takes into consideration changes in power relations as the result of leadership interventions from high political level and from citizen initiatives from below. He suggests a four-pronged approach as follows: The first aspect of changing power relations is articulation, or the readiness and ability of individuals to demand freedom necessary to make decisions of their own on issues that concern the use of resources that they share with others, This is also called empowerment from below. The second aspect is mobilization, seeking out the other for common action to maximize gains for themselves. This would imply developing skills of civic engagement and creation of social capital ${ }^{102}$. The third aspect is distribution. As more and more groups will compete for influence and use of resouroes, leadership should be ready to distribute power so that the political system becomes nore pluralist and groups secure access to complementary resources through market, state; and other relevant institutions. This means decentralization and delegating authority In other words, sharing power in rather bold ways. The fourth aspect is confirmation, which typically takes place through the decislons taken by the judiclal institutions, bit is generally more dependent on the readiness of both citizens and public institutions lo respect the pilinciple of the rule of law

\subsubsection{Good Governance may contribute to Accountability for Nutrition}

A good governance government sets its priorities and allocates its resources transparently, equitably and is accountable to its population. In support of this goal, poverty reduction strategies (PRSP) were promoted in the late 1990s. The underlying principles of the PRSP-process include a country-driven approach which should involve broad-based participation, be results-oriented and pro-poor. The application of these principles may contribute to a more enabling environment for malnutrition to be recognized as a development problem and addressed appropriately.

\subsubsection{Broad-based Participation}

The most profound impact the international focus on good governance could have on poverty reduction may be through its potential to increase citizen's participation. One of the

\footnotetext{
${ }^{102}$ Building on Toqueville and Putnam's 'Making democracy work in Italy'."

103 This aspect also points to the rights-based approach of sustainable development and agrees in particular with the definition of goad governance of for example the United Nations.
} 
underlying principles of good governance in the PRSP-process is it should be based on broad participation. Broad-based participation means the inclusion of non-traditional government actors from civil society, including the rural population, the poor segments of society, and private sector in the decision-making process about the national priorities in the poverty reduction strategy. By promoting broad participation, the likelihood that malnutrition will be raised as a development problem increases, but is not assured. The first part of the participatory process sets up a dialogue so all stakeholders can give and receive information and discuss perspectives. Concerned groups are more likely to be heard and the poor, who suffer disproportionally more than richer groups from malmutrition, are more likely included in the decision-making process.

In this regard, it is important to keep in mind that malnutrition is not always recognized as a development problem, the first challenge to creating PA-nutrition mentioned in chapter one. Creating awareness about malnutrition, and as a result increased demand for nutrition services and programs, is therefore an imperative part of building accountability for nutrition. Awareness of malnutrition and its solutions can be seen as a precursor to 'voices in institutional economics theory ${ }^{104}$. However, exercising 'voice' for malnutrition reduction is generally lacking in developing countries, the second challenge mentioned in chapter one.

Institutional economics, such as Albert Hirschman's trilogy of institutional economics that focuses on voice, exit, and loyalty (Hirschman 1970) offer insights for building public accountability. For example, following Hirschman's definition, voice for malnutrition reduction would be an expression of concern to the higher political levels about the problem of malnutrition and the need for services. This would lead to demanding public accountability. Exit, the stronger alternative of voice in Hirschman's theory, would provide the population suffering from malnutrition with an alternative to get the nutrition services, because exit reflects choice between alternatives. If clients are not satisfied with one, they can try another alternative for the same service or product. Thus defined, exit remains a rather theoretical concept for nutrition services in developing countries $^{105}$. If these services are provided at all, there is hardly

\footnotetext{
${ }_{105}$ Hirschman's accountability theory: trillogy of Exit, Voice and Loyalty.

105 But one exception to the above is worth mentioning. An example of exit can be demonstrated by what happened in Indonesia. In Indonesia a certain number of women preferred buying iron tablets ${ }^{t 05}$ from local shops rather than having to return to health centers, where the tablets were free of charge, but often not available. Alternatives to the services were created because there was a
} 
ever an alternative to turn to, so there is in reality little choice. In fact, even voice for malnutrition reduction in countries where malnutrition rates are very high often does not exist and will need to be built or created first.

In the context of governance, voice is understood to describe how citizens express their interests and react to government decision-making, as well as respond to problems in the provision of public goods such as education, healthcare and malnutrition services (Goetz 2002:9). Pritchett and Woolcock (2002) argue: 'markets create managerial discipline and induce efficacy through the exercise of private choice. Governments are (or should be) disciplined through the exercise of voice to enforce representative public choice'. The raising of awareness should be part of the dialogue process that precedes the broad participation mentioned. Hyden's articulation and mobilization of power-levels refer to this (see box 6.1). Though community participation has long been recognized as essential to malnutrition reduction, the attention has mostly been on participation in the design and implementation of services and less on demanding the services.

Citizens' voice could be strengthened if they had a better understanding of the causes and consequences of malnutrition, through improved access to information. Nutrition education campaigns should therefore be a key good governance element of any nutrition policy. By increasing awareness, "voice" benefits as well as accountability. Better information raises the possibilities for feed-back on quality of services (Ndulu 2004:274). However, even without voice, national governments should be concerned with malnutrition because it constitutes a heavy drag on development (see chapter three). Good governance, with its focus on broad participation, coupled with the renewed commitment to the MDGs, in theory opens the door to improving the 'voice' for malnutrition reduction.

\subsubsection{Result-oriented Strategies and Pro-poor focus}

In addition PRSP-processes being participatory, they are results-oriented and focused on outcomes that benefit the poor; in other words they are more accountability to the poor and they recognize the multi-dimensional nature of poverty. Malnutrition, as explained in chapter three, has a higher prevalence among the poorest segments of the population. If development is better

demand, women were aware of the risk of anemia in pregnancy, and started buying the tablets where they knew they would be avallable. There was also a perception that the tablets they paid for were of better quality, which may have been caused by the more attractive packaging (Galloway 2003). 
targeted, malnutrition is more likely to be addressed. The comprehensiveness with which PRSPS address the multidimensional nature of poverty is of crucial importance to malnutrition reduction because it is a multidimensional problem, and should thus be treated as such.

As the government focuses on poverty reduction, it is more likely to define institutional arrangements for malnutrition and thus malnutrition would be addressed. Nutrition policymaking and program implementation encounters difficulties because of the many sectors that are involved in it (see chapter 3 ) and it does not have a natural organizational identity, the fourth challenge mentioned in chapter one. The PRSP framework and guidelines offer the possibility of looking at malnutrition as a multisectoral issue in the decision-making process because it helps to establish multisectoral entities to guide the process. Also, it supports more accountability institutional arrangements for malnutrition to monitor execution of interventions.

By improving the system for policy-monitoring and information, cabinet and parliament can receive information on time for strategic decision-making. When malnutrition reduction is a target in the MDG-challenges, it should be monitored. Here again, by monitoring the malnutrition situation deterioration can be prevented and targeting of interventions improved if monitoring is tied to action. However, even though malnutrition reduction is a MDG target and should be monitored and reported on, only $52 \%$ of PRSPs in fact include an indicator for malnutrition monitoring (see box 6.3).

\subsubsection{Country-driven Processes}

Last, but not least, broad-based participation and poverty strategy development should be led by the country itself. One of the principles of good governance is to ensure development agendas are 'owned" by the country. Although ownership is an ambiguous concept ${ }^{106}$ (Piron 2004), here it means owned by the national government and extended to civil society through broadbased participation during preparation, execution, and monitoring. But, development agendas have been, and in some cases continue to be, often dominated by development partners, not by the national governments. Governments may not always have agreed with the imposed agenda and may simply not have implemented it. Johnson and Wasty found a significant

\footnotetext{
${ }^{106}$ Often it refers to ownership by the slate and is not identical to the "nation" The principal seems to be based on consensus between national actors, beyond the political elite, but it remains open which actors are most important (Piron
$2004: 5$ ).
} 
relationship between program outcomes and borrower ownership in their review of more than 100 structural adjustment programs (Johnson and Wasty 1993:10).

The international nutrition community by some token has generally taken over national nutrition agendas ${ }^{107}$ "often out of frustration about lack of action on an 'obvious' problem. Weak demand from national governments and lack of awareness of the problem at the national level may have contributed to the dominance of the international community over the malnutrition problem. A few examples of donor-driven agendas in the nutrition domain include vitamin $A$, salt iodization and the National Action Plans for Nutrition. Although the first became more country-owned during the implementation process possibly thanks to the successful results and large amounts of external resources attached to them, the latter started off somewhat more homegrown, but did not last (box 6.2). Vitamin A though continues to be largely externally financed. There are few countries that buy vitamin A capsules themselves.

\section{Box 6.2: Implementation of National Plans of Action for Nutrition}

\section{Few National Plans of Action for Nutrition were actually implemented}

In 1992, the International Conference on Nutrition (ICN) was held in Rome and 159 country officials declared their "determination to eliminate hunger and to reduce all forms of malnutrition. In the same declaration these leaders commit themselves to ensure that the development programs and policies that lead to a sustainable improvement of human well-being are mindful of the environment and conducive to better nutrition and health for present and future generations" (1992:2). All 159 government officials also pledged to develop National Plans of Action for Nutrition (NPANs) before 1994. In 1994, the large majority had started developing plans, however, less than half $(23$ out of 49 countries that were reviewed for this study ${ }^{\circ}$ ) implemented them the decade following the IGN And; the majority of these did so only partly, There appears to have been little ownership of the NPANs, which may have contributed to the low level if implementation (Kavishe 1996). The directives that were glven by the international donors for the development of the NPANs for example, left little room for countries' own interpretation. But despite the detailed instructions, no directives were given for policy-analysis. The NPANs did not receive sufficient attention and subsequent financing for the implementation of the programs they planned for.

\footnotetext{
${ }^{103}$ That what is considered important to reduce and prevent malnutrition and is given priority over other issues.

708 The progress reports on the National Plans of Action for Nutrition were reviewed to gather this information. This information is not based on interviews or actual research but on what countries themselves reported in the progress reports. The 49 countries include all for which information was available. Other countries may have developed and even implemented the plans but no information was available at the time of the review.
} 
For malnutrition reduction, as for other sectors, it is important that government 'owns' the design, prioritization and monitoring of the process. Of course, as discussed in chapter one, here is where the challenges to building PA-nutrition, most particularly the lack of incentives to address the issue, are important. In fact, in a way, this was in many countries the underlying reason for the international nutrition community to intervene in the nutrition domain. National governments were not aware, did not take action, and insufficient attention was paid by the international nutrition community to building up national level country ownership and capacity. When good governance prevails, country-ownership of nutrition policies, programs, and monitoring is emphasized and the MDGs provide a new incentive. Countries must establish development programs, and donors should assist countries in developing them, instead of writing them themselves, as was often done in earlier years.

Although it is too early to do a review of how many countries have actually implemented the planned actions as stated in the PRSPs, the review 54 PRSP documents (see box 6.3) provides some interesting insights. A large majority, $65 \%$, recognizes malnutrition as a development problem in the PRSP country, but only $38 \%$ makes it a priority area to be addressed in the development policy. And only a small number includes a budget for malnutrition reduction. The results reflect to a certain extent the common challenges to malnutrition reduction. A total of 17 countries where malnutrition is a serious development problem do not recognize it as such. And only 18 countries of a total of 48 make reducing malnutrition a priority area and fewer still allocate a budget (annex 2 provides the detailed scores). 
Box 6.3: Poverty Reduction Strategy Papers from a Nutrition Perspective

\section{Summary description of results of review of 54 Poverty Reduction Strategy Papers from a Nutrition Perspectlve}

Of the 54 countries for which the PASPs were reviewed, 48 have high or medium levels of malnutrition among children under five at the national level The following analysis if carried out using the PRSPs tor these 48 countries.

- 31 PRSPs (65\%) mention mainutrition as a development problem in their countries:

- 18 PRSPS (38\%) identified malnutrition reduction as a priority area in the countries where malnutrition rates are higher than $20 \%$ among children under 5 .

- 26 PASP (54\%) have included targets to monitor the limprovement of malnutrition in their countries, $\mathrm{A}$ number of counthies where malnutrition reduction was not identified as a priority stillinclude target to manitor,

- The majority of PRSPs that ldentify malnutrition as a development problem also include actions to address the issue in the strategies. Whether those are effective and appropriate interventions for the identified problems was not included in the review.

- Only 14 PRSPs included a budget for nutrition interventions. However, the value of the proportion of this data is difficult to interpret because many PRSPs did not include any budgets for any sector or activity, and some of the PRSPS were interim-PRSPs, often without a budget.

Source: author's review

\subsubsection{Good Governance may contribute to Malnutrition Reduction through Government Effectiveness}

The World Bank supports countries directly with financial and technical advice, including in the area of public sector management. Although the World Bank has long supported and provided credit for public sector improvements, since the mid 1990 there is more focus on good governance principles in public sector management (World Bank 2000a ${ }^{109}$ ). Civil service reforms, introduction of performance based promotion and merit-based recruitment mechanisms, support to decentralization and community-based actions, and interventions to strengthen budgetary and accounting systems all are among the World Bank's efforts to assist countries in improving governance. ${ }^{110}$ The

${ }^{109}$ World Bank (2000a) Strategy for Public Sector and Governance - Reforming Public Institutions and Strengthening Governance Its four main strategies were: (1) to move the governance and institutional reform agenda center stage; (2) to broadien the approach from only supply advice and technical support to promote ownership and advocate for but not force nationally owned demand for reforms: (3) to deepen analytical work for better understanding of local situations; and (4) to move to more flexible and longer term lending instruments in order to be able to support and accompany reforms.

${ }^{110}$ See for details about public sector management supported by the World Bank Strategy: Reforming Public Institutions and Strengthening Governance, World Bank November 2000. 
underlying motivation to focus on these areas is that wellfunctioning governments are generally responsive to citizenry and reasonably efficient in delivering services (World Bank 2000; Grindle 1997). The most direct channel through which government reduces poverty is via its impact on service delivery (World Bank $2004^{11}$ ), through improving financial management, decentralization and local participation and ownership.

Many developing country governments have poor functioning public expenditure management systems, which severely limits their service delivery capacity. First, they have limited domestic revenues and weak service delivery. Often budgets are prepared without any links to the development strategies or sector ministry work-plan proposals. Long expenditure chains and complex and frequent control systems further make the transaction costs very high and the system slow to react to changes, which are frequent due to poor planning. By improving public expenditure systems and re-aligning public finance and strategic decisions to poverty reduction strategies and sector-ministry work-programs, service delivery to the poor, including malnutrition reduction services, can be much improved.

Decentralization of public service delivery is an area where improvement can very much contribute to malnutrition reduction, because it empowers the local level governments and bring services closer to communities. It would also bring the decision-making closer to the community-level where malnutrition, as a household level problem, is experienced and can be prevented. Following the subsidiarity principle ${ }^{i t 2}$, implementing malnutrition interventions is most effective at the decentralized levels. It has long been known that communityparticipation is crucial to malnutrition reduction because it improves the effective use of resources controlled by those responsible for nutrition. Those concerned with malnutrition problems, care-givers at the community level, are more interested in malnutrition reduction interventions and allocate resources more effectively (Gillespie et al 1996:59).

\footnotetext{
"111 And in World Bank (2000b) Reforming Public Institutions and Strengthening
Governance PREM - Public Sector Group

"112 The economic principle of subsidiarity states that expenditure decisions should occur at the lowest level of government that can fully capture the costs and benefits of providing a public service (Fengler 2003:22). The communes in Madagascar have the following competencies: administrative services; management of public domain and economic infrastructure; waste management and public hygiene; social services; security; and development planning.
} 


\subsubsection{Good Governance may contribute indirectly to Malnutrition Reduction through Anti-corruption and Legal reforms}

The main objective of anticorruption work is not only to discuss the issue (something unheard by financial partners in development before the 1990s), but also to restore credibility in countries' legal and judiciary systems. Transparency and monitoring of public expenditures, budget execution and the execution of the poverty reduction strategy all fall under this objective and are linked to government effectiveness in service delivery as well. Corruption is often related to deficiencies in the structure of public administration. By reducing corruption, public administration and delivery of services will be improved indirectly.

Fighting corruption empowers the poor to hold the government accountable for its actions and use of resources, as well as for improved service delivery. Malnutrition reduction may be positively affected by these activities. For example, discussions on corruption may contribute to better and more equitable distribution of resources and mitigation of resource losses. Subsidized feeding programs may benefit most from corruption reduction ${ }^{113}$. If food hand-outs are used to 'buy' votes during elections they may have a short-term positive effect on food-availability in areas with pervasive hunger, but it undermines transparency and distorts voice. Corruption undermines the effectiveness of foreign aid and, since malnutrition interventions are often financed through external funds, reducing corruption should contribute to making this aid more effective.

Accountability is strengthened through the promotion of anti-corruption policies and actions to enhance the oversight function of parliament. Under World Bank supported programs, training programs and other capacity building interventions as provision of small equipment (computers) to parliamentarians and policy-makers is carried out to make their tasks more efficient ${ }^{14}$. Transparent merit-based recruitment policies may have important influence on the development of policies and implementation of programs. Especially since often attention and success depends on personal leadership.

Since this study focuses on good governance in the narrow sense, no discussion is included on the possible

\footnotetext{
113 Feeding programs are not considered the most effective ways to reduce malnutrition in this study.

${ }^{114}$ Klein Haarhuis (2005) evaluated the implementation of the World Bank anticorruption program in seven African countries.
} 
influence of democracy or political regime on malnutrition reduction. Countries as Cuba and China in fact offer interesting cases in this regard. Cuba and China's malnutrition rates have declined remarkably over the years, while their scores on political freedom are rather low. Smith and Haddad found that democracy is a relatively strong explanatory variable for malnutrition in their 1996 meta-analysis (Smith and Haddad 2000:57). The more democratic a government, the more likely it is to spent resources on social sectors, including malnutrition reduction services.

In conclusion, there are three routes through which good governance is expected to have a positive impact on malnutrition reduction. First, improving the enabling environment in which PAnutrition is more likely built. Second, strengthening public sector management, so service delivery is improved. And third, reducing corruption may indirectly influence malnutrition reduction positively. Figure 6.1 displays the original framework in which the three routes are now illustrated.

Figure 6.1: Adapted Conceptual Framework: Relation between Good Governance and Malnutrition Reduction

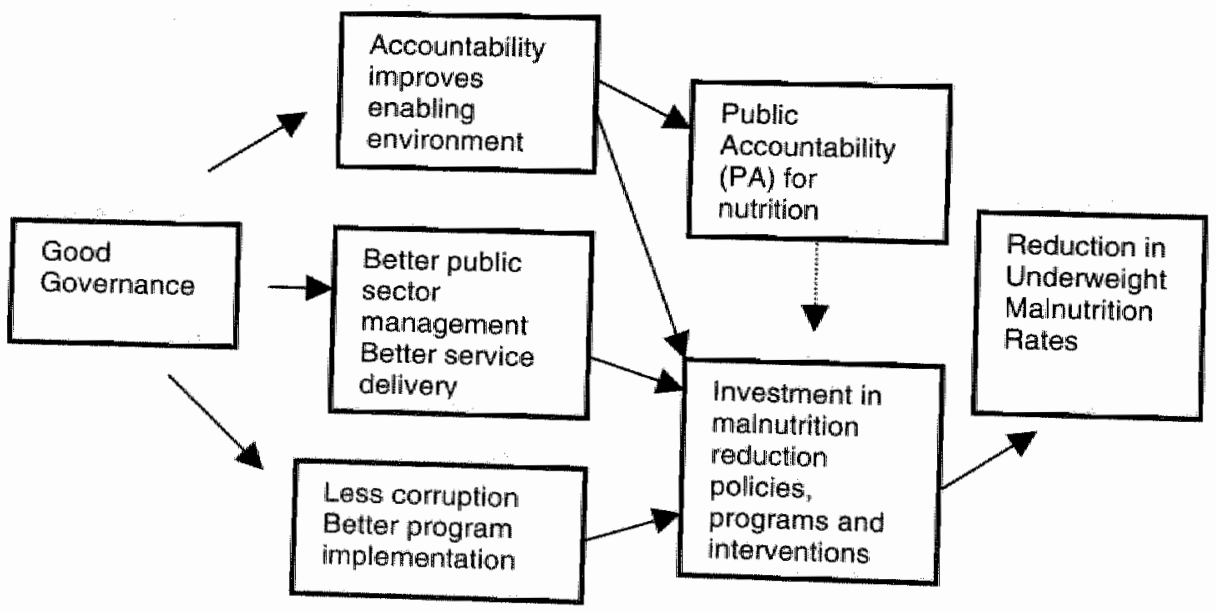




\subsection{A Measurement for Public Accountability for Nutrition}

All of the above remain theoretical considerations. The next step is to analyze the relation between governance and PAnutrition, which will be done in the next two chapters. But first, a measurement for PA-nutrition is constructed.

There are no readily available data-bases that compile information on the attention given to malnutrition in official documents and development programs, investments in nutrition, or specific organizational or institutional structures for reducing malnutrition from a representative number of countries. In order to conduct the analysis of the relationship between governance and PA-nutrition, a measurement from different 'signals of evidence' of PA-nutrition was created. From the literature, it is reasonably clear that in order to get nutrition adequately addressed several actions are needed.

First, awareness about the problem, second it should be made a priority in the development agenda, so that action can be taken. Indicators to monitor progress and the setting of targets will make information about malnutrition important. Information is the first step to accountability. Countries that really take the mainutrition problem seriously should allocate a budget for it. The latter is considered a very important sign of PA-nutrition. As indicated in the UNICEF model (chapter two) potential resources and quantity and quality of resources are considered basic determinants for malnutrition. The level of investment in malnutrition is an important indicator of true engagement and willingness to address the issue seriously. However, it should be kept in mind that the measurement of the level of investment does not account for the quality of the policy or its effectiveness. 
Table 6.1: Variables making up the proxy-measurement of PA-nutrition

Variables o PANGutrition
Mainutition is recognized
as a development problem
in the PRSP
What it measures:

The PRSP is the official national development agenda for poverly reduction. If mainutrition is recognized as a development problem in this agenda, awareness about the seriousness of the problem is existent and a first step towards actions to address it.

Nutrition is a priority area in the national Poverty (PASP) in those countries where malnutrition rates constitute a public health problem - higher than $20 \%$.

Indicators or targets to monitor maimutrition are included in the PRSP. Reduction Strategy

Areias that are prioritized in the official national development programs as PRSPs are likely to be financed, and if national budgets are inadequate. external financing may be sought. Development partners are more inclined to provide financing if a country can demonstrate it is serious about allocating resources. Prioritizing malnutrition reduction in the PRSP would provide that justification.

The Millennium Development Goals (MDGs) are internationally agreed upon indicators of development. The majority of the development partners have committed to supporting actions that contribute to achieving these goals. Malnutrition reduction is one of the indicators of the first goal, which is Poverty Reduction. National development programs that include malnutrition indicators in their monitoring system are more likely to take this indicator serious and support actions to reduce it. Malnutrition indicators are Data-collection is part of any monitoring system
regularly monitored - - and having data and making it available is a sign regular DHS or national of openness of acknowledging a problem. It is not survey data are indicate action to address it though. available ${ }^{115}$.

Malnutrition reduction
interventions are foreseen in the budget provided in the PRSP.
Following prioritization, including an actual budiget in a national poverty reduction program is a very strong signal that action will be taken to seriously address malnutrition reduction.

\subsubsection{Data-sources}

Data to construct the proxies are collected from a detailed review of the Poverty Reduction Strategy Papers (PRSP) and the WHO Global Data-base for Malnutrition. Because the PRSP process is strongly linked to debt-relief ${ }^{116}$, the PRSPs are concentrated in poorer and aid-dependent countries and are pre-dominantly African. Data on investments in nutrition interventions and programs are collected from the World Bank nutrition lending database. To measure investment in nutrition, ideally one would review national finance laws in order to get information on national expenditures on nutrition. However, those laws are often difficult to obtain retrospectively and lack sufficient

\footnotetext{
115 Two or more surweys are available in the last decade.

"116 See chapter 5
} 
specificity to disaggregate nutrition interventions. Nutrition expenditures are most often embedded in other sector-budgets.

Investment in nutrition is measured as World Bank lending for nutrition. No other data on investment in nutrition or nutrition expenditures could provide a sufficiently large amount of observations at this point, nor is it compiled. In addition there are problems with double counting and disentangling nutrition from related interventions when reviewing nutrition expenditures because the data is often part of other sector budgets. World Bank nutrition investments are available from a data-base the World Bank's nutrition group updates on a regular basis, using the same methodology since the early $1990 \mathrm{~s}^{117}$. National governments use World Bank lending to close finance gaps in their national budgets and to borrow resources for those areas in which they want to increase investments. Therefore, these data are considered to be indicative of the trend in investment in nutrition interventions in develloping countries.

\subsection{Measuring Governance Key-elements}

The Kaufmann et al dataset, of which more details are provided in the next chapter, is used to discuss the relationship between PA-nutrition and governance key-elements. Four indices are used to measure progress on governance contributing to malnutrition reduction by providing an enabling environment. The index voice and accountability is used as the proxy for a country's broad-based participation and local ownership over the development agenda (or route one). The second route, improved public sector management and service delivery, is measured using the index government effectiveness. The third route, improving transparency and anti-corruption influences on malnutrition reduction are tested using the index rule of law and control of corruption.

\subsection{Summary and Conclusions}

This chapter analyzed the links between good governance and malnutrition reduction. It identified three routes through which malnutrition could improve if governance improves (figure 6.1) because they address the specific challenges to making malnutrition a public responsibility.

Malnutrition suffers from weak voice (demand). It is mainly a poor people's condition, and poor people are not easily

i17 World Bank Nutrition portfolio report 1997.

www. worldbank, org/humandevelopmenthnp/nutrition/lending 
heard. In addition, chronic malnutrition is a gradual process which goes largely unrecognized until it is severe in form, and thus there is little demand for prevention. The first route through which governance may contribute positively to improving the awareness about malnutrition is by making space for voice to be heard. Good governance principles include the promotion of broad-based participation, and listening to citizens' voices. Further, it helps address the invisibility problem by promoting pro-poor and results-oriented development and nutrition programs. In order to have results, the situation needs to be monitored. By monitoring malnutrition, the magnitude of the problem should become visible. Malnutrition is multisectoral and multidimensional and does not get attention in a largely sectordriven world. Good governance facilitates addressing the multidimensionall nature of poverty and including malnutrition, and makes governments more accountable to monitoring poverty reduction progress.

Malnutrition reduction is slow because it suffers from weak program implementation service delivery and underinvestment. The second route through which governance is expected to positively influence malnutrition is through public sector management reforms and service delivery improvement. Basic service delivery, including nutrition services, is at the root of poverty reduction programs.

The third route for good governance to contribute to improving malnutrition is indirect via anti-corruption and rule of law. This is an important, but longer term, link because it will take time for the effects of more transparent management to trickle down to micro-level implementation of programs. These correlations between governance indices and malnutrition outcomes, and governance indices and PA-nutrition, are analyzed in the next two chapters. 


\section{Chapter 7: Governance Indices and Malnutrition Outcomes}

\subsection{Introduction}

Following the principles of good governance emerged as a development priority by which many of the major development partners will determine their priorities together with the commitment to the MDGs. Reduction in underweight malnutrition is both a development outcome and one of the Millennium Development Goal (MDG) indicators, and will be closely monitored by the international development community. But, how important is governance to malnutrition reduction? Kaufmann, Kraay and Zoido-Lobaton (1999), Isham, Kaufmann and Pritchett (1997) and Narayan et al (2000) all find positive correlations between governance indicators and development outcomes, such as literacy rates and infant mortality. In this chapter the correlation between malnutrition outcomes, measured as underweight malnutrition, and aggregate governance indicators will be analyzed.

First, this chapter discusses how governance can be measured. The Kaufmann et al dataset is used for the governance indicators. Its value as an internationally recognized data-set and use in research is described in this chapter. Second, using the Kaufmann et al data-set, a review of whether and where governance has improved since 1996 is included. The main part of this chapter is the analysis of the research question on the correlation ${ }^{18}$ between malnutrition outcomes and aggregate governance indices in developing countries in Africa, Asia and Latin America.

Figure 7.1: Conceptual Framework: Relatlon between Good Governance and Malnutrition Reduction

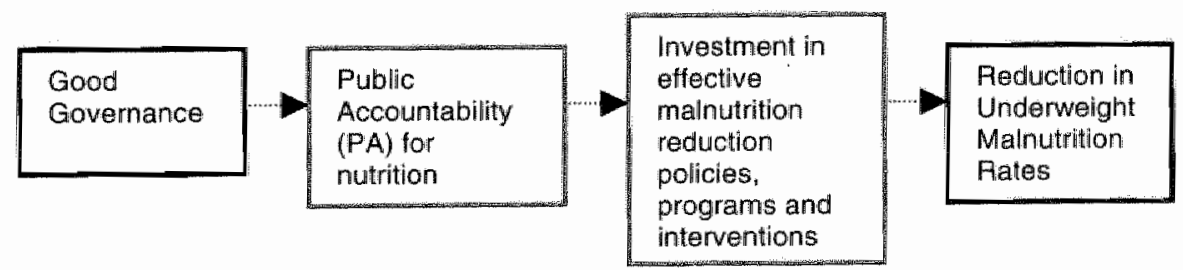

${ }^{118}$ Stata-8 is the statistical program used for the analysis. 


\subsection{Measuring Governance}

The debate on governance in the first half of the 1990s focused on the "rediscovery" or recognition of the importance of governance for development. In the latter part of the 1990s, the debate focused more specifically on how to measure progress.

During the first half of the $1990 \mathrm{~s}$, governance could be measured in a large number of ways, as long as they investigated the relationship between governance, broadly defined, and some measure of well-being (Knack and Manning 2000:2). The dimensions along which the differences between the indicators were then evaluated were primarily replicability and transparency, quality and accuracy, and data coverage across countries and over time (Knack and Manning 2000:3).

In the latter half of the 1990s though, the Development Assistance Committee ( $D A C^{119}$ ), realized that these dimensions were not sufficient to allow evaluating how specific institutions were implicated, and which outcomes represented governance and progress on dimensions of governance. Two dimensions were added to the criteria to evaluate the value of different indicators, the number of which had grown in recent years. By adding these criteria, a large number of the indicator-sets were consequently deemed less appropriate than when only the first three criteria are applied. Knack and Manning evaluated each of the 27 datasets they selected on all five criteria and concluded only five fulfilled all. The Kaufmann et al dataset, used in this study, fulfills the three original criteria it fulfills the new one criterion, showing which institution and what policy, to a much lesser extent (Knack and Manning 2000:16). However, the dataset remains recognized as the most appropriate set to measure overall governance progress. The Kaufmann et al dataset has been used recently in a number of studies that assess the effectiveness of aid; Easterly (2004); Kaufmann,

\footnotetext{
11 The Development Assistance Committee (DAC) of the Organization for Economic Cooparation and Development (OECD) was established in 1960 as the principal strategy-setting and policy and performance review of the major bilateral donors. It searches to assess the contribution of finance institutions to development in general. On of the aspects of particular interest is that of good governance. And within the broader interest in governance, DAC has been working to establish indicators that measure progress towards meeting the United Nations Development Goals. In 1996, in its publication "Shaping the $21^{\text {st }}$ Century: the contribution to development cooperation', it stated that democratic governance (good governance, human rights, democratization and participatory development) is crucial to achieving the goals. In the same year. DAC's working group on indicators reported it had failed to forge a consensus around the core indicators to measure progress and DAC re-launched the effort in 1998 .
} 
Kraay and Zoido-Lobaton (1999); and Burnside and Dollar (2004).

Kaufmann and Kraay constructed six dimensions of governance by aggregating indicators from 25 different sources, produced by 18 different organizations. Included among the sources are the often used International Country Risk Guide ${ }^{120}$ (ICRG), the Business Environmental Risk Intelligence ${ }^{121}$ (BERI)。 and Freedom House indicators. The indices cover hundreds of variables measuring perceptions of governance. By aggregating several indicators from different sources they limit as much as possible the problem of noise caused by the subjectivity of the data. The expansion of the database over the last 5 years and number of indicators in the indices has reduced the error margins from $0.26-0.36$ to $0.18-0.27$, an illustration of improved precision: however, they remain relatively large since the changes between units (countries) are small (Kaufmann and Kraay 2005:7). The error margins do at the same time provide an explicit measure of precision to determine significance in statistical measures. The Kaufmann et al dataset is used in the next section to review how good governance has made progress across countries worldwide.

\subsection{Changes over Time in Governance Indices between 1996 and 2004}

The Kaufmann et al dataset is regularly updated and covers a world-wide data-base of 6 governance indices, made up of indicators from a large number of different sources. The governance estimates are normally distributed with a mean of zero and a standard deviation of one in each period, which implies that basically all scores are between -2.5 and 2.5 with positive scores corresponding to better outcomes (Kaufmann 2005). What the indices actually measure is described in box 7.1.

\footnotetext{
120 The data-set is produced by the Political Risk Services (PRS) Group of Syracuse in New York, covers over 130 countries since 1982, ratings are subjective assessments produced monthly by local experts and averaged on a annual basis.

121 BERI indicators have been available since 1972 , but for only 50 countries, if developing countries, then the larger middle income ones.
} 
Box 7.1 Kaufmann and Kraay Governance Indices

The Kaufmann and Kraay Governance Indlices measure the following:

- Volce and Accountability measures various aspects of the political process. civil liberties and human rights it measures the extent to which citizens are able to participate in the selection of governments. If also includes Independence of the media.

- Political stability measures the perceptions of the population regarding the likelihood that the government in power would be overthrown by unconstitutional and or violent means.

- Government effectiveness measures the perceptions among the public of the quality of public service provision. Included are the quality of the bureaucracy competence of civil servants, the independence of civil servants rom political pressures, and the credibility of the government's commitment to policies and their implementation.

- The indicator regulatory qually locuses on the government policies themselves, but is narket foclised For example the incidence of marketunfriendly policies as price-controls and excessive regulation in areas such as forelgn trade.

- Hule of law measures the extent to which government agents have confidence in and abide by the rules, the effectiveness and predictability of the ludiclary and entorceability of contracts.

- Control of contuption measures the exercise of public power for personal gain, also called rent-seaking.

The most recent paper by Kaufmann and Kraay (2005) reported on changes over time in governance. The changes over time are relatively small over the eight-year period for all six indices. Only for $10 \%$ of the countries are significant changes seen. If a more relaxed confidence interval is used, $75 \%$ instead of $90 \%$, about $20 \%$ of the countries show significant changes. For example in the case of Zimbabwe voice and accountability and control of corruption measures have significantly ${ }^{122}$ worsened since 1996. In the case of Nigeria, the data shows a significant improvement on the voice and accountability measure. Table 7.1 shows the countries with significant changes, applying the $90 \%$ confidence interval. Eight African nations show significant changes since 1996 (table 7.1). Half of those improved significantly: Gambia, Ghana, Nigeria and Sierra Leone. The other 4 worsened significantly: CAR, Eritrea, Ivory Coast and Zimbabwe. Of the six African nations that have significant changes in political stability, four worsened and 2 improved. Ivory Coast is the only country in that group that worsened significantly on 5 of the 6 indicators. Only three

\footnotetext{
122 Significant here is not used in the meaning of a formal statistical test, but a transparent rule of thumb; countries where the $90 \%$-confidence interval does not overlap in the two periods measured are considered as having made significant change in the governance indicators.
} 
countries have significant changes in control of corruption, all three worsened. Also, regarding rule of law and regulatory quality, the only significant changes observed are negative.

Table 7.1: Significant changes in Governance between 1996 and 2004 in selected countries ${ }^{123}$

\begin{tabular}{|c|c|c|c|c|c|c|c|}
\hline Coluntry & 2004 & 1996 & Change & Country & 2004 & 1996 & Tamge \\
\hline \multicolumn{4}{|c|}{ Voice and Accountability } & \multicolumn{4}{|c|}{ Political Stability } \\
\hline CAR & -1.2 & -0.17 & -1.03 & Angola & -0.95 & -2.17 & 1.22 \\
\hline Eritrea & -1.96 & -1.1 & -0.86 & Bienin & -0.37 & 1.2 & -1.57 \\
\hline Gambia & -0.59 & -1.34 & 0.75 & CAR & -1.43 & -0.01 & $-1.4 \overline{2}$ \\
\hline Ghana & 0.39 & -0.35 & 0.74 & Haiti & -1.87 & -0.21 & -1.66 \\
\hline Haiti & -1.5 & -0.46 & -1.04 & Indonesia & -1.38 & -0.45 & -0.93 \\
\hline Indonesia & -0.44 & -1.15 & 0.71 & Ivory Coast & -2.28 & 0.32 & -2.6 \\
\hline Ivory Coast & -1.46 & -0.19 & -1.27 & Lao PDA & -0.76 & 1.2 & -1.96 \\
\hline Mexico & 0.36 & -0.23 & 0.59 & Nepal & -1.74 & -0.35 & -1.39 \\
\hline Nepal & -1 & 0.14 & -1.14 & Phillippines & -1.01 & -0.12 & -0.89 \\
\hline Nigeria & -0.65 & -1.49 & 0.84 & Sierra L. & -0.61 & -2.25 & 1.64 \\
\hline Peru & -0.04 & -0.73 & 0.69 & Zimbabwe & -1.86 & -0.11 & -1.75 \\
\hline Sierra L. & -0.49 & -1.37 & 0.88 & \multicolumn{4}{|c|}{ Regulatory Quality } \\
\hline Zimbabwe & -1.48 & -0.3 & \begin{tabular}{|l|}
-1.18 \\
\end{tabular} & Argentina & -0.81 & 0.82 & -1.63 \\
\hline \multicolumn{4}{|c|}{ Government Effectiveness } & Bolivia & 0.05 & 0.82 & -0.77 \\
\hline Argentina & -0.33 & 0.45 & -0.78 & Indonesia & -0.42 & 0.27 & -0.69 \\
\hline Ivory Coast & -11.3 & -0.11 & -1.19 & Venezuela & -1.24 & -0.08 & -1.16 \\
\hline Sierra L. & -1.32 & -0.24 & $-1,08$ & Zambia & -0.49 & 0.27 & -0.76 \\
\hline Tanzania & -0.37 & -1.18 & 0.81 & Zimbabwe & -2.15 & -0.87 & -1.28 \\
\hline Zimbabwe & -1.2 & -0.26 & -0.94 & \multicolumn{4}{|c|}{ Rule of Law } \\
\hline \multicolumn{4}{|c|}{ Control of Corruption } & Argentina & -0.71 & 0.28 & -0.99 \\
\hline China & -0.51 & -0.01 & -0.5 & Indonesia & -0.91 & -0.36 & -0.55 \\
\hline Ivory Caast & -1.01 & 0.41 & -1.42 & Ivory Coast & -1.42 & -0.69 & -0.73 \\
\hline Zimbabwe & -1.01 & -0.12 & -0.89 & Phillippines & -0.62 & -0.11 & -0.51 \\
\hline & & & & Swazilland & -0.95 & 0.4 & -1.35 \\
\hline & & & & Thailland & -0.05 & 0.49 & -0.54 \\
\hline & & & & Zlimbabwe & -1.53 & -0.24 & -1.29 \\
\hline
\end{tabular}

Source: Kaufmann and Kraay 2005

Besides asking the question whether countries individually make progress, global trends are important. However, global trends are difficult to show using the Kaufmanndataset. The aggregate governance indices are not informative about trends in global averages because these averages have been normalized to zero in each period, as a choice of units (Kaufmann 2005). They are only informative about individual countries relative performance. For global trends, the original data-sets should be consulted ${ }^{124}$. Kaufmann and Kraay do that in

${ }^{123}$ Selected on the basis of being in the data-set of 82 countries used in section 4 for analysis of correlation between changes in Governance and Malnutrition outcomes in developing countries

${ }^{124}$ Kaufmann and Kraay provide an overview of changes in global trends using a variety of original data-sets, such as Freedom House and Heritage, in their 2005 publication. 
their most recent analysis (2005) and report that there is very little evidence of systematic improvements in regional averages for governance in most regions. What they particularly find in almost all regions is that there are as many countries improving as there are declining, leaving most of the global trends flat (ibid 2005). Kaufmann and others are starting to ask questions regarding the effectiveness of traditional approaches to improving governance, including the World Bank's approaches. Klein Haarhuis (2005) evaluated the implementation of the World Bank's anti-corruption program in seven Africa countries. She found that for example, the National Anti-Corruption Action Plan, although implemented on paper (documents prepared and endorsed, reforms addressed and decision taken), died out during actual implementation ${ }^{125}$ (Klein Haarhuis 2005).

\subsubsection{Status and Changes Over time in Governance Indices in Selected Countries}

The trends in governance for the 82 countries in SubSaharan Africa, Asia and Latin America that make up the database for use in the following section in the analysis with malnutrition reduction are not much more promising ${ }^{126}$. The majority of the countries not only had negative scores in 2004 , they have also shown worsening trends since 1996. Of the 82 countries, 48 score negative and worsening trend regarding political stability, 34 score negative on voice and accountability and 49 on rule of law. The other three indicators do not fare any better (graphs 7.1 through 7.6). Very few countries score both positive and improving since 1996. Only in regard to the voice and accountability are there 20\% (16 countries) with positive status in 2004 and improving trends since 1996.

\footnotetext{
1.35 Implementation in this context can be defined as the extent to which implementers (in this case countries) incorporate contents of an agreed upon program into actual actions.

Although the changes are not necessarily significant, the trends do provide
insights in direction of change.
} 
Graphs 7.1 to 7.6 Scores and Trends in Governance Indices (Kaufmann) between 1996 and 2004 by number of countries
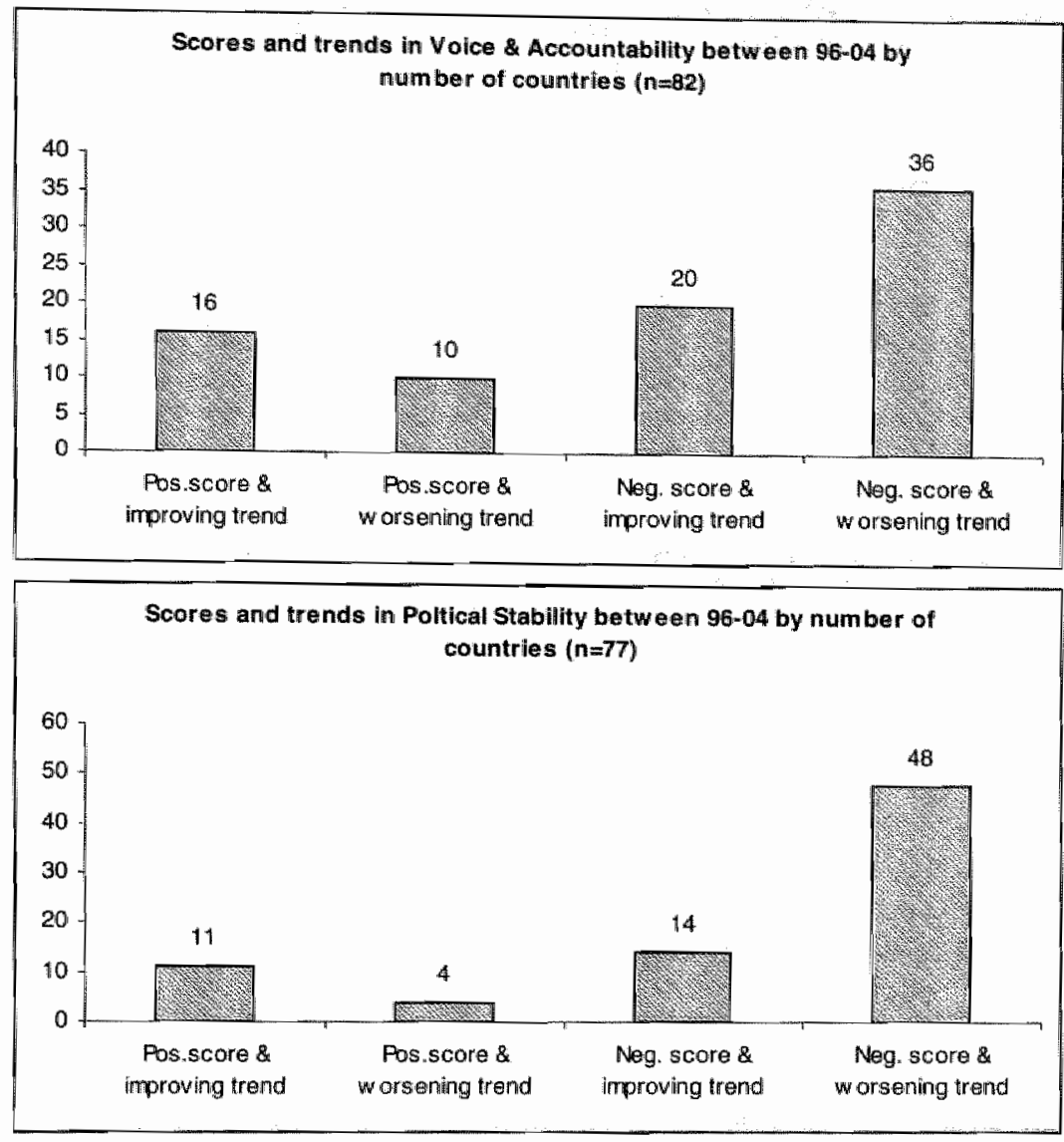

Scores and trends in Government Efectiveness between 96-04 by number af countries: ( $n=81$ )

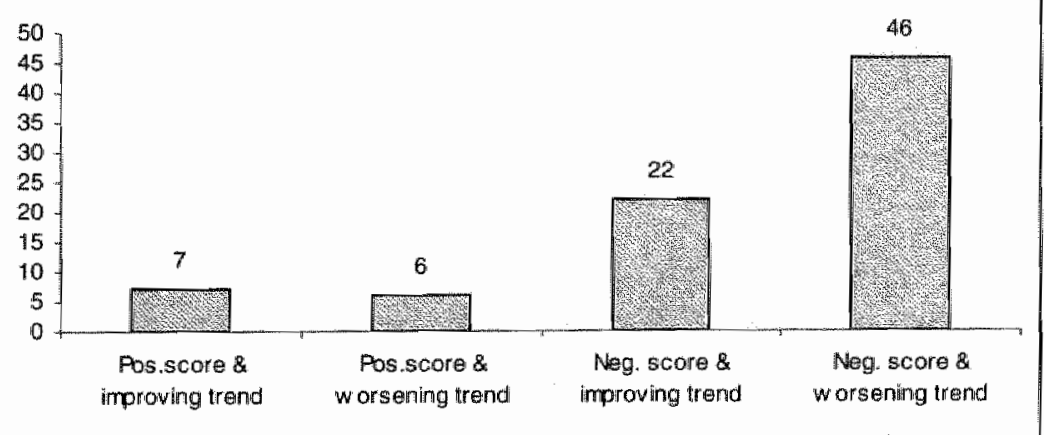



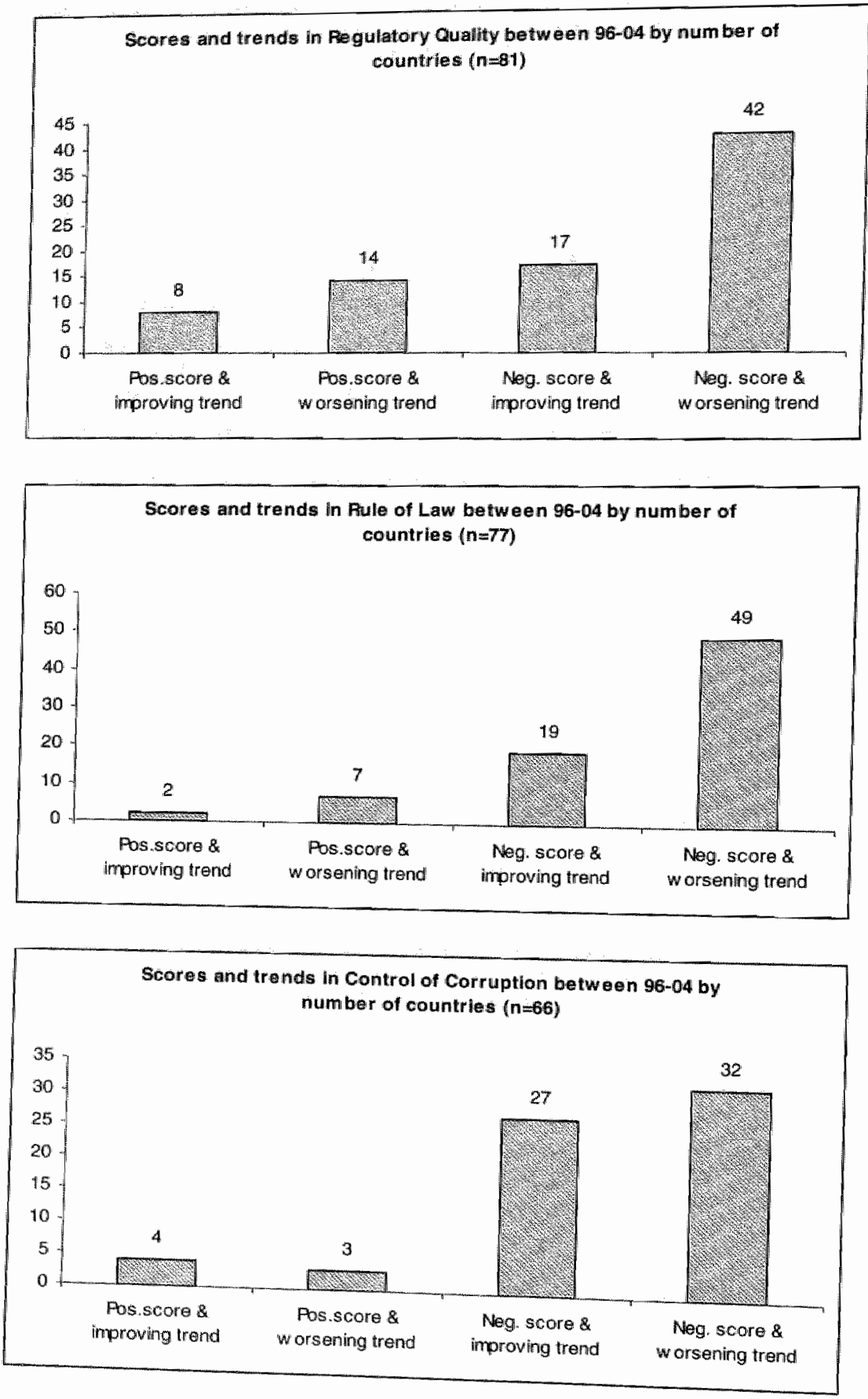
Of the three regions in this data-set; Latin America scores best. For example, 8 of the 16 countries that score positive both on status in 2004 and trend since 1996 on voice and accountability are in Latin America, which shows a very different pattern (graph 7.7). However, this is the only index where Latin America shows a different pattern from the other regions. On the other five indices all three regions show the same pattern.

Graph 7.7: Scores and Trend in Voice and Accountabillity Index in Latin America between 1996 and 2004

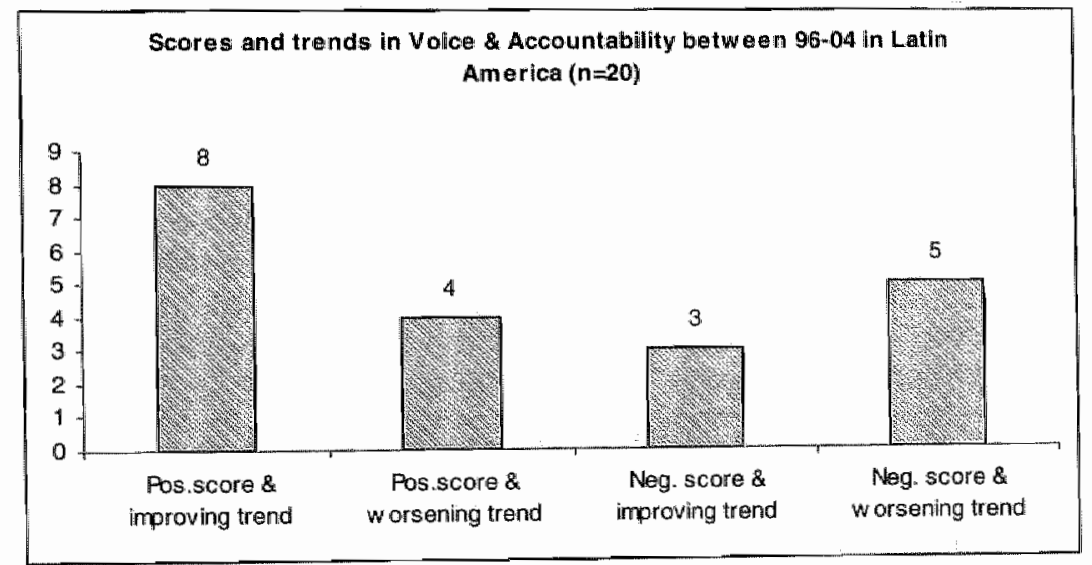

Although most of the countries show few significant changes in governance indices, the majority shows a negative trend and status in 2004. The only exception to be made is on voice and accountability in Latin America.

\subsection{Correlations between Governance and Underweight Malnutrition}

In the following, the correlation between the aggregate governance indices and underweight malnutrition rates is analyzed. For underweight malnutrition, the WHO Global Database on Malnutrition is used to obtain underweight rates from the second half of the 1990 s closest to 2000 . The final data-set includes a total of 82 countries, of which 42 are from SubSaharan Africa (with the exception of Libya), 24 are countries from Asia, and 20 are from Latin America (Annex 2, table 1 provides a complete list of countries). 
Figure 7.2: Framework: Relation between Good Governance and Malnutrition Reduction

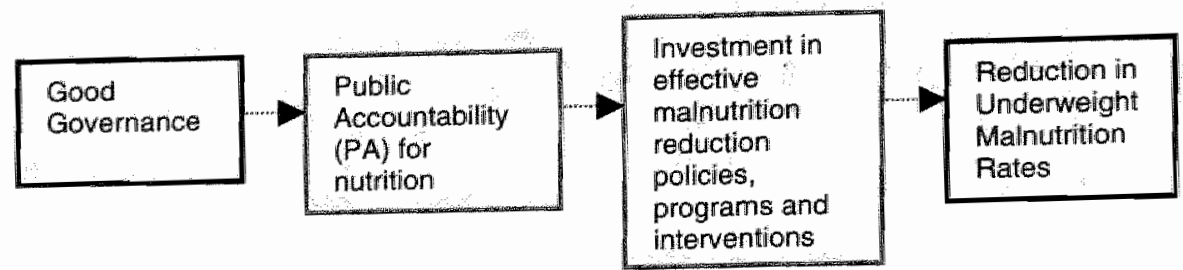

Research question: Is there a correlation between aggregate governance indicators and underweight malnutrition rates in developing countries in Africa, Asia and Latin America?

The graphs below show the unconditional correlation between underweight malnutrition and the aggregate governance indices. Countries with higher scores in 1996 demonstrate better nutrition outcomes, measured as underweight malnutrition, in 2000. The correlations shown in section 7.4.1 are unconditional, and therefore remain merely illustrative. How much is explained by economic development and regional differences is addressed in section 7.4.2.

\subsubsection{Voice and Accountability Index}

The governance index voice and accountability includes civil liberties and human rights, as well as independence of the media and the extent to which citizens are able to participate in the selection of governments. Graph $7.8^{127}$ shows the correlation between the index voice and accountability in 1996 and underweight malnutrition rates in 2000 .

${ }^{127}$ Country-names: 


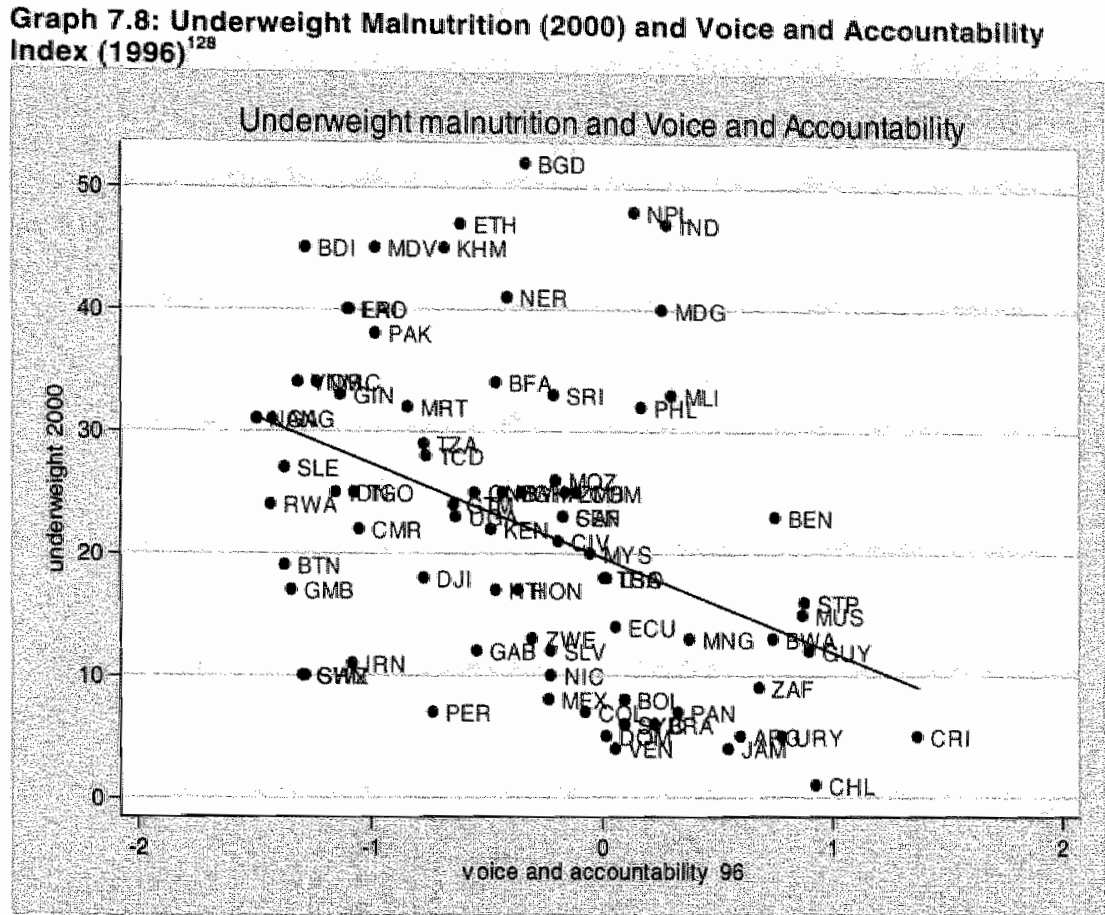

$n=82 ;$ * Correlation coefficient -0.4168

\subsubsection{Political Stabillity Index}

The political stability index measures the population's perception regarding the likelihood the government would be overthrown. The analysis of underweight malnutrition rates and

128 $\quad A F G=$ Afiganistan; $\quad A N G=A n g o l a ; \quad A R G=A r g e n t i n a ; \quad A Z E=A Z$ zerbaijan: $B G D=$ Bangladesh; $\quad B E N=B e n i n ; \quad B T N=B h u t a n ; \quad B O L=B o l i v i a ; \quad B W A=B o t s w a n a ;$ $B A A=B r a z i l ; B F A=B u r k i n a$ Faso; $B D I=B u r u n d i ; C A F=C e n t r a l$ African Republic; $\mathrm{KHM}=$ Cambodia; $\quad \mathrm{CMP}=$ Cameroon; $\quad \mathrm{TCD}=\mathrm{Chad}$; $\mathrm{CHL}=\mathrm{Chile;} \quad \mathrm{CH}$; $=$ China; $\mathrm{COL}=$ Colombia; $\mathrm{COM}=\mathrm{Comoros} ; \mathrm{CAl}=\mathrm{Costa}$ Rica; $\mathrm{CIV}=$ Cote divoire/vory Coast; DRC=Congo Dem. Rep.; DJl=Djibouti; DOM=Dominican Republic; ECU Ecuador: $S L V=E I$ Salvador; $E R I=E$ ritrea; $E T H=E$ thilopia; $G A B=G a b o n ; G M B=T$ The Gambia; GHA=Ghana; $G T M=$ Guatemala; $G(N=G u i n e a ; G N B=G$ uinea-Bissau; GUY=Guyana; $H T I=$ Haiti; HND=Honduras; IND=India; IDN=Indonesia; IRN $=$ Iran; JAM=Jamaica; KEN=Kenya; PRK=Korea, Dem. Rep.; LAO=Lao PDR; LSO=Lesotho; MDG=Madagascar; MWI=Malawi; MYS=Malaysia; MDV=Maldives; MLl=Mall; MRT=Mauritania; $\quad$ MUS=Mauritius; MEX=Mexico; MNG=Mongolia; MOZ=Mozambique; MMR=Myanmar; $\quad$ NPL=Nepal; NIC=Nicaragua; NEP=Niger; NGA=Nigeria; PAK=Pakistan; PAN=Panama; PER=Peru; PHL=Philippines: RWA=RWanda; STP $=$ Seo Tome and Principe; SEN=Senegat: SYC=Seychelles; $S L E=S i e r r a$ Leone; SOM $=$ Somalia; $Z A F=$ South Africa: LKA $=S$ ri Lanka; SWZ=Swaziland; TZA=Tanzania; THA=Thailand; TGO=TOgo; UGA=Uganda; URY=Uruguay; VEN=Venezuela; VNM=Vietnam; YEMI=Yemen; ZMB=Zambia; ZWE=Zimbabwe. 
the governance index political stability for all 82 countries in this data-set shows a positive correlation, graph 7.9. Smith and Haddad in 2000 found a relatively strong explanatory correlation between underweight malnutrition and a country's score on democracy (1-7, with 7 being best) (Smith and Haddad 2000:57). The more democratic a government is, the more likely they are to spent resources on social sectors, including malnutrition reduction services.

Graph 7.9: Underweight Malnutrition (2000) and Political Stability Index (1996)

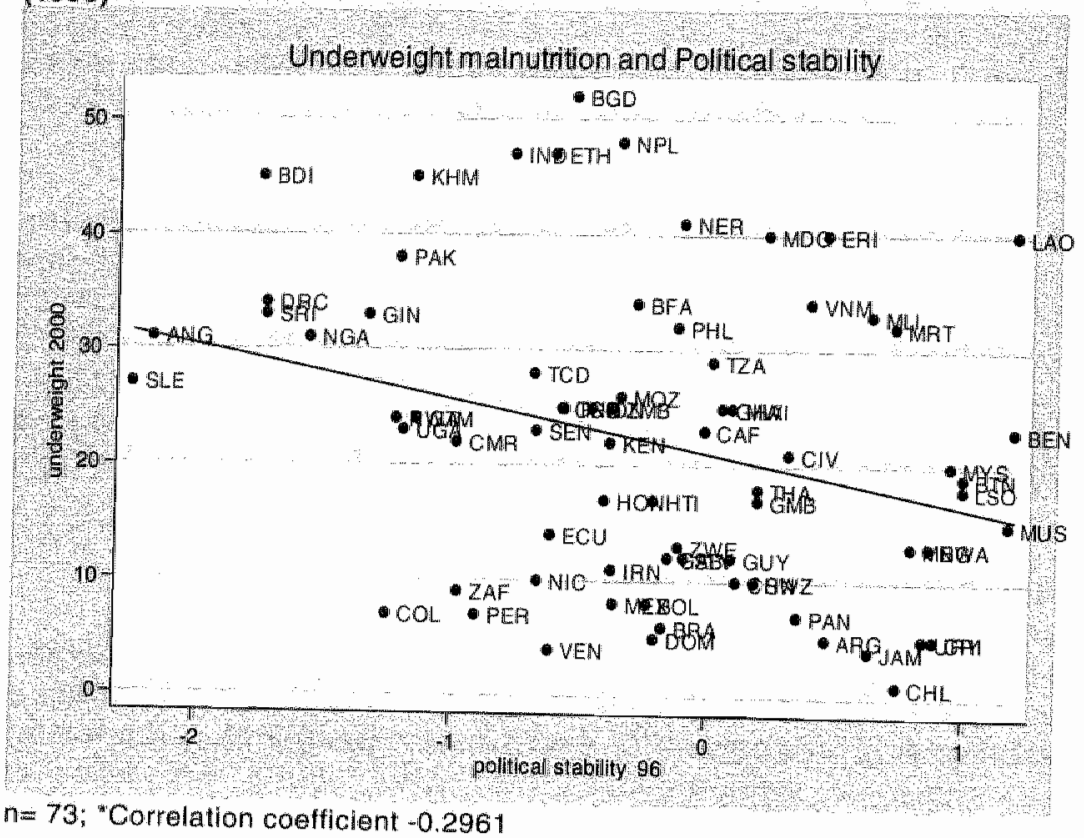

\subsubsection{Government Effectiveness Index}

The government effectiveness index measures the perceptions among the population of the quality of public service delivery. Basic nutrition services, such as child growth promotion and micronutrient provision - the key-nutrition interventions that make up public nutrition - are part of public service delivery. 


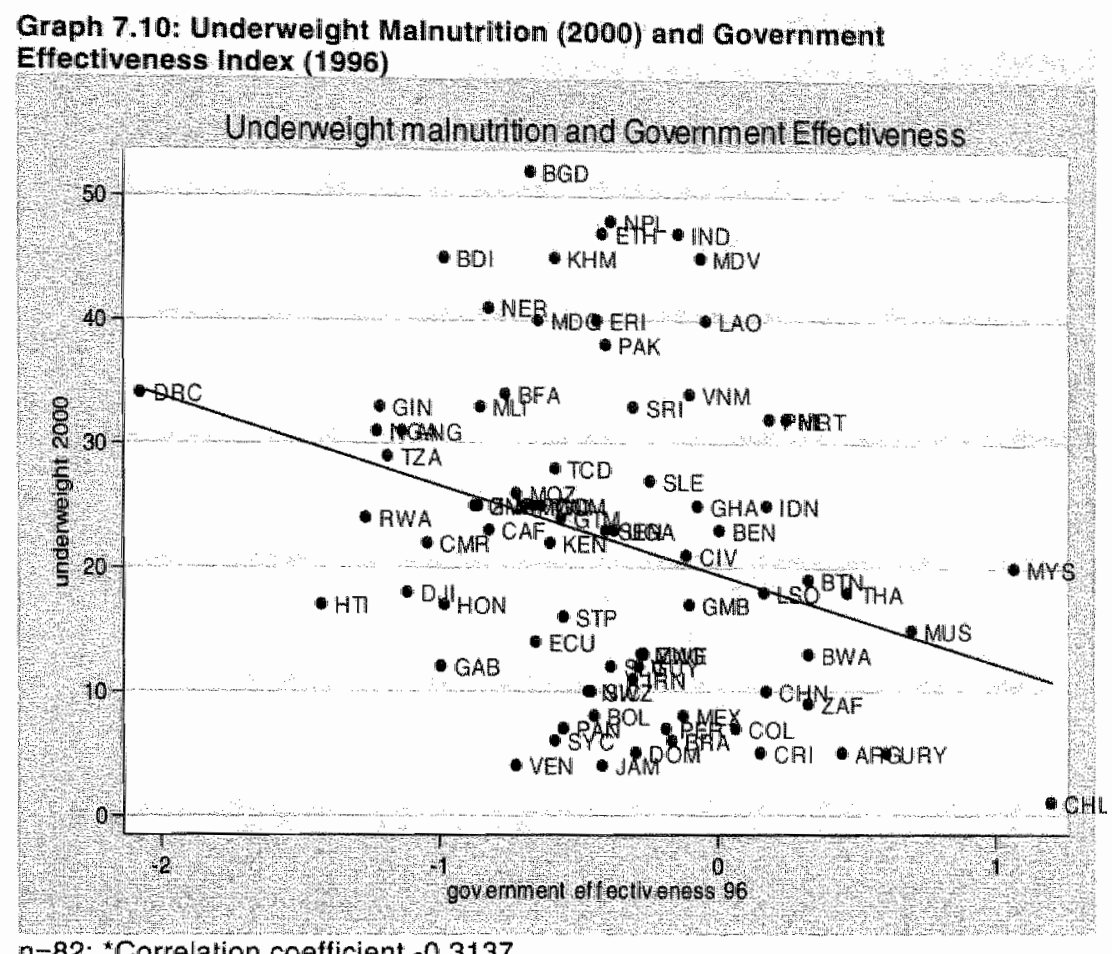

$n=82 ;$ * Correlation coefficient -0.3137

\subsubsection{Regulatory Quality Index}

The index regulatory quality focuses on policies itself, but measures largely market and private sector investment proxies. 
Chapter 7: Governance Indices and Malnutrition Outcomes

Graph 7, 11: Underweight Mainutrition (2000) and Regulatory Ouality Index (11996)

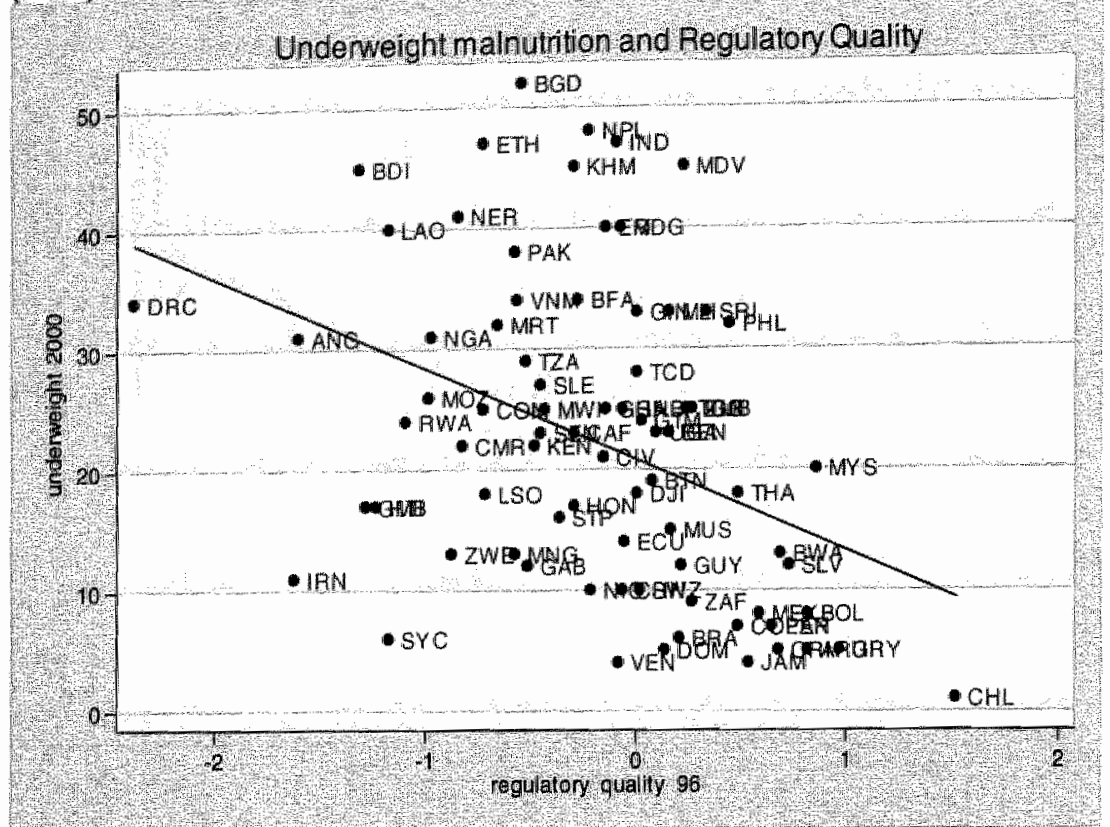

$n=82$; Carrelation coefficient -0.4044

\subsubsection{Rule of Law Index}

The index rule of law has been correlated in earlier research on the importance of governance to social development outcomes, such as infant mortality (Rajkumar and Swaroop 2002:11). Rule of law measures the extent to which government agents have confidence in and abide by the law. 
Graph 7.12: Underwelght Malnutrition (2000) and Rule of Law Index (1996)

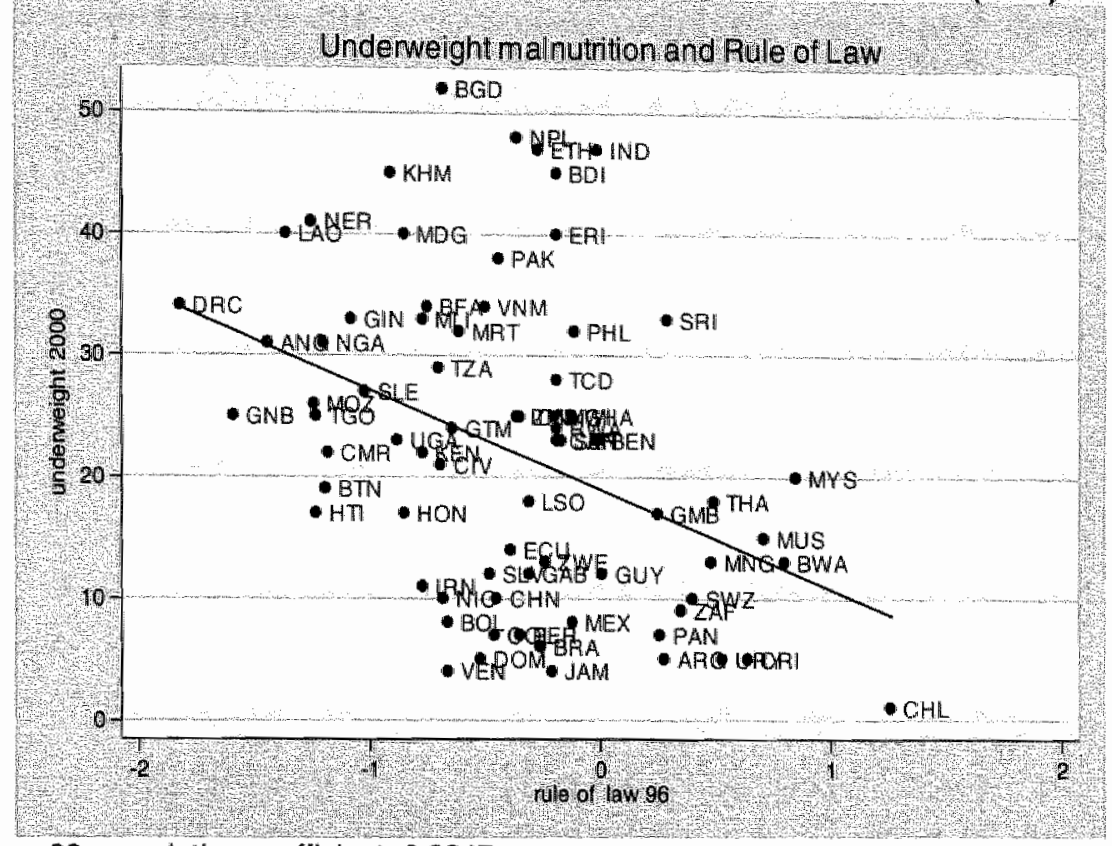

$n=82$; correlation coefficient -0.3947

\subsubsection{Control of Corruption Index}

The index control of corruption measures the exercise of public power for personal gain, including petty and grand corruption. 
Graph 7.13: Underwelght Malnutrition (2000) and Control of Corruption Index (1996)

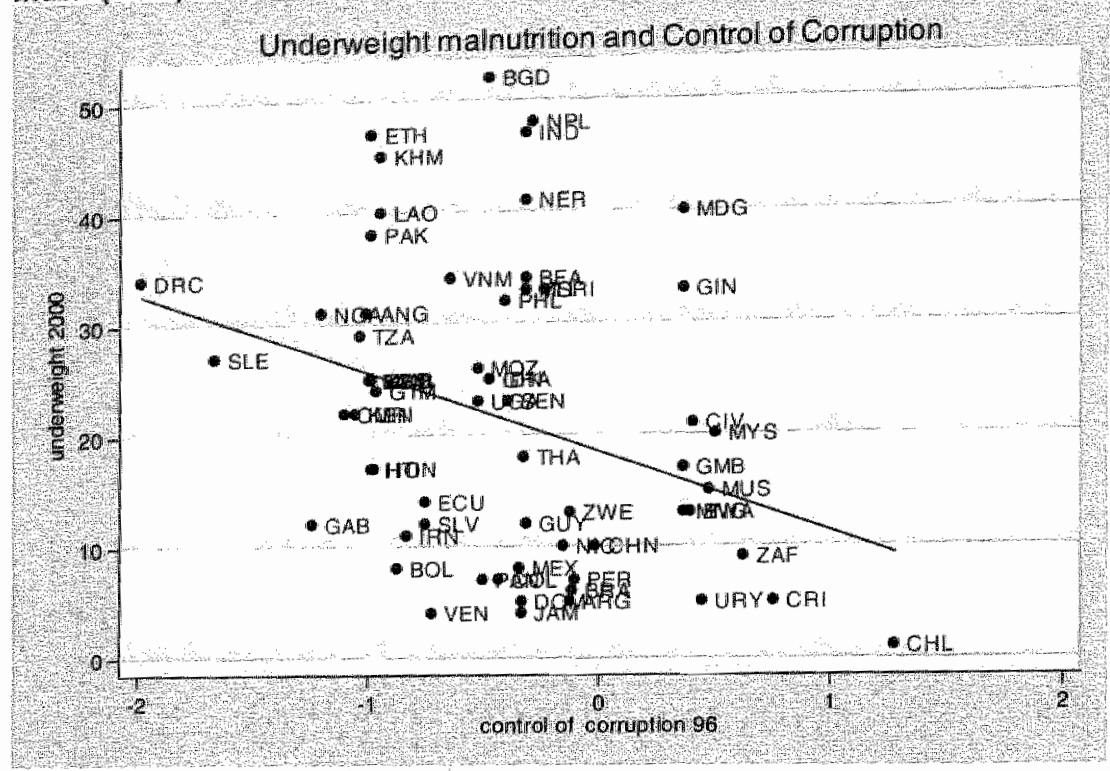

$n=63$; correlation coefficient -0.3365

\subsection{Correlations conditioned on Income and Regional Differences}

There is a strong correlation between economic development and underweight malnutrition, as well as between economic development and governance. In the following the analysis is conducted controlling for economic development, measured as GDP per capita and regional differences as follows:

$W A_{t-1}=\partial+\beta G_{t-1}+\gamma G D P_{t-1}+\lambda \sum R+E r$

Whereby WA is the underweight malnutrition rate in 2000; $G$ is the value of the governance index in 1996; GDP is gross domestic product per capita in 1995; and $R$ is the region. 
Graph 7.14: Underwelight Mainutrition in 2000 and Volce and Accountabillty Index in 1996, controlled for GDP per capita and reglonal differences

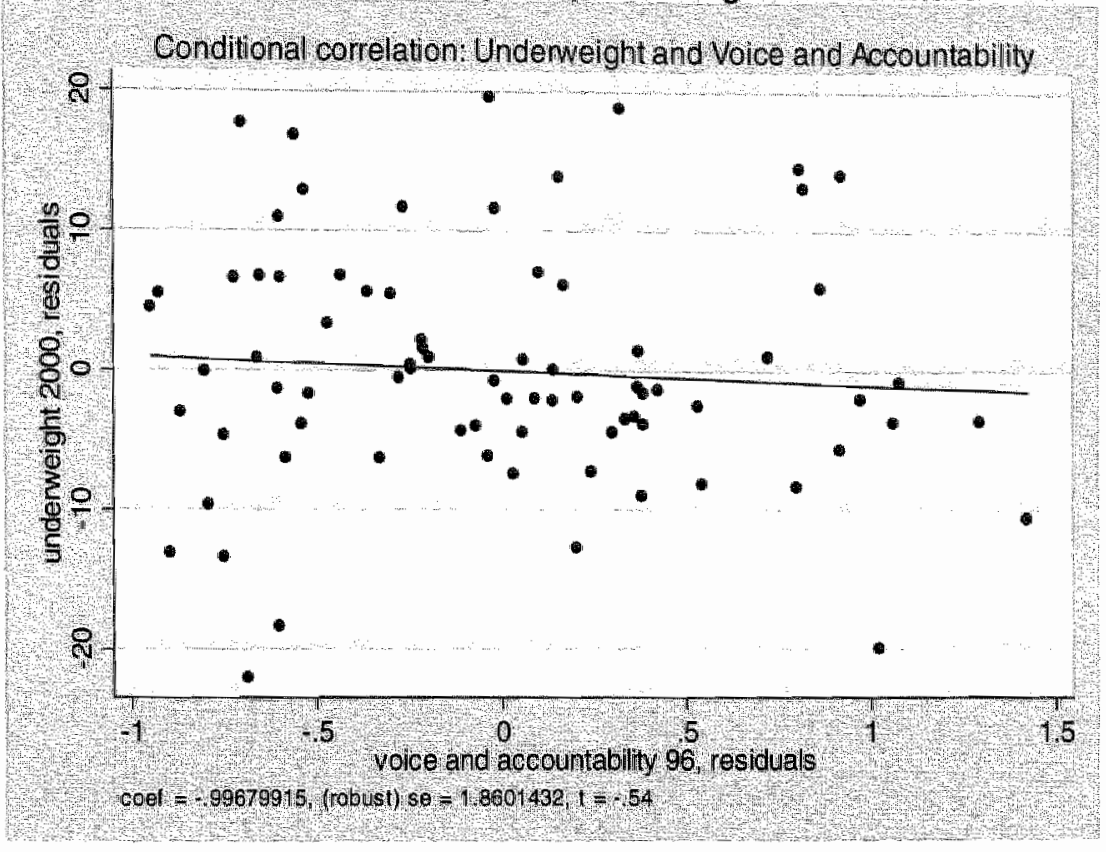

Graph 7.15: Underweight Malnutrition in 2000 and Political Stability Index in 1996, controlled for GDP per capita and regional differences

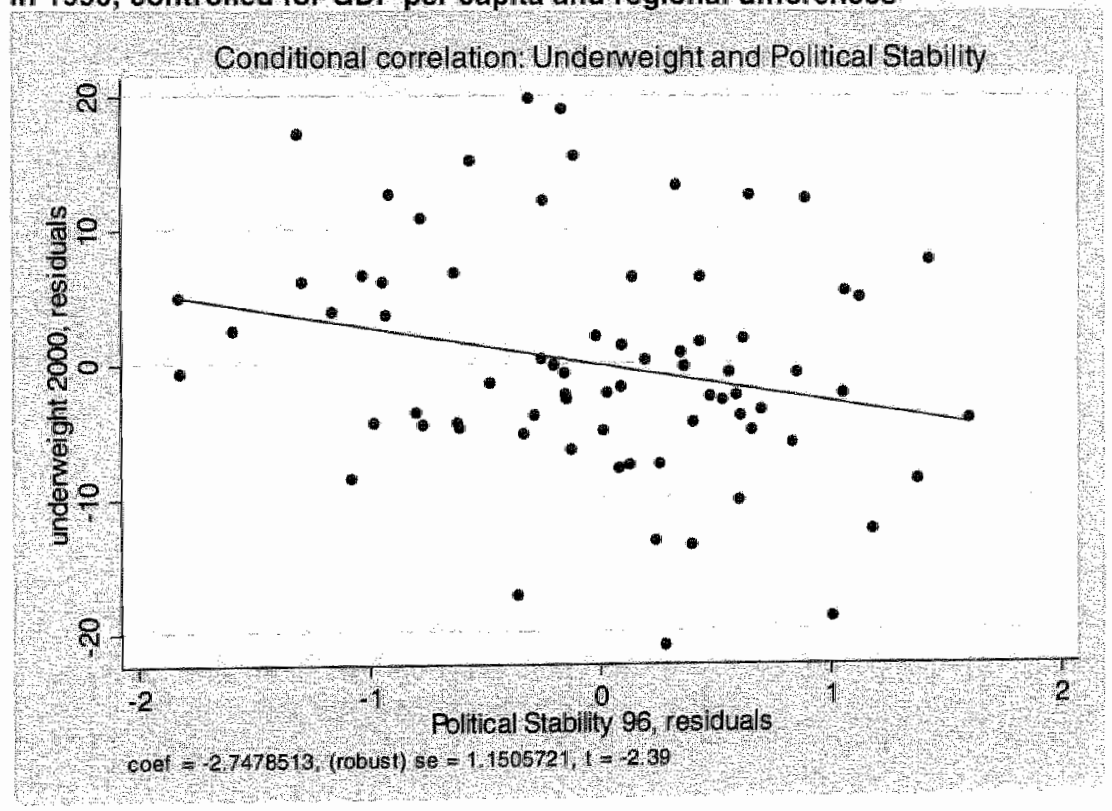


Chapter 7: Governance Indices and Mainutrition Outcomes

Graph 7.16: Underweight Malnutrition in 2000 and Government Etfectiveness Index in 1996, controlled for GDP per capita and regional differences

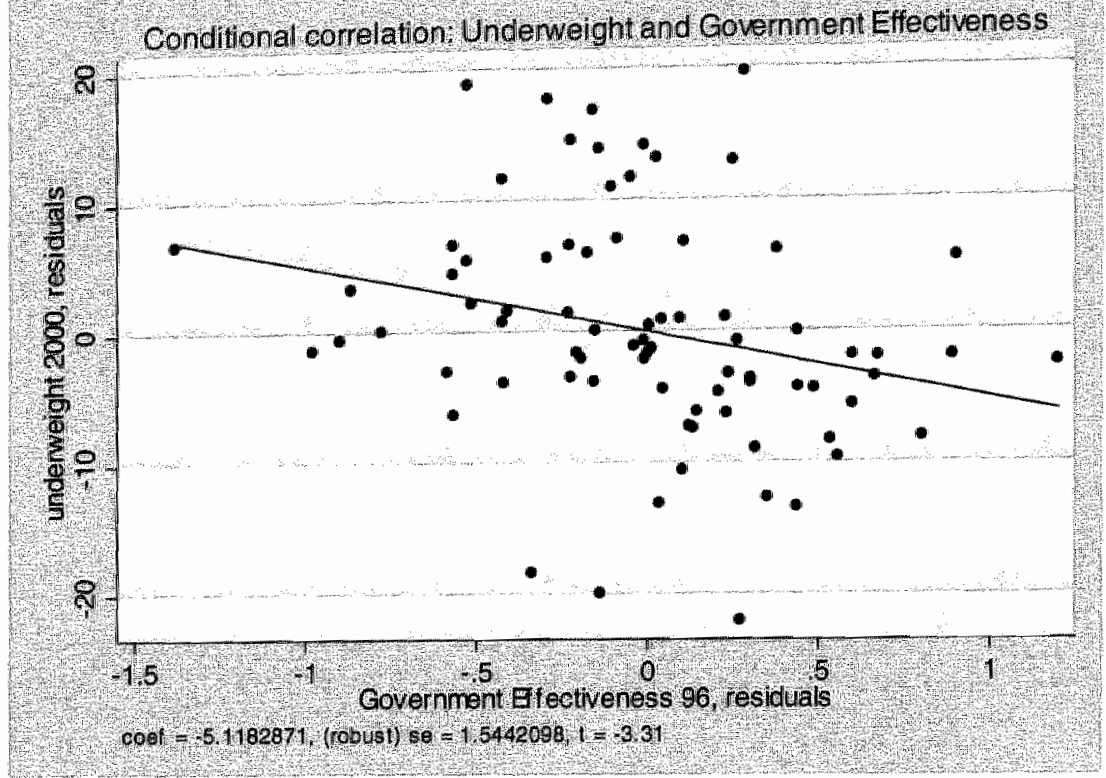

Graph 7.17: Underweight Malnutrition in 2000 and Regulatory Quality Index in 1996, controlled for GDP per capita and reglonal differences

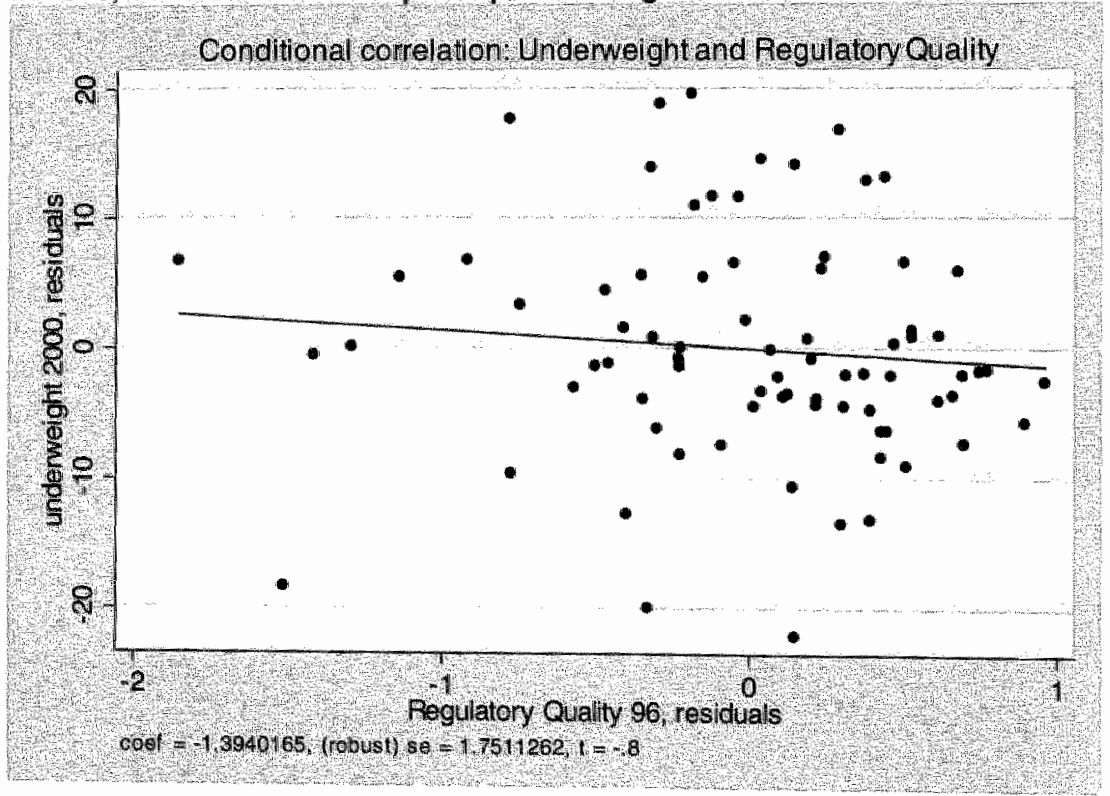


Graph 7.18: Underweight Malnutrition in 2000 and Rule of Law Index in 1996 , controlled for GDP per capita and regional differences

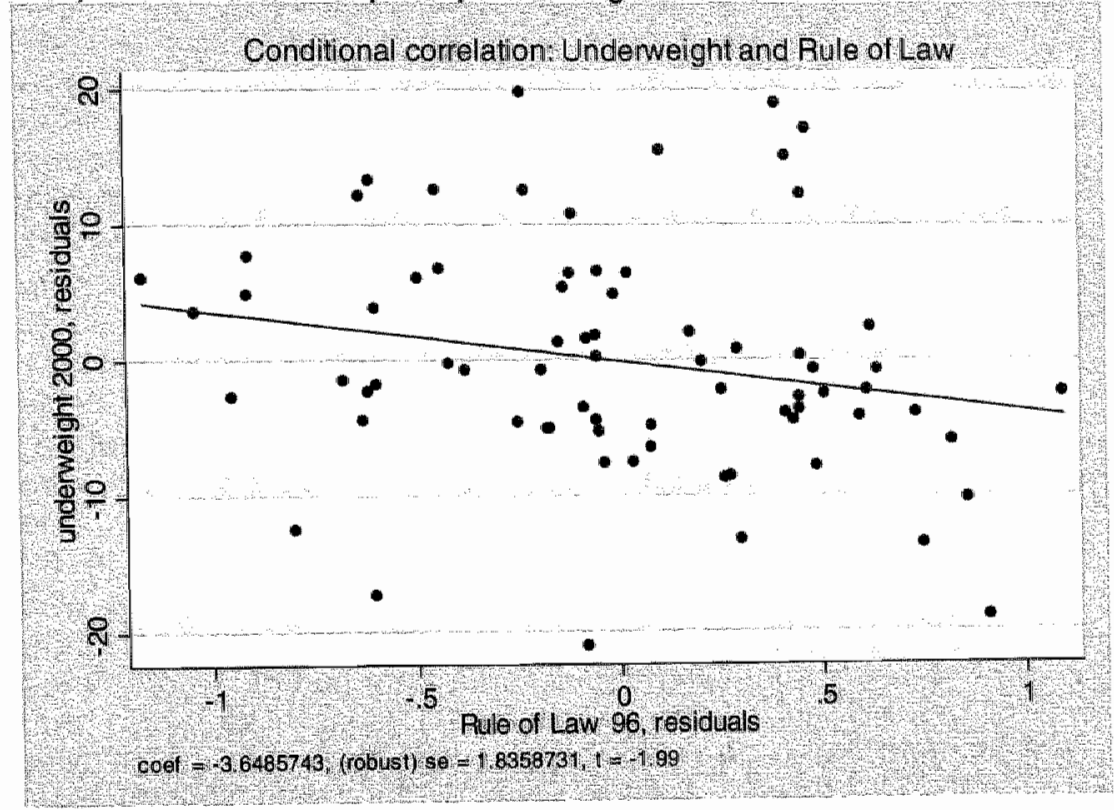

Graph 7.19: Underwelght Malnutrition in 2000 and Control of Corruption Index in 1996, controlled for GDP per capita and regional differences

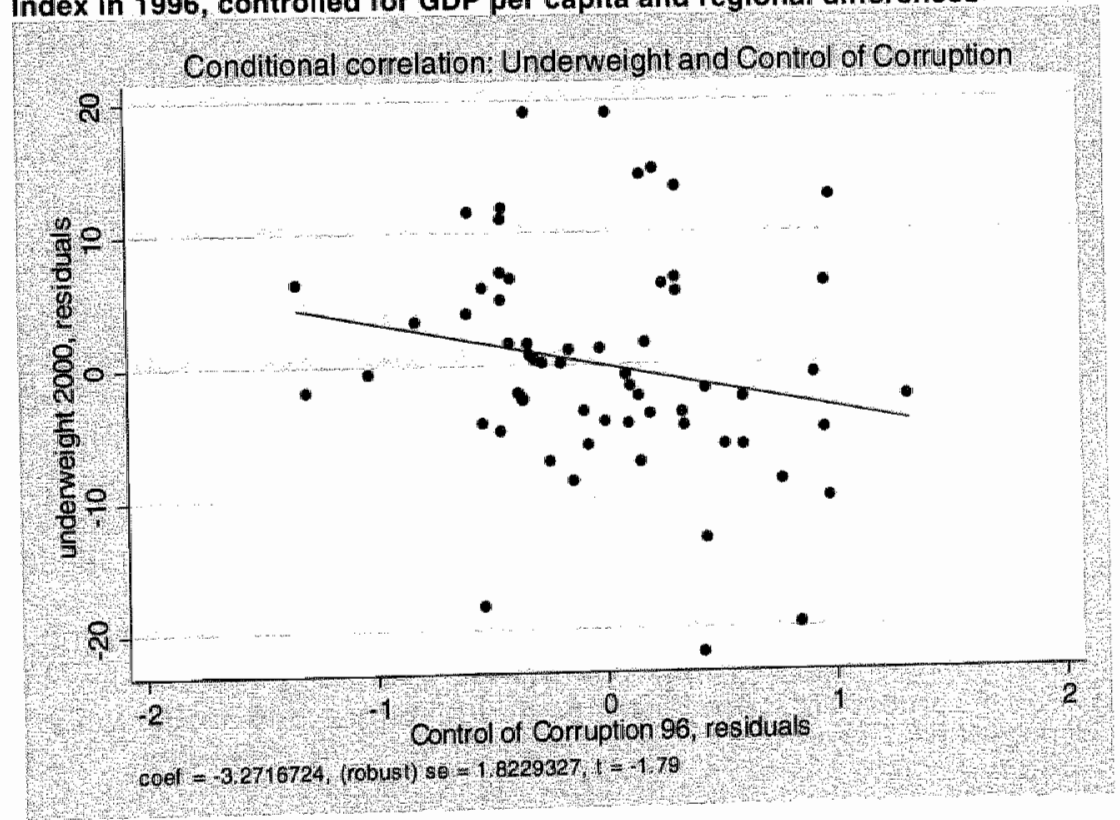


The graphs 7.14 to 7.19 show that the governance indices government effectiveness, political stability, rule of law and control of corruption explain a significant part of the residual variation in underweight malnutrition in countries, after controlling for income and regional differences. Of those, control of corruption is only marginally significant. The governance indices regulatory quality and voice and accountability do not show significance.

\subsection{Summary and Conclusion}

In chapter four, the assumption was made that with the intensified focus on governance in the 1990s, the enabling environment for malnutrition reduction would be improved. The correlation between aggregate governance indices, the Kaufmann dataset, and underweight malnutrition rates in 82 developing in Sub-Saharan Africa, Asia and Latin America was tested in this chapter. First an analysis of the data shows that the governance situation worsened in more than half of the countries in this dataset on all six governance indices. The voice and accountability index has the highest number of countries with improving trends and a positive score in 2004 with 16 countries, or $20 \%$, of the total. Underweight malnutrition rates in fact have not fared much better in many of these countries either (chapter three). This is especially true in Sub-Saharan Africa, where malnutrition has been the slowest to improve among all regions over the last two decades, and where a significant number of countries actually have increasing rates of malnutrition. In both Asia and Latin America there have been important decreases, but they are driven by a few countries and there is much variation between the individual countries.

The trends in governance are important for malnutrition reduction. There is a significant or explanatory correlation between the governance indicators tested in this chapter and underweight malnutrition. Political stability, government effectiveness, and rule of law are the governance indicators for which the correlation with malnutrition outcomes is significant at the $5 \%$ confidence level. Control of corruption is marginally significant at the $10 \%$ confidence level. Two indicators, voice and accountability and regulatory quality are not significantly correlated with malnutrition outcomes. The significance levels found in this study on governance indicators and underweight malnutrition outcomes are comparable in direction and magnitude to the findings of other macro-studies. Although there are no other studies on governance indicators and malnutrition, 
Smith and Haddad found correlations of $26 \%$ for food security, $44 \%$ for women's status, and $12 \%$ for relation with improvements in health environment. Kaufmann, Kraay and Zoido-Lobaton (1999) found positive correlations but do not report on the explanatory values.

The fact that there is a correlation between aggregate governance indicators and malnutrition outcomes is important. However, malnutrition reduction is a process and is influenced by many different factors. In the following chapter, the PA-nutrition and aggregate governance indices are analyzed in order to get more insights in the importance of governance on the process of building public accountability for malnutrition. 


\section{Chapter 8: Governance and Public Accountability for Nutrition}

\subsection{Introduction}

The theoretical considerations about the links between governance and public accountability for nutrition were laid out in chapter six. In this chapter they will be tested in a cross-country analysis. The following research questions are addressed:

1. Do developing countries that display better scores on governance also demonstrate Public Accountability for nutrition?

2. Did developing countries with better scores on governance invest more in malnutrition reduction interventions?

The organization of this chapter is as follows. A description of what is being tested is visualized in the frame-work at the beginning of each section, together with a repetition of the research question that is addressed. The results are presented followed by a discussion and introduction to the next question. The chapter starts with the correlation between the elements of governance included in the analysis and PA-nutrition (figure 8.1). The data-sources used include the earlier described Poverty Reduction Strategy Papers (PRSP), World Bank nutrition lending data and the Kaufmann data-set. Where possible the information and results are presented in both table and graph format. The chapter ends with a discussion of the findings.

Figure 8.1: Conceptual framework: Relation between Good Governance and Malnutrition Reduction

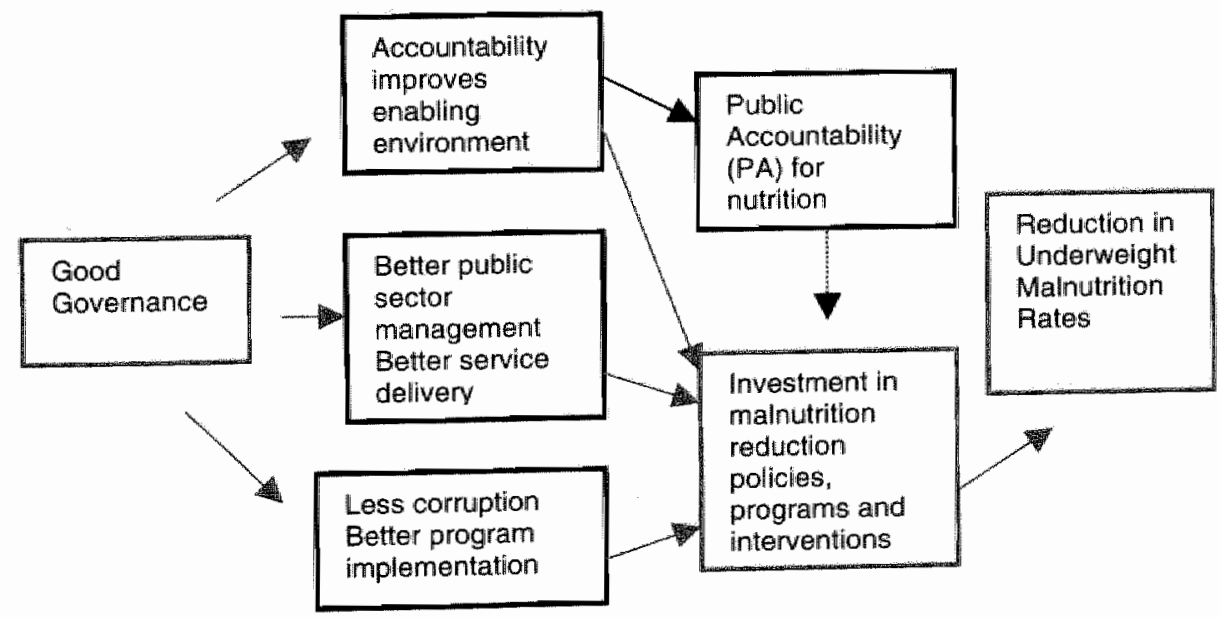




\subsection{Description of the data}

\subsubsection{Public Accountability for Nutrition}

Between 1999 and 2004, a total of 54 countries developed Poverty Reduction Strategy papers. A measurement for PA-nutrition was constructed (chapter six) and the data was collected from all available PASPs ${ }^{129}$. A total of 40 countries are included in the data-base (table two). The majority of countries (29) are from the Sub-Saharan Africa region, nine countries represent the Asia region, and there are only two Latin American countries, Nicaragua and Guyana. This is a fair representation of the PRSP process which was instigated by debt-relief, and therefore largely dominated by the poorest countries. SubSaharan Africa is the region with the highest number of eligible countries for debt-relief, and is by far the poorest region. Malnutrition rates are also highest in Sub-Saharan Africa and Asia. All countries in the data-set are low-income with GDP per capita less than US\$ $765^{130}$, except Nicaragua with US\$779, Indonesia with US\$800, Sri Lanka with US\$884 and Guyana with US\$939 GDP per capita.

Table 8.1 shows the observations of the variables collected from the PRSPS. The majority of the countries, 29, recognize malnutrition as a development problem in their overall poverty reduction strategy. The majority also monitors nutrition indicators, measured as having two or more national survey data-points between 1990 and 2000. Although 31 countries monitor malnutrition through national surveys, only 25 include malnutrition as an indicator in the PRSP. Less than half, only 17 countries make malnutrition a priority area in the overall poverty reduction strategy, and 16 foresee an actual budget for the interventions mentioned in the area of malnutrition reduction.

\footnotetext{
129 Only countries with malnutrition rates over $10 \%$ are included - Albania, Armenia, Bolivia, Bosnia-Herzegovina, Georgia, Honduras, Kyrgyz Republic, Macedonia, Moldova and Serbia-Montenegro are not included for that reason even though a PRSP is available. Cape Verde and Tajikistan were excluded because PRSPS lacked basic information in those that were produced before January 2004.

Cut off in 2003 for definition of low income country
} 
Table 8.1: Data-description of variables for PA for Nutrition (n=40)

\begin{tabular}{|c|c|c|c|}
\hline $\begin{array}{l}\text { Variables measuring } \\
\text { Accountability for Nutrition }\end{array}$ & $\begin{array}{l}\text { No. of } \\
\text { countries } \\
\text { with } \\
\text { positive } \\
\text { score }\end{array}$ & $\begin{array}{l}\% \\
\text { countries } \\
\text { with } \\
\text { pasilive } \\
\text { score }\end{array}$ & $\begin{array}{l}\text { Data not } \\
\text { availlable }\end{array}$ \\
\hline $\begin{array}{l}\text { Malnutrition is recognized as a } \\
\text { development problem in the PRSP }\end{array}$ & 29 & $75 \%$ & \\
\hline $\begin{array}{l}\text { Malnutrition indicators are regularly } \\
\text { monitored }\end{array}$ & 34 & $78 \%$ & \\
\hline $\begin{array}{l}\text { Malnutrition-reduction is a priority-area in } \\
\text { the PRSP where malnutrition rates } \\
\text { constitute a public heaith problem - higher } \\
\text { than } 20 \%\end{array}$ & 17 & $44 \%$ & $1 *$ \\
\hline $\begin{array}{l}\text { Indicators to monitor malnutrition are } \\
\text { included in PRSP }\end{array}$ & 25 & $63 \%$ & \\
\hline $\begin{array}{l}\text { Malnutrition reduction interventions are } \\
\text { foreseen in the budget provided in the } \\
\text { PRSP }\end{array}$ & 16 & $47 \%$ & $6^{* *}$ \\
\hline
\end{tabular}

* National malnutrition rate is less than $20 \%$ in Nicaragua

*No budget data avallable for any sector in PRSP

Although recognizing malnutrition as a development problem is important, it does not guarantee actions will be taken to do something about it. Many governments have signed several international agreements to reduce and even eliminate certain forms of malnutrition ${ }^{131}$, but have done little to take it forward with concrete actions. Countries that include targets to measure progress show greater commitment than recognizing it as a problem. If malnutrition is further put forward as a priority area, it is more likely attention would be given to concrete actions. If a budget is provided specifically for malnutrition reduction interventions, this is considered an important sign of commitment to nutrition and results in a higher score on PA-nutrition.

Table 8.2 displays the results from the PRSP review ranked by score; with five positive scores being the highest. The shaded areas visualize the positive scores. Countries that include a budget for mutrition interventions all have recognized malnutrition as a development problem, and all but a few have included targets in their development monitoring program to track progress on malnutrition rates. All but four of the countries with a budget for nutrition have made malnutrition reduction a priority area. Five of the 40 countries in this data-set recognize malnutrition as a development problem, monitor it, and made it a priority area in their overall development program, but did not go as far as allocating resources for it. Countries that recognize malnutrition as a development problem, monitor progress, and

159 Nations signed in 1992 the International Conference on Nutrition (ICN) Declaration which included the elimination of Vitamin A deficiency. 
prioritize malnutrition in their overall development program (PRSP) are considered as high scoring on PA-nutrition.

Overall, there is little relationship between the underweight malnutrition rates in 2000 and the score on PAnutrition. There are an equal number of countries with very high malnutrition rates that have a high score, for example Ethiopia, Cambodia, Madagascar, Mali and Burkina Faso for example, and those that have a low score but very high malnutrition rates, for example Nepal, Burundi, Niger, Lao PDR and Guinea. However, countries which allocate a budget for nutrition have on average national underweight malnutrition rate of $28.5 \%$, while those that prioritize nutrition, but do not allocate a budget, have on average $37 \%$ underweight malnutrition at the national level.

There is also little relationship between the countries' PA-nutrition and the changes in underweight malnutrition rates over the last half decade. Mauritania, Burkina Faso, Zambia and Sri Lanka all have worsening underweight malnutrition rates, but all show higher scores on PA-nutrition. The only clear relationship is between countries that have data-available to analyze trends (i.e. two or more data-points between 1992 and 2004) score better on average on PA-nutrition than those that do not have the data available. Of the 23 countries that have trenddata, ten also allocate budget to nutrition interventions in their development programs, and five more prioritize nutrition, but without a budget allocation. It is difficult to do this analysis, given the differences in time. The malnutrition outcome data dates from the period between 1995 and 2000, while the PA-nutrition is collected from documents after 2000. The dataset does offer a base-line, and it would be interesting to collect the same data from PRSP about five years from now and compare what has happened overtime. Only then can something be said about the direct relationship between PA-nutrition and malnutrition status.

In this chapter the concern therefore is on PA-nutrition and how governance elements influence nutrition through the routes described in chapter six, it is not linked directly to nutrition outcomes but via investments (figure 8.1). 
Chapter 8: Governance and Public Accotntability for Nutrition

Table 8.2: Country-scores on PA-nutrition in PRSP shaded = positive score

\begin{tabular}{|c|c|c|c|c|c|c|c|}
\hline $\begin{array}{l}\text { Country- } \\
\text { name }\end{array}$ & $\begin{array}{l}\text { Nutrition } \\
\text { recognized } \\
\text { problem }\end{array}$ & $\begin{array}{l}\text { Nultrition } \\
\text { progress } \\
\text { monitored }\end{array}$ & $\begin{array}{l}\text { Nutrition } \\
\text { targets } \\
\text { included }\end{array}$ & $\begin{array}{l}\text { Nutrition } \\
\text { is } \\
\text { priority }\end{array}$ & $\begin{array}{l}\text { Nutrition } \\
\text { budigot } \\
\text { included }\end{array}$ & $\begin{array}{l}\text { WA } \\
\text { In } \\
2000\end{array}$ & $\begin{array}{l}\text { GDP } \\
\text { in } \\
2000\end{array}$ \\
\hline Cambodia & + & +1 & $3+$ & $\mathrm{CH}$ & $\mathrm{Bt}$ & 45 & 283 \\
\hline Cameroom & + & + & \pm & + & + & 22 & 587 \\
\hline Ghana & + & + & \pm & \pm & + & 25 & 254 \\
\hline Madagascar & + & + & $t$ & + & + & 35 & 250 \\
\hline Malawi & + & + & \pm & 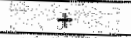 & $t$ & 25 & 169 \\
\hline Mali & + & + & + & + & + & 33 & 223 \\
\hline Senegal & + & + & 4 & $t$ & + & 17 & 459 \\
\hline Tanzania & + & + & + & \pm & + & 29 & 269 \\
\hline Zambia & \pm & 3 & + & + & + & 25 & 328 \\
\hline Burkina $F$. & + & + & & \pm & + & 34 & 231 \\
\hline Nicaragua & + & 4 & 4 & & + & 10 & 779 \\
\hline Bangladesh & + & + & + & + & & 52 & 347 \\
\hline Chad & + & \pm & \pm & + & & 28 & 177 \\
\hline Mauritanla & + & + & \pm & $t$ & 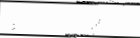 & 32 & 355 \\
\hline Sri Lanka & + & + & + & 4 & & 33 & 884 \\
\hline Vietnam & + & + & $t$ & + & 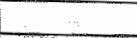 & 34 & 397 \\
\hline Gambla & \pm & + & \pm & & + & 17 & 321 \\
\hline Mozambique & + & & & + & + & 26 & 208 \\
\hline Ethiopia & \pm & & + & & + & 47 & 102 \\
\hline Pakistan & + & +1 & & & 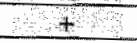 & 38 & 531 \\
\hline DRC & + & & 4 & + & & 34 & 89 \\
\hline Benin & + & + & + & & & 23 & 362 \\
\hline Niger & + & + & \pm & & & 41 & 167 \\
\hline Nepal & & + & & & \pm & 48 & 238 \\
\hline Kenya & & \pm & + & & & 22 & 347 \\
\hline Awanda & & +1 & \pm & & & 24 & 235 \\
\hline Uganda & & +4 & +4 & & & 23 & 253 \\
\hline Burund! & + & & + & & & 45 & 100 \\
\hline Mongolia & \pm & \pm & & & & 13 & 395 \\
\hline SierraLeone & 3 & & + & & & 27 & 126 \\
\hline Ivary-Coast & & + & & & & 21 & 670 \\
\hline Guinea & & $t$ & & & & 33 & 420 \\
\hline Guyana & & + & & & & 12 & 939 \\
\hline Indonesia & & + & & & & 25 & 800 \\
\hline Lao PDR & & \pm & & & & 40 & 326 \\
\hline Lesotho & & 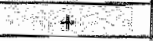 & & & & 18 & 493 \\
\hline Dllbouti & \pm & & & & & 18 & 830 \\
\hline Guinea- $B$. & + & & & & & 25 & 158 \\
\hline Sao Tome & $2+$ & & & & & 16 & 314 \\
\hline CAR & & & & & & 23 & 256 \\
\hline
\end{tabular}

W/A $A=$ underweight; $G D P=G r o s s$ Domestic Procuct per capita

Data on changes in WA between 92-04 is included in Annex 2, table 3

\subsubsection{Governance}

Key-principles of governance may affect reductions in underweight positively through creating or improving the enabling environment in which PA-nutrition can be built or thrive (route 1), having positive impact on malnutrition reduction through better investment and service delivery (route 2), and using resources 
more uransparently (route 3). These principles include accountability in general and ownership for route one, public sector management and reforms for route two, and anticorruption and transparency for route three. The variables to measure how countries are classified on governance performance and progress are collected from the Kaufmann et al dataset. Table 8.3 displays the data for the 40 countries for which PA-nutrition data is also available and which constitute the research population in this chapter. Both the score in 2000 and progress in performance, measured as the change in scores between 1996 and 2004, are used to analyze how they influence PA-nutrition.

Table 8.3" Classification of country performance on key-principles of governance $(n=40)$

\begin{tabular}{|l|c|c|c|c|}
\hline $\begin{array}{l}\text { Governance } \\
\text { Indices }\end{array}$ & \multicolumn{3}{|l|}{ No and \% of countrles classified as Good } \\
\hline & $\begin{array}{l}\text { No and \% of countries } \\
\text { good in 2000 }\end{array}$ & $\begin{array}{l}\text { No and \% of countries with } \\
\text { positive trend between } \\
1996 \text { and 2004 }\end{array}$ \\
\hline $\begin{array}{l}\text { Route 1: Voice } \\
\text { and Accountability }\end{array}$ & 7 & $18 \%$ & 18 & $45 \%$ \\
\hline $\begin{array}{l}\text { Route 2: } \\
\text { Government } \\
\text { Effectiveness }\end{array}$ & 6 & $15 \%$ & 14 & $35 \%$ \\
\hline $\begin{array}{l}\text { Route 3a: Rule of } \\
\text { Law and }\end{array}$ & 1 & $3 \%$ & 13 & $33 \%$ \\
\hline $\begin{array}{l}\text { Route 3b. Control } \\
\text { of Corruption }\end{array}$ & 3 & $8 \%$ & 16 & $40 \%$ \\
\hline
\end{tabular}

Overall, of the 40 countries in the data-base, there are no high performers on any of the Kaufmann governance indices as shown in Table 8.3. In fact, only very few of the countries even score positive. The group of countries used as research population in this chapter (40) is doing, on average, worse on all indices than the group of countries used to carry out the analysis between malnutrition outcomes and governance. Even the Africa region, the least performing region, does better on average. This is expected though, because the group of 40 countries represents the poorest countries eligible for debt-relief. As an illustration, the average scores of the countries with higher than US $\$ 800$ per capita are included in table 8.4 ; all score better, although the average remains less than zero. 
Table 8.4: Average governance scores research populations

\begin{tabular}{|l|c|c|c|c|c|}
\hline $\begin{array}{l}\text { Average scores } \\
\text { on: }\end{array}$ & $\begin{array}{l}\text { All } \\
\text { research } \\
\text { population } \\
\text { Chapter 5 }\end{array}$ & Africa & $\begin{array}{l}\text { GDP/per } \\
\text { caplta } \\
\text { over } \\
\text { US\$ 800 }\end{array}$ & $\begin{array}{l}\text { GDP/per } \\
\text { Capita } \\
\text { Under } \\
\text { US\$765 }\end{array}$ & $\begin{array}{l}\text { Research } \\
\text { population } \\
\text { Chapter 8 }\end{array}$ \\
\hline $\begin{array}{l}\text { Voice and } \\
\text { Accountability }\end{array}$ & -0.40 & -0.53 & -0.11 & -0.64 & -0.57 \\
\hline $\begin{array}{l}\text { Government } \\
\text { Effectiveness }\end{array}$ & -0.40 & -0.60 & -0.21 & -0.57 & -0.55 \\
\hline $\begin{array}{l}\text { Rule of Law } \\
\text { Control of } \\
\text { Corruption }\end{array}$ & -0.52 & -0.61 & -0.32 & -0.68 & -0.69 \\
\hline
\end{tabular}

\subsection{Results Governance and PA-Nutrition}

\subsubsection{Route 1}

The theoretical link made in chapter seven assumed that countries that are more accountable in general, and where citizens enjoy more opportunities to exercise 'voice' are more likely to have an enabling environment in which malnutrition could be addressed in the decision-making processes. The average group-score is taken as the cut-off point above which countries are considered as having a better score and those under the group-average as having a worse score. Since governance changes over time, the influence of the trenddirection is analyzed. Table 8.5 to 7 displays the results for the four governance indices and PA-nutrition. Column 1 shows the cut-off point and column 2 the number of countries that fall in that category. The right five columns to the right of these show the percentages of countries that score positive on the PA-nutrition variable in that category. For example for 'voice and accountability', the average status in 2000 in the group of 40 countries included was -.56. All countries with scores above 0.56 , a total of 22 , are considered the better performers. The rows below 'status' in the table shows the 'trend', positive when performance improves, negative when it worsens.

Regarding route 1 , measured as voice and accountability, half of the countries that score above the group's average in 2000, include in their PRSP a budget for nutrition. Only $22 \%$ of the countries that have scores below the average of the group have a budget for nutrition interventions. Taking a closer look at changes in voice and accountability between 1996 and 2004 , more countries include a budget for nutrition when there is a positive trend, $44 \%$ versus $32 \%$ when countries have worsening trends. It appears that more countries, $45 \%$, include nutrition as a priority when they have decreasing trends in voice and accountability, although the difference is very small, $6 \%$. 
Countries monitor progress on malnutrition rates better when they have a positive trend and above average scores on voice and accountability. An important difference is seen between countries with above average scores on voice and accountability regarding displaying all variables of PA-nutrition, from recognizing malnutrition as a development problem to allocating a budget. Eight countries among those with higher scores in 2000 display all variables, versus only one country among those with lower scores.

The data from the 40 countries in this data-base regarding route 1 , measured as voice and accountability and PAnutrition, provides descriptive statistical support for the assumption that PA-nutrition is better - higher scores - when voice and accountability is better - higher score.

Table 8.5: Country scores on volce and accountability index and PAnutrition

\begin{tabular}{|l|c|c|c|c|c|c|}
\hline ndicator & Cut & $\begin{array}{c}\text { Nutrition } \\
\text { budget } \\
\text { included }\end{array}$ & $\begin{array}{l}\text { Nutrition } \\
\text { is } \\
\text { priority }\end{array}$ & $\begin{array}{l}\text { Nutrition } \\
\text { targets } \\
\text { included }\end{array}$ & $\begin{array}{l}\text { Nutrition } \\
\text { progress } \\
\text { Monitored }\end{array}$ & $\begin{array}{l}\text { Nutrition } \\
\text { Is a } \\
\text { problem } \\
\text { Accountability: }\end{array}$ \\
\hline Status 2000 & $1-.56$ & $50 \%$ & $55 \%$ & $59 \%$ & $87 \%$ & $77 \%$ \\
\hline & $1-.57$ & $22 \%$ & $28 \%$ & $67 \%$ & $67 \%$ & $67 \%$ \\
\hline Trend 96-04 & Pos. & $44 \%$ & $39 \%$ & $67 \%$ & $83 \%$ & $72 \%$ \\
\hline & Neg. & $32 \%$ & $45 \%$ & $59 \%$ & $73 \%$ & $73 \%$ \\
\hline
\end{tabular}

= average score research population

\subsubsection{Route 2}

The index government effectiveness measures the quality of public service delivery and the competence of the bureaucracy. In particular, the quality of public service delivery is assumed to be important to malnutrition reduction. Countries that score above the group's average in 2000 have twice as often a budget allocated to nutrition and made reducing malnutrition is priority in their overall development programs, the PRSP. Table 8.6 shows the results. There is also an important difference between countries with a positive trend in government effectiveness between 1996 and 2004 in terms of allocating a buldget and prioritizing nutrition in the PRSP. Almost $50 \%$ more prioritize nutrition when trends are positive.

In chapter seven, government effectiveness is significantly correlated with malnutrition outcomes. Part of the explanation of the link between the two aggregate indicators may be that government effectiveness plays an important role in 
assuring malnutrition is made a priority and a budget is allocated. PA-nutrition may be important in the process between better government, and prioritizing and ensuring allocation of funds to malnutrition reduction programs.

Table 8.6: Country scores on government effectiveness index and PAnutrition

\begin{tabular}{|l|l|l|l|l|l|l|}
\hline $\begin{array}{l}\text { Indicator } \\
\text { Government } \\
\text { Effectiveness }\end{array}$ & $\begin{array}{l}\text { Cut } \\
\text { off }\end{array}$ & $\begin{array}{l}\text { Nutrition } \\
\text { budget } \\
\text { incluided }\end{array}$ & $\begin{array}{l}\text { Nutrition } \\
\text { is } \\
\text { priority }\end{array}$ & $\begin{array}{l}\text { Nutrition } \\
\text { targets } \\
\text { included }\end{array}$ & $\begin{array}{l}\text { Nutrition } \\
\text { progress } \\
\text { Menitored }\end{array}$ & $\begin{array}{l}\text { Nutrition } \\
\text { Is a } \\
\text { problem }\end{array}$ \\
\hline Status 2000 & $1-.54$ & $43 \%$ & $57 \%$ & $65 \%$ & $96 \%$ & $74 \%$ \\
\hline & $1-.55$ & $29 \%$ & $24 \%$ & $59 \%$ & $53 \%$ & $71 \%$ \\
\hline Trend 96-04 & Pos. & $57 \%$ & $71 \%$ & $64 \%$ & $79 \%$ & $79 \%$ \\
\hline & Neg. & $27 \%$ & $27 \%$ & $62 \%$ & $77 \%$ & $69 \%$ \\
\hline
\end{tabular}

= average score research population

\subsubsection{Route 3}

Transparent management of resources and decentralized financial management, both important in community-based nutrition programs, are dependent on a system that does not allow corruption. Table 8.7 shows that countries where the trends regarding performance on rule of law and control of corruption are positive, in approximately half of the cases a budget is allocated to nutrition and malnutrition reduction is made a priority in the overall development program. Progress on malnutrition rates is also consistently monitored more often in countries that are performing better on the application of anti-corruption governance principles. 
Chapter 8: Governance and Public Accountability for Nutrition

Table 8.7: Country scores on rule of law and control of corruption indices and $P A$-nutrition

\begin{tabular}{|c|c|c|c|c|c|c|}
\hline Indicator & out & $\begin{array}{l}\text { Nutrifion } \\
\text { budget } \\
\text { included }\end{array}$ & $\begin{array}{l}\text { Nutrition } \\
\text { is } \\
\text { priority }\end{array}$ & $\begin{array}{l}\text { Nutrition } \\
\text { targets } \\
\text { included }\end{array}$ & $\begin{array}{l}\text { Mutrition } \\
\text { progress } \\
\text { Monitored }\end{array}$ & $\begin{array}{l}\text { Nutrition } \\
\text { is a } \\
\text { problem }\end{array}$ \\
\hline \multicolumn{7}{|l|}{$\begin{array}{l}\text { Murcalor } \\
\text { Rule of } \\
\text { Law }\end{array}$} \\
\hline \multirow[t]{2}{*}{$\begin{array}{l}\text { Status } \\
2000\end{array}$} & 1,68 & $43 \%$ & $43 \%$ & $57 \%$ & $83 \%$ & $74 \%$ \\
\hline & +69 & $29 \%$ & $41 \%$ & $71 \%$ & $71 \%$ & $71 \%$ \\
\hline \multirow[t]{2}{*}{$\begin{array}{l}\text { Trend } 96- \\
04\end{array}$} & Pos. & $54 \%$ & $54 \%$ & $62 \%$ & $77 \%$ & $76 \%$ \\
\hline & Neg. & $32 \%$ & $40 \%$ & $68 \%$ & $84 \%$ & $68 \%$ \\
\hline \multicolumn{7}{|l|}{$\begin{array}{l}\text { Control of } \\
\text { Corruption }\end{array}$} \\
\hline \multirow[t]{2}{*}{$\begin{array}{l}\text { Status } \\
2000\end{array}$} & +0.64 & $38 \%$ & $43 \%$ & $57 \%$ & $81 \%$ & $67 \%$ \\
\hline & $1-.65$ & $37 \%$ & $42 \%$ & $68 \%$ & $74 \%$ & $74 \%$ \\
\hline \multirow[t]{2}{*}{$\begin{array}{l}\text { Trend 96- } \\
\text { D4 }\end{array}$} & Pos. & $44 \%$ & $50 \%$ & $81 \%$ & $69 \%$ & $88 \%$ \\
\hline & Neg. & $33 \%$ & $38 \%$ & $50 \%$ & $83 \%$ & $63 \%$ \\
\hline
\end{tabular}

" = average score research population

In conclusion, PA-nutrition displays better scores in countries where the scores on progress on the application of governance principles, measured as aggregate governance indices, are better than average and where the trend improves. The next key-question is whether this leads to better investment in nutrition and to subsequently to better outcomes.

\subsection{Governance and Investment in Nutrition}

Studies have shown that large-scale nutrition programs accelerate the reduction in underweight malnutrition rates. The Seecaline program in Madagascar, for example, reduced underweight in children under three by $20 \%$ in the target-zones over a period of two years (Galasso 2005:17). But, they are dependent on financing. The Madagascar study-case in chapter nine illustrates very clearly what can be achieved with adequate financing, and what happens without it.

Underinvestment has also been identified as an important underlying constraint to scaling up nutrition programs and achieving national level results in evaluations of the TINP. program in India, the AlN-programs in Bolivia and Honduras, and the Iringa project in Tanzania. Underinvestment is believed to be largely due to the challenges malnutrition faces to build commitment or public accountability, and may be positively influenced by good governance. In order to test this in the context of cross-country analysis, the level of investment in 
nutrition programs is used as a proxy for the outcome of societal factors and the input to nutrition programs, the lower box of the UNICEF conceptual model (chapter two, figure 2.1).

Figure 8.2: Framework: relation between good governance and investment in malnutrition reduction programs and interventions

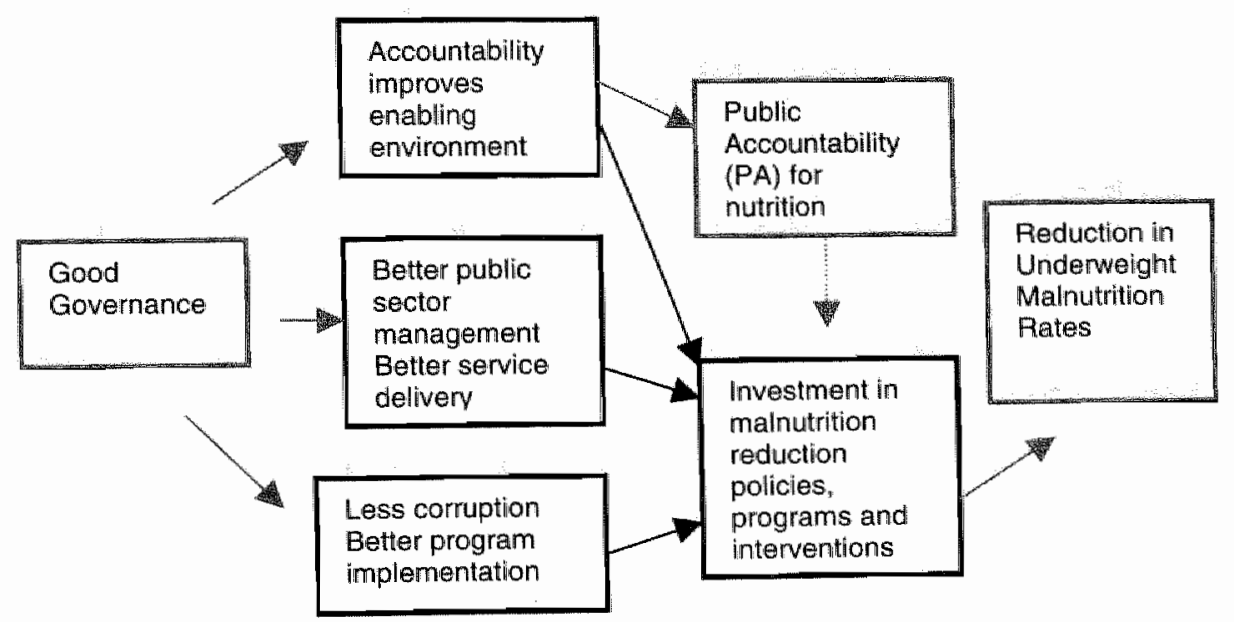

Research questions: Did developing countries with better scores on governance invest more in malnutrition reduction interventions?

The question addressed in this section is how the level of investment in nutrition interventions with World Bank support is related to the changes in governance indices over the same period. Investment in malnutrition reduction policies, interventions, and programs are measured as World Bank lending for malnutrition reduction ${ }^{132}$. The data-set used for this analysis is made up of World-Bank supported projects. A total of 61 World Bank projects in 32 developing countries, that were designed and approved by the World Bank board of Directors ${ }^{133}$ between $1993^{134}$ and 2000 , are used as the research population.

Almost half a billion US-dollars was invested in nutrition interventions through these 61 projects. The criteria for selecting

${ }^{132}$ In principle all countries, members of the World Bank group, are eligible for lending for nutrition interventions, but it depends on countries" interest and response from the Warld Bank team responsible for the specific country.

${ }^{133}$ See for details on project cycle and World Bank Board approvals annex I:

World Bank Basic facts.

134 With one exception - Tanzania Health and Nutrition was approved in 1990. 
this group of projects were: (i) lending activities had as an objective to reduce or prevent malnutrition; (ii) PRSP data for the particular country is available; (iii) the project was implemented between the mid-nineties and 2004. All investments in those years are included, so even if a country had several projects with nutrition components; all these have been added together and one per capita investment calculated (table 8.8).

The 32 countries included in the data-base are a sub-set of the 40 countries for which the PA-nutrition and governance analysis is carried out. Most are African nations, 26, five are Asian, and there is one Latin American country included. All are low-income, with the exception of Nicaragua, Indonesia, and Sri Lanka, who have per capita income levels above US $\$ 765$, but below US\$ 900 . PA-nutrition is included in the table as an illustration only; there is no relation because the timing of PAnutrition score is only available after the period covered for the investment data. Countries that invest more than a dollar for nutrition in the 1990s have on average $25 \%$ underweight malnutrition $(n=10)$, while those that invest less than a dollar in the 1990s have underweight malnutrition average of $30.1 \%$ $(n=22)$. 
Chapter 8: Governance and Public Accountability for Nutrition

Table 8.8: Per capita investment for nutrition interventions between 1993 and 2000 in US-dollars $(n=31)$

\begin{tabular}{|c|c|c|c|c|c|}
\hline Country & $\begin{array}{l}\text { Per Capita } \\
\text { Investment }\end{array}$ & PA-nut & Country & $\begin{array}{l}\text { Per Capita } \\
\text { investment }\end{array}$ & PA-nut \\
\hline Bangladesh & US\$ 0.91 & Good & Madagascar & USS 2.43 & Good \\
\hline Berin & US\$ 2.25 & Poor & Malaw & US $\$ 0.47$ & Good \\
\hline $\begin{array}{l}\text { Burkina } \\
\text { Faso }\end{array}$ & US\$0.93 & Good & Malli & US\$ 0.33 & Good \\
\hline Burundi & US\$2.12 & Poor & Mauritania & UIS\$2.57 & $\begin{array}{l}\text { Priority, } \\
\text { no } \\
\text { budget }\end{array}$ \\
\hline Cameroon & US\$ 0.93 & Good & Mozambique & US\$ 0.03 & Good \\
\hline CAR & US $\$ 1.35$ & Poor & Nicarragua & US\$ 1.29 & $\begin{array}{c}\text { Budget, } \\
\text { no } \\
\text { priority }\end{array}$ \\
\hline Chad & US\$0.88 & $\begin{array}{c}\text { Priority, } \\
\text { no } \\
\text { budget }\end{array}$ & Niger & US\$ 0.04 & Poor \\
\hline $\begin{array}{l}\text { Cote } \\
\text { d'lvoire }\end{array}$ & US\$0.05 & Poor & Pakistan & US\$ 0.02 & $\begin{array}{l}\text { Budget, } \\
\text { no } \\
\text { priarity }\end{array}$ \\
\hline Ethiopia & US\$ 0.06 & $\begin{array}{l}\text { Budget, } \\
\text { no } \\
\text { priority }\end{array}$ & Rwanda & US\$0.12 & Poor \\
\hline Gambla & US\$1.77 & $\begin{array}{l}\text { Budget } \\
\text { no } \\
\text { priority }\end{array}$ & Senegal & US\$2.00 & Good \\
\hline Ghana & US\$0.05 & Good & $\begin{array}{l}\text { Sierra } \\
\text { Leane } \\
\end{array}$ & US\$ 0.48 & Poor \\
\hline Guinea & US\$ 0.70 & Poor & Sri Lanka & USS 0.15 & $\begin{array}{c}\text { Piriority, } \\
\text { no } \\
\text { budget }\end{array}$ \\
\hline $\begin{array}{l}\text { Guinea } \\
\text { Bissau }\end{array}$ & US\$0.83 & Poor & Tanzania & US\$ 0.71 & Good \\
\hline Indonesia & US\$ 0.38 & Poor & Uganda & US\$1.03 & Poor \\
\hline Kenya & US\$0.10 & Poor & Vietnam & US\$ 0.07 & $\begin{array}{c}\text { Priority, } \\
\text { no } \\
\text { budget }\end{array}$ \\
\hline Lesotho & US\$ 0.01 & Poor & Zambia & USS 1.48 & Good \\
\hline
\end{tabular}

- PA-nutrition is classified as good if a budget is allocated for nutrition and nutrition is made a priority in national development program (PRSP).

It is worth mentioning here that the investment levels as shown in table 8.8 are a far cry from what is now commonly believed needed to achieve the MDG-indicator for nutrition; halving underweight malnutrition by 2015 . Mason estimates the need for investment in nutrition interventions at US\$1.00-5.00 dollars annually per capita in order to successfully achieve the MDG in countries with high malnutrition rates ${ }^{135}$ (Mason in

135. Mason estimates the need for nutrition investment 10 reduce malnutrition rates significantly varies between 1 and 5 US\$ per child under the age of five per year. Children under five make up about $16 \%$ or one sixth of the population 
Chapter 8: Governance and Public Accountability for Nutrition

Gillesple et al 2004:25). The investment data shown here vary between US $\$ 0.01$ and US $\$ 2.57$, but for a period of on average 5 to 8 years. And even though this is only investment with World Bank support, it is unlikely that national budgets, especially in African nations, contribute more than half to the overall budget.

A note of caution regarding the data that are used here is needed. The dataset is limited in number, and nutrition investment data is available only for World Bank supported investments. As explained in chapter two, governments themselves invest resources in nutrition, and other partners in development also invest in nutrition interventions in developing countries. When countries borrow from the World Bank it is in general to close a finance gap, which justifies using the data as an indication of overall investment in nutrition. Progress and status of governance is measured using the same Kaufmann et al dataset governance indices. 
Table 8.9: Nutrition investment per capita and trends in governance indices

\begin{tabular}{|c|c|c|c|c|c|}
\hline Country & $\begin{array}{l}\text { Nutrition } \\
\text { inyestment } \\
\text { per caplta } \\
\text { between } \\
1993-2000\end{array}$ & $\begin{array}{l}\text { trend } \\
\text { VAO4- } \\
\text { VA96 }\end{array}$ & $\begin{array}{l}\text { trend } \\
\text { GE04. } \\
\text { GE } 96\end{array}$ & $\begin{array}{l}\text { trend } \\
\text { R04-RL } 96\end{array}$ & $\begin{array}{l}\text { trend } \\
\text { ceou } \\
\text { cco6re }\end{array}$ \\
\hline Mauritania & 2.57 & -0.32 & -0.03 & -0.01 & 0.31 \\
\hline Madagascar & 2.43 & -0.20 & 0.21 & 0.55 & -0.52 \\
\hline Benin & 2.25 & -0.45 & -0.40 & -0.46 & 0.41 \\
\hline Bunundi & 2.12 & 0,15 & -0.27 & -1.31 & -0.36 \\
\hline Semegal & 2.00 & 0,36 & 0,26 & -0.03 & -0.01 \\
\hline Gambia & 1.77 & 0.75 & -0.39 & -0.56 & 0.97 \\
\hline Zambia & 1.48 & -0.20 & 002 & .0 .19 & 0.24 \\
\hline CAR & 1.35 & -1.03 & -0.84 & -1.25 & -0.82 \\
\hline Nicaragua & 1.29 & 0.28 & -0.25 & 0.03 & -0.20 \\
\hline Uganda & 1.03 & -0.01 & -0.05 & 0.09 & -0.19 \\
\hline $\begin{array}{l}\text { Cameroon } \\
\text { Burkina }\end{array}$ & 0.93 & -0.13 & 0,39 . & 0.18 & 0.32 \\
\hline Faso & 0.93 & 0.09 & 0.24 & 0.13 & -0.04 \\
\hline Bangladesh & 0.91 & -0.35 & -0.06 & -0.17 & -0.62 \\
\hline Chad & 0.88 & -0.33 & -0.71 & -0.96 & -0.30 \\
\hline $\begin{array}{l}\text { Guinea- } \\
\text { Bissau }\end{array}$ & 0.83 & -0.07 & -0.37 & 0.33 & 0.27 \\
\hline Tanzania & 0.71 & 0.42 & 0.81 & 0.21 & 0,46 \\
\hline Guinea & 0.70 & 0001 & 0.29 & -0.02 & -1.17 \\
\hline Sierra Leone & 0.48 & 0.88 & -1.07 & -0.08 & 0.78 \\
\hline Malawi & 0.47 & $-0,07$ & -0.12 & -0.09 & 0,16 \\
\hline Indonesia & 0.38 & 071 & -0.54 & -0.55 & -0.43 \\
\hline Mall & 0.33 & 0.05 & 0.56 & 0.43 & -0.22 \\
\hline Sri Lanka & 0.15 & 0.05 & 0.02 & -0.32 & 0.07 \\
\hline Rwanda & 0.12 & 0.33 & 0.69 & -0.71 & 0.18 \\
\hline Kenya & 0.10 & 0.14 & -0.21 & -0.21 & 0,16 \\
\hline Vietnam & 0.07 & -0.22 & -0.20 & -0.09 & -0.110 \\
\hline Ethiopia & 0.06 & -0.50 & -0.56 & -0.73 & 0.13 \\
\hline Ghana & 0.05 & 0.74 & -0.09 & -0.04 & 0.30 \\
\hline Cote d'lvoire & 0.05 & -1.27 & -1.19 & -0.74 & -1.41 \\
\hline Niger & 0.04 & 0.29 & -0.05 & 0.34 & -0.57 \\
\hline Mozambique & 0.03 & 0.07 & 0.32 & 0.64 & -0.27 \\
\hline Pakistan & 0.02 & -0.33 & -0.17 & -0.35 & 0.11 \\
\hline Lesotho & 0.01 & 026 & -0.50 & 0.28 & -0.07 \\
\hline
\end{tabular}


Chapter 8: Governance and Public Accountability for Nutrition

There is a positive relationship between the trend in government effectiveness and average per capita investment in nutrition services (table 8.10 ). The analysis shows average per capita investment in nutrition interventions is US\$.89 over the period between early 1990 s and 2000 in countries with a positive trend in performance on government effectiveness. Average per capita investment is US\$.80 in countries with a negative trend in performance (Table 8.10).

Table 8.10: Average per capita investment In nutrition in the 1990s and performance scores on government effectiveness index $(n=32)$

\begin{tabular}{|l|l|}
\hline & $\begin{array}{l}\text { Government Effectiveness (GE) trend } \\
\text { between 1996 and 2004 }\end{array}$ \\
\hline $\begin{array}{l}\text { Average per capita } \\
\text { investment in nutrition in the } \\
1990 \mathrm{~s}\end{array}$ & $\begin{array}{l}\text { Countries with positive GE trend invested on } \\
\text { average US\$.89 per capita in nutrition ( } n=11)\end{array}$ \\
\cline { 2 - 2 } & $\begin{array}{l}\text { Countries with a negative GE trend invested on } \\
\text { average US\$.80 per capita in nutrition ( } n=21)\end{array}$ \\
\hline
\end{tabular}

The changes in voice and accountability, rule of law, and control of corruption all show opposite relationships; countries where the trend is negative are investing less in nutrition intervention than countries where the trend is positive (table 8.11). The trend analysis does not take status into account. The same analysis using the scores in 2000 shows a different picture. The investment in nutrition in countries where the index on voice and accountability is above the average of the 32 countries in this dataset is US\$0.87 ( $(n=17)$, while US $\$ 0.78$ when under the average. When the score on rule of law is above the average, the per capita investment in nutrition is almost twice as high as when the score is below the average, US $\$ 1.01 \quad(n=18)$ and
US\$0.59. 
Table 8.11: Average per capita investment in nutrition in the 1990s and performance scores on voice and accountability, rule of law and control of

\begin{tabular}{|c|c|}
\hline & $\begin{array}{l}\text { Volce and Accountabilty trend between } 1996 \\
\text { and } 2004\end{array}$ \\
\hline \multirow{2}{*}{$\begin{array}{l}\text { Average per capita } \\
\text { investment in nutrition in the } \\
1990 \text { s }\end{array}$} & $\begin{array}{l}\text { Countries with positive VA trend invested on } \\
\text { average US } \$ .66 \text { per capita in nutrition }(n=17)\end{array}$ \\
\hline & $\begin{array}{l}\text { Countries with a negative VA trend invested on } \\
\text { average US\$.1.02 per capita in nutrition }(n=15)\end{array}$ \\
\hline 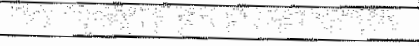 & Rule of Law trend between 1996 and 2004 \\
\hline \multirow{2}{*}{$\begin{array}{l}\text { Average per capita } \\
\text { investment in nutrition in the } \\
\text { 1990s }\end{array}$} & $\begin{array}{l}\text { Countries with positive RL trend invested on } \\
\text { average US } \$ .78 \text { per capita in nutrition }(n=11)\end{array}$ \\
\hline & $\begin{array}{l}\text { Countries with a negative } \mathrm{AL} \text { trend invested on } \\
\text { average US\$.86 per capita in nutrition }(n=21)\end{array}$ \\
\hline & $\begin{array}{l}\text { Control of Colruption trend between } 1996 \text { and } \\
2004\end{array}$ \\
\hline \multirow{2}{*}{$\begin{array}{l}\text { Average per capita } \\
\text { investment in nutrition in the } \\
\text { 1990s }\end{array}$} & $\begin{array}{l}\text { Countries with positive CC trend invested on } \\
\text { average US } \$ .73 \text { per capita in nutritlon }(n=14)\end{array}$ \\
\hline & $\begin{array}{l}\text { Countries with a negative CC trend invested on } \\
\text { average US\$.91 percapita in nutrition }(n=18)\end{array}$ \\
\hline
\end{tabular}

The governance index government effectiveness appears to have a positive influence on the level of investment in nutrition interventions. Both changes over the period analyzed and the scores in 2000 support the positive relationship. Regarding the voice and accountability and rule of law, only the score supports a positive relationship. Changes show the opposite, as countries with worsening governance indicators have invested more in nutrition. Regarding control of corruption, both the score and trend show a negative relation with the level of investment in nutrition interventions. The question whether the score on PAnutrition has an effect on the level of investment cannot be addressed using the data available due to coverage of different periods. It would be interesting to revisit the data in five years in order to review changes and use this database as a base-line.

\subsection{Summary and Conclusion}

In this chapter, the three theoretical routes through which the principles of good governance may influence malnutrition reduction were examined using cross-country data analysis. A database for PA-nutrition was developed and the data collected from national Poverty Reduction Strategy Papers (PRSP). Estimates of investments in nutrition were collected from World Bank-supported nutrition and health projects and used to review 
the links between governance scores and investments in nutrition. Data from a total of 40 countries for the three route analysis and data from 32 countries for the relationship between investment and governance scores were used.

The cross-country data-analysis shows supports for the assumptions made in chapter seven regarding the three routes through which governance influences PA-nutrition. In countries where voice and accountability, government effectiveness, and rule of law, as well as control of corruption, score better the score on PA-nutrition is also better. This holds both for progress on performance on the governance indicators, measured as the trend in the indicator between 1996 and 2004, and the score in 2000. For example for countries where government effectiveness improves over the period between 1996 and 2004 , over $70 \%$ of the countries made malnutrition reduction a priority in their development plans and $57 \%$ allocated a budget.

The second question explored in this chapter was whether governance scores bear a relation to the level of investment in nutrition interventions. There appears less support for a positive relationship between governance scores and investment levels for nutrition than PA-nutrition and governance. Only government effectiveness scores show a positive relationship on both trend and status and PA-nutrition. Countries with improving scores on government effectiveness invested on average US $\$ 0.89$ per capita with World Bank support for nutrition, while those with worsening trends invested US $\$ 0.80$
per capita.

Countries with scores above the average in this research population invested on US\$0.90 per capita, while those will scores below the average invested US\$0.72 per capita. However, the opposite is true on the other indices of governance. Countries with positive trends on voice and accountability, rule of law and control of corruption all invest less in nutrition over the period reviewed than countries with negative trends.

There are considerable data limitations in this dataset that should be kept in mind. The investment figures only represent what the World Bank supported over that period. They do not include potentially important national budgets. It may well be that the relationship is negative precisely because of low level of attention to nutrition from the national government side, and As discuse external assistance may have been higher as a result. has often in chapter one, the international donor community malnutrition problems but low levels of countries with serious 
The question to what extent PA-nutrition matters for malnutrition outcomes is important, but cannot be tested empirically with the available data. The data on PA-nutrition that is collected from the PRSPS is largely after 2000, and the data available on changes in malnutrition and the most recent malnutrition survey-data dates from before most of the PRSPS were developed.

In the next chapter a case-study on Madagascar is presented with the purpose to test how the three identified routes through which governance influences malnutrition reduction, and to demonstrate whether the relationships are borne out by reality. 


\section{Chapter 9: Governance and Malnutrition in Madagascar, A Case-study}

\subsection{Introduction}

Although many countries have tried successful small scale nutrition pilots, few have transformed them into successful large-scale interventions with impact on malnutrition rates at the national level. Poor governance, lack of high-level political commitment and accountability, insufficient financial resources, and weak capacity all have been mentioned as major constraints to scale up successful pilots. Madagascar offers an example of a country where malnutrition programs not only were piloted, but also scaled up; where commitment was strong, and remained strong even in the face of changes in government; and where investments in nutrition programs have increased many-fold over the last decade. Impact evaluations show positive results on reducing underweight malnutrition. The case describes two main periods with differences in governance and PA-nutrition, allowing analysis between periods. Describing the case for Madagascar adds value to the theoretical framework developed in chapter six and the empirical results of chapters seven and eight.

There are ample data available on the communitynutrition programs in Madagascar, which can be used to analyze nutrition investments and expenditures and malnutrition rates for the period between 1990 and 2004. Governance data are avallable from the data used in earlier chapters and from process details from documentation on governance programs. The information is obtained from sources varying from: (i) document reviews of World Bank economic and governance reports, nutrition program supervision reports and technical notes, as well as official national documents; (ii) data-bases from the projects and national statistics office; (iii) key-person interviews and discussions with stakeholders; and (iv) author"s experience of eight years working on nutrition and being a key-player in the institutionalization of nutrition in Madagascar.

This chapter starts with a brief overview of Madagascar's history and economic progress since the early 1990s, with the purpose of describing the context in which the discussions about governance and malnutrition can be placed. After the introduction the chapter contains three main parts: first, a chronological review of Madagascar's governance policies and progress made; second a chronology of Madagascar's policies and programs addressing malnutrition, and a last section discuses how governance key-elements influenced nutrition in Madagascar. 
In addition to the key-elements of governance and public accountability signals for nutrition as identified in chapter seven, country-ownership over the nutrition agenda and decentralization are addressed. These two aspects of governance, although recognized as important to malnutrition reduction, were not given much attention in the empirical analysis in chapter seven for lack of data. This chapter examines 1990 to 2004 as the main period.

\subsection{Background}

\subsubsection{Madagascar: Geography and Brief History ${ }^{136}$}

Madagascar is the fourth largest island in the world after Greenland, New Guinea and Borneo. It is comparable in size to France and The Netherlands combined. Madagascar is sparsely populated with only 28 people per square $\mathrm{km}$. The terrain is mountainous and about $80 \%$ of its population lives in the rural areas. Madagascar is assumed to have split of the African continent at the end of the Paleozoic era about two hundred million years ago. According to archeologists, the long separation from other land masses explains the uniqueness of the flora and fauna of the island ${ }^{137}$. This uniqueness provides Madagascar with a potential for a strong tourism industry as one of its possible areas for economic growth.

The first inhabitants of Madagascar came from Indonesia, and immigration first took place in the second half of the first Millennium. The coastal people, nowadays also identified as 'Cotier', apparently came to the island later but are today more numerous. The 'Merina', as the Malagasys of Indonesian and Malaysian descent are called, have always dominated the administration and governed the country. One of the most important eras and kings in Madagascar were King ruled after his kings dominated father's death in 1808 until 1828. The MerinaMadagascar island up to the French occupation in 1895. 26, 1960. Between independence and 1990 France on June

\footnotetext{
${ }^{136}$ Draws on Mervyn Brown (2000) A

the former British ambassador to Madagastory of Madagascar. Mervyn Brown is culture and history, this is a very informative book.
1,3 It is thought that the interested in Malagasy

because of their isolation, lemurs, nowadays only found in Madagascar, survived aggressive animals. 138 Unfortunately for Madagascar, Radama's mother took over after his early
death at 36 years of age, and instituted a very harsh regime which
contributed to depoputa contributed to depopulating Madagascar bery harsh regime which considerably executions and starvation.
} 
from a modestly socialistic republic under the first President Tsiranana, from 1960 to 1972 , to a Marxist regime under Didier Ratsiraka, 1972-1992. The latter received strong support from the Soviet Union. After 1992, Madagascar returned to a more democratic regime with the change in power to Albert Zafy. The democratic trend continued even with a second term of Didier Ratsiraka. Marc Ravalomanana, a Merina businessman came to power mid-2002 after a political stand-off. Political tensions between the two main ethnic groups in Madagascar remain, and influential appointments to high level positions in the administration are often subject to a divisive Presidential confirmation process that can create many tensions.

Political support for Marc Ravalomanana rose during 2000 and 2001. Mr. Ravalomanana was the Mayor of Antananarivo, and in that publicly visible position he showed not only strong support to anti-corruption policies, but also managed to get tangible results. Under his mayor-ship between end of 1998 and 2001. Antananarivo was cleaned up and local small business development was visible. His election to the Presidency in 2002 was a response to the widespread concern about corruption and reform fatigue in Madagascar under Didier Ratsiraka. Marc Ravalomanana clearly won on an anti-corruption platform, and he continued on this track after taking office. The 2002 political and economic strategy of the new Ravalomanana Government is centered on three pillars: (1) restoration of the rule of law and strengthening of governance; (2) economic growth; and (3) human development and social protection. The strategy is consolidated in the Poverty Reduction Strategy Paper which was finalized in $2003^{139}$. However, tensions between the ethnic groups remain, and are especially felt in the relationship between the two highest levels in the country, the President and the Prime Minister. The political system in Madagascar is based on a French-inspired system ${ }^{140}$. These tensions also had implications for the nutrition policies and implementation of the programs.

${ }^{139}$ For details on the Malagasy PRSP see Box 9.3

${ }^{140}$ The President is elected through general elections for a mandate of five years and the president appoints the Prime Minister. The Prime Minister heads the and the president appoints the Prime Minister senate for government actions.
cabinet and is held accountable by the senate mandate of five years. The
Parliament is elected in general elections for a mated and one third senate, responsible for judicial matters, is for two thirds elected and one third appointed by the President. 


\subsubsection{Madagascar Economic Growth, Decline and Poverty}

Madagascar is a potentially rich country, but has experienced economic decline and a deterioration of public service delivery almost since its independence in 1960 from France. It is ranked among the 20 poorest countries in the world. Average income fell by about one third in real terms between 1960 and 1999 , from US $\$ 430$ in 1960 to less than US\$250 in 1999. This weak economic performance is largely the result of poor nationalist policies, stressing self-sufficiency and extensive state-interventions that were adopted in the $1970 \mathrm{~s}$ and 1980s. In 2004, about $70 \%$ of the population is poor (Paternostro $\left.2001: 1^{141}\right)$. In the rural areas, where more than $4 / 5$ of the Malagasy population lives, the poverty rate is $80 \%$.

Immediately after independence in the 1960 s

Madagascar's economy grew modestly, but it stagnated during the early 1970s, and deteriorated after 1980. In 1988, the country started reversing the nationalist policies of the 70 s and $80 \mathrm{~s}$, and focused on price and trade liberalization. It was thereby supported by the structural adjustment credits of the World Bank and the IMF. Between 1988 and 1990 there was positive economic growth for the first time in two decades. However, the political liberalization coincided with political unrest and general strikes between 1991 and 1993 against the Ratsiraka regime. The instability hindered government and commercial activity, and resulted in a drop in GDP. Private investment had been increasing, but the political turmoil basically wiped out much of the gain made in during the 1988-1990 period. Although a new democratically elected government was installed in 1993, tensions within government and between government and parliament continued to block economic reforms until the mid1990s.

In 1993, the new government succumbed to political pressure to reduce taxes and finance government expenditures, which resulted in high inflation rates, and deteriorated performance in the social sectors such as health and education even further. In 1996, the government managed to stabilize the macro-economy and attract new investments. It had also returned to the second term of Didier Ratsiraka, after Albert Zafy's government has done little to improve the highly anticipated policies to reduce poverty among the Malagasy. In 1997 there was a 1 percent real increase in GDP, and inflation

\footnotetext{
14 This paper examines three household datasets from 1993,1997 and 1999 to examine changes in poverty in Madagascar over that period. The report addressed the question whether the observed changes in poverty are consistent with changes in other indicators of well-being including nutritional outcomes.
} 
was reduced to single digits for the first time in 18 years (Paternostro 2001:3).

Between the mid-nineties to 2001 economic growth was stable at about $5 \%$ annually, a growth period not experienced in Madagascar since the 1960s. However, political instability flared up again a decade after the first one, as contested presidential elections in December of 2001 led to a 7 -month standoff which resulted to reductions in trade and economic activity. GDP contracted by about $12 \%$ in 2002 .

In addition to dismal economic growth, over time productivity assets were distributed unequally and access to economic opportunities were heavily skewed to the richest quintile in both urban and rural areas. According to surveys carried out in 1989 in the capital Antananarivo, the Ginicoefficient $^{142}$ was close to 0.800 , which signifies extreme inequality. According to the same study, the top $10 \%$ of the urban population earned over $80 \%$ of urban income. Inequality significantly worsened in Madagascar over the past decades.

Translated into household food insecurity, in 1990 almost $40 \%$ of the Malagasy population is food insecure because their own production, or their purchasing power, is insufficient (World Bank 1993:2). This is unacceptable in a country where overall food production is estimated to exceed the needs by $20 \%$ in the same period. Small scale agriculture households have suffered most from the crises ${ }^{143}$, and according to later studies (Paternostro 2001, Minten et al 2003) have been among the extreme poor during the past decade. Although poverty levels have slightly decreased, the decreases are seen in urbanized areas, but are very slow in reaching the most remote rural areas, where these small scale agriculture households are located.

\subsection{Governance in Madagascar between 1990 and 2004}

Madagascar has faced severe governance problems over the past twenty years, and has repeatedly been ranked among the most poorly governed countries world-wide, but has been making improvements over the last few years. In the $2005 \mathrm{TI}$ anti-corruption index, Madagascar is rated no. 97 out of 158 countries $^{144}$ - after no. 82 out of 145 in 2004 and no. 88 out of

$\$ 42$ Gini-coefficient is an economic measure of income equality. Gini $=0$ denotes a perfect equality; Gini $=1$ denotes perfect inequality, ile. the higher the value the more inequal the income distribution.

${ }_{143}$ Madagascar suffered from crisis of both of political and natural nature.

144 Other countries in AFR which are doing much better include Botswana (no.

32), South Africa (no. 46), Mauritius (no. 51), Seychelles (no. 55), Ghana (no

65), Burkina (no. 70) and Senegial (no. 82). Countries which are rating worse 
133 in 2003. Without improving the functioning of Government and the management of the economy, economic growth would not easily be forthcorning. The new government took office in June 2002 and identified weak governance as the main constraint to reducing poverty. Between 1997 and 2001, despite stable economic growth, poverty had hardly been reduced. The government undertook a wide range of reforms and actions to improve governance, which are described in more detail in the following sections. However, the low rating on the $\mathrm{Tl}$ Transparency index seems to demonstrate that the activities of the Government do not yet have sufficient traction - at least from the perspective of the people who contributed to the $\mathrm{TI}$ perception index (mainly the business community).

The Kaufmann and Kraay governance indices are constructed from 25 different sources, including the TITransparency index, show overall a more positive trend (figure 9.1). The voice and accountability index is fairly stable and positive, with a dip in 2002 , probably due to the political turmoil in 2001/2. Political stability fell sharply between 1998 and 2000 , but is positive again after 2002. Government effectiveness improved gradually to a positive score in 2004. These improvements may be related to the emphasis that was given, and promoted by all development partners including the World Bank, to Madagascar's public sector reforms. Regulatory quality also shows an improving trend with a positive score in 2004. There appears some evidence of this improvement in the increase in foreign investments in Madagascar, however, private investments in Madagascar, or total foreign domestic investment
(FDI) ${ }^{145}$, remains very small compared to other developing
countries.

The rule of law and control of corruption indices show the government's efforts to reduce corruption and rent-seeking were perceived by the population as successful, but this has changed in 2004. As shown in graph 9.1, control of corruption improved 2004 the rating is back and even became positive. However, in independent anti-corruption buro. The GOM established an independent audits, which are regureau (BIANCO) and instated

\footnotetext{
than Madagascar include Eritrea, Zambia, Zimbabwe (no. 107), Uganda (no 117). Cameroon, Ethiopia (no. 137), DRC, Kenya (no. 144). At the very end of
the scale are Bangladesh and Chad.

development increases interest from foreign investors to invest in domestic investors are interested in two main factors in markets, banking system. Foreign make in the foreign country than in their - how much more money they can investments and how easy it is to take their own or where they currently have
} 
Figure 9.1: Kaufmann and Kraay Governance Indices between 1996 and 2004 in Madagascar

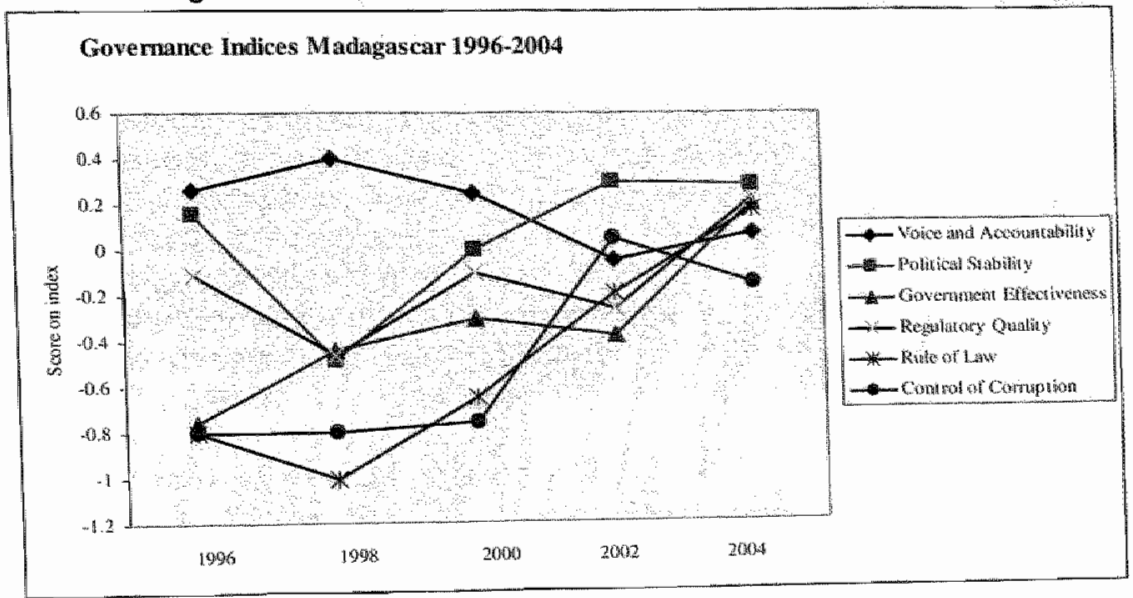

Table 9.1: Kaufmann and Kraay Governance Indices between 1996 and 2004 in Madagascar

\begin{tabular}{|c|c|c|c|c|c|c|}
\hline $\begin{array}{l}\text { Indlcator of } \\
\text { Governance }\end{array}$ & 1996 & 1998 & 2000 & 2002 & 2004 & Measures: \\
\hline $\begin{array}{l}\text { Voice and } \\
\text { Accountability }\end{array}$ & .26 & .40 & .25 & -.05 & .07 & $\begin{array}{l}\text { Measuring political witl } \\
\text { and civil and human } \\
\text { rights }\end{array}$ \\
\hline $\begin{array}{l}\text { Political } \\
\text { Stability }\end{array}$ & .16 & -.48 & 0 & .3 & .28 & $\begin{array}{l}\text { Measuring the likelinood } \\
\text { of violent threats to or } \\
\text { changes in government }\end{array}$ \\
\hline $\begin{array}{l}\text { Government' } \\
\text { Effectiveness }\end{array}$ &. .76 & -.44 & -3 &.- .38 & 0.2 & $\begin{array}{l}\text { Measuring the } \\
\text { competence of the } \\
\text { bureaucracy and the } \\
\text { quality of ptiblic service } \\
\text { delivery }\end{array}$ \\
\hline $\begin{array}{l}\text { Regulatory } \\
\text { Quality }\end{array}$ & -.11 & -.46 & -.1 & -.26 & .22 & $\begin{array}{l}\text { Measuring the incidence } \\
\text { of market-untriendly } \\
\text { policies }\end{array}$ \\
\hline Rule of Law & -.8 & -1.0 & -.65 &. .19 & .17 & $\begin{array}{l}\text { Measuring the qually of } \\
\text { contract entarcement, } \\
\text { the pollice and the court } \\
\text { as well as the likelihood } \\
\text { of crime and violence }\end{array}$ \\
\hline $\begin{array}{l}\text { Contral of } \\
\text { Corruption }\end{array}$ & n.a. & -.8 & -.76 & .05 & -.15 & $\begin{array}{l}\text { Measuring the exercise } \\
\text { of public power for } \\
\text { private gain, including } \\
\text { both petty and grand } \\
\text { corruption }\end{array}$ \\
\hline
\end{tabular}

Source: Kaufmann D. and A Kraay, Governance Matters III and IV. 2004, 2005.

In the following section more detalls on how the Government of Madagascar addressed the governance since the 1980 s are provided. Before the 1990s, there was less emphasis on governance and as a result little specific information is 
available. Following the public recognition that poor governance laid at the root of the lack of progress in development in developing countries, the donor community, including the United Nations, the European Union, World Bank, IMF, and USAID in Madagascar emphasized the need to improve governance. Starting in 1998, the emphasis was placed on the Government itself to lead a participatory poverty reduction strategy development, following the guiding principles of the PRSP. process. Despite the political crisis that broke out in 2002, following contentious elections, the last five years have seen improvements in several areas of governance as well as country ownership of its development agenda.

\subsubsection{Early 1990 s -1997}

In the late 1980 s and early 90 s, the GOM recognized that the economic decline was largely due to inappropriate economic policies. Between 1978 and 1980 , the GOM had embarked on a massive public investment program, which led to a large fiscal deficit, inflation percentage of up to $30 \%$, built up external debt, and left the country with a lower GDP per capita than at independence in 1960. Although between 1980 and 1987 policyreforms were put in place and the fiscal and external debt situation improved, due to exogenous factors as world-wide economic instability and uncertainty, the results of the reforms in Madagascar were disappointing. A larger segment of the population lived in poverty and had insufficient income to meet its basic needs, as reflected in the high malnutrition and mortality
rates in the 1980s.

In the early 1990s, with World Bank support the GOM developed a program to address government effectiveness with public sector reforms as budgetary quality improvements and expenditure management. The World Bank at that time supported primarily public sector reforms and focused less on the private sector. It was also the era in which the World Bank implemented structural adjustment and included safety nets to mitigate the negative impact of the structural adjustment for the poor. As a result, in addition to the support from the World Bank to the public sector reforms, there was attention to develop a community-based malaria, family planning, and food-security
program under which the earlier mentioned malnutrition
reduction pilot project was included. reduction pilot project was included.

In 1996, the strategy for public sector reform, which had modernization and strengthening of public services as the cornerstone of its action program, was published. The program
called for more effective government by increasing transparency 
and rationality in budget allocations, improved programming, monitoring, and execution of expenditures and the introduction of new methods of management. Training and a number of reforms, including civil service reform and establishment of an oversight committee for program implementation were proposed in order to achieve these goals. Decentralization was very high on the agenda in the Government's strategy on public sector reform in 1996. And last, legal and business law reforms were proposed with the objective to improve rule of law. The World Bank supported the government's strategy with a Public Management Capacity Building project (also in 1996), which included a detailed monitoring plan with regards to the strategy.

\subsubsection{Changes in governance between $1996-2004$}

Accountability for government actions improved during this period. In order to make the budget-process more transparent, program budgeting was introduced. Budget programming allows the linking between government policy priorities and budgetary allocations ${ }^{146}$. Although progress was made, the actual implementation started only in 2004 and most sectors are currently experiencing a learning period. In terms of more building accountability to the poor, between 1996 and 2003 , the capacity of the national statistics office was strengthened. It increased its capacity to produce reliable data to evaluate the results of the new reforms and policies, which have a pro-poor orientation. Household surveys to monitor changes in living conditions were carried out beginning in 1992, and were carried out on a more regular basis thereafter.

Although pre gress was made since 1997, in 2003 there is still no clear system in place which allows policy, planning, service delivery, and public investment management to be linked. The initial improvement efforts focused largely on datacollection and analysis but less on use of data and results in policy-dialogue. This is also linked to the problems encountered with budget programming, which concerns trying to link policies with budget allocation and spending.

146 Each program consists of detailed objectives, related activities and expected results. The system allows program managers greater flexibility in moving resources between categories of expenditures and as carry over budget possibilities. The latter is done on the basis of a joint decree between the Minister of Finance and the sector minister. The implication of sector ministries in the preparation process for the new budget improved over time. By simplifying expenditure management and by advancing the timetable for the preparation of the budget, so that sector ministries could better align with the budget process, the Government facilitated the process. 
Political accountability in Madagascar is made difficult by the delays in functioning of the budgetary control that is usually only possible years after the budget has been spent. There is little opportunity for remedies or adjustments. It is the executive that is largely in control of decision-making, while the parliament has a weak voice, due to not only weak capacity but also to very limited governmental communication mechanisms. For example, only in 2004 were parliamentary members getting access to internet and computers in their offices.

Several actions have been taken to improve transparency in the bureaucracy and to reduce corruption. Since 2002, the increasingly important role of the legis/ative in overseeing and monitoring poverty reduction increases the checks and balances in government. Also in 2002, the new government was quick to establish an Anti-Corruption Commission and the anti-corruption bureau (BIANCO) in charge of implementing the anti-corruption strategy as was promised during the election campaign. BIANCO is independent and the results of its investigations are transmitted to the Ministère Publique. The Director General of BIANCO is protected from any sort of intimidation or political pressure. The World Bank provides financial support to ensure the bureau disposes of adequate financial and material needs to accomplish its mission independently.

The legal system itself has been strengthened with the training of new judges and improved training of magistrates by opening a new school. In general, Madagascar has made steady progress on the anti-corruption agenda; an anti-corruption commission was established in 2002; awareness about corruption was raised; a new anti-corruption law was adopted and made effective in September 2004; new legislation regarding the declaration of assets of higher public officials, the establishment of an independent anti-corruption agency and the regulation of recruitment into the public sector, all were part of the achievements made on anti-corruption in 2004.

In terms of government effectiveness, the emphasis on strengthening the public sector has had some impact. The public expenditure review (PER) ${ }^{147}$ carried out in 2004 reports encouraging improvements in the public finance reform domain. Strong technical capacity has been built in the Ministry of Finance, which led to improved information availability about actual spending. Between 1997 and 2001, the GOM simplified and modernized the budget-system and accounting system. A

\footnotetext{
${ }^{147}$ Public expenditure reviews are carried out to callculate how much is spent on a specific sector and what the annual increases to the sector are.
} 
comprehensive reform of the public finance system started and at the center of the reforms was the computerization and integration of the budget and expenditure system, which before 1997 was not linked. However, as discussed above, the implementation of budgetary programming has only recently started and the capacity is not yet extended to the sectorministries.

\subsubsection{Decentralization}

Decentralization (see box 9.1 for definition) is often thought to be a key instrument for improving governance, and important to the enabling environment to reducing malnutrition. Lower levels of government have an information advantage: they are able to identify cheaper and more appropriate ways of providing public services. But, it has to be realized that decentralization in a country such as Madagascar is difficult given the lack of required financial and administrative capacity.

\section{Box 9.1: Definition and Modalities of Decentralization}

\section{Definition and modalities of decentralization}

Decentralization deals with the transter of authority and responsibility from the central government to subordinate of quas/-independent government organizations or the private sector it can take several forms: i) Deconcentration is the transter of clearly specified decision-making, financing, and management functions to local line agencies, which depend directly on central government ministries, for example ministry of health transferting authority to district level health officials, 1) Delegation is the transfer of decision-making authority to semi-autonomous organizations, which are not completely controlled by the central government, but ultimately accountable to It, For example the Ministry of Health dividing service dellvery and policy-making and delegating service delivery to a separate semi-autonomous agency, In Devolution ts the transter modality nearest to decentralization, the transfer of authority and decision. making power to legally and politically autonomous sub national governments: For example, the Ministry of Health transfers authority 10 local municipalitles.

The Malagasy territorial administration comprises five main levels: provinces (6), regions (22), districts $(111$, and the key level of deconcentrated social service delivery), communes (1395), and villages. Madagascar's public administration is highly centralized, as many are in Francophone Africa. One of the new Government's mantras is 'bring government closer to the people', and it has made progress in establishing communes, yet these communes remain the only operational level below central

${ }^{148}$ Ghana Health Services is a good example of such a delegation. Ghana Health Services is the service delivery agency of the Ghana Ministry of Health. 
government. In addition, the reality is that budget-wise the central government receives about $96-97 \%$ of the budget, and the communes together only receive 3-4\% (Public Expenditure Review 2004). Budgetary control and decision-making remain firmly concentrated at the centrall level.

The main argument for decentralizing expenditures is based on the concept of information advantage and allocative efficiency (Bardhan 2002). Local agents can often identify more efficient, cheaper, and more appropriate ways of providing public services. So, by giving the local governments more decisionmaking power and having the local constituency, resources would be available more quickly and flexibly. Using this argument, decentralization is beneficial also for nutrition service delivery. The fact that decentralization is limited in Madagascar is a disadvantage for malnutrition reduction, which is very community-based and for which local participation is key.

The most notable achievement of Madagascar's decentralization polices to date was the establishment of 1392 communes in 1995. In 2004, the communes represented the only effective and viable layer of decentralized government (World Bank 2003), and thus there remain challenges regarding decentralization in Madagascar. A major challenge for decentralization in any developing county, but in particular in Africa and Madagascar especially, is the fiscal gap. This is the mismatch between increasing expenditure responsibilities and insufficient generation of own revenues. In Africa, the revenue base, measured as the revenue-to-GDP ratio, is particularly low. Government revenues reach barely $26 \%$ of GDP in SSA. In the poorest countries, among which Madagascar is included, this is only 18\%. In Madagascar during the 1990s, this was even below $10 \%$, and has only slowly starting to increase since 2000; in 2003 it was 12\% (Fengler 2003:19). There is little capacity at the lower levels and there is a weak legal system, which should be strong to provide support. And finally, since the process is ongoing and fairly recent, there remains a lot of confusion between the roles and responsibilities for each of the decentrallized levels. For example it is not at all clear how the mayors and the regional chiefs are interacting, and who is responsible for what. The mayors are elected and the regional chiefs appointed by the President, however, the latter would also be elected come the next round of local/regional voting.

There are clear signs of improving trends in governance in Madagascar. The Kaufmann and Kraay indices visualize this. Also, the more detailed review of the processes as discussed in this section shows that Madagascar is in the process of improving, but also that much remains to be done. Although 
steady progress was made since the mid-nineties, with exception of 2002 with the political stand-off, the governance situation is better over the last five years. Voice and accountability is reasonably stable, but all other indicators have improved. The changes offer an opportunity to review possible influences of governance elements on the nutrition situation, which will be described in the next section, following the same periods.

\subsection{Malnutrition in Madagascar: Government Response and PA-Nutrition between 1990 and 2004}

\subsubsection{Early 1990 s to 1997}

Chronic food insecurity, combined with poor health conditions and lack of attention to prevention, has led to very high malnutrition rates in Madagascar. Although no comprehensive nutrition surveys were carried out before 1987. local surveys and clinical observations made it evident that child malnutrition was of major concern.

Before the late 1980s, little attention was given to malnutrition as a specific problem that should be addressed in addition to economic growth and improved food security. Malnutrition policy in Madagascar evolved similar to the international evolvement of thinking about malnutrition. In the 1970 s and 80 s, malnutrition was thought to be predominantly a consequence of food insecurity and by improving food production and economic growth, malnutrition would be reduced. Prior to 1992, nutrition actions with the objective to reduce chronic malnutrition and underweight were very limited in size and scope. Little, if any, political attention was spent on the issue, very small budget allocations were made to it, and leadership to take the issue forward was non-existent.

Nutrition actions were heavily compartmentalized by subsector between the ministries of Applied Research for Development (MOR), Agriculture, and Health. The MOR was at the time the lead ministry for nutrition, and as a result of their overall mandate of research, actions regarding nutrition focused on nutrition surveillance. The Ministry of Health was engaged in nutrition education and recuperation of severely malnourished children, which dates from 1975, but for lack of funds, the ministry had to abandon expansion plans for recuperation centers (Mulder-Sibanda 2003). At the time, thinking about malnutrition in the international nutrition community was largely dominated by UNICEF and USAID, who at the time were of the opinion that malnutrition was conceptually a health sector 
issue ${ }^{149}$. The focus of the nutrition programs was predominantly on micronutrients, vertical programs, and management of child malnutrition at the district level health-posts.

During the 1990 s the understanding that adequate caretaking of infants, young children and pregnant and lactating women, as well as the significance of appropriate feeding practices were as important to improving malnutrition as improving household food security and access to health services, took hold. Also, Madagascar recognized malnutrition as a multisectoral development problem, and it became clear that more than vertical health sector programs were needed to effectively reduce malnutrition rates. The first official engagement by the GOM in this direction came with the ratification of the Human Rights for Children Convention in 1990. A few years later, in 1992, at the International Conference on Nutrition (ICN), Madagascar, together with 158 other nations, signed the Declaration to eliminate malnutrition.

In the early $1990 \mathrm{~s}$, small scale community nutrition pilots were started. In line with the World Bank's policy to support safety nets alongside structural adjustment operations, the World Bank-supported Economic Management and Social Action Project (EMSAP) included a small research component to pilot community nutrition. This pilot, although not very successful, did lead to increased interest to address malnutrition through community-based interventions. In 1991, the GOM requested the World Bank to finance a larger pilot called the Secaline program (Box 9.2) in the two most food-insecure ${ }^{150}$ provinces of Madagascar, Tulear and Antananarivo. It took almost three years to prepare the project, not for lack of commitment, but due to the $1991 / 2$ political crisis. Commitment to address malnutrition as a multisectoral and community-driven problem remained strong, and continued after a change in government.

UNICEF and USAID, through their partners LINKAGES/BASICS, started around the same time communitybased nutrition interventions to address the very serious malnutrition problems in Madagascar. However, these three main partners in development in the area of nutrition in Madagascar in the second half of the 1990s, UNICEF, USAID and the World Bank, all worked through different implementation mechanisms and with different counterparts at the central government level. UNICEF focused largely on the Ministry of Agriculture, with its community-based interventions, and on the Ministry of Health for

\footnotetext{
149 Levinson in Gillespie et al 2003

important, if not more as forstandings that appropriate feeding practices were as
} 
its micronutrient program support. USAID worked mainly through the Ministry of Health, while the World Bank insisted on a multisectoral arrangement which placed the project's management unit, to support the Seecaline program, under direct supervision of the Prime Ministry. As a result, the collaboration between the project management unit and the two other keyministries, Health and Agriculture, became difficult and fragmented. The line-ministries interpreted the decision as a vote of no-confidence for their ministry and loss of potential resources $^{151}$ to build their programs. This situation did not improve until the early 2000s. Lack of strong leadership for relationship building ${ }^{152}$ and weak donor coordination were important factors in the long duration of this lack of collaboration. Also, the divisions between the international partnerorganizations, and through their support (and hold on) the national partners, were not conducive to a national popular move against malnutrition. Instead, ownership was put at risk, and the efficacy of the projects may have been reduced because of increased and unnecessary transaction costs.

The fact that the national community nutrition program was placed under the Prime Ministry, rather than a line-ministry was justified. The earlier EMSAP project's overall implementation had been hampered by a very weak management structure. Madagascar's overall administration was held back by bureaucratic delays, procurement problems because of cumbersome procedures, and weak managerial capacity. The focus on improving government effectiveness and governance had not yet started.

The decision to place the nutrition management unit outside of the traditional administrative structure was made in order to make it more effective and efficient. This was in line with the thinking then about the management of projects. The creation of special agencies or implementation units allows for the recruitment of professionals at higher salaries, thus attracting the better staff (although often taking them away from the public sector) and the provision of inputs, cars, and computers not available to public sector staff (Grindle 2004:541). Transaction costs were considerably reduced by placing the management of the nutrition interventions in a unit outside of the administration and by contracting NGOs to deliver the services to the communities. However, long term consequences are that no capacity is built at the public sector level, and once a project

151 World Bank resources were considerably more important in terms of dollar amount than the other partner development aid contributions.

${ }^{152}$ Otherwise leadership of the program has been consistently strong. 
closes, the implementation unit ceases to exist. Also, accountability issues arise from these arrangements. Project management may feel more responsible to outside financiers than to the national government, and in return may encounter problems having direct access to decision-makers. The Seecaline project unit encountered at crucial times difficulty to gain access to government and parliament for decisions for which it needed government approval. Ten years later, the World Bank promoted strongly the creation of a national nutrition office which would be responsible for the implementation of the national nutrition policy in order to facilitate sustainability and institutionalization. Although in hindsight, the fact that the project unit was outside the official administration had indeed facilitated rapid responses to crises situation during the 2000 cyclones and droughts and the political stand-off in 2001. The Seecaline management unit could much faster re-allocate funds and redirect its services to include the worst hit areas at the time. 
Box 9.2: Seecaline Community Nutrition Program

\section{Seecaline Community Nutrition Program and World Bank Involvement:}

The Community Nutrition Program Seecaline is designed to help households make more efficient use of the resources avallable to them to prevent chronic malnutrition among their children. It is a large-scale nutrition program that was started in 1993, and gradually scaled up after 1999 to cover more than half of the districts in 2004. The main objective was to improve the nuitritional status of children under the age of three, primary school children, and pregnant and lactating women. The program also aims to ensure the long-term sustainability of nutritional outcomes by improving the quality and quantity of food intake by children at home.

In order to maximize geographical coverage and provide quality services in remote areas, the implementation of the program is contracted out to local NGOs who are in charge of implementation and management of the delivery of services. So-called nutrition sites are established in villages where the community has agreed to elect a community nutrition worker (Agent Communautaire de Nutrition- $A C N$ ) and provide a physical space. Each site attends about 200 children under the age of three, covering approximately a population of 2000 inhabitants within a radius of $5 \mathrm{~km}$ to minimize transport cost for the participants and workload for the ACN. The program is implemented by the ACNs, who are selected by their community and supervised by social workers working for the local NGO. The program revolves around the monthly growth promotion, the interventions focus on preventing malnutrition. The $A C N$ mobilizes the community to raise awareness about malnutrition and engages the commurity to improve nutrition and child-care practices and to improve hygiene.

While the $A C N$ is directly responsible for all nutrition interventions at the center, the NGO-social worker is in charge of promoting community mobilization and developing community-based activities aimed at improving nutrition, hygiene, and sanitation in the village. All children under the age of three are weighed monthly by the ACN, with the assistance of a group of volunteer mothers. The ACN counsels the mothers on the nutritional status of their children, and micronutrient supplements are provided to the relevant agegraups. Children that are malnourished, and those that miss weighing sessions, may receive home-visits and sometimes enter the food supplementation program. Also cooking demonstrations are held where the ACN prepares recipes that make use of locally available sources of food.

Every trimester, the ACN and the social worker discuss with the village community leaders the nutrition situation in the village (based on the evolution of the nutritional status of children), and the likely determinants of malnutrition in their community. The social worker assists the community to identify solutions and design feasible and sustainable activities. The social worker identifies sources of financing for these activities or simall projects. Or he/she assists the community in writing a proposal for small grants to be financed as a last resort from the project. These types of projects typically finance small water works, sanitation activities and improvements to local markets, roads and community gardens.

The school nutrition program, which is strongly linked with the community-based program, prowides school-aged children with an ironsupplement, all school-aged children (enrolled and non-enrolled) with a desupplement, all school-aged children fenrrition aducation, and monitoring of
worming program every six months, nutrition as in the community-nutrition
household use of iodized salt. In addition, as program, small grants are made available to schools for improvements in sanitation, water, school-gardens, and fruit tree planting.

The so-called "Inter-Sectoral Component" finances the management of severely malinourished children in collaboration with the health sector and the development of training materials for the agriculture sector.

Source: Project Appraisal Document Second Community Nutrition Project, 1998 


\subsection{2. $1997-2002$}

In 1997 a new Demographic and Health Survey was conducted and the results highlighted the malnutrition situation was worsering. An economic analysis in the same year showed that almost half a million children would die before the age of five, if the nutritional status would not improve. Around 1998 a program called Profiles ${ }^{153}$, a computer-based nutrition policy analysis and advocacy tool that estimates the consequences of malnutrition on survival and on the three key development sectors (health, education and economy) was introduced in Madagascar. The present value of future productivity losses due to chronic malnutrition occurring between 2000 and 2010 in Madagascar were estimated at US\$255 million dollars, almost 2 billion FMG ${ }^{154}$ (Profiles 2001). The need to do more, and on a bigger scale, was obvious. While the period between 1990 and 1997 was primarily dedicated to starting up interventions and pilots, after 1998 the Government of Madagascar (GOM) and its partners focused on scaling-up.

The success of the salt-iodization program demonstrated that political capital can be built with commitment, coordination, clear management directives, and showing results. The saltiodization program resulted in lowering the prevalence of goitre, the clinical sign of iodine deficiency, from 20.4 percent to less than 9 percent among children nationwide in 1998 (Goh 2001:1). The consequences of iodine-deficiency include mental retardation, and it can be prevented by consumption of iodized salt. The salt-iodization program ${ }^{155}$ in Madagascar started in 1993 with capsule distribution, in 1995 salt-iodization was included, and in 1996 a law on universal salt-iodization was approved.

After 1998, commitment to malnutrition reduction and government ownership grew. Results from the initiatives such as the salt-iodization program, vitamin $A$ distribution, and community-based nutrition programs became known and were presented internationally. Also the costs, as mentioned above, were widely presented. The World Bank prepared the second project to support the Seecaline program and the GOM programmed to scale up to all six provinces in order to achieve

\footnotetext{
159 Profiles is a computer-based nutrition policy analysis and advocacy tool that estimates the consequences of malnutrition on survival as well as three key sectors of development: health, education and economy. Profiles was developed by the US-based Academy for Educational Development (AED) and introduced
to Madagascar in 1999.

154 In 1997 FMG $6500=$ US\$ 1

${ }^{155}$ Largely financed by the first Secaline project
} 
$50 \%$ national coverage over the coming five years. The community nutrition program, Seecaline, was managed by a strong national director " the ex-minister of poverty of Madagascar, who had close political connections. These connections contributed to creating stronger commitment and interest from the Prime Minister's Office and a number of senators for the community nutrition program.

On the other hand, pride and little attention to intersectoral and donor coordination by Seecaline's management led to serious harmonization and coordination problems at the local community level. There was growing competition between several community programs which were being implemented, sometimes in the same villages and using different approaches.

In response to this and other coordination problems, an informal group, the Groupe d'Action Interagencial Nutrition (GAIN) was established in 1997, with the objective to improve coordination between the different programs and groups (Raveloson et al 2001). Despite the fact that this was initially at the initiative of the international community, mainly USAID, the Malagasy nutrition community became more involved and has gradually claimed ownership. Several agreements ${ }^{156}$ and subcommittees have grown out the initiative, but despite these successes, GAIN never enjoyed real authority to coordinate or establish policies because it remained an informal forum.

After 1998, more attention was paid to building stronger accountability mechanisms at the central government level. In 1998 , the technical committee that developed the second Seecaline project to continue financing the community nutrition interventions was to become the advisory and oversight committee on the implementation of the investments and for policy development. The cammittee consisted of representatives of the key-ministries who were to report directly to the Prime Minister and Parliament regarding implementation, budget approvals, audits and high-level appointments. The committee never functioned for a variety of reasons. First, there was little incentive for the representatives on the committee to spend time on the program after the initial preparation. During the preparation, the different sectors included interventions that addressed malnutrition in their own sectors, thereby securing resources for their sectors. During implementation, the relations were more of a sector by sector nature than oversight by multiple sectors at the time. Second, not only the representatives on the committee, but also the management team, had little incentive to

159 Some concrete examples are the harmonization of nutrition education materials and the carte de sante. 
keep the oversight committee involved. The committee was marginalized. There was at the time also concern for possible political pressure from the oversight committee. Although during implementation the direct influence from the Prime Minister and senators appears to have been much stronger, in hindsight this body might have served as a useful intermediary to deflect these influences. In addition, there were a number of very important decisions that would also have benefited from the insights of a multisectoral committee, such as the interventions during the emergencies and the much needed collaboration between the sectors in these instances.

The reliance on NGOs was another sign of the times for the project, which has come under more discussion as the program continued to grow. The GOM and World Bank strategy in the period discussed was to rely increasingly on NGOs and other private organizations with a proven track record in the field for efficient delivery of programs reaching the poorest. This practice was started under the first Secaline program and was evaluated as successful. The subsidiarity ${ }^{157}$ principle supports the decisions of using locally based organizations and national non-governmental organization (NGOs). Current thinking (2004) continues in that direction, following the decentralization policy of Madagascar for putting local communes ${ }^{158}$ in charge of the contracting and building their capacity for monitoring.

In 2000, Madagascar was hit by three consecutive cyclones and suffered serious consequences. The most important export-crop, vanilla, was badly damaged and much needed revenue from exports were reduced. Food-crops were also badly damaged, putting the poorest at risk for malnutrition. As often happens, the crisis put the malnutrition problem higher on the agenda, and the Seecaline management unit was charged with the implementation of a safety-net program; a Food for Work-program. This program was targeted at the same population groups seecaline worked with and had been successfully reaching for years, so this was a logical choice. After the immediate crisis, the safety-net program continued, and was financed using HIPC-funds ${ }^{159}$. There are some interesting

157 The economic principle of subsidiarity states that expenditure decisions should occuir at the lowest level of government that can fully capture the costs and benelits of providing a public service (Fengler 2003:22). The communes in Madagascar have the following competencies: administrative services; management of public domain and economic infrastructure; waste management and public hygiene; social services; security; and development planning.

158 The lowest sub-national governmental level in Madagascar - see more on decentralization in section 4.3 of this chapter.

159 So-called HIPC-Funds are resources available from debt-relief. The resources used to pay interest the donors would now be spent on sociall 
ownership issues to be highlighted here. First, the safety-net program was a government-initiative and was financed with funds under their control (HIPC). It received much quicker and more attention than the original Seecaline program, which was, although initiated by the government, prepared with donorinfluence and externally financed. In addition, Food for Work activities are politically more attractive than interventions such as child growth promotion that emphases behaviors change. On the positive side, the safety-net program did provide Seecaline management with an entry-point to the highest political leveis for both programs.

\subsubsection{2-2004}

Madagascar was among the countries eligible for debt relief and started preparing their poverty reduction strategy (PRSP), a condition to debt-relief, in 2000. In 2003, the final strategy was adopted by parliament. Thanks to the strong awareness building program, Seecaline had become known as a successful program for the poor. Demand from locally elected leaders and community-members for the program in their community grew, and was communicated to the higher political levels ${ }^{160}$. In other words, it appears 'voice' had been created and local accountability from elected leaders started to be demanded.

The first PRSP did not recognize malnutrition as a priority area because the nutrition community had been insufficiently involved in the process, despite all the participatory efforts. However, the environment was open to corrections, and in response to efforts from the Malagasy nutrition community to gain recognition for the problem, the PRSP was amended and nutrition inserted as a priority. The PRSP them identified malnutrition as a priority problem and included a budget for nutrition interventions (box 9.3).

programs - is one of the agreements for debt-relief. The safety-met program Food for Work was one of those programmed financed from debt-relief recourses.

760 In Columbia in the 1970 s the Food Security program continued while the community nutrition program was closed down thanks to political support at the local level for the food security program. The nutrition program in Columbia had invested little in building political support at the community level, while the food security program had done just that and survived the change in governmen (Mosquera in Pinstrup-Andersen 1993). 
Box 9.3: Poverty Reduction Strategy Paper Madagascar and Nutrition

\section{Madagascar's PRSP and Nutrition}

The overarching goal of the Madagascar PRSP is to cut the poverty rate by half in 10 years, from $70 \%$ in 2003 to $35 \%$ in 2013 . Three main strategic axes would lead to this goal: (i) restoring bule of law and a well-governed society; (ii) promoting economic growth with a large social base; and (iii) promoting systems to establish human security and enlarge social protection. The intensification of malnutrition reduction and its determinants as basic health services and food security are embedded under the third stratlegic pillar. Creating an institutional framework of Good Governance to foster fast and sustainable growth and the rate to effectively and iransparently assume its role as driver of the economy constitutes the first pillar.

The PRSP has several strengths and weaknesses. The strategy is very strongly owned by the country. The new government, which took office in 2002 , held a widle consultation process in which all groups of society participated (Country Assistance Strategy 2003 and WB/IMF joint staff assessments), uncluding a former Chief of State, former and current Prime Ministers and Ministers, opposition parties and the donor community. The strategy includes a very comprehensive poverty analysis and it develops a number of scenarios for poverty reduction.

Weak in the PRSP is the realism regarding the costing of the very ambitious growth and poverty reduction programs, with regard to the projected poverty reduction of halving poverty by 2013 . In order to achieve this goal, Madagascar would have to grow at an annual rate of $9.3 \%$ of GDP, with an averagle annual irivestment rate of $24.8 \%$ of GDP. These growth rates far exceed any growth rate seen in the best years between 1997 and 2001. In that period growth was $4.6 \%$ of GDP and investment $15 \%$ of GDP (Public Expenditure Review 2004). Another weakness is that several programs have not been derived from an analysis of why the particular sector in the past had failled. Last, implementation capacity in Madagascar is low, and the implementation of this ambitious program will tax this capacity heavily. The PRSP does foresee training and building capacity, but appears to do so inadequately.

Despite the fact that malnutrition rates were unacceptably high in Madagascar and large scale nutrition programs were being implemented, the interim-PRSP (or the first draft of the finall PRSP), hardly mentioned it. The Ministry of Health $(\mathrm{MOH})$, under which the responsibility for nutrition remained at the time of preparation, considered reducing and preventing malnutrition its lowest ranking priority. The chiel nutritionist at the MOH was obliged to pass by lour hierarchical levels before thaving access to the Minister or histher direct advisors. As a result, tew if any of the efforts to create more awareness about the issue at the highest level ever made it through. At the same time the national nutrition program. Seecaline, was considered a safety met program and not identified as a program contributing to improving thealth indicators.

Coordinated efforts of the management unit of Seecaline, supported by the Prime Ministry, and public demand managed to include malnutrition as a development problem and the results of the community nutrition programs in the tinal PASP in 2005.

Following the PRSP, the subsequent Poverty Reduction Credit (PRSC), supported by the World Bank and the IMF, stated the financing of nutrition interventions as a priority. It had become a general World Bank policy to support countries that were making good progress on governance with budget support 
Chapter 9: Governance and Malnutrition in Madagascar; a Case-study

rather than projects. This was part of the World Bank's operationalization of the governance agenda and to stimulate national ownership and responsibility over the development agenda.

With the decision to support nutrition through budgetary support, the Malagasy government needed to rethink the institutional set up for nutrition. The PRSP and PRSC led to the necessity to upgrade the community nutrition projects to become a coordinated national program and to discuss the institutional arrangements and the institutionalization of nutrition within the Malagasy administration. The decision ten years earlier of making the management unit of Seecaline an independent semiautonomous agency was now called into question. Not only the nutrition sector was faced with this need for institutionalization of the management unit, the education and health sectors encountered the same need. The difference however, was that while the health and education project management units were to be inserted into the existing ministries, the nutrition management unit did not have direct links to a line-ministry, but reported directly to the Office of the Prime Minister.

In 2004, participatory workshops with substantial debates on the changes in institutional arrangements and the harmonized approaches led to the need for a national policy. The National Nutrition Policy (NNP), the first in Madagascar, was elaborated in 2004. Its development was led by a group made up of representatives from the different key ministries and the international partners were involved in technical discussions. There were advantages to the fact that the policy was only developed after a long period of programs in the country. First, experience and polices had matured over the years. Second, there was a genuine felt need and demand for it. It was closely guided and followed from the highest levels in the administration and it had something to report based on results. Third, the NNP is a more home-grown country-led and nationally owned product than the NPAN that was developed in the early $1990 \mathrm{~s}^{161}$, but never validated by a political entity. The NNP was validated by the government in April 2004, only 2 months atter its finalization. A major effort during the development had been made to involve

164 Following the International Conference on Nutrition in 1992, a National Plan of Action for Nutrition (NPAN) was developed and approved by a technicial committes, but not by a politicall entity. The plan never really made it beyond the ech of nutrionists in Madagascar, who were already convinced of the importance and in fact had been involved in developing the NPAN. Although the NPAN called for the establishment of a National Council tor Nuto provide

create awareness, develop policies and strategic developmentize.
oversight for the implementation of the Plan, this did mot materialize. 
local level officials, the newly appointed 'chefs de region', and the newly elected mayors. This led to strong support from the base.

When the NNP was validated, parliament requested it to be translated into programs for implementation. With the approval and demand for implementation, the institutional arrangements - establishing clear responsibilities - for nutrition became important. In order for the government to monitor the National Nutrition policy and to make progress in reducing malnutrition, first a national entity that could be held accountable was needed. Since Seecaline had been successful in implementation and had been actively involved in the development of the NNP, transforming the Seecaline management unit became a logical next step for Madagascar's nutrition institutionalization policy ${ }^{162}$. Similarly, the 'initiating group' which led during 2003 and 2004 the development of the policy and the creation of the National Nutrition Council and the National Nutrition Office were to become the future members of the Council (CNN).

In conclusion, PA-nutrition in Madagascar was gradually built up from a very low interest and commitment level to considerable levels of commitment. Awareness of the malnutrition problem at the community level as well as the build up of demand through dialogue to the higher political levels lay at the root of this increase in accountability for nutrition. Once political interest existed, the GOM took more responsibility and ownership over the nutrition agenda and its programs. The PRSP process and the development of the NNP had a positive effect on the coordination between the donor-agencies in the nutrition domain in Madagascar. Discussion to provide financial support for the National Nutrition Program instead of components of it, and harmonizing reporting back to reduce transaction costs, have been initiated. And last, an important outcome for the nutrition agenda in Madagascar of the NNP is the inclusion of a separate budget-line for nutrition in the national budget so that the CNN/ONN can propose its budget in the annual budgetary discussions. Before 2002, there was no separate budget-line for nutrition in the national budget.

\footnotetext{
${ }^{162}$ This decision encountered strong resistance at first but was later on accepted by general consensus. The entire process had positive effects on the raising of
the nutrition issue in Madaglascar.
} 


\subsection{Investment in Nutrition between 1994 and 2004}

In chapter six, the case was made that with an enabling environment, malnutrition reduction is more likely to be addressed as a development problem. As a result, it is expected that governments will improve budget allocations to nutrition programs in order to reduce high malnutrition rates. As shown in this case-study, the enabling environment in Madagascar for malnutrition improved since 1996, and PA-nutrition was built. In the following, the investments and expenditure-levels on malnutrition reduction in the same period are analyzed.

Investments in nutrition interventions to reduce the very high levels of malnutrition started in the 1990 s with UNICEF, WFP, internationally and locally-based NGOs, and a World Bank supported loan which included a large nutrition component in support of the national Secaline program. Although the national government invested in nutrition before the $1990 \mathrm{~s}$, the amount was minimal and the budget only covered staff costs of a small unit at the central level only and some operational budget.

Collecting information on expenditures for malnutrition reduction is a challenge. Because of the multisectoral character of the interventions, they are not located in one ministry or institution. Many institutions spent resources for nutrition services. Also, the expenditures are often small, ill-defined, and need to be derived from larger budgets. A final challenge is that they are often, as is the case in Madagascar, financed by external donors and resources and therefore are not part of public accounting. Data on disbursement forecasts from World Bank supported nutrition and PRSC projects and programs are available and shown in graph 9.2. After 2004, data from the national Finance Law is available, thanks to the fact that Madagascar included a budget-line for nutrition in their national budget. Before 2002, this was only a line for the small percentage of national budget that was co-financing the externally supported nutrition programs.

Budget allocations to nutrition supported by World Bank financed credits grew steadily between 1994 and 2004. The investments follow a similar trend to the build-up in PA-nutrition, which peaked after 2002. An interesting peak is seen in 2005 just after the approval of the National Nutrition Policy and subsequent demand from government to propose programs to implement the policy. At that time, an allocation of US\$23 million was approved for nutrition in the national finance law. This was more than double the amount of the year before. It was also the first year that nutrition would be financed using budgetary support. It can be seen as an important sign of commitment from 
government to continue with nutrition programs and allocate adequate budget.

Graph 9.2: Investment in nutrition with World Bank support between 1994 and 2006 in million of dollars

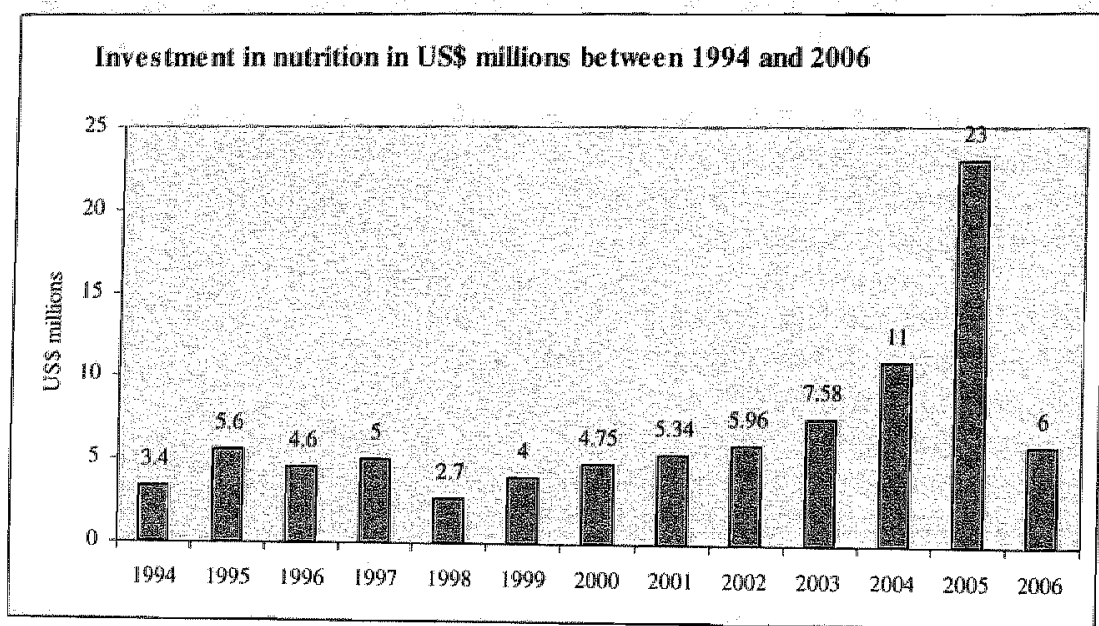

Source: World Bank project documents - disbursement forecast and PRSC I and II documents

However, in practice, even though budget has been approved and finance laws enacted, the budget execution depends on available resources. Although nutrition had been allocated US $\$ 23$ million in 2005 , in reality it received only part of this, a third of the funds were transferred to the CNN/ONN and its program management office late in the calendar year of 2005 . Of the resources that were allocated in the finance law 2004, only $20 \%$ was eventually transferred. Both years, Madagascar's macro-economic projections were overestimated which led to fiscal deficits and unavailability for resources for the lineprograms. So, even though budgets are approved, this is not necessarily a guarantee for resource availability. In fact, the level of unpredictability of funding is high in Madagascar in most sectors, including nutrition, health, and education, and is an important factor in the ineffectiveness of government delivery of
services.

The year 2005 was a very difficult year economically for Madagascar, with the increases in oill and rice prices, rice being the staple food of the Malagasy, and the loss of food-crops to cyclones in 2004. These factors help explain the unforeseen fiscal deficit with had serious negative consequences for availability of recourses. Provisions for 2006 are far below the needs, and show a decrease in support for nutrition. This may be 
explained by lower general revenue availability, but also a decrease in support, although all social sectors in Madagascar suffer from a decrease in budgets.

\subsection{Malnutrition in Madagascar Improved}

Despite the variable allocations and expenditures for malnutrition reduction, the Seecaline program has been able to make impact. An important factor has been the stable and predictable input of resources through World Bank investment. This is becoming particularly clear now that the program is depending more on national budget support, resources that, although promised, are not transferred. As a result, the program faces major constraints to keep its activities going. Long term implementation of these types of programs is crucial for sustainable results.

Between 1992 and 1997, malnutrition in Madagascar continued to increase. Between 1998 and 2004, the trend in underweight malnutrition was reversed and reduced by 5 percentage-points ${ }^{163}$. In the areas where the nutrition program was implemented - in $40 \%$ of the countries poorest regions underweight was reduced by 8 percentage-points, from 43 to $35 \%$ (Galasso 2005). This is more than $1 \%$-point annually, which is comparable to the Thailand achievement. On average, the Seecaline program reduced underweight malnutrition by $20 \%$ in the actual nutrition sites after a two-year implementation period (Galasso 2005:17).

Regarding the progress made on the MDG nutrition indicator - halving underweight malnutrition by 2015, Madagascar has reversed the negative trend as well as accelerated progress. Graph 9.3 shows that with an increase in investment, the target may be more likely to be achieved. The GOM is aware of this achievement and has allocated double the resources for malnutrition reduction in 2005. However, as discussed in section 9.5.2, the allocated resources are not transferred, causing major implementation problems.

163 The DHS-2004 shows very marginal improvements in underweight malnutrition over the same period. The data here presented are part of the malnutrition over the same period. The data her 1998 and 2004 and data-collection
impact studies that were conducted between 1998 in
was carried out over the same period in both years in order to reduce seasonal 1997 and DHS 2004 data collections were not carried out in effects. The DHS 1997 explain the difference in results. The 2004-data collection the same season and explain the lean season and shows very high levels of acute malnutrition that drive up the underweight indicator. 
Box 9.4: Millennium Development Goals - Trend on Nutrition and Estimated Progress with increased investments

Madagascar: Estimating Trands towards MDG of halwing Underweight Mathutrition by 2015

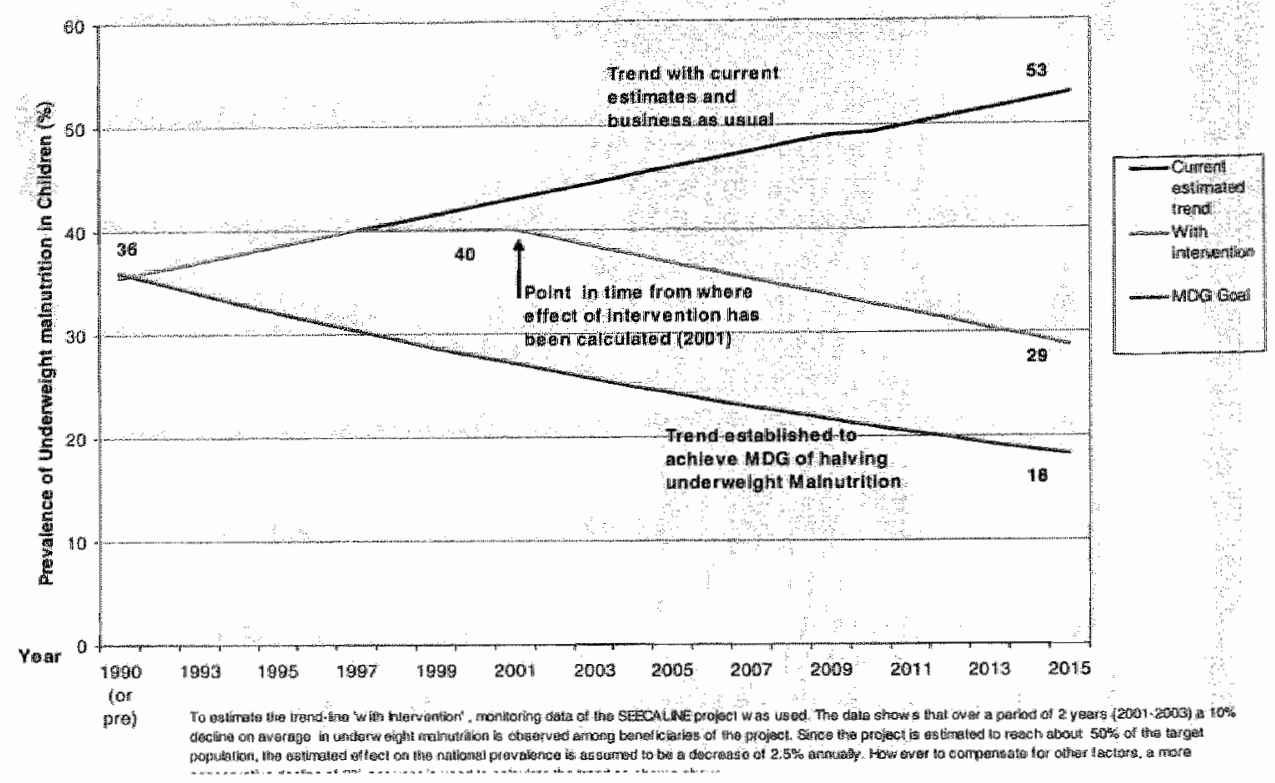

Source: Peproduced from supervision reports

\subsection{Discussion and Conclusion}

As described in detail in this chapter, several periods of changes in governance, building up of public accountability and evolvement in investments and outcomes in malnutrition can be distinguished in Madagascar. In the first half of the 1990s, when governance became recognized as a crucial factor in development, Madagascar focused on public sector management primarily. Malnutrition rates were very high and little attention was given to the issue. External assistance made efforts to bring malnutrition as a development problem to the forefront and started providing assistance to different government agencies and implementing small pilots.

Although the assistance was fragmented, small, and largely uncoordinated in the earlier part of the 1990s, it did bring nutrition to the attention of decision-makers at high political levels in Madagascar. Development assistance to reducing malnutrition grew over the years, but remained fragmented and uncoordinated. In the meantime, corruption and government effectiveness and providing voice to the poor started to being discussed with government. There is a marked improvement in 
governance after 1998. The governance indices, except for voice and accountability, which remains fairly stable, all show improvements after 1998. PA-nutrition was built up over that period as well, especially at the community level. The Seecaline program became widely known, and subsequently demand grew at the local level and was voiced repeatedly in parliament by senators representing their regions.

In 2002, the decision to support Madagascar with budgetary support was an important step towards ownership over the development agenda and application of the principles of good governance. The results of the focus on more pro-poor development are apparent in the way malnutrition reduction is included in the poverty reduction strategies. The nutrition projects became a national program, and institutions with the mandate to reduce malnutrition were created. Investment levels increased and impact evaluations show that underweight malnutrition has decreased since 1998.

Various governance factors appear to have contributed to the increase in commitment and PA-nutrition over the period between 1997 and 2004. First, the awareness of high-level government officials and parliamentarians grew over the years, in part because of the PRSP process which focused the attention on poverty-reduction. Malnutrition is a condition that is proportionally higher among the poorest. In addition to the PRSP-process, new data on what can be done to reduce malnutrition and what works in Madagascar became available. The very strong constituency built at the local level and given voice through the NGOs and the locally elected Commune leaders or mayors has been very important and remains so for sustainability. It may help to prevent a downfall of the program for lack of local commitment as happened with the national nutrition program in Colombia when a government change took place $^{164}$.

The improvement in government effectiveness through public sector management reforms coupled with the pro-poor focus of the PRSP development process provided a much better environment for malnutrition to be financed and nutrition services delivered. The introduction of program budgeting in Madagascar appears to have been advantageous for malnutrition reduction. It made the creation of a separate budget-line necessary and it obliged program managers to apply the government's procedures (and not the donors) as well as gave them a place at the decision-making table.

${ }^{154}$ See chapter 1 - reference Mosquera in Pinstrup Andersen (1993) 
The National Nutrition Policy calls for an extension of the Community based Nutrition Program. The program has clear objectives, budgets and results. Before program budgeting, the budget for nutrition interventions would have been divided between several sector ministries, each of which has different priorities before malnutrition reduction. As a result, malnutrition reduction often fell through the cracks and did not get adequate budget. In 2004 and 2005, under program budgeting and with the recognition of nutrition as a program based on a national policy, the nutrition program was allocated more budget per capita then in any precedent year with external funding.

However, the program did not receive the entire amount of funds that were allocated. This clearly shows the importance of integrating malnutrition into the government agenda, budgeting for it, and gaining access to decision-makers. It also shows that building PA-nutrition is not enough; sustaining it is crucial. True commitment, as defined by Heaver, was to act and keep acting until the job is done. Those making decisions regarding financing and allocating the state budget have to be convinced too.

Although the period reviewed in this study does not go beyond 2004, the latest developments in the nutrition domain in Madagascar in 2005 do illustrate the fragility of PA-nutrition, and how easily it can be lost if governance and its influence on the enabling environment for nutrition can have a negative impact.

Latest developments In 2004, also the Office National de Nutrition (ONN), the National Nutrition Agency was established, concluding the institutionalization of nutrition in Madagascar. The ONN is directly placed under the Prime Ministry, as was the implementation unit of SEECALINE, and reports to the CNN, which is chaired and led by the Prime Minister. Although this has been a very positive development in Madagascar, recent poor governance decisions have made the ONN a less functional Office than it could have been and may be in the future. The ONN is managed by a National Coordinator whose function it is to coordinate the implementation of the NNP, the coordination among the stakeholders and implementers of nutrition programs, as well as overall donor coordination in the nutrition domain.

At the time of upcoming elections, the nomination of the National Coordinator for Nutrition in Madagascar was influenced by political interests. Headed by a politically appointed person, the ONN did not take its coordinating role as described, but instead focused on centering the programs towards more politically motivated actions. This led to instability within the program management team and put the carefully built up donorcoordination at risk. Confusion and instability about rolles and 
responsibilities between coordinating and execution agencies resulted in implementation problems and a stark reduction in implementation coverage.

At the time of the writing of this case-study, the Prime Minister of Madagascar confirmed the government's strong support to continue the successful interventions and to govern the program transparently ${ }^{165}$. The local level implementers are organizing themselves into associations who became important forces in the struggle to keep the program and maintain its achievements. It may be that the efforts to create "voice" over the years at the decentralized levels become even more important factors in the efforts to continue the successful implementation of the nutrition programs in Madagascar.

${ }^{165}$ In an editorial in the Lancet of The Lancet, Volume 366, Issue 9502, 10 December 2005-16 December 2005. Pages 1988-1989 Macky Sall, Prime Minister of Senegal and Jacques Sylla. Prime Minister of Madagascar confirm their commitment to reducing malnutrition. 


\section{Chapter 10: Conclusions and Discussion}

Malnutrition is a serious development problem that is insufficiently addressed in development policy. In the new Millennium, the combined attention to achieving the MDGs, of which malnutrition reduction is one, and the development policy attention on good governance, may change this picture. The likelihood of that was tested by analyzing whether there is a statistical correlation between indicators of governance and malnutrition outcomes and what key-elements of governance particularly influence the attention given to malnutrition reduction - public accountability for nutrition.

\subsection{Introduction}

The evidence base regarding the immediate and underlying causes of malnutrition, inadequate food intake, disease, access to food, caring practices and access to health and clean water, is fairly large. The research base regarding the influence of basic societal causes to malnutrition, the lower part of the UNICEF conceptual model on the causes of malnutrition (figure 2.1), is very small. This study concentrated on the lower part of the model by taking a closer look at how governance influences malnutrition reduction.

It is important to gain a better understanding for the influence of governance on mainutrition because general development assistance theory has made the promotion of the principles of good governance its dominant theory. The largest development agencies, such as the World Bank and IMF, have adapted their lending policies and way of doing business to operationalize good governance. At the same time, malnutrition is among the most devastating development problems in the world today, showing very little improvement over the last decades and receiving little attention. As depicted in the UNICEF causal model, governance ultimately influences mainutrition outcomes, so the main concern underlying this study is the uncertainty about how this influence of good governance as the dominant development policy on malnutrition may play out.

\subsection{Theoretical considerations}

The first research question addressed is why mainutrition is a development problem and why it is a public sector responsibility. Malnutrition is an important development problem because it affects young children and has a long-term negative impact on their health, cognitive development, and productivity. It 
is costly in human, social and economic terms. Despite efforts to address malnutrition in the past 40 years, prevalence remains unacceptably high. Almost one third of the world's children are suffering from malnutrition. Progress is very slow and it is unlikely that the Millenrium Development Goal for nutrition, halving underweight by 2015 , will be achieved without a substantial increase in attention and resources to nutrition. One of the first questions raised in this study is about who should be addressing it.

That malnutrition reduction is a public sector responsibility can be justified by several arguments, including the public goods and human rights arguments, as explained in more detail in chapter seven. Good nutrition leads to higher welfare, a utilitarian argument. Reducing mainutrition reduces costs otherwise spent on health care because children that are malnourished are more likely to become sick and will need medical attention. A number of nutrition interventions fall in the category of public goods, which justifies public financing of nutrition interventions. And lastly, as a basic human right, malnutrition prevention and reduction should be a role for the state. That governments should take action has been assumed a responsibility, but within government it has been much less clear which sector should do this. Among others issues, this lack of clear responsibility has contributed to the neglect to address malnutrition. Although no one would disagree with its importance, there are few that will stand up and take it as their task and mandate to carry the malnutrition reduction flag forward.

The second broad theoretical question raised concerned the evolvement of development assistance, and how malnutrition did or did not figure in the broader debate. It was argued in chapter four that the time might be right for malnutrition to get a better place on the development agenda and for governments to address it more seriously and effectively. In the 1970s, overall development assistance focused on reducing poverty and basic human needs. At the same time, the link between malnutrition and poverty became clearer. However, development assistance remained rather supply-driven "and the nutrition community did not have the experience it has today about the type of programs that work and what is needed in the environment to make it work. The 1980 s is considered a lost era for development in general, but the 1990s have put poverty back on the agenda. Also regarding nutrition, much was learned in the last decade of the $20^{\text {in }}$ century. The new millennium offers hope for malnutrition reduction through the combination of good governance as the dominating development policy, coupled with renewed commitment to reduce poverty through the MDGs. 
What is good governance and how could it potentially contribute to reducing malnutrition was the last of the theoretical research questions in this study. Good governance puts the responsibility for development back to national governments, which demands commitment. Without commitment to malnutrition reduction, nutrition programs are not implemented, and even if implemented will not be sustainable. Good governance, thus interpreted, requires governments to make malnutrition reduction an important development issue where malnutrition rates are of public health concern (over $20 \%$ of national population of underfives). What are then the key-elements that would contribute to making this happen?

The principles of 'good governance' include promotion of broad-based participation in decision-making processes, sharing of information, anti-poverty programs, improved public sector management, anti-corruption programs, and a strong anti-poverty focus. Good governance strongly promotes national ownership and budget-aid, instead of project directed aid. Good governance puts national governments in charge of their poverty reduction and development agenda and creates ownership. Without commitment and ownership, poverty reduction is unlikely to be addressed. Good governance emphasizes public discussions on corruption, transparency, and accountability. Delivery of basic services, in particular to the poor, depends on a transparent and "clean" system. Good governance focuses on public sector management reforms, which, as shown also in the case-study and with cross-country data, is of importance to malnutrition reduction to ensure not only allocation of resources but also transferring resources so it can actually be spent. Good governance addresses the problem of high transaction costs for national governments dealing with a number of different donors in one domain. As shown im the case-study, harmonization of donor strategies is crucial in this respect.

The links between good governance and malnutrition were the subject of chapter six, in which the following framework was proposed. The operationalization of the principles of good governance, such as focus on pro-poor results and national ownership over (and responsibility for) the development agenda, would make the enabling environment more conducive to mainutrition reduction. Better public accountability for nutrition would lead to more investments. And more investment in nutrition programs, if implemented effectively, would ultimately lead to reductions in underweight malnutrition rates in developing countries (figure 10.1). Good governance offers a variety of ways in which it can contribute to building PA-nutrition. 
Figure 10.1: Conceptual Framework: Relation between Good Governance and Malnutrition Feduction

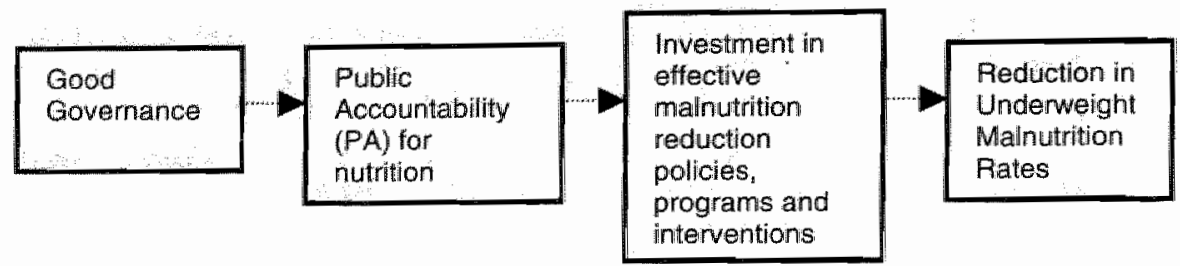

\subsection{Empirical Findings}

There is a positive significant correlation between four of the six governance indices that are used to measure progress on governance across countries, and malnutrition outcomes, measured as underweight. The data-set used in this study includes 82 developing countries in three regions: Sub-Saharan Africa, Latin America and Asia.

Controlling for income levels and regional differences, the political stability index, which measures the perceptions of the population regarding the likelihood that the government in power will be overthrown is significantly correlated with lower rates of malnutrition. Countries that are politically stable are more likely to have lower malnutrition rates than those countries where political stability is perceived as being low. The voice and accountability index, which is related to the political stability index because it measures various aspects of the political process, civil liberties, and human rights, does not show a correlation with malnutrition outcomes. However, it is positively correlated with public accountability for nutrition, which is explained in further in the next section.

The explanatory value found for the correlation between the governance index government effectiveness and mainutrition outcomes is significant at the $5 \%$ confidence level. The government effectiveness index measures the perceptions among the population of the quantity and quality of public services. The correlations are controlled for income level and regional differences. Also the correlation between the rule of law Index and control of corruption index are positive and significant. The rule of law index measures the extent to which government agents have confidence in and abide by the rules. Countries where the index rule of law is positive do significantly better on malnutrition outcomes than countries where the index scores low. The same result is found for the relation between control of 
corruption and malnutrition, except the latter is only marginally significant when controlled for income level and regional differences. These findings confirm the hypothesis that governance is important to malnutrition outcomes, and that in countries where governance is considered to be better, malnutrition outcomes are also more positive.

But that is only part of the story. The justification for this study was two-fold: 1) analyze whether there is a significant correlation between aggregate governance indices and malnutrition outcomes and if so, 2) gain a better understanding of the process between the two aggregate indicators. The second part is important for policy makers to gain insights on where and when it would be most effective to intervene. Two questions were asked: 1) Do countries that display better governance scores also demonstrate more accountability for malnutrition reduction? and 2) Do they invest more in nutrition interventions aimed at reducing malnutrition? In the theoretical considerations, three main routes were identified through which it was assumed governance would influence malnutrition reduction (figure 10.2).

Figure 10.2: Adapted conceptual tramework: Relation between Good Governance and Malnutrition Reduction

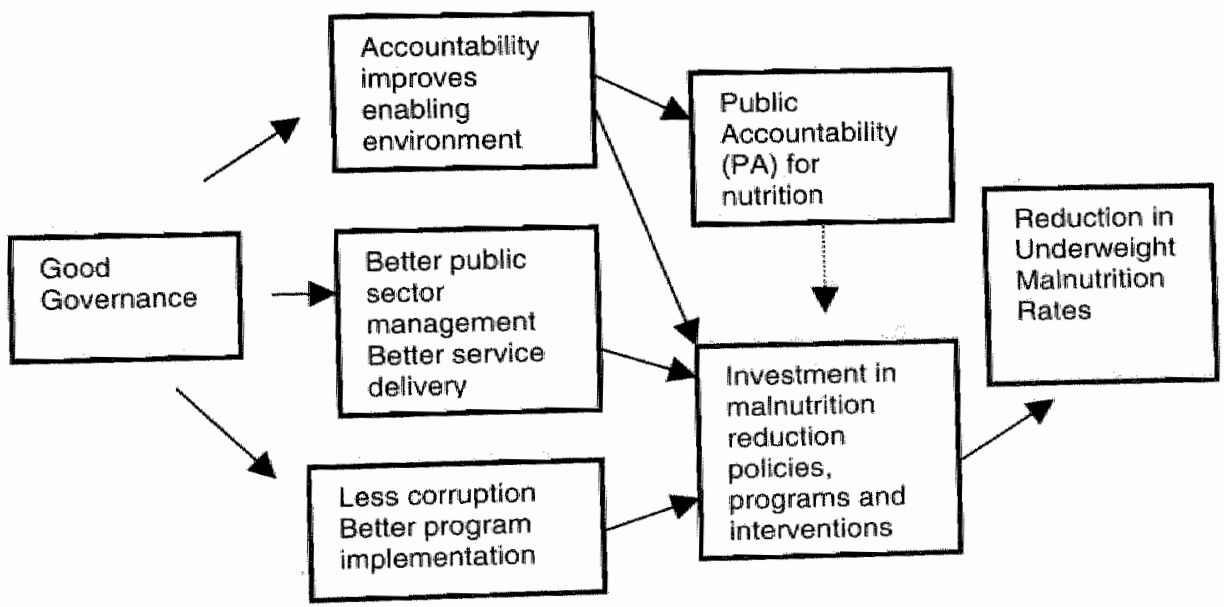

In order to analyze the relation between PA-nutrition and governance, first a measurement for PA-nutrition was developed. In order to ensure malnutrition is adequately addressed, awareness about the problem is a first requirement. The recognition of malnutrition as a development problem in the 
national poverty reduction strategies is one of the variables that measure the score on PA-nutrition. Second, including targets for malnutrition reduction and monitoring the nutritional status of the population are needed to address the problem. Targets included in the national poverty strategy as well as availability of data from surveys are part of the score on PA-nutrition. Of course making nutrition a priority among other important poverty reduction interventions is a variable. Lastly, true commitment to actions is shown by allocating resources, via a budget, for nutrition interventions. Those five variables together make up the score by which PA-nutrition is measured. Poverty Reduction Strategy Papers (PRSPS) were used to collect data on the variables of PA-nutrition and for the key-elements of good governance the Kaufmann and Kraay governance indices were used. Nine of the 40 countries included in the dataset score positive on all variable on the PA-nutrition score. All 40 countries are low income, and in 32 malnutrition rates are above $20 \%$, or considered a public health problem, following the standards of the World Health Organization.

The cross-country data-analysis shows supports for assumed links shown in figure 10.2 between the three routes through which governance influences PA-nutrition. In countries where voice and accountability, government effectiveness, and rule of law as well as control of corruption is better, the scores on PA-nutrition are better. Those national governments more often make nutrition a priority in their national development plans and allocate resources to nutrition. This holds both for progress on performance on the governance indicators, measured as the trend in the indicator between 1996 and 2004, and the score in 2000. For example, countries where government effectiveness improves over the period between 1996 and 2004, over $70 \%$ of the countries made malnutrition reduction a priority in their development plans, and $57 \%$ allocated a budget.

The findings on the research question whether governance scores bear a relation to the level of investment in nutrition interventions are less supportive of the assumption. Only government effectiveness-scores show a positive relationship on both trend and status with the score on PAnutrition. Countries where government effectiveness improved invested on average US\$0.89 per capita with World Bank support for nutrition, while those where government effectiveness worsened, invested US $\$ 0.80$ per capita for nutrition. However, the opposite is true on the other indices of governance. Countries with positive trends on voice and accountability, rule of law and control of corruption all invested less in nutrition over the period reviewed than countries with negative trends. There are 
considerable data limitations in this dataset that should be kept in mind. The investment figures only represent what the World Bank supported over that period. It does not include potentially important national budgets. It may well be that the relationship is negative precisely because of low level of attention to nutrition from national government side, and therefore external assistance may have been higher as a result. As discussed in chapter one, the international donor community has often started interventions in countries with serious malnutrition problems, but low levels of awareness and attention.

The question as to what extent PA-nutrition matters for malnutrition outcomes is important, but cannot be tested empirically with the available data. The data on PA-nutrition that is collected from the PRSPs is largely after 2000, and the data available on changes in malnutrition and the most recent malnutrition survey-data dates from before most of the PRSPS were developed. It may be though interesting to conduct a similar exercise five years from the data of this study, using the measurements developed in this study to analyze changes in PA-nutrition, changes in governance, and changes in mainutrition outcomes.

The last research question that was posed at the start of this study was how the assumptions play out in a real case. Madagascar is an example of a country where malnutrition projects were piloted and scaled-up, and where governance factors have influenced the process of making it a political priority the resulting allocation of resources to malnutrition. The Madagascar case-study provides insights into the relationship between governance and malnutrition reduction that could not be shown with the cross-country analyses.

First, the Madagascar case shows support for the four phases in the framework. Governance indices have improved over time. Over the same period, PA-nutrition was built and investments in nutrition programs increased gradually. Finally, impact studies show that underweight malnutrition rates have improved over the period that governance improved and PAnutrition was built. The four links could not be made using crosscountry analysis due to data-limitations.

Second, the Madagascar-case shows that it is possible to create 'voice' through building local support and creating widespread demand. Community participation has long been recognized as important to the design and implementation of nutrition programs, but has received much less attention as an accountability building instrument in the nutrition literature.

Third, the Madagascar case-study offers insights in the ownership issues that could not be addressed in the cross- 
country analysis for lack of data. In the Madagascar case, the problems related to lack of ownership and donor-driven nutrition policies and programs were highlighted. It took many years to harmonize approaches, to reduce transaction costs, and to institutionalize nutrition under national institutes.

Besides these additional insights, the Madagascar case also provides further support to the results from the crosscountry analysis. It shows that a more conducive environment can create the space to make nutrition a priority. Before the PRSP process, the results of Profiles ${ }^{166}$, a program that calculates the costs to the national economy due to malnutrition and what can be saved if prevented, was presented to government. Although it was well received and the nutrition issue gained some interest, attention to nutrition was obtained at the highest levels during the PRSP-process, and created the opportunity to develop the National Nutrition Policy and the creation of institutions.

The Madagascar case provides strong support to the argument that general public sector management is important for malnutrition reduction. Once donor-support changed from direct support to support through Madagascar"s national budget, the nutrition sector was institutionalized and integrated into the public sector. Annual budgets and approval into finance law, thanks to improved management, were relatively swiftly accomplished. However, the actual resource transfers and reporting have encountered many obstacles, which have put the program's achievements and future operations at risk. The importance of fiscal policy is very clear in the Madagascar case. For example in 2005, a total of US $\$ 23$ million dollars was allocated to malnutrition reduction. This was more than nutrition had ever been allocated in previous years, and a sign that accountability has been built. Yet, even though approved in the finance law, the program had not received any of the resources halfway through the year 2005, because of a fiscal deficit as a result of the increase in oil-prices, increased need for rice imports due to poor harvest, and fiscal policy decisions.

Finally, a number of interesting insights can be gleaned from this case. Voice can be created for malnutrition reduction, high-level decision-makers can be convinced of the importance to invest in nutrition programs and do approve generous resource allocation, and national ownership can be built with both time and willingness from governments and donors. At the same time, practical realities have also provided lessons. The

\footnotetext{
Development

program, developed

by

Academy of Education
} 
first is that including voice for malnutrition reduction can also be seen as an opportunity for electoral campaigning. The second is that financing nutrition programs through national budget is more sustainable and expected to be better implemented because of ownership, but puts nutrition programs at risk when the fiscal balance is not properly managed. Although high level political attention is important, it may also constitute a risk in countries with less than good governance in areas such as recruitment policies.

\subsection{Discussion}

The main justification to conduct this study was to contribute to the continuing debate on how to raise long-term commitment for malnutrition. It is therefore important to try and answer the following question at this point: How and what do the results from this predominantly exploratory study contribute to the continuing debate on raising awareness and attention for malnutrition reduction in order to make more progress in reducing malnutrition rates in developing countries?

First, raising the question as to the importance of the latest development policy of good governance in relation to malnutrition reduction is valid. Good governance influences various aspects of the environment which are important to getting malnutrition reduction on the development agenda. The interaction between better policies that are pro-poor, and emphasize equality and accountability for malnutrition reduction, is positive. Government effectiveness and public sector management reforms help improve the likelihood that malnutrition services will be financed and implemented. And finally, anti-corruption policies can contribute to a better environment in which high levels of malnutrition can be addressed. The cross-country analysis of aggregate governance indicators and malnutrition outcomes demonstrates significant correlations between the two indicators.

The findings from the cross-country analysis as well as the case-study both confirm the importance of good governance to malnutrition reduction. There is a clear and significant correlation between countries that score better on political stability, government effectiveness, rule of law, and control of corruption indices and malnutrition outcomes. There is also a clear positive relationship, although not statistically analyzed, between the governance indices and public accountability for nutrition in developing countries.

contributes to the creation of an 
enabling environment in which public accountabillity for malnutrition reduction can be built and investment in nutrition interventions is more likely. The confirmation of the hypothesis is important in the debate around raising long-term commitment to nutrition and raising adequate resources for nutrition programs and interventions.

Secondly, this study contributes to the debate through its focus on the interface between context and program, rather than the programs themselves. For example, the discussion on the possible contribution of good governance principles on creating awareness and voice for the largely invisible issue of chronic malnutrition provide new insights for the debate. The Madagascar case shows that it is possible to create 'voice' through building local support and creating widespread demand. Community participation has long been recognized as important to the design and implementation of nutrition programs, but has received much less attention as an accountability building instrument in the nutrition literature. In this study, the latter aspect of community participation was highlighted.

The assertion made in chapter one, that the timing in the 1990 s and new millennium is better than before for general development policy to have positive influence on malnutrition reduction appears valid from the review that was done in chapter four, and the subsequent findings in the empirical analysis. Currently, new millennium development assistance provides new opportunities with its focus on building and supporting good governance and national government ownership over development agendas. This new thinking, coupled with the MDGs, is expected to ensure malnutrition reduction is included in national development programs.

The experience in Madagascar shows what can be done with political commitment, accountability, voice, and financing for nutrition: impressive reduction in underweight malnutrition rates. Whether the achievements will be maintained and further improved will depend on the continuation of good governance, commitment of the local and high-level decision-makers, and the advocacy of the nutrition community in Madagascar. The data that is becoming available from the impact-studies does show clearly what can be achieved if continued, and what will be lost if not.

Two aspects that have not been addressed in this study, but which are important in the framework to reduce malnutrition, are capacity and coverage. Capacity, human resources to develop nutrition policies, translate them into programs, and implement and monitor them, is not always sufficiently available in developing countries. The lack of capacity is also a result of 
lack of attention. Once more demand for nutrition services exists, and it is highlighted as a priority and resources allocated, capacity is expected to be built at the same time. Lastly, we come to the issue of coverage. As was discussed in the introduction of the case-study on Madagascar, there are many successful nutrition projects, but they are often small-scale and remain too small to have impact on the nutrition situation at the national level.

The main conclusions from this study can be summarized as follows. Good governance matters to malnutrition reduction. Countries with better governance indicators show better outcomes for malnutrition. The specific factors of governance that appear most important include government effectiveness, political stability and rule of law. The likelihood that the combination of attention to MDGs and good governance has a positive spin-off for malnutrition reduction is good.

However, the likelihood that there is more attention to MDGs and good governance is another question on which the discussion is ongoing. Despite the commitment to MDGs in public speeches, it appears sometimes to be only rhetoric and no action. The new commitments from the rich countries to development assistance remain small in comparison to the needs and to current assessments of slow progress on the achievement of many MDG indicators. And it is a pity that worldwide governance indicators are not improving more rapidly. Globally, governance indicators are almost stagnant, according to the Kaufmann governance data-set. Countries that do better are off-set by countries that worsen; so on balance there is little change. However, when looking at population, rather than number of countries, the improvements appear more impressive, since in countries as India and China governance improved.

Finally, good governance in development policy appears not to be 'just a new fad', as some of its staunched critics have called it. The recognition of its importance, and the redirection of development assistance that was started 15 years ago, is continuing. It matters to development, it matters to human development, and it matters to malnutrition reduction. It is important for the nutrition community to use the insights and the links between governance and nutrition to ensure that nutrition is a priority development issue that receives the resources it needs. Closer collaboration with the public sector, more efforts to create voice and demand at both the local and central levels, and closer collaboration between donor agencies all will help developing countries to achieve this. 


\section{Executive Summary (English)}

Malnutrition is a serious development problem that is insufficiently addressed in development policy. In the new Millennium, the combined attention to achieving the Millennium Development Goals as formulated by the United Nations, of which malnutrition reduction is one, and the development policy attention on good governance, may change this picture. In this study the likelihood of this happening was tested by posing the following questions:

- Is there a correlation between indicators of governance and malnutrition outcomes that can be shown statistically?

- Are there key-elements of governance that particularly influence the attention given to malnutrition reduction public accountability for nutrition - and do they show correlations in a cross-country analysis?

- What is the evolution of general development policy and nutrition theory and are they more compatible in the new Millennium?

These questions were discussed and analyzed in detail in this study; the following provides a summary of the discussions and results of the analyses.

The promotion of good governance is the dominant development assistance policy of the new millennium. The ultimate goal is worldwide poverty reduction. Malnutrition, an important determinant and consequence of poverty, has struggled and continues to struggle to be recognized and addressed as a development problem. The basic premise of this study is to show that good governance also matters to malnutrition reduction and that in fact better governance can help improve malnutrition. It is therefore important to understand the process that takes place between governance and building accountability for malnutrition reduction. There are three main parts in which the questions are addressed. The first chapters provide the overall background to the premise as well as the problem statement. The second part of the study is the empirical analysis to test the hypothesis posed and answer the research questions. Besides the analysis of aggregate indicators of governance and malnutrition, the question about the processfactors of governance and building accountability for malnutrition through dealing with the challenges malnutrition faces is discussed in detail. Better understanding may help future policy advice. The third part of the study is the conclusion and discussion. 
Two basic arguments are made to place the premise into context. First, that development assistance theory and thinking about malnutrition reduction are becoming more integrated than ever before (chapter 4). And second, that malnutrition reduction is a public sector responsibility and therefore requires public accountability (chapter 6).

A large part of this study is focused on the World Bank. This is because it is one of the largest development assistance agencies and the largest investor in nutrition programs in developing countries since 1970 .

\section{Malnutrition is a Development Problem and 'Good Governance' Matters}

In chapter one the problem malnutrition faces to become recognized and adequately addressed, is described. Malnutrition is an indicator of nutritional stress, and when it occurs in early life, has a long-term negative impact on health, cognitive development and productivity. It is costly in human, social and economic terms, and so should be among the priorities of development. Almost one-third of all children in the developing world are chronically malnourished. Over the past dlecades much has been learned about interventions that reduce malnutrition. For example the notion that protein, although important, is not the main cause of malnutrition, became known in the 1960s. That distributing food is not the only answer is more widely accepted since the 1970 s, when malnutrition was recognized as a multisectoral household-level development problem. Much has been learned about implementing programs and a significant number of studies that show positive impact and costeffectiveness of these interventions are also available.

However, although it is recognized that governance, political and environmental factors also influence malnutrition, much less is known about the process between those factors and malnutrition. This study therefore seeks to contribute to remedying this knowledge gap by searching for explanatory indicators of good governance that contribute to the success of nutrition programs. Nutrition programs are considered successful if they contribute to the prevention and reduction of malnutrition rates. But there are many problems in getting high-level decision makers to commit to addressing malnutrition and subsequently to allocating resources to it. There are a number of important constraints to getting commitment, or public accountability for nutrition (PA-nutrition).

First, there is a lack of awareness about the problem itself, both at the political and household level. Chronic 
malnutrition is largely an invisible problem. Until it becomes severe, even parents do not see their children's gradual growth failure leading to chronic malnutrition. Second, the malnourished, primarily women and young children, in the poorest areas, do not have a voice to demand political attention for their concerns. Third, there is little incentive for accountability from high-level decision-makers. Addressing malnutrition is not only complex, it is also a long term process, which is not attractive for politicians who are more likely to support interventions that demonstrate quick results. Fourth, it is multisectoral. Defining institutional arrangements for malnutrition policy-making and program implementation is difficult because it is a multi-solutions problem and does not have a natural organizational identity.

The fifth challenge that can be added is lack of national ownership over the nutrition agenda and therefore lack of interest of national governments. Although the international nutrition community recognized the importance of addressing reducing malnutrition for overall development in the 1970s, it has failed to invest sufficient resources for capacity building and ensuring government's interest in continuing interventions. The bias for external funding for nutrition exacerbated the ownership problems. In order to reduce mainutrition, long term assistance and investment is needed, as well as making countries take the responsibility for it by building ownership and accountability. In chapter six, the case is made that malnutrition reduction is a public sector responsibility and therefore should be the responsibility of national governments. This is based on human rights and economic arguments.

Good governance may be beneficial to malnutrition reduction because it addresses a number of the underlying governance problems identified in the challenges to building PAnutrition. But it could go either way. It may prove beneficial because it puts multisectoral poverty reduction issues, of which malnutrition reduction is one, on the development agenda and it promotes close monitoring of the situation. It may also prove a disadvantage because of its emphasis of placing the responsibility for poverty reduction back to national governments. Many countries in the developing world have high mainutrition rates but do not consider malnutrition a development problem. The lack of recognition may be caused by a variety of reasons, ranging from lack of awareness to lack of commitment to lack of financing and combinations of these factors. 


\section{Hypothesis and research questions}

In chapter two the hypothesis, research questions and methodology is described. The hypothesis in this study is: a country that applies the principles of good governance is expected to have more accountability about malnutrition reduction and to mobilizing resources to invest in nutrition programs. Effectively implemented malnutrition reduction programs would lead to accelerated decreases in malnutrition. Alternatively, poor governance contributes to no action for malnutrition and creates the opportunity for international donors to define national policies and control resources which is more likely to lead to poor implementation because of lack of ownership and less successful nutrition programs.

Governance is defined as the manner in which power is exercised in the management of a country's economic and social resources (World Bank 1997). Good governance leads among other things to participatory, transparent and accountable policies. It promotes rule of law, it ensures that political, social and economic priorities are based on broad consensus in society and that the voices of the poorest and most vulnerable are heard in decision making over the allocation of resources (UNDP 1997). Good governance broadens participation in decisionmaking to non-traditional actors in government; civil society and private sector.

Public Accountability (PA) for nutrition is defined as: the public sector being responsive to malnutrition problems by not only raising awareness to create knowledge and public demand, but also taking action to address the problem and providing information on how, why and what and for whom, to the population at large, and the poorest in particular. In this study PA-nutrition is considered as good when a country has made nutrition and or malnutrition reduction a priority in their overall development program and has allocated resources to implement interventions and programs.

The research questions in this study comprise two parts, theoretical considerations and development of the framework and the analysis itself. The main theoretical question can be defined as: what are the key-elements of good governance that contribute to malnutrition reduction through building accountability for nutrition and increased investment. The empirical questions test the presumed links. A quantitative crosscountry analysis of the correlation between aggregate governance indices and malnutrition outcomes is conducted and results presented in chapter 7 . A cross-country analysis of the governance indices and PA-nutrition and investment levels in 
nutrition programs is conducted and results are presented in chapter 8. Finally, with the objective to be true to the explanatory nature of this study, a case-study is included to test the theoretical framework in reality.

\section{Research questions}

1. What is malnutrition, why is it a development problem, and why is it a public sector responsibility to which the principles of governance apply?

2. How did development assistance theory evolve, and when does the environment become more enabling to malnutrition reduction?

3. What is 'good governance", and when and why did it become a dominant development policy?

4. What are the key-elements of governance that in theory may contribute to malnutrition reduction?

5. How do these key-elements contribute to malnutrition reduction in developing countries, and through which processes?

6. Has governance improved in developing countries since the mid-nineties?

7. Is there a correlation between aggregate governance indices and underweight malnutrition rates in developing countries in Africa, Asia and Latin America?

8. Do developing countries that display better scores on aggregate governance indicators also demonstrate PAnutrition?

9. Did developing countries with better scores on governance invest more in malnutrition reduction interventions?

\section{Malnutrition}

Direct determinants of mainutrition are poor dietary intake, quantitative as well as qualitative, and a high morbidity load. Household food insecurity, lack of adequate care, lack of access to health services and clean water and sanitation facilities are underlying determinants of malnutrition (figure 2. 1. chapter two). Poverty, gender inequality and female illiteracy are basic determinants of malnutrition. In chapter three a detailed literature review of what malnutrition is, why it is a development problem and what can be done about it, is provided as background. At present more than 180 million children under the age of five suffer from chronic malnutrition. Children that are malnourished tend to have more severe illnesses. It has been estimated that out of 11.6 million child deaths that occurred in 
1995 among children under five in developing countries, 6.3 million (54\%) were associated with malnutrition (Pelletier 1993:1130). In other words, 6.3 million deaths could have been prevented had these children not be malnourished. Capacity to learn is negatively affected by malnutrition, and malnutrition in the long term undermines development and poverty reduction. In chapter 3 , the global magnitude of the problem is described in more detail and an account of the types of projects and programs the World Bank supports is included.

\section{Development assistance and Malnutrition}

A chronological review of the evolution of development assistance since the $1950 \mathrm{~s}$ and thinking about malnutrition reduction over the same period shows malnutrition is more likely to be addressed in the 1990s than in the earlier years of development assistance. Before the 1970 s malnutrition was seen as a metabolic disease and recognized and addressed only in very severe cases and mainly in the hospital setting. In the $1970 \mathrm{~s}$, by the time the focus of general development assistance was on the poor and basic human needs, moderate chronic malnutrition was recognized as a development problem and no longer a metabolic disease. But aid was still very much donordriven and did not emphasize long-term in-country capacitybuilding. The National Nutrition Commissions that were established in the 1970s were premature and have largely failed. At the time there was also still little attention to building local leadership and ownership of the nutrition and general poverty reduction policies and strategies. And far less was known about interventions that contribute to reducing malnutrition in the 1970 s.

In the 1980s, there was even less complementarity in thinking about macro-level development assistance and microlevel implementation of malnutrition reduction interventions. The focus regarding malnutrition was on vertical nutrition interventions, mainly through the health sector. Macro-level structural adjustment was the dominant development strategy at the World Bank, and there was little opportunity for malnutrition to be addressed as a multisectoral development problem.

In contrast, in the 1990 s and continued in the new millennium, general development assistance appears to focus more on building an enabling environment for poverty reduction in which malnutrition can be better addressed. At the same time, those thinking about malnutrition started looking more at the importance of an enabling environment. Broad participation, meaning inclusion of civil society, non-governmental 
organizations, and private sector in the public sector debates on poverty reduction are strategic directions that were promoted by international development agencies and nutritionists alike. The chronological review shows that since the 1990 s, there are more opportunities for malnutrition to be included on the development agenda. Malnutrition reduction is a public sector responsibility, and good governance offers a window of opportunity to remind national governments to address it as such.

\section{Good Governance}

Before going into details on how governance may influence malnutrition reduction, chapter five provides an overview of what good governance is, and how it is interpreted by development agencies such as the World Bank. The World Bank, in its publication Assessing Aid, in 1998 asserts that foreign aid has had a positive impact on development and most effectively so in countries with good policies. In 1992 the World Bank was the first development agency to publicly discuss the problems of poor governance for development in its long-term perspective study Sub-Saharan Africa: From Crisis to Sustainable Growth, Underlying Africa's Development Problem is a Crisis of Governance. In 1996, the World Bank President James D. Wolfensohn put corruption in the public debate on development failure. A review of the underlying evidence to support the attention to good governance is included in chapter 5.

There has been much discussion on whether good governance in fact is a critical factor to development policy, and whether or not improving it worked or is likely to work. Although it is not the objective of this study to add to that broad debate, it is important to review it so that the more focused debate regarding governance and malnutrition, to which this study does attempt to contribute, is put into context. For example, recent discussion papers published by the World Bank's sister organization, the International Monetary Fund (IMF), bring the debate back to the initial question of effectiveness of aid, asserting that the results of the research do not show robust enough correlations that aid leads to economic growth, not even in countries that apply good policies. The jury is still out, and a verdict will probably not be made for another decade or so. The debate, as well as the studies regarding the application and implementation of good governance principles continues.

Although many critics have blamed the World Bank for abusing the term governance and from using it to hide its poor performance behind yet another new World Bank policy, good 
govemance has brought many new issues to the agenda and has had a positive influence on development thinking in general. In addition, with the emergence of governance as a dominant development policy, data to measure governance factors; such as political stability, accountability, and rule of law has become available.

\section{Good Governance and Malnutrition}

Cross-country analysis show positive correlations between governance and social indicators, such as literacy rates and infant and child mortality. One of the objectives of this study is to analyze whether there is such a relationship between governance and malnutrition outcomes. However, besides the analysis of aggregate indicators of governance and malnutrition, the question about the process-factors of governance and building accountability for malnutrition by addressing the challenges that were identified in chapter one may help gain better understanding and future policy advice. In this chapter a measurement for PA-nutrition is developed

As was highlighted earlier, malnutrition as a development issue encounters challenges in the process of getting recognized as a problem, getting on the development agenda and the radarscreen of decision-makers, and finally getting resources allocated to address it. In reviewing the different factors or elements of governance, emphasis is given to the possible relations of these factors with regards to the challenges malnutrition encounters. In chapter 6 , the three possible routes that help explain the relation between governance indicators and malnutrition outcomes are discussed.

First, lack of attention to malnutrition is a result of weak voice (demand). It is mainly a poor people's condition and poor people are not generally invited to speak nor are they listened to. In addition, chronic malnutrition is a gradual process which goes largely unrecognized until it is severe and thus there is little demand for prevention. The first route through which good governance may contribute positively to improving the awareness about malnutrition is by making space for the voice of the malnourished to be heard. Good governance promotes broad-based participation, implying listening to citizens' voices. Further, it may help address the invisibility problem by promoting pro-poor and results-oriented development. In order to have results, the situation needs to be monitored, by monitoring malnutrition; the magnitude of the problem becomes visible. Malnutrition is multisectoral and multidimensional and does not get attention in a largely sector-driven world. Good governance 
promotes addressing the multidimensional nature of poverty, including malnutrition and makes governments more accountable to monitoring poverty reduction progress.

Malnutrition reduction is slow because of weak program implementation, service delivery, and under-investment. The second route through which for good governance is expected to positively influence malnutrition is through improving government effectiveness and public sector management reforms. This is the key-mechanism of good governance focus on improving service delivery. Basic service delivery, which includes nutrition services, is at the root of poverty reduction programs. Public sector management reform coupled with the pro-poor focus of good governance may provide for a much better environment for malnutrition to be financed and implemented. The third route for good governance to contribute to improving malnutrition is indirect via anti-corruption and rule of law. Although, this is largely seen as an important, but longer term link because it will take time for effects of more transparent management to trickle down to micro-level implementation of programs.

Governance Indices and Malnutrition Outcomes

In chapter seven the quantitative analysis of the correlation between aggregate governance indicators and malnutrition outcomes is conducted, in chapter eight the analysis is done using the three routes as process-indicators.

Using the six governance indices compiled by Kaufmann and Kraay (1999-2005) significant positive correlations were found with malnutrition outcomes, measured as underweight in children under five. The database used for the analysis consists of 82 countries from three regions: Africa, Latin America and Asia. Unconditional correlations show the relationship and further statistical analysis, controlling for differences in income-levels and regional influences, shows that the governance indicators political stability, government effectiveness, and rule of law explain the variance in malnutrition outcomes at the $5 \%$ confidence level. Control of corruption is marginally significant at the $10 \%$ confidence level. Voice and accountability and regulatory quality do not show any correlation. The latter can be explained by the fact that regulatory quality measures the incidence of market-unfriendly policies which have very little relationship to malnutrition. Voice and accountability was expected to have a stronger correlation with malnutrition but maybe too far in time to see impact after a couple of years only. Voice and accountability measures political will, civil and human rights. 


\section{Gavernance Indices and Public Accountability for Nutrition}

In chapter eight the three theoretical routes through which the principles of good governance may influence malnutrition reduction are examined using cross-country data analysis. Two main research questions are explored. First, do countries that display better scores on governance also demonstrate better PA-nutrition? And second, do countries with better scores on governance invest more in nutrition interventions? In chapter six a measurement for PA-nutrition was developed and in this chapter the data is described. The data are collected from national Poverty Reduction Strategy Papers (PRSP). Estimates of investments in nutrition were collected from World Bank-supported nutrition and health projects and used to review the links between governance scores and investments in nutrition. Data from a total of 40 countries for the three route analysis and data from 32 countries for the relationship between investment and governance scores are used.

The cross-country data-analysis supports the assumptions made in regarding the three routes through which governance influences PA-nutrition. In countries where 'voice and accountability', 'government effectiveness', and 'rule of law' as well as 'control of corruption' score better, the score on PAnutrition is also better. This holds both for progress on performance on the governance indicators, measured as the trend in the indicator between 1996 and 2004, and the score in 2000. For example, countries where government effectiveness improves over the period between 1996 and 2004, over $70 \%$ of the countries made malnutrition reduction a priority in their development plans and $57 \%$ allocated a budget.

However, there is less support regarding the hypothesis that countries that score positive on governance have higher levels of investment in nutrition. Only government effectiveness scores show a positive relationship on both trend and status in governance and PA-nutrition. Countries with improving scores on government effectiveness invested on average US $\$ .89$ per capita with World Bank support for nutrition, while those with worsening trends invested US $\$ .80$ per capita. Countries with scores above the average in this research population invested on US\$.90 per capita, while those will scores below the average invested US $\$ .72$ per capita. However, the opposite is true on the other indices of governance. Countries with positive trends on voice and accountability, rule of law and control of corruption all invest less in nutrition over the period reviewed than countries
with negative trends. 
There are considerable data limitations in this dateset that should be kept in mind. The investment figures only represent what the World Bank supported over that period. It does not include the potentially important national budget. It may well be that the relationship is negative precisely because of low level of attention to nutrition from national government side, and therefore external assistance may have been higher as a result.

The question to what extent PA-nutrition matters for mainutrition outcomes is important but cannot be tested empirically with the available data. The data on PA-nutrition that is collected from the PRSPS is largely after 2000, and the data available on changes in malnutrition and the most recent malnutrition survey-data dates from before most of the PRSPS were developed. It would be interesting to do a similar analysis in five years for the data of this study using similar indicators and analyze changes in PA-nutrition, governance and nutrition outcomes.

\section{Governance and Malnutrition in Madagascar, a Case-study}

A case-study adds value to the analysis by bridging the theoretical with the empirical in a real setting. Madagascar is the country where the review for the case-study was conducted. It applied many of the governance and nutrition policies the World Bank supported over that period, and the author of this book has been involved in addressing malnutrition in Madagascar over the past nine years.

The findings from the Madagascar confirm the empirical findings and the theoretical framework drawn in chapter six. The focus of general development policy in Madagascar, including the good governance focus on broad-based participation, anticorruption and pro-poor policy-making had a positive influence on the process of institutionalization of nutrition in Madagascar. There are two periods than can be identified in Madagascar with distinct governance and PA-nutrition characteristics. In the first half of the 1990s, governance did not get much attention beyond public sector reforms, and malnutrition reduction was being piloted and dominated by international donors. In the latter half of the 1990s, governance indices improved and more attention was given to nutrition. PA-nutrition was built up which led also to increased investments in nutrition services. Madagascar is also among the few countries in Sub-Saharan Africa that has reduced underweight malnutrition between 1997 and 2004. An impactevaluation is being conducted and preliminary results show the reduction is more important in areas where the nutrition program has been implemented (Galasso 2005:17). 


\section{Conclusion and Discussion}

Malnutrition is an important development problem because it affects young children and has a long-term negative impact on their health, cognitive development and productivity. The fact that it is costly in human, social and economic terms is recognized. However, despite efforts to address malnutrition in the past 40 years, prevalence remains unacceptably high. Almost one third of the world's children are suffering from malnutrition. Malnutrition reduction is a public sector responsibility based on public goods and human rights arguments, and reducing malnutrition is a role for the state. For long, the international community has taken the lead in developing nutrition policies and implementing small scale pilots, in the hope of convincing national government to scale up the interventions. Good governance puts the responsibility for development, including malnutrition reduction, back to national governments.

This study found a positive significant correlation between four governance indices that are used to measure progress on governance across countries and malnutrition outcomes.

Countries that are politically stable are more likely to have lower malnutrition rates than those countries where political stability is perceived as being low. Countries with better scores on government effectiveness do better on malnutrition outcomes. And the correlation between the rule of law and control of corruption indexes and malnutrition are positive and significant at the $5 \%$ and $10 \%$ confidence level respectively. These findings confirm the hypothesis that governance is important to malnutrition outcomes and that countries where governance is considered to be better malnutrition outcomes are also more positive.

The justification for this study was two-fold: to analyze whether there is a significant correlation between aggregate governance indices and malnutrition outcomes, and if so, gain better understanding of the process between the two aggregate indicators. The cross-country data-analysis shows supports for assumed routes through which governance influences PAnutrition. In countries where "voice and accountability", "government effectiveness', and 'rule of law' as well as 'control of corruption' is better, the scores on PA-nutrition is better. Those national governments more often make nutrition a priority in their national development plans and allocate resources to nutrition. The findings on the research question whether governance scores bear a relation to the level of investment in nutrition interventions show support for the relation between government 
effectiveness and investment levels, but not for the other governance indices.

The last research question that was posed at the start of this study was how the assumptions play out in a real case. Madagascar is an example of a country where malnutrition projects were piloted and scaled up and where governance factors have influenced the process of making it a political priority and influences the allocation of resources to malnutrition. The Madagascar case-study provides insights in the relation between governance and malnutrition reduction that could not be shown with the cross-country analyses.

How and what do the results from this predominantly exploratory study contribute to the continuing debate on raising awareness and attention for malnutrition reduction? The main hypothesis of this study can be accepted as follows: good governance contributes to the creation of an enabling environment in which public accountability for malnutrition reduction can be built and investment in nutrition interventions is more likely. The confirmation of the hypothesis is important in the debate around raising long-term commitment to nutrition and raising adequate resources for nutrition programs and interventions.

Finally, the main conclusions from this study can be summarized as follows. Good governance matters to malnutrition reduction. Countries with better governance indicators show better outcomes for malnutrition. The specific factors of governance that appear most important include government effectiveness, political stability and rule of law. The likelihood that the combination of attention to Millennium Development Goals (MDGs) formulated and supported by the United Nations and good governance has a positive spin-off for malnutrition reduction is good.

However, the likelihood that there is more attention to MDGs and good governance is another question on which the discussion is ongoing. Despite the commitment to MDGs in public speeches, it appears sometimes to be only rhetoric and no action. The new commitments from the rich countries to development assistance remain small in comparison to the needs and to current assessments of slow progress on the achievement of many MDG indicators. And it is a pity that worldwide governance indicators are not improving more rapidly. Globally, governance indicators are almost stagnant, according to the Kaufmann governance data-set. Countries that do better are off-set by countries that worsen; so on balance there is little change. However, when looking at the population level, rather than number of countries, the improvements appear more 
impressive, since in countries as India and China governance improved.

Good governance in development policy appears not to be "just a new fad", as some of its staunchest critics have called it. The recognition of its importance and the redirection of development assistance started in some countries nearly fifteen years ago, and continues. It matters to development, it matters to human development and it matters to malnutrition reduction. It is important for the nutrition community to use the insights and the links between governance and the battle to make nutrition a development issue that receives the resources it needs. Closer collaboration with the public sector, more efforts to create voice and demand at both the local and central levels, and closer collaboration between donor agencies all will help developing countries to achieve this. 


\title{
Executive Summary (Samenvatting in het Nederlands)
}

\begin{abstract}
Ondervoeding is een serieus ontwikkelingsprobleem dat onvoldoende aandacht krijgt in het algemene ontwikkelingsbeleid. Echter, de huidige combinatie van aandacht voor de Milennium Development Goals, waarvan het verminderen van ondervoeding er een is, en de aandacht voor good governance in algemeen ontwikkelingsbeleid kan dit negatieve beeld, in positief opzicht, veranderen. De waarschijnlijkheid dat dit inderdaad zou gebeuren wordt in deze studie onderzocht door het stellen van de volgende vragen:
\end{abstract}

- Wat is de correlatie tussen de indicatoren van good governance en ondervoeding en is dit verband statistisch aan te tonen?

- Wat zijn de belangrijkste elementen van good governance die de publieke verantwoordelijkheid voor voeding beinvloeden, en is er een correlatie als hiervoor een brede landenstudie wordt uitgevoerd?

- Wat is de evolutie van algemeen ontwikkelingsbeleid en ondervoedingstheorie en waarom zijn ze meer complementair in het nieuwe Millennium?

In deze studie worden deze vragen besproken en in detail geanaliseerd.

Het promoten van good governance is sinds de negentiger jaren een dominante stroming in de politiek voor ontwikkelingshulp en heeft als algemeen doel het wereldwijd bestrijden van armoede. Ondervoeding daarentegen wordt niet als ontwikkelingsprobleem anderkend noch erkend, terwijl ondervoeding zowel een belangrijke oorzaak als gevolg van armoede is. Het doel van deze studie is aan te tonen dat good governance ook van belang is voor ondervoeding. Mede daarom is het ook van belang om een beter zicht te hebben op het bestrijden van ondervoeding en het verband tussen good governance en het opbouwen van overheidsverantwoordelijkheid De studie bestaat uit drie delen om het bovenstaande doel te beantwoorden. Het eerste deel beslaat de probleembeschrijving, de problemen die ondervoeding als onderwerp ondervindt in de strijd om als ontwikkelingsprobleem te worden herkend en hoe good governance kan helpen om deze problemen te voorkómen. In dit eerste deel wordt ook uitgelegd hoe dit onderzocht kan worden met behulp van bestaande en nieuw te ontwikkelen databanken. Het tweede deel van de studie 
bestaat uit de analyse van de data. Naast de analyse van governance indexen wordt de vraag gesteld hoe procesindicatoren van governance de problemen voor het onderkennen van ondervoeding als ontwikkelingsprableem ondersteunen en dit wordt eveneens empirisch onderzocht. Deel drie is de conclusie en discussie.

Alvorens verder te gaan met de probleembeschrijving is het belangrijk twee onderliggende argumenten voor deze studie te beschrijven. Allereerst wordt in deze studie er vanuit gegaan dat ontwikkelings- en voedingspolitiek in de jaren negentig meer dan voorheen open staan voor het bereiken van overlappende doeleinden: armoede en ondervoeding. Dit komt deels door meer aandacht voor good governance. Dit argument wordt uitgebreider beschreven in hoofdstuk vier. Ten tweede wordt er in deze studie vanuit gegaan dat het bestrijden van ondervoeding ook de verantwoordelijkheid is van de overheid, de publieke sector. Dit argument wordt meer in detail beschreven in hoofdstuk zes. En als laatste dient hier te worden genoemd dat een groot deel van deze studie op de Wereldbank is geconcentreerd omdat het één van de belangrijkste ontwikkelings-organisaties is en de grootste financier van voedingsinterventies in ontwikkelingslanden is.

\section{Ondervoeding is een ontwikkelingsprobleem en Good
Governance is belangrijk}

In hoofdstuk een worden de problemen behandeld rond ondervoeding en het onderkennen door de nationale overheden dat ondervoeding inderdaad een serieus ontwikkelings-probleem is. Ondervoeding is een indicator van voedingsstress. Het is een conditie die, wanneer het op jonge leeftijd vóórkomt, zeer negatleve en langdurige consequenties heeft voor wat betreft gezondheidstoestand, leervermogen en op latere leeftijd ook productiviteit. Het is daarom een zeer groot probleem, zowel in humaan, sociaal als economisch opzicht. Bijna één op de drie kinderen in ontwikkelingslanden lijdt aan chronische
ondervoeding.

Gedurende de laatste decennia is veel geleerd over het nemen van maatregelen om ondervoeding te verminderen. In de jaren zestig werd bijvoorbeeld duidelijk dat eiwitgebrek, weliswaar belangrijk, niet de enige of belangrijkste oorzaak van chronische ondervoeding is. Ook het feit dat het uitdelen van voeding, in de zin van voedselhulp, als antwoord op chronische ondervoeding niet juist was, werd geaccepteerd in de jaren zeventig. Toen werd ondervoeding ook onderkend als een veelzijdig of multisectoraal ontwikkelingsprobleem. Sindsdien is veel geleerd over het implementeren van programma's en over 
de kostenefficiëntie van de verschillende maatregelen die ondervoeding bestrijden.

Hoewel het bekend is dat beleids-, politieke en omgevingsfactoren ook invloed hebben op het voorkómen van ondervoeding, veel minder is bekend over welke die invloed is en welke deelfactoren het belangrijkste zijn. Deze factoren en de relatie tot het voorkómen van ondervoeding staan in deze studie daarom centraal. El zal worden gezocht naar factoren die het succes of falen van voedingsprogramma's in ontwikkelingslanden mede kunnen verklaren. Voedingsprogramma's zijn succesvol als ze bijdragen aan het verminderen en voorkómen van ondervoeding. Echter, er zijn talloze factoren die de toezegging van beleidsmakers op hoog niveau in de bureaucratie om letts aan het probleem te doen, bemoeilijken. Aan dit gebrek aan betrokkenheid - commitment of publieke verantwoordelijkheid, liggen voor voeding specifieke problemen ten grondslag.

Allereerst is er een algemeen gebrek aan onderkenning van de betekenis van ondervoeding (en aspecten daarvan), zowel op politiek als huishoudelijk niveau. Chronische ondervoeding is een grotendeels onzichtbaar fenomeen. Pas als het een ernstige vorm aanneemt wordt het witerlijk zichtbaar. Chronische ondervoeding is een relatief langzaam en geleidelijk proces wat zelfs ouders van ondervoede kinderen miet zien totdat het ernstig wordt. Jonge kinderen lijken gezond, maar groeien onvoldoende door frequente ziektes en gebrek aan goede voeding. Doordat ze onvoldoende groeien en het immuunsysteem niet voldoende wordt opgebouwd, worden ze vaker zlek, eten daardoor minder, groeien nog minder, en komen zo in een vicieuze cirkel terecht. Daarom is het van belang dat het controleren en bevorderen van groel op jonge leeftijd frequent wordt uitgevoerd om onvoldoende groei tijdig op te merken, ouders hierop te wijzen en maatregelen te nemen. Dit is een korte beschrijuing van wat een zogenoemde kinder-groelpromotie en voedingsvoorlichtingsprogrammas in ontwikkelingslanden als doel hebben.

Ten tweede, ondervoeding komt voornamelijk voor onder de armste en meest kwetsbare bevolkingsgroepen: jonge kinderen en vrouwen. Dit zijn tevens de bevolkingsgroepen die weinig politieke aandacht krijgen, omdat ze zich niet laten horen en er niet naar ze wordt geluisterd. Ten derde is er weinig motivatie bij de beleidsmakers om verantwoordelijkheid te nemen voor de vermindering van ondervoeding. Behalve dat ondervoeding een complex onderwerp is, is het aanpakken hiervan een langdurig proces. Dit laatste is politiek gezien niet erg aantrekkelijk, omdat politici zich vaak richten op zaken die in 
een periode van vier à vijf jaar te realiseren zijn, met het oog op herverkiezingen. Omdat het aanpakken van de ondervoedingproblematiek vaak een langere periode beslaat, zijn politici er niet snel in geïnteresseerd. Dan is er ten vierde het probleem dat ondervoeding een multisectoraal probleem is, waardoor het door verschillende sectoren tegelijkertijd aangepakt zou moeten worden. Er is vaak geen zelfstandig instituut of ministerie aan te wijzen die zich bezig dient te houden met dit probleem.

Het vijfde en laatste grote probleem voor het verkrijgen van meer aandacht voor ondervoeding op nationaal niveau in ontwikkelingslanden is het gebrek aan ownership (eigen verantwoordelijkheid) voor de voedingsagenda. De internationale voedingsgemeenschap heeft sinds de jaren zeventig hard gewerkt om het enorme ondervoedingsprobleem wereldwijd aan te pakken. Maar men heeft weinig gedaan en dus gefaald, om dit onderwerp op lokale ontwikkelingsagenda's te krijgen waarmee duurzame vermindering van ondervoeding bereikt kan worden. $\mathrm{Er}$ is te weinig geïnvesteerd in het opbouwen van middelen, zoals het trainen van voedingskundigen om voedingspolitiek te ontwikkelen, uit te voeren en te evalueren. Het gebrek aan ownership is verergerd doordat voedingsaktiviteiten ook nog grotendeels door externe donoren wordt gefinancierd. Degene die de activiteiten onder die omstandigheden uitvoeren voelen zich meer verantwoordelijk tegenover de donoren dan tegenover hun eigen bevolking. Teneinde duurzame vermindering van ondervoeding te bewerkstelligen is langdurige technische en financiële hulp naast het opbouwen van ownership en verantwoordelijkheid nodig. Het argument dat het bestrijden van ondervoeding ook de verantwoordelijkheid van de overheid is, is gebaseerd op mensenrechten en economische argumenten (in
hoofdstuk zes).

Gezien deze context kan een politiek gericht op good governance een belangrijke bijdrage leveren aan het voorkómen en verminderen van ondervoeding. Een aantal belangrijke onderdelen van het good governance concept kunnen de eerder genoemde problemen met betrekking tot het nemen van verantwoordelijkheid door beleidsmakers voor ondervoeding, Positief als dankzij kan zowel positief als negatief uitwerken. armoedebestrijding on andere multis van good governance ondervoeding aan de andere multisectoriele problemen zoals worden gehouden. Het kan komen en resultaten in de gaten overheden, die meer verantwook negatief uitpakken als nationale governance "geen interesse tonen voor krijgen dankzij good 
ondervoeding, vanwege de problemen die zojuist zijn beschreven.

\section{Hypothese en onderzoeksvragen}

In hoofdstuk twee worden de algemene hypothese en de onderzoeksvragen opgesteld. De hypothese is als volgt: van een land dat de principes van good governance volgt kan worden verwacht dat het ondervoeding als ontwikkelingsprobleem onderkent en fondsen mobiliseert om in voedingsprogramma's te investeren. Als deze programma's effectief en efficiënt worden uitgevoerd, kunnen ze tot het voorkómen en verminderen van ondervoeding leiden. Aan de andere kant, als een land geen deugdelijk bestuur voert, zal er weinig actie worden ondernomen om ondervoeding te verminderen en heeft de internationale voedingsgemeenschap de mogelijkheid om nationale voedingspolitiek te beînvloeden hetgeen kan leiden tot verminderde ownership en daardoor minder efficiënte en effectieve uitvoering van het beleid.

Good governance is in deze studie gedefinieerd als de manier waarop macht wordt gebruikt in het besturen van de economische en sociale welvaartsbronnen in een land (World Bank 1997). Good governance bevordert 'wetgeving' en het verzekert dat politieke, economische en sociale prioriteiten zijn gebaseerd op een brede consensus van de bevolking en dat de armen en kwetsbaren een stem hebben in de beslissingen over de toewijzing van publieke fondsen (UNDP 1997).

Publieke verantwoordelijkheid (public accountability) voor voedingsproblematiek is in deze studie gedefinieerd als de publieke sector, de overheid, die verantwoordelijkheid neemt voor de voedingsproblematiek. Allereerst door aandacht te vragen voor dit probleem, ten tweede door het nemen van actie om ondervoeding te voorkómen en te verminderen, en ten derde door fondsen beschikbaar te stellen voor het uitvoeren van geschikte activiteiten en programma's.

De onderzoeksvragen in deze studie zijn in twee delen gesteld. De theoretische overwegingen en ontwikkeling van een raamwerk en de analyse van de data zelf. De algemene theoretische vraag is gedefinieerd als volgt: wat zijn de sleutelfactoren van good governance, die aan het bestrijden van ondervoeding bijdragen, doordat ze publieke verantwoordelijkheid voor voeding creëren en investeringen in voedingsinterventies bevorderen. Door middel van de empirische vragen worden deze factoren getest. In hoofdstuk zeven is de kwantitatieve cross-country analyse van governance indexen en ondervoeding weergegeven. In hoofdstuk acht worden de 
resultaten ven de kwantitatieve analyse tussen governance indexen en publieke verantwoordelijkheid voor voeding en investeringen besproken. In hoofdstuk negen tenslotte is een casus opgenomen, omdat deze studie grotendeels exploratief is, en deze casus aan de exploratie bijdraagt door te analyseren hoe het raamwerk in de realiteit uitpakt.

\section{Onderzoeksviagen}

De kernvragen laten zich als volgt samenvatten:

1. Wat is ondervoeding, waarom is het een ontwikkelingsprobleem en waarom is het de verantwoordelijkheid van de overheid er lets aan te doen, zodat de principes van good governance ertoe doen?

2. Hoe is ontwikkelingsbeleid geëvolueerd en wanneer is er meer complementariteit tussen algemeen ontwikkelingsbeleid en voedingsbeleid waar te nemen?

3. Wat is 'good governance' en wanneer en waarom werd het de dominante stroming in hel algemene ontwikkelingsbeleid?

4. Wat zijn de meest belangrijke aspekten van 'good governance' in de strijd tegen ondervoeding, via welke, in theorie, het voedingsbeleid in ontwikkelingslanden kan worden geholpen?

5. Hoe dan dragen deze specifieke elementen bij aan voedingsbeleid in ontwikkelingslanden, via welke processen?

6. Is governance in ontwikkelingslanden van een hoger niveau in de tweede helft van de negentiger jaren van de vorige eeuw dan daarvoor?

7. Is er een correlatie tussen governance indezen en ondervoedingswaarden in ontwikkelingslanden in Africa, Azie en Latijns-America?

8. Als ontwikkelingslanden beter scoren op governance indexen, scoren ze dan ook beter op de score voor publieke verantwoordelijkheid voor voeding?

9. Als ontwikkelinslanden beter scoren op governance indexen, investeren ze dan ook meer in voedingsaktiviteiten?

\section{Ondervoeding}

Gebrek aan voldoende voedsel, onvoldoende verzorging, onvoldoende toegang tot adequate gezondheidsvoorzieningen, gebrek aan schoon water en sanitaire faciliteiten zijn de welbekende directe oorzaken van ondervoeding. Armoede, analfabetisme onder vrouwen en algemeen gebrek aan voedsel zijn indirecte corzaken van ondervoeding (figuur 2.1 hoofdstuk twee). Hoofdstuk drie geeft een gedetailleerd verslag van een literatuurstudie over wat ondervoeding is, waarom het een 
ontwikkelingsprobleem is en wat eraan gedaan kan worden. Meer dan 180 miljoen kinderen jonger dan vijf jaar in ontwikkelingslanden lijdt aan ondervoeding. Deze kinderen zijn vaker en ernstiger ziek. Meer dan 11,6 miljoen kindersterften in ontwikkelingslanden zijn geassocieerd met ondervoeding (Pelletier 1993:1130). Met andere woorden, deze kinderen zouden nog in leven zijn als ze niet ook ondervoed waren geweest. Ondervoede kinderen hebben slechtere resultaten op school en op de lange duur ondermijnt ondervoeding armoedebestrijding en ontwikkeling. Naast meer gedetailleerde beschrijvingen over de consequenties van ondervoeding wordt in hoofdstuk drie tevens de omvang van het probleem besproken. De beschrijving van de verschillende voedingsprogramma's die de Wereldbank financiert vormen het laatste deel van dit hoofdstuk.

\section{Ontwikkelingshulp en Ondervoeding}

Een chronologisch overzicht over de evolutie van ontwikkelingsbeleid sinds de jaren vijftig, tezamen met een overzicht van het denken over ondervoedingsbeleid over dezelfde periode laat zien dat er eind jaren negentig meer complementariteit is gekomen. Tot de jaren zeventig werd ondervoeding vooral gezien als een metabole ziekte en werden alleen zeer ernstige vormen van ondervoeding behandeld, grotendeels in ziekenhuizen. In de zeventiger jaren, toen de algemene ontwikkelingspolitiek zich meer ging richten op het bestrijden van armoede, werd tegelijkertijd ingezien dat chronische ondervoeding een veel voorkomend ontwikkelingsprobleem was. Maar ontwikkelings-hulp was nog altijd aanbodgestuurd in plaats van vraaggericht en gaf weinig aandacht aan het opbouwen van capaciteit in de jaren zeventig. De National Nutrition Commissions die in diezelfde periode waren opgezet onder nationale planningbureaus of ministeries, met externe assistentie weliswaar, waren in feite te prematuur hiervoor en hebben weinig succes geboekt. Toentertijd was er te weinig aandacht voor lokaal ownership over beleid en beleidsprogramma's van de kant van de nationale overheden. En ook moet worden gezegd dat er destijds veel minder bekend was over effectieve maatregelen met als doel het verminderen en voorkómen van ondervoeding.

In de jaren tachtig van de vorige eeuw was er nog minder complementariteit in het denken over ontwikkelingshulp op macroniveau en het uitvoeren van voedingsprogramma's op microniveau. In de voedingswereld was de focus gericht op meer verticale interventies via de gezondheidssector. Op macroniveau 
richtte men zich op de zogenaamde en inmiddels welbekende structural adjustment programma's. Deze jaren boden dus weinig mogelijkheden op het gebied van complementariteit.

Vanaf de jaren negentig van de vorige eeuw richt het algemene internationale ontwikkelingsbeleid van zich weer op armoedebestrijding en is het voedingsdenken tevens meer gericht op het aanpakken van de bredere ontwikkelingsproblematiek. Het voedingsdenken begon in de richting van het denken over het belang van de context, enabling environment, te gaan. Bijvoorbeeld brede participatie in besluitvormingsprocessen over armoedebestrijding door de civil society, waaronder niet-gouvernementele organisaties, werd sterk gestimuleerd door zowel internationale ontwikkelingsorganisaties als vanuit de voedingswereld. Door middel van dit beknopte chronologische overzicht wordt duidelijk dat er in de jaren negentig meer mogelijkheden ontstaan om ondervoeding als publieke verantwoordelijkheid te bevorderen en dat de aandacht voor deugdelijk beleid hieraan bijdraagt.

\section{Good Governance}

Alvorens een gedetailleerd overzicht te geven van hoe good governance bij zou kunnen dragen aan het bestrijden van ondervoeding, is in hoofdistuk vijf eerst een overzicht gegeven van wat good governance inhoudt en hoe het wordt geînterpreteerd door de verschillende ontwikkelingsinstanties, zoals onder andere de Wereldbank. De Wereldbank publicatie

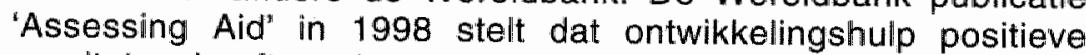
resultaten heeft en het meest effectief is in landen met good governance. Het was in 1992 dat de Wereldbank ondeugdelijk bestuur als problematisch en verantwoordelijk voor het falen van ontwikkelingsbeleid aandroeg in de publicatie 'Sub-Saharan Africa: From Crisis to Sustainable Growth, Underlying Africa's Development Problem is a Crisis of Governance'. In 1996 plaatste Wereldbank president James D. Wolfensohn corruptie in het publieke debat over de effectiviteit van ontwikkelingsbeleid. Dit laat zien dat good governance, ook al is het uitermate bekritiseerd, toch belangrijke factoren zoals corruptie op de agenda heeft geplaatst. Een overzicht van de literatuur, die de argumenten om good governance te bevorderen ondersteunt, is ook te vinden in hoofdstuk vijf.

$\mathrm{Er}$ is veel discussie over de vraag of good governance nu wel of niet een kritieke factor in ontwikkelingspolitiek is en of het werkt of niet. Het is niet de doelstelling van deze studie om specifiek aan dit debat bij te dragen. Het is echter wel belangrijk de kritiek te bespreken. Recente publicaties van het 
Internationale Monetaire Fonds, een zusterorganisatie van de Wereldbank, hebben het debat weer teruggebracht naar de initiële vraag of ontwikkelingsbeleid überhaupt effectief is of niet. Een van de laatste studies bijvoorbeeld stelt dat de bewijzen niet voldoende robuust zijn om de effectiviteit te bewijzen, zelfs niet in landen met deugdelijk bestuur. Hoewel over dit laatste het vonnis nog niet is geveld, en waarschijnlijk ook niet geveld zal worden in de komende tien jaar, zal het debat doorgaan en worden verrijkt met nieuwe informatie en kennis.

Alhoewel critici de Wereldbank verwijten het begrip good governance te misbruiken om haar eigen falen te verbergen, is vooral de Wereldbank's aandacht voor factoren als corruptie publiekelijk besproken. lets wat vóór de negentiger jaren van de vorige eeuw zelden voorkwam. Naarmate de aandacht voor good governance toenam, zijn er ook meer data beschikbaar gekomen om het te meten, zoals in de vorm van een operationalisatie van politieke stabiliteit, rule of law, en anti-corruptiemaatregelen.

\section{Good Governance en Ondervoeding}

Diverse studies laten zien dat er positieve correlaties bestaan tussen good governance en sociale indicatoren als kindersterfte en analfabetisme. Een van de doelstellingen van deze studie is te analyseren of deze relatie ook bestaat tussen governance en ondervoeding in ontwikkelingslanden. Echter, naast de analyse van de "governance"indexen is de vraag naar de relatie tussen governance en publieke verantwoordelijkheid voor voeding in ontwikkelingslanden met hoge ondervoedingswaarden belangrijk. Het beantwoorden van deze vraag kan helpen met het beter formuleren van voedingspolitiek en het opbouwen van verantwoordelijkheid op nationaal niveau. In dit hoofdstuk is tevens een meetinstrument voor publieke verantwoordelijkheid voor voeding ontwikkeld.

In hoofdstuk een is een aantal problemen genoemd die ondervoeding als ontwikkelings-probleem ondervindt. In dit hoofdstuk worden drie routes beschreven die de relatie tussen good governance en ondervoeding mogelijk geheel of ten dele kunnen verklaren, waarbij het accent op de genoemde problemen ligt.

Ondervoeding is een conditie die grotendeels onder de armen voorkomt die politiek weinig inbreng hebben. Zelden wordt naar de mening van de armen gevraagd, noch wordt vaak naar hen geluisterd. Good governance kan bijdragen aan het verbeteren van het luisteren naar de armen, omdat het nemen verbeteren van het luisteren naar de armikelingsbeleid gebaseerd
van beslissingen in het kader van ontwiknt te zijn op brede participatie, inclusief civil society. Good
dient 
governance bevordert dat de armen gehoord moeten worden en hun behoeften in aanmerking moeten worden genomen. Daarnaast kan het bijdragen aan het creëren van erkenning van chronische ondervoeding in de publieke sector, omdat het armoedebeleid bevordert. Ondervoeding is een multidimensionaal probleem dat weinig aandacht krijgt in een sectoreel gestructureerde wereld. De principes van good governance houden in dat het armoedeprobleem in haar multisectoraliteit moet worden bekeken. Zodoende opent politiek, gericht op good governance, wegen om ondervoeding als ontwikkelingsprobleem anderkend en erkend te krijgen.

De tweede route wordt geopend door de focus van good governance op het verbeteren en hervormen van de publieke sector. Er wordt te weinig geïnvesteerd in ondervoedingprogramma's en ze worden vaak niet goed uitgevoerd. Het verbeteren van de effectiviteit waarmee de overheid diensten uitvoert, service delivery, is een zeer belangrijk aspect van good governance. Door de aandacht hierop te richten kan ondervoeding hiermee ook voordelen behalen, vooral in combinatie met de focus op armoede.

De derde route via welke good governance kan bijdragen aan het verbeteren van de ondervoedingssituatie is meer indirect via het anti-corruptie beleid en ondersteuning van rule of law. Hoewel deze één van de belangrijkste invloeden zou kunnen zijn, is het resultaat hiervan mogelijk pas op zeer lange termijn zichtbaar. Er is tijd nodig om de effecten van transparant bestuur in de uitvoering van programma's te zien.

\section{Governance Indexen en Ondervoedingsstatistieken}

In hoofdstuk zeven is het eerste deel van de kwantitatieve analyse uitgevoerd tussen de indexen van governance en ondervoedingswaarden. Als governance indicatoren worden data van de Kaufmann en Kraay-databank gebruikt. De complete databank gebruikt in deze studie beslaat 82 landen in drie regio's: Latijns-Amerika, Afrika en Azië. Voor zes 'governance'indexen is een positieve correlatie met ondervoeding geconstateerd. De volgende vraag is of sprake is van een significant verband, indien de invloed van de variabelen inkomen en verschillen in regio's onder controle wordt gehouden. De tweede statistische analyse laat zien dat vier van de zes indicatoren positief en significant saemhangen met ondervoeding, onder constanthouding van inkomen en regioverschillen. Zowel political stability, government effectiveness, rule of law en control of corruption zijn significant gecorreleerd. Behalve control of corruption zijn ze alle significant 
op het $95 \%$ betrouwbaarheidsniveau. Echter, voice and accountability en regulatory quality ziinn niet gecorreleerd met ondervoeding. Dat de laatstgenoemde geen relatie laat zien, kan worden verklaard doordat de indicator het vóórkomen van marktonvriendelijk beleid meet, hetgeen vrijwel geen relatie tot ondervoeding heeft. Dat voice and accountability geen direkte relatie laat zien, is verrassend. Dit wordt mogelijk veroorzaakt doordat het optreden van samenhang een kwestie van tijd is en een verschil van vier jaar, de tijdsperiode tussen de data, te kart is om een statistisch verband te constateren.

\section{Governance indexen en Publieke verantwoordelijkheid voor voeding}

In dit hoofdstuk worden de aannamen van de drie theoretische routes, die het verband tussen governance en ondervoeding proberen te verklaren, getest. Twee onderzoeksvragen zijn hier van belang. Kan de hypothese worden bevestigd dat landen die zich meer inzetten voor good governance, beter scoren op de governance-indexen, en ook meer aandacht geven aan het bestrijden van ondervoeding? En kan de hypothese wordt ondersteund dat landen die zich beter inzetten voor good governance meer investeren in voedingsinterventies en programma's?

In hoofdstuk zes is een meetbare score op publieke verantwoordelijkheid voor voeding ontwikkeld en de nationale armoedebestrijding strategische beleidsdocumenten (PRSPS) zijn gebruikt om de data te verzamelen. De gezondheids- en voedings-projecten van de Wereldbank zijn gebruikt om data met betrekking tot investering in voeding te verzamelen. In totaal is een databank bestaande uit 40 landen voor de eerste vraag en 32 landen voor de tweede vraag ontwikkeld voor de analyse.

De analyse bevestigt de hypothese dat voeding meer aandacht krijgt, vaker tot een prioriteit wordt gemaakt en een budget krijgt aangewezen, in landen die zich beter inzelten qua governance. Dit kan worden bevestigd voor alle drie de aangenomen routes die zijn gemeten met behulp van de governance-indexen voice and accountability, government effectiveness, rule of law en control of corruption. De aanname is bevestigd voor zowel veranderingen in inzet, dus verbeterd over de gemeten periode, als de inzet gemeten in het jaar 2000. Bijna twee-derde van de landen waar 'government'- effectiviteit verbeterde in de periode tussen 1996 en 2004, maken het bestrijden van ondervoeding een prioriteit in het armoedebestrijdingsbeleid. Terwijl dit percentage veel lager (een 
derde) ligt in landen waar de indicator verslechterde over dezelfde periode.

Echter de aanname dat deze landen, die beter scoren qua governance, ook meer investeren kan niet worden bevestigd. In tegendeel, er is voor alle indicatoren, behalve government effectiveness, een negatieve relatie met de verantwoordelijkheid voor voeding. Alleen government effectiveness laat een positieve relatie met publieke verantwoordelijk voor voeding zien. Per hoofd van de bevolking wordt een gemiddelde van US\$ 0.89 geînvesteerd in landen waar government effectiveness verbetert. Waar het verslechtert, wordt per hoofd van de bevolking gemiddeld US\$ 0.80 geïnvesteerd. Maar landen waar de andere indicatoren verbeteren, investeren per hoofd van de bevolking minder in voeding dan de landen waar het verslechtert.

Er moet rekening worden gehouden met eventueel grote problemen met de kwaliteit van de data. Bijvoorbeeld de data met betrekking tot investeringen in voeding zijn afkomstig van de Wereldbank projecten en zijn exclusief eventueel ander belangrijke bronnen van financiering. Een verklarende factor kan in feite zijn dat juist omdat er weinig aandacht aan voeding wordt gegeven door de nationale overheden, de Wereldbank dit financiert.

Alhoewel de vraag over de relatie tussen publieke verantwoordelijkheid voor voeding en het niveau van investering ook interessant is in dit verband, laten de data geen analyse toe. De data over verantwoordelijkheid voor voeding zijn afkomstig uït documenten die in 2000 en later zijn ontwikkeld en geschreven, terwijl de investeringsdata uit de jaren 90 komt. Het zou interessant zijn deze studie na 5 jaar te herhalen, gerekend vanaf de datum van deze eerste studie en de data hier verzameld en geanalyseerd als beginniveau te gebruiken.

\section{Governance en Ondervoeding in Madagascar, een Casus}

De aanvulling van de analyse met een casus maakt de algehele analyse waardevol door het overbruggen van theorie, kwantitatieve analyse en praktijk. Als casus is Madlagascar gebruikt, omdat Madagascar over de periode die in deze studie is onderzocht belangrijke veranderingen in zowel governance als voedingpolitiek heeft doorgemaakt. Daarnaast is de auteur van deze studie de laatste negen jaar bij dit proces betrokken geweest.

De bevindingen van de casus bevestigen de centrale hypothese van deze studie. $\mathrm{Er}$ is in Madagascar een sterk verband tussen de verbeterde aandacht voor het armoedebeleid 
van de overheid en de mate van publieke verantwoordelijkheid voor voeding. De algehele ontwikkelingsfocus op brede participatie in besiuitvormingsprocessen en de anti-corruptie politiek heeft in belangrijke mate bijgedragen aan de institutionalisering van voeding in Madagascar. Twee perioden met duidelijke verschillen in governance en mate van verantwoordelijkheid voor voeding kunnen worden onderscheiden. Begin negentiger jaren kreeg good governance weinig aandacht buiten het hervormen van de publieke sector. Maatregelen om andervoeding te bestrijden waren toentertijd beperkt tot kleinschalige activiteiten en werden grotendeels door de donoren begeleid. Governance-indexen verbeterden tegen het einde van de negentiger jaren. Dee nationale overheid werd meer betrokken bij het bestrijden van ondervoeding. Publieke verantwoordelijkheid werd opgebouwd en investeringen in voedingsactiviteiten namen toe. Madagascar is in 2004 één van de weinige Afrikaanse landen waar ondervoeding vermindert.

\section{Conclusie en discussie}

Ondervoeding is en blift een belangrijk ontwikkelingsprobleem dat jonge kinderen treft en langdurig negatieve gezondheids- en leervermogenseffecten heeft. Op latere leeftijd zijn volwassenen, die als kind ondervoed waren, minder productief. Echter, zelfs met de erkenning dat ondervoeding hoge kosten in economische termen heeft, wordt er erg weinig gedaan om het te verminderen en te bestrijden. $\mathrm{Na}$ 40 jaar blijft de omvang van het ondervoedingsprobleem onacceptabel hoog met bijna een derde van de kinderen onder de vijf jaar in ontwikkelingslanden die ondervoed zijn. De bestrijding van ondervoeding is een verantwoordelijkheid van de publieke sector. Deze stelling is gebaseerd op mensenrechten en economische argumenten. De internationale voedingsmaatschappij heeft lang de leiding genomen in het ontwikkelen van voedingspolitiek. Ook heeft ze lang de leiding genomen in het opzetten en uitvoeren van kleinschalige projecten met de hoop dat nationale overheden het zouden overnemen indien dit succesvol bleek. Er zijn aanwijzingen dat wanneer de nationale overheid niet bij programmas is betrokken en er niet achter staat, investeringen niet rendablel zijn. Good en er niet achter staat, investeringen deze verantwoordelijkheid
governance geeft nationale overheden dez
en verbetert de kans op succes voor ontwikkelingsprogramma's, inclusief voeding.

In deze studie is een significant positief verband In deze studie is een sije governance factoren en
gevonden tussen vier belangrijke
ondervoeding in een onderzoekspopulatie van 82 landen 
verdeeld over drie regio"s: Latinns Amerika, Afrika en Azlë. Politiek stabiele landen hebben lagere ondervoedingswaarden dan landen waar de perceptie voor politieke stabiliteit laag is. Landen met betere scores met betrekking tot de effectiviteit en efficiêntie wan overheden hebben lagere ondervoedingswaarden. Landen die beter scoren op anti-corruptie en wetgeving hebben lagere ondervoedingswaarden. Deze bevindingen bevestigen de hypothese dat landen met good governance betere voedingswaarden hebben. Met andere woorden, governance matters for nutrition.

Deze studie had twee doelstellingen. Het analyseren van de relatie tussen governance-indexen en ondervoeding. Indien dit positief was, dan hiervoor beter begrip krijgen over het waarom van dit verband. Daarvoor waren drie routes geidentificeerd. De analyse laat zien dat het verband tussen governance en publieke verantwoordelijkheid voor voeding wordt bevestigd terwijl de relatie tussen governance en investeringen alleen voor één van de indexen wordt bevestigd.

Een belangrijke vraag is ook hoe de resultaten van deze studie bijdragen aan het debat over meer aandacht voor ondervoeding, zodat ondervoeding wereldwijd kan worden verminderd. Allereerst wordt met deze studie het belang van het beter begrijpen van de invloed van een macroniveau belleid op een multisectoraal probleem belicht. En de resultaten laten zien dat die invloed van belang kan zijn. De casus heeft een meerwaarde in de zin dat het laat zien dat met good governance meer verantwoordelijkheid voor voeding kan worden bereikt, hetgeen tot meer investering kan leiden en positieve resultaten worden bereikt.

De belangrijkste conclusies zijn als volgt.

Good governance is belangrijk voor het verminderen van ondervoeding. Landen die beter scoren op governance, hebben lagere ondervoedingswaarden. De governancefactoren government effectiveness, political stability en rule of law, blijken van specifiek belang te zijn.

Met grote waarschijnlijkheid zal ondervoeding meer aandacht krijgen door de combinatie van attentie op de Millennium Development Goals en good governace. Echter, de waarschijnlijkheid dat er inderclaad meer attentie wordt gegeven aan de MDGs en good governance is een andere vraag. Het is bekend dat hoewel er veel aandacht is voor de MDGs in publieke toespraken, dat ook vaak niet meer dan retoriek blijkt te zijn en er weinig concrete actie op volgt. Wat aan nieuwe toezeggingen door de westerse landen voor ontwikkelingshulp wordt gedaan, is veel lager dan de thuidige behoeften. Daarnaast is het jammer dat nu duidelijk is dat good governance het verminderen van 
ondervoeding bevordert, good governance zelf geen duidelijke wereldwijde verbetering laat zien. Wereldwijd blijken de indicatoren te stagneren (Kaufmann 2005). Echter als wordt gekeken, niet qua aantal landen wat verbetert, maar qua bevolkingsaantailen, zien we een positiever beeld omdat zowel China en India, de meest dichtbevolkte landen, verbeteren.

Het belang van good governance in ontwikkelingsbeleid is niet een tijdelijke 'gril' in het beleid. Het is 15 jaar geleden herkend als een kritiek element van ontwikkeling en heeft tot belangrijke hervormingen in ontwikkelingsbeleid van tal van landen geleid. Het is van belang voor ontwikkeling, voor humane ontwikkeling en voor ondervoedingsbestrijding. Het is belangrijk dat de voedingsmaatschappij de inzichten en het verband tussen governance en de strijd om ondervoeding een ontwikkelings'issue' te maken, herkent. Meer samenwerking met de publieke sector en tussen donoren kan dit proces versterken. 


\section{References}

(The term "processed" describes intormally reproduced works that may not be commonly available through libraries).

Abrahamsen R. (2000) Disciplining Democracy: Dewelopment Discourse and Good Governance in Africa Zed Books, London

ACC/SCN (2000) Fourth Report on the World Nutrition Situation ACC/SCN, Geneva

Alderman $H_{.}$. J. Hoddinott and B. Kinsey (2002) Long-term Consequences of Early Childhood Malnutrition World Bank, Washington DC (processed)

Alesina A and D. Dollar (2000) Who Gives Foreign Aid to Whom and Why? Journal of Economic Growth 5(1):33-63

Allen L.H. and S.R. Gillespie (2001) What Works? A Review of the Efficacy and Effectiveness of Nutrition Intenventions Asiam Development Bank Nutrition and Development Series report no.5 and Nutrition Policy Paper no.19 ACCISCN, Geneva.

Anten L.M., H.C. Baak, P. Dijkhuizen, F. Van der Haar, A.P. den Hartog, J. Hinderink, W. Klaver, J.A. Kusin, F.G. Ory, A.P. Remmelzwaal, M.W. van Roosmalen-Wiebenga and J.A. Zwartz (1986) Voeding in Ontwikkelingslanden Samson Stafleu, Alphen a/d Rijn

Bardhan P. (2002) Decentralization and Governance Journal of Economic Perspectives $x x$

Barker D.J.P. (1998) Mothers, Babies and Diseases in Later Life Churchill Livingstone, London

Behrman J.R. (1993) The Economic Rationale for Investing in Nutrition in Developing Countries World Development (21)11:1749-72

Berhman J...H Alderman and J. Hoddinott (2004) Malnutrition and Hunger in Lomborg B. (ed) Global crisis, global solutions. Copenhagen Consensus 2004 Cambridge University Press, Cambridge

Berg A. (1973) The Nutrition Factor: Its Role in Development The Brookings Institute, Washington DC Berg A. (1987) Malnutrition, What Can Be Done? Johns Hopkins University
Press, Baltimore

Biswas M. and P. Pinstrup-Andersen (eds) (1985) Nutrition and Development Oxford University Press

Black R.E., S.S. Morris and $\Downarrow$. Bryce (2003) Where and Why are 10 Millian Children Dying Every Year? Lancet 361:2226-34

Booth D. (ed.) (2003) Fighting Poverty in Africa: Are PRSPS making a Difference? Oversees Development Institute, London

Brautigam D. (1991) Governance and Economy; a Review Policy Research Working Paper no.815 World Bank, Washington DC (Processed) 


\section{References}

Brautigam D. (2000) Ald, Dependence and Govemance Expert Group on Development Issues (EDGl) 2000:1 Slockholm, Sweden

Brown M. (2000) A History of Madagascar Markus Wiener Publishers, Princeton NY

Brown M. B. (1995) Africa's Choices; After Thirty Vears of the World Bank. Westview Press, Inc.

Bryce J, S el Arifeen, G. Pariyo, C.F. Lanata, D. Gwatkin, J.P. Habicht (2003) Reducing Chila Mortality can Public Health Deliver? Lancet 362:159-64

Burnside C. and D. Dollar (2004) Aid, Policies and Growth: Revisiting the Evidence Policy Research Working Papers Series 3251, World Bank, Washington DC (processed)

Clemens M.A., S. Radelet and R. Bhavnani (2004) Counting Chickens when they Hatch: the Short-term Effect of Aild on Growth working paper no. 44 Centre for Global Development, Washington DC (processed).

Coase R.H. (1988) The Firm, The Market, and the Law University of Chicago Press, Chicago

Collier P. and D. Dollar (2001) Development Effectiveness: What have we learnt? World Bank, Washington DC (processed)

Cornia G.A., R. Jally R. and F. Stuart (1987) Adjustment with a Human Face; protecting the vulnerable and promoting growth A UNICEF study Clarendon Press, Oxford

Davidson S., R. Passmore, J.F. Brock and A.S. Truswell (1983) Human Nutrition and Dietetics Churchill Livingistone NY, seventh edition

Degnboll $J$, and P. Engberg-Pedersen (2003) Aid" understanding international Development Cooperation Zed Books Lid, London

Del Rosso J.M. and T. Marek (1996) Class Action: Improwing School Performance in the Developing World through Better Health and Nutrition World Bank, Washington DC

Dollar D. and L. Pritchett (1998) Assessing Aid: What Works, What Doesn't and Why? Oxford University Press

Doombos M. (2003) Good Governance: Metamorphosis of a Policy Metaphor Journal of International Affairs Fall 2003:3-17 - reproduced from 2001 paper in Journal of Development Studies 37 (2001) 6:93-108

Dreze J. and A. Sen (1989) Hunger and Public Action Clarendion Press, Oxford Easterly W. (2003) Can Foreign Aid Buy Growth? Journal of Economic
Perspectives $17(3): 23-48$

Easterly W., A. Levine and D. Roodman (2004) New Data, New Doubts: Comments Burnside and Dollar's Aid, Policies and Growth American Economic Review (Forthcoming)

Eggertson T. (1990) Economic Behavior and Institutions New York: Cambridge
University Press 
Fengler W. (2003) Madagascar Decentralization Report no. 25793, World Bank Washington DC (processed)

Field J.O. and J.F Levinson (1975) Nutrition and Development Dynamics of Political Commitment. Food Policy (11) 1975

Field J.O. (1985) Multisectoral Nutrition Planning: a Post-Mortem Food Policy Vol.12(1):15-28

Field J.O. (1987) Implementing Nutrition Programs: Lessons from an Unheeded Literature Annual Review Nutrition (5):143-72

Filmer D. and L. Pritcheft (1999a) The Effect of Household Wealth on Educational Attaimment: Evidence from 35 countries. Population and Development Review 25 (1):85-120

Filmer D. and L. Pritchett (1999b) The Impact of Public Spending on Health; Does Money Matter? Social Science and Medicine 49 (10):1309-23

Findlay R. (1991) The New Poltical Economy: Its Explanatory Power for LDCs Politics and Policy Making in Developing Countries Gerald M. Meier (ed) San Francisco ICS Press

Frongillo E., M. de Onis and F. Hanson (1997) Commentary Socioeconomic Inequalities and Child Growth Joumal of Epidemiology 32(4) 503

Fukuda-Parr S. and R. Ponzio (2002) Governance: Past, Present and Future Setting the Governance Agenda for the Millennium Declaration Human Development Report 2002, United Nations, Development Program, New York

Fukuyama F. (2004) State-Building: Governance and World Order in the $21^{\text {sit }}$ Century Cornell University Press, Ithaca NY

Galasso M. and J. Yau (2005) Improving Nutritional Status through Behavioral Change: Lessons from the SEECALINE Program in Madagascar Preliminary data presented at Brown University.

Gallioway R., E. Dusch, L. Elder, E. Achadi, R. Grajeda, E. Hurtado, M. Favin, S. Kanani, J. Marsaban, N. Meda, K.M. Moore, L. Morison, N. Raina, J. Rajaratnam, J. Rodriguez and C. Stephen (2002). Women's perceptions of iron deficiency and anemia prevention and control in eight developing countries Social Science and Medicine 55:529-544

Galloway R. (2003) Anemia Prevention and Control: What Works USAID, World Bank, UNICEF, PAHO, WHO and Micronutrient Initlative

Gearge S. and F. Sabelli (1994) Faith and Credit; The World Bank's Secular Empire West View Press Boulder, CO

Gillespie S. R and J.B Mason (1991) Nutrition Relevant Actions; Some Experiences from the Eighties and Lessons for the Nineties ACC/SCN, Geneva

Gillespie S. R., J.B. Mason and R. Martorell (1996) How Nutrition Improves ACC/SCN, Geneva 
Gillespie S. R. (2001) Strengthening Capacity to Improve Nutrition Food Consumption and Nutrition Division Discussion Paper no. 106 IFPRI, Washington DC (processed)

Gillespie S.R., M. McLachlan and R. Shrimpton (eds) 2003 Cambating Mainutrition, Time to Act World Bank, Washington DC

Glahe F. and F. Vorhies (1989) Religion, Liberty and Economic Development: An Empinical Investigation Public Choice 62(3):201-215

Glewwe P. and $H$. Jacoby (1995) An Economic Analysis of Delayed Primary School Enrollment and Childhood Malnutrition in a Low Income Country Review of Economics and Statistics $77(1): 156-69$.

Goetz A.M and R. Jenkins (2002) Voice, Accountability and Human Development: The Emergence of a New Agenda. Background paper for Human Development Report 2002 UNDP, NY (processed)

Goh C. (2001) An Analysis of Combating lodine Deficiency: Case-studies of China, Indonesia and Madagascar OED Working Paper Series World Bank, Washington DC

Government of Madagascar (2005) National Nutrition Policy Madagascar

Grantham-McGregor S. (1993) Assessments of the Effects of Nutrition on Mental Development and Behavior Jamaican Studies American Journal of Clinical Nutrition 57 (supplement):303S-9S

Grindle M.S. (ed.) (1997) Getting Good Government; Capacity Building in the Public Sectors of Developing Countries Harvard University Press

Grindle M.S. (2004) Good Enough Governance: Poverty Reduction and Reform in Developing Countries Governance International Journal of Policy, Administration and Institutions $17(4): 525-548$

Gupta S. H.R. Davoodi and E.R. Tiangson (2002) Corruption and the Provision of Health Care and Education Services in George T. Abed and S. Gupta (eds) Governance, Corruption and Economic Performance. The International Monetary Fund Washington DC

Gwatkin D. and M. Guillot (2000) The Burden of Disease among the Global Poor: the Current Situation, Future Trends and Implications for Strategy World Bank, Washingtan DC

Haddad L., H. Alderman, S. Appleton, L. Song and Y. Yohannes (2003) Reducing Chid Malnutrition; How Far Does Income Growth Take Us? The World Bank Economic Review 17 (1):107-131

Haddad L. (2003) Nutrition and Poverty A Foundation for Development Publication, brief no.8 ACC/SCN, Geneva

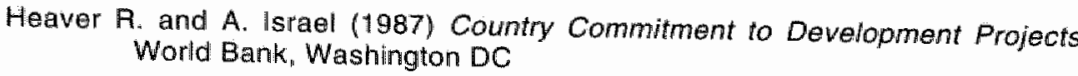

Heaver R. (2002) Improving Nutrition; Issues in Management and Capacity Development World Bank, Washington DC (Processed) 
Heaver A. and Y. Kachondam (2002) Thailland"s National Nutrition Program: Lessons in Management and Capacity Development World Bank, Washington DC (processed)

Heaver R. (2005) Strengthening Country Commitment to Human Development: Lessons from Nutrition World Bank, Washington DC (forthcoming)

Hirschman (1970) Exit, Voice and Loyalty: Responses to Decline in Firms, Organizations and States Harvard University Press

Hoogerwerf A. and M. Herweijer (2003) Overheidsbeleid Kluwer, Alphen aid Rijn (seventh edition)

Horton S. (1999) Opportunities for Investment in nutrition in low-income Asia Asian Development Review $17(1,2): 246-273$

Hout W. (2001) Institutions and Development Background study for Scientific Council for Government Policy $5 \mathrm{~B}^{\text {th }}$ Report Development Policy and Good Governance WRR, The Hague

Hyden G. (2001) Operationalizing Governance for Sustainable Development Koninklijke Brill NV, Leiden Joumal of Developing Societies 17(2):1332

IMF/IDA. (2003) PRSP progress report Washington DC (processed)

Isham J. D. Kaufmann and L. Pritchett (1997) Civil Liberties, Democracy and the Performance of Government Projects World Bank Economic Review 11(2)

Johnson J.H. and S.S. Wasty (1993) Borrower Ownership of Adjustment Programs and the Political Economy of Reform World Bank. Washington $\mathrm{DC}$

Jonsson U. (1990) UNICEF Malnutrition Framework Cornell University Press, Ithaca NY

Jonsson U. (1993) Integrating Political and Economic Factors within Nutritionrelated Policy-Research: An Economic Perspective. In PinstrupAndersen (ed) (1993) The Political Economy of Food and Nutrition Policies. The Jolnn Hopkins University Press, Baltimore MD

Jonsson U. D. Pelletier and R.K. Shrimpton (1998) A UNICEF strategy for Improving Decision-making at the Household. Community and National Levels NY, UNIICEF

Jones G., R. W. Steketee, R. Black, Z.A. Bhutta and S.S. Morris (2003) How Many Child Deaths can we Prevent this Year? Lancel 362:65-71

Kavishe F. (1996) Nutrition in Social Policy Context in the Eastern and Southern Africa Region Nairobi, East and South Africa Regional Office (ESARO) annual report (Processed)

Kapur D., J.P. Lewis and R. Webb (1997) The World Bank, Its First Hall Century (volume 1 and 2) Brookings Institution Press, Washington DC 


\section{References}

Kaufmann D., A. Kraay and P. Zoido-Lobaton (1999) Aggregating Governance Indicators World Bank Policy Research Paper no.2195, Washington DC (processed)

Kaufmann D., A. Kraay and M. Mastruzzi (2004) Govenance Matters M: Governance Indicators for 1996, 1998, 2000 and 2002. World Bank Economic Review (18):235-258

Kaufmann D., A. Kraay and M. Mastruzzi (2005) Govemance Matters IV. Governance Indicators for 1996-2004. The World Bank, Wasthington DC

Kjaer A.M. (2004) Govemance Polity Press, UK

Klein Haarhuis C. (2005) Promoting Anti-Carruption Reforms; Evaluating the Implementition of a World Bank Anti-Corruption Program in Seven Africa Countries ICS-Dissertation, Utrecht

Knack S. and P. Keefer (1995) Institutions and Economic Performance CrossCountry Tests Using A/ternative Institutional Measures Economics and Pollitics 7 (3):207-227

Knack S. and N. Manning (2000) Towards a Consensus on Governance Indicators: Selecting Public Management and Broader Governance Indicators World Bank, Washington DC (Processed)

Korsten A.F.A and C. Rokx Goed bestuur volgens de Wereldbank. Inhoud en belekenis van een spraakmakend concept in van Dam R. and B. Beusmans (ed) Natuurlijk ondernemen, kompas op de toekomst Uitgeverij Stichting Expertise Centrum Leren voor Duurzame ontwikkeling, Heerlen

Krasowec, K. and M.A. Anderson (1991) Maternal Nutrition and Pregnancy Outcomes Anthropometric Assessment Scientific Publication No. 529 Pan American Health Organization

Kusin J.A (1986) Ondervoeding bij Biologisch Kwetsbare Bevolkingsgroepen in Anten L.M. Voeding in Ontwikkelings landen Samson Stafleu, Alphen a/d Fijn

Leeuw F.L., G.H.C. Van Gils and C. Kreft (1999). Evaluating Anti-Corruption Initiatives: Underlying Logic and Mid-Term Impact of a World Bank program Evaluation (5):194-219.

Leftwich A. (1993) Governance, Democracy and Development in the Third World Third World Quarterly (14) ni. 3:605-623

Levin H.M. (1986) A Benefit-Cost Analysis of Nutritional Interventions for Anemia World Bank Research Observer $₫(2): 219-245$

Levinson J. (1995) Multisectoral Nutrition Planning: A Symthesis of Experience in Pinstrup-Andersen P., D. Pelletier and H. Alderman (eds) Child Growth and Nutrition in Developing Countries: Priorities for Action Cornell University Press, Ithaca NY Levinson J. and M. McLachllan (1999) How did we ever get there? In Marchione
T.J. (ed) Scaling Up, Scaling Down 
Levinson J. (2002) Institutionalization of Nutrition in Gillespie S.R., M. McLachlan and R. Shrimpton (eds) Combating Malnutrition; Time to Act World Bank, Washington DC

Levinson J., and C. Dolan. (2003) Will We Ever Get Back? The Derailing of Tanzanian Nutrition in the 1980s in Gillesple S.R., M. McLachlan and R. Shrimpton (eds) Combating Malnutrition; Time to Act World Bank, Washington DC

Lewis J.P. (ed) (1988) Strengthening the Poor: What Have We Learned? USThird World Policy Perspectives no. 10 Oversees Development Council, Washington DC

Lomborg B. (ed) (2004). Global Crises, Global Solutions Cambridge University Press

Marchione T.J. (ed.) (1999) Scaling Up, Scaling Down: Overcoming Malnutrition in Developing Countries Gordon Breach Publishers, Amsterdam

Martorell R., L. K. Kahn and D.G Schroeder (1994) Reversibility of stunting: epidemiological findings in children from developing countries. European Journal of Clinical Nutrition 1994:S45-S57

Mason J. (2003) How Nutrition Improves and What that Implies for Policy Decisions in Gillespie S.R., M. Mclachlan and R. Shrimpton (2003) Combating Malnutrition. Time to Act World Bank, Washington DC

Mauro P. (1995) Corruption and Growth Quarterly Journal of Economics $110(3): 681-712$

McGuire J.S and B. Popkin (1990) Helping Women Improve Nutrition in the Developing World: Beating the Zero Sum Game World Bank, Washington DC

McGuire J.S. and B. Popkin (1989) Beating the Zero-Sum Game: Women and Nutrition in the Third World, Part / Food and Nutrition Bulletin II (4):3863

McLachlan M. and P. Kuzwayo (1997) Bold Choices, Making the South African Nutrition Strategy Work Development Paper Development Bank of South Arrica, Pretoria (processed)

Minten B., J.C. Fandrianarisoa and L. Randrianarison (eds) (2003) Agriculture, Pauvreté rurales et politiques économiques a Madagascar Cornell University, Ithaca NY

Mosquera T.U. (1993) The Political Economy of Colombia's PAN in PinstrupAndersen P. (ed) The Political Economy of Food and Nutrition Policies Johns Hopkins University Press, Baltimore

Mulder-Sibanda M. and F. Crelerot (2003) Madagascar Case-study in Gillespie S.R. M. Mclachlan and R. Shrimpton (2003) Combating Malnutrition. Time to Act World Bank, Washington DC

Musgrove P. (1991) Feeding Latin America's Children World Bank, Washington DC (Processed) 
Musgrove P. (1996). Public and Private Roles in Health Discussion Paper no. 339 World Bank, Washington DC (processed)

Narayan D., A. Patel, K. Shaffi, A Rademacher and S. Koch-Schulte (2000) Voices of the Poor" Can Anyone Hear Us? Oxtord University Press

Ndulu J.B. (2004) Development Assistance in Sub-Saharan Africa Oxford University Press

North D. (1990) Institutions, Institutional Change and Economic Performance Cambridge University, Cambridge

OED (2004) The Poverty Reduction Strategy Initiative: An Independent Evaluation of the World Bank's Support Through 2003 Operations Evaluation Department World Bank, Washington DC

Pacey A, and P. Payne (eds) (1985) Agriculture Development and Nutrition Hutchinson Publishers

Parsons W. (1996) Public Policy; An Introduction to the Theory and Practice of Policy Analysis Edward Elgar Publishing, Inc. Massachusetts

Paternostro S., J. Razafindravonona and D. Stifell (2001) Changes in Poverty in Madagascar: 1993-1999 Africa Riegion Working Papers Series no. 19 World Bank, Washington DC

Pelletier D.I. E.A. Frongillo and J.P. Habicht (1993) Epidemiological evidence for a potentiating effect of malnutrition on chivd mortality American Journal of Public Health 83:(8):1130-1133.

Perry J.L. (1996) Handbook of Public Administration Jossey-Bass Publishers, San Francisico (second edition)

Piccioto R. (1995) Putting Institutional Economics to Work: From Participation to Governance World Bank, Washington DC (Processed)

Pinstrup-Andersen (Ed) (1993) The Political Economy of Food and Nutrition Policies The John Hapkins Umiversity Press, Ballimore

Pirion L. and A, Evans (2004) Politics and PRSP Approach: Synthesis Paper no. 237 Oversees Development linstitute, London (Processed)

Pincus J.R. and J.A. Winters (2002) Reinwenting the World Bank Cornel University Press, Ithaca NY

Pollitt E., K. Gormarn, E. Engle, R. Martorell, and J. Rivera (1993) Early Supplementary Feading and Cognition: Effects over Two Decades. Society for Research in Child Development Monograph 235 University
of Chicago Press, Chicago

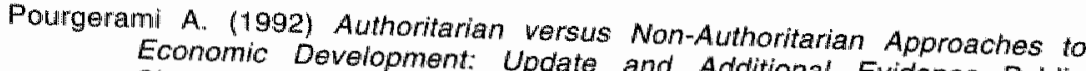
EConomic Development: Update and Additional Evidence Public

Preker A.S., A. Harding and P. Travis (2000) Make or buy" decisions in the institutional of health care goods and services: new insights from Health Organization $78(6): 779$ organizational theory. Bulletin World 
Pritchett L. (1995) Divergence, Big Time Policy Research Paper 1552, World Bank, Washington DC

Pritchett L. and L.H. Summers (1996) Weathier is Healthier Journal of Human Recourses $31(4): 84 \%-868$

Pritchett L. and M. Woolcock (2002) Solutions when the solution is in the problem; arraying the disarray in development Working Paper no.10 Harvard University, Cambridge Massachusetts

Rajan G.R. and A. Subramanian (2005) What Undermines Aid's Impact on Growth? IMF Working paper WP/05/126 (processed)

Rajkumar A.S. and V. Swaroop (2002) Public Spending and Outcomes: Does Governance Matter? Policy Research Working Paper no.2840 IMF, Washington DC (processed)

Ravelosoa R. and R. Key (2004) Safety Net Programs in Madagascar: Strategic issues and Options, Working Paper World Bank, Washington DC (processed)

Raveloson H.R., A. Guyon, S.M. Rakotonirina and M. Kajeckas (2001) Intersectoral Collaboration on Nutrition: A Case Situdy on Madagascar's Groupe d'Actions Intersectoriel pour la Nutrition (GAIN). Madiagascar, USAID (processed)

Ray D. (1998) Development Economics Princeton University Press, New Jersey

Ritzen J. (2005) A Chance for the World Bank Anthem Press, London.

Rogers B. (2003) Health and Economic Consequences of Malnutrition in Gillespie S.R., M. Mclachlan and R. Shrimpton (2003) Combating Malnutrition, Time to Act World Bank, Washington DC

Rokx C. (2000) Who Should Implement Nutrition Interventions? The Application of Institutional Economics to Nutrition World Bank "Washington DC (processed)

Romzek, B.S. and M.J. Dubnick (1987) Accountability in the Public Sector: Lessons from the Challenger Tragedy Public Administration Review $1987(47): 227-238$

Roodman D. (2004) The Anarchy of Numbers; Aid, Development and Crosscountry Empirics Centre for Global Development, Wastington DC (processed)

Sachs J. and A. Warner (1995) Economic Reform and the Process of Global Iniegration Brookings Papers on Economic Activity, no. \#

Samuel P. (1991) Strengthening Public Service Accountability World Bank Discussion Paper World Bank, Washington DC (processed)

Sanchez P., M.S. Swaminathan. P. Dopie and N. Yuksell (2005) Halving Hunger; It Can Be Done. Taskforce on Hunger, Millennium Project, United Nations, NY 
Scholl T.O., M.L. Hediger and D.H. Belsky (1994) Prenatal Care and Matemal Health During Adolescent Pregnancy; a review and meta-analysis Journal of Adolescent Health 15(6):444-456

Schultz T.S. (1961) Investment in Human Capital, American Economic Review (51) pp $1-17$

Scientific Council for Government Policy (WRA) (2001) $58^{\text {th }}$ Report Development Policy and Good Governance, The Hague, the Netherlands

Selowsky M. (1991) Protecting Nutrition Status in Adjustment Programs: Recent World Bank Activities in Projects in Latin America. Internal Discussion paper World Bank (processed)

Sen A. (1999) Development as Freedom New York "Knopf Press

Seshadiri S. and T. Gopaldas (1989) Impact of iron-supplementation on cognitive function in pre-school and school-aged children: The Indian experience American Joumal of Clinical Nutrition (supplement) 50(3):675-84

Singer H.W. (2001) International Development Cooperation; Selected Essays by H.W. Singer on Aid and the United Nations System Antony Rowe Ltd, Chippenharm, Wiltshire

Skoufias E. and B. McClafferty (2003) Is PROGRESA Working? Summary of Results of an Evatuation by IFPRI, International Food Policy and Research Institute (IFPRI), Washington DC

Smith L.C. and L. Haddad (2000) Explaining Child Malmutrition in Developing Countries: a Cross-Country Analysis IFPRI Research Report 111 International Food Policy and Research Institute (IFPRI), Washington DC

Strauss $\Downarrow$. and D Thomas (1998) Health, Nutrition and Economic Development Journal of Economic Literature XXXVI:766-817

Standing Committee on Nutrition (SCN) (2004) Nutrition for Improved Development Outcames: $5^{\text {th }}$ Report on the World Nutrition Situation SCN, Geneva

Tennekes H.J. (2005) Donors and Good Governance: analysis of policydiscourse in The Netherlands and Germany KOTA print Itd

Tramkins $A_{1}$, Watson F. (1989). Malnutrition and Infection; a Review London, Clinical Nutrition Unit, Centre for Human Nutrition, London School of Hygiene and Tropical Medicine and ACC/SCN State of the Art Series, Nutrition Policy Discussion Paper No. 5, ACC/SCN, Geneva

Transparency International (2004) Transparency International Corruption Perceptions Index 2004 htlp//www transparency.org

Tuck. L. and K. Lindert (1996) From Universal Food Subsidies to a SelfTargeted Program, a Case-study in Tunisian Reform World Bank, Washington DC

Underwood B.A. (1983) Nutrition Intervention Strategies in National Development Academic Press Inc. NY 
United Nations Development Program UNDP (1997) Humen Dewelopment report
1997 United Nations, New York

United Nations (1997) Governance for Sustainable Development; A UNDP
Policy Document, UNDP. New York:

UNICEF (1998) State of the World Chilaren Report 1998, United Nations, New
York

Van Llere M.J., J.A. Kusin and A Ellander (2001) Annotated Bibliography on Household Food and Nutrition Security. Koninklijk instituut woor de Tropen (KIT). Amsterdam (processed)

Wan Roekel K., B. Plowman, M. Griffiths, V. de Alvarado, J. Matute and M. Calderon BASICS 112002 Mid Term Evaluation of the AIN Program in Honduras 2000, BASICS II for USAID, Arlington, Virginia

Victora C., A. Wagstaff, J. Armstrong Schellenberg, D. Gwatkin, M. Claeson and J.P. Habicht (2003) Applying an Equity Lens to Child Health and Mortality Lancet 362:233-41

Wagstaff A. and M. Claeson (2004) Fising to the Challenges; the Millennium Development Goals for Health World Bamk, Washington DC

Williamson O.E. (1985) The Economic institutions of Capitalism The Free Press, New York

Winikoff B. (Ed.) (1978) Nutrition and National Pollcy MIT University Press

World Bank (1989) Sub-Saharan Africa: From Crisis to Sustainable Growth, World Barik, Washington DC

World Bank (1993) Food Security and Nutrition Project Staff Appraisal Report World Bank, Washington DC

World Bank (1993) Investing in Health World Development Report Oxford University Press

World Bank (1994) Governance, The World Bank Experience World Bank, Washington DC

World Bank (1997) The State in a Changing World World Development Report Oxford University Press

Warld Bank (1998a) Beyond the Washington Consensus Institutions Matter Worid Bank, Washington DC

World Bank (1998b) Second Community Nutrition Project Appraisal Document World Bank Washington DC

World Bank (2000a) Entering the $21^{\text {al }}$ Century World Development Report Oxford University Press

World Bank (2000b) Strategy for Public Sector and Governance - Reforming Public institutions and Strengthening Governance World Bank Washington DC 
World Bank (2000/1) Attacking Poverty, World Development Rieport Oxford University Press

World Bank (2001) Institutions Matter World Development Report Oxford University Press

World Bank (2002) Reforming Public Institutions and Strengthening Governance: a World Bank Strategy Implementation Update World Bank Washington DC

World Bank (2003a) The HIPC Initiative; Progress and Prospects. World Bank, Operations Evaluation Department World Bank Washington DC (processed)

World Bank (2003b) Making Services Work for Poor People World Development Report Oxford University Press

World Bank (2004) The Poverty Reduction Strategy Initiative; an Independent Evaluation of the World Bank's support through 2003 World Bank, Operations Evaluation Department World Bank Washington DC (processed)

World Bank (2005) Public Expenditure Review: The Challenge of Poverty Reduction World Bank, Washington DC

World Bank and International Monetary Fund (2005) Global Monitoring Report.
World Banik, Washington DC

World Health Organization (1995) Physical Status: the use and interpretation of anthropometry WHO, Geneva

World Health Organization (1995) Maternal Anthropometry and Pregnancy Outcomes A WHO Collaborative Study Supplement to Volume 73 of the Bulletin of the World Health Organization WHO, Geneva

World Health Organization (2000) Global Database on Child Growth and Malnutrition Forecast of Trend's WHO/NHD/00.3 WHO, Geneva

WRA Wetenschappelijke Raad for het Regeringsbeleid (2001)
Ontwikkelingsbeleid en Goed Bestuur Rapporten aan de Regering 58 Sdu Uitgevers, Den Haag

Yin R.K. (1994) Case Study Research; Design and Methods Sage Publications,
London (second ediction)

Zegers $M$. $R$. Randrianasolo and $R$. Hasimahery (2004) interventions en Couverture consultant a Madagascar: Inventaire et Analyse de Madagascar (processed) report to SEECALINE, Government of 


\section{Annex I: World Bank Basic Facts}

\section{I.1. Introduction}

The World Bank Group consists of five institutions. It started out with the International Bank for Reconstruction and Development (IBRD) in1945. IBRD supports poverty reduction in middle-income countries by providing them with access to capital in large volumes, at low interest rates and with longer maturities than the market. In 1956, the International Finance Corporation (IFC) was added with the mandate to further economic development through the private sector. IFC invests in projects in regions and sectors underserved by private investment and finds new ways to develop promising opportunities in markets deemed too risky by commercial investors.

It was under the World Bank's third president, Eugene Black that it became discontent with the way its Articles of Agreement inhibited lending to countries that had no creditworthiness (Kapur 1997:12). Poverty reduction was not seen as a mandate for the World Bank until after the mid-1960s. Born out of the discontent was the international Development Agency (IDA) which changed the history of the Bank. IDA increased available resources significantly. It supports the world's poorest countries reduce poverty by providing credits, which are loans at zero percent interest rates, so-called soft loans.

The International Center for Settlement of International Disputes (ICSID) was established in 1966 and encourages foreign investment by providing international facilities for conciliation and arbitration of investment disputes to create an atmosphere of mutual confidence between states and foreign investors. And finally, the Multinational Investment Guarantee Agency (MIGA) was added in 1988 and further encourages foreign investment in developing countries by providing guarantees to foreign investors against losses caused by noncommercial risks, such as expropriation, currency inconvertibility and transfer restrictions, as well as civil disturbances.

The World Bank is owned and governed by national governments and its clients are national governments. In 2002, 184 countries are member of IBRD and 162 of IDA. Control of the Bank is not, as with the United Nations, divided equally among its members, but is founded on economic power (voting power equal to financial contributions). When a country joins ${ }^{167}$, it

${ }^{167}$ Countries have to be members of the IMF before they can become member of the World Bank Group. 
must pledge a capital subscription, of which the amount depends on its wealth, but it only pays a small percentage of this in capital $^{168}$ (George and Sabelli 1994:31). The rest is 'on call' in case countries default, which only very rarely happens. The United States of America has, and always had the largest share and thus the heaviest weight in decision making.

\subsection{Purposes of the World Bank}

As stated in the Articles of Agreement ${ }^{169}$ "the purposes of the World Bank are (i) to assist in the reconstruction and development of territories of members by facillitating the investment of capital for productive purposes, including the restoration of economies destroyed or disrupted by war, (ii) to promote private foreign investment by means of guarantees or participants in loans and other investments made by private investors; (iii) to promote the long-range balanced growth of international trade and the maintenance of equilibrium in balances of payments by encouraging international investment for the development of the productive resources of members, thereby assisting in raising productivity, the standard of living and conditions of labor in their territories; (iv) to arrange the loans made or guaranteed by it in relation to international loans through other channels so that the more useful and urgent projects, large and small alike, will be dealt with first; and $(v)$ to conduct its operations with due regard to the effect of international investment on business conditions in the territories of members and, in the immediate postwar years, to assist in bringing about a smooth transition from a wartime to a peacetime economy".

\section{I.3. Bank Resources and Lending}

Resources for IBRD loans come largely from private financial markets through issuance of IBRD bonds. In 2002, cumulative lending reached US\$ 360 billion for IBRD and US\$135 billion for IDA. Funding for IDA credits, however, comes from member government's national budget, tax-payers money. Thus, IDA draws on very different resources than the IBRD, which has broadened the Bank group's clientele. Whereas IBRD consists of owner government guarantees, with minimum need for tax-payers money, IDA relies almost entirely on that. It is

\footnotetext{
10. Keynes, the main founding father of the World Bank, invented this scheme as the pooling of credlit insurance among nations (George and Sabelli, 1994 p. 31)

isg Articles of Agreement, World Bank Article 1 - as amended effective in
} 
therefore that the Executive Directors tend to pay more attention to IDA credits approvals than to IBRD loans.

IBRD uses concessional lending - interest rates are lower than market value - for two reasons. First, national economies may be too poor to get loans on the private markets. Second, aside from the macro-economic consideration, countries may require help to establish systems and services which do not generate recoverable returns on capital investment (Kapur 1997:1121). IBRD loans have a five-year grace period, after that borrowing governments have 15 to 20 years to pay back their loans at market interest rates ${ }^{170}$. IDA loans are on soft terms, meaning zero percent interest, a grace period of 10 years and about 40 years to pay back. At the time IDA was established much discussion was held on whether IDA should be grants, but in the end the vote was for soft loans (Kapur 1997:1122). At present, some experimentation is being done with credits that consist of both; part credit and part grant. Many problems regarding procedures though have to be dealt with. The basic idea is that countries get a credit and if they fulfill the development objective within the time agreed, it becomes a grant. The Nigeria Polio Eradication program is an example of a credit that may become a grant if the triggers set at the out start will be reached in the determined time. So, there is an important incentive built into the credit. But, IDA credits may be soft on interest rates; they are not soft on policy requirements. IDA is for those countries that lack IBRD creditworthiness but show that they are capable of making profitable use of funds. IDA funds are replenished every 3 to 5 years by donor countries as part of their Oversees Development Assistance (ODA).

\subsection{The World Bank Project Cycle}

Loans and credits are developed in phases. The client country or borrower first identifies and prepares a projectproposal. During identification the main objectives and keyindicators are defined and a timeline for preparation set. The client country prepares the project-design and the Bank verifies its viability through appraisal of the technical, financial, environmental, institutional and social aspects of the design. During negotiations the Borrower and the Bank agree on development objectives, development outcomes, implementation plan and disbursement schedule of the loan or credit. Once the project is approved by the Bank's Board of Directors, the project

170 Average of the last decades is about 7.5 percent annually (George and Sabelli, 1994 p.11). 
becomes effective after the client country complies with the effectiveness conditions. The client country is responsible for the implementation of the project with Bank supervision and together the evaluation of results is carried out.

\subsection{Policy Influence Instruments}

The Bank has various lending and policy influencing instruments. When the Bank started in the 1970 s to make economic growth more favorable to the poor, it had two main instruments, policy influence and projects (Kapur 1997: 269). The latter was widely publicized because that is what the Bank did, but the former was thought to have most significant gain. In Kapur, the World Bank, its First Half Century, case studies ${ }^{171}$ on Brazil, Guatemala, Malaysia, Kenya, India, Bangladesh, Chile, Tanzania, and Sri Lanka illustrate the difficulty the Bank had and continues to have in the policy dialogue and the efforts to intervene in the client countries distributive policies. At present the Bank is going more into dialogue with country governments under the Comprehensive Framework and is leaning towards programmatic lending where much depends on this dialogue.

\section{I.5.1. Policy Instruments}

The former Country Program Paper (CPP) and current Country Assistance Strategy (CAS), Economic Sector Work (ESW) and investment loans all are part of the Bank's instruments to influence a country's policy (Kapur 1997:485). But they have to be combined. For example, ESW by itself will provide interesting suggestions but will not induce policy change. Financlal support, loans and credits are needed. The CAS is prepared for every country about every three years, for very large countries more often. The objective of the CAS is to develop a strategy that will guide the Bank's efforts in a client country to reach the goals of poverty reduction and economic well-being it has set for itself. The main authors are usually the country economists, guided by the country director, and it is designed in consultation with the Government. Not only consultation with Governments and in private sector and civil society "the CAS is also internally discussed several times within the country teams before it is presented to the board. Inputs from sectors can be provided through different channels and at

\footnotetext{
${ }^{171}$ What II get in short form the cases: problems addressing poverty and equality issues largely because of resistance from governments, deep rooted concerns about AAA status and market dependence and very sllow progress much disappointing and frustrating to staff.
} 
several points in the process: first, by the client country government or other consulted groups and internally during the country team meetings. For example in the case of nutrition. if nutrition is mentioned as a priority-area in the CAS documents, there will be follow up and it is highly likely a nutrition operation would be included in the lending program over the following three years. CAS-documents are only made public if the concerned Government agrees to disclose it.

\subsection{Lending Instruments}

The Bank has two basic types of lending, investment loans and adjustment loans. Investment loans have a long term focus (5-10 years) and adjustment loans have a short term focus (1 to 3 years). Investment loans typically finance goods, infrastructure and other works and services in support of economic and social development. Adjustment loans provide quick disbursing external financing to support policy and institutional reforms. It is the latter type that has received much criticism for increasing poverty rather than supporting the Bank's overall goal of poverty reduction.

Specific Investment loans (SIL) is, until recently, the most used lending instrument for a broad range of projects, transport, education, health, energy, water among others. A typical SIL in the area of nutrition is for example the Madagascar Community Nutrition Project (42 million US\$).

Sector Investment and Maintenance Loans (SIM) focus on public expenditure programs in specific sectors. They aim to bring sector expenditures and pollicies in line with the country's development priorities by helping create a balance among new capital investments, rehabilitation and reconstruction and maintenance. There are no nutrition projects using this instruments, best examples are roads, ports, and other infrastructure and high maintenance projects.

Adaptable Lending Programs are more long term and provide phased support. APLs normally include agreements on the different phases of the program and the triggers to move to the next phase, on the policies and priorities. The basis for the APL is the sector policy as proposed by the country and which should be approved in Parliament before the APL can be negotiated with the Bank. APLs are used when sustained changes in institutions, organizations or behavior are of keyimportance to the successful implementation of the program. An example of an APL in nutrition is the Senegal Nutrition Enhancement Program (NEP). 
Learning and Innovation Loan (LIL) support small pilottype investments and capacity-building projects, that if successful can lead to larger projects. When started the LILS were supposed to be more rapidly prepared, using simplified procedures, than other projects because of the limited amount of lending, US $\$ 5$ million maximum. However, experience has shown that the preparation takes about the same time, and budget requirements, as other projects and APL may be a good alternative, converting the LIL into a first phase of the LIL. But, this is would not properly address the pilot idea and may run the risk of countries committing to long-term programs without knowing whether they would work. Two nutrition project examples fall into this category; the Mauritania Community Nutrition Project and the Ghana Community-Based Poverty Reduction Project which has a main component on nutrition.

Technical Assistance Loan (TAL) is used to build institutional capacity in the borrower country. They are usually smaller in terms of amount and are often prepared to accompany structural adjustment, governance and overall poverty reduction strategy credits. An example of a TAL for nutrition was the first ever project that was approved by the Board for nutrition, the Brazil Nutrition and Development project in 1976.

Emergency Recovery Loans (ERL) support the restoration of assets and production levels immediately after an extra-ordinary event, such as a war, civil disturbance, or natural disaster. ERLs focus on the rapid reconstruction of economic, social and physical systems within a limited period of time, normally 2 to 3 years. There are no examples of nutrition ERL, but nutrition was included as a component in the Madagascar ERL that was provided to the country after devastating cyclones in 2000. Although SILs are used for recurrent events such as floods and droughts, ERLs could be appropriate instruments to address crisis food security needs.

Non-project or adjustment lending instruments are the Structural Adjustment (SAL) and Sector Adjustment Loans (SECAL). They provide quick disbursing assistance to countries with external financing needs, to support structural reforms in a sector (SECAL) or the economy as a whole (SAL). They are supposed to improve a country's economic climate and its capacity to attract foreign investment. These loans are characterized by: (i) privatization of government corporations and severe downsizing of public employment and government bureaucracy; (ii) promotion of exports of raw materials and of export industries to earn foreign currency; import liberalization and ellimination of trade barriers; (iii) elimination of sharp reduction in subsidies for agriculture, food staples, health care, 
education etc.; (iv) restrictive monetary policies and high interest rates to curb inflation: and $(v)$ a reduction in real wages demand management. The Bank has been heavily criticized for its extensive use of SAL and SECALs in the 1980 s and early 1990 s.

Poverty Reduction Strategy Credits (PRSC) is a series of operations, which together support IDA countries medium term policy and institutional reform programs to help implement their poverty reduction strategies. The medium term program is linked to the PRSP, which is the government owned development strategy plan. The PRSC focuses on priority actions that were formulated in a national participatory process (the PRSP). PRSCs are based on the principles of country ownership of the development process and partnership in support of the PRSP process, and the underlying principles of the Comprehensive Development Framework (CDF). Poverty reduction is the central focus. PRSCs recognize the importance of good country-owned policies - structural and social as well as macro-economic - and good institutions to deliver them as the main drivers of sustainable growth and poverty reduction, and as the basis for effective development assistance and stronger and more explicit cooperation between agencies and donors. The PRSC also recognizes that a transparent and participatory approach to policy making is important to sustain good policies and build institutional capacity. It is therefore expected that, while preparing the PRSC, staff will rely, as appropriate, on the approaches as described in the country's PRSP-process ${ }^{172}$.

\section{I.7. Resource Allocation}

IBRD funds are allocated on demand, but since IDA resources are scarce, country allocations are based on allocative guidelines. IDA resources are only allocated to those countries that have GDP lower than US\$720 (2002) and who are insufficiently creditworthy to obtain substitute credits elsewhere on serviceable terms. The country has to show a record of good economic performance and it has to have good projects that are ready for financing (Kapur 1997:1152). The actual allocation then is based on yearly Country Policy and Institutional Assessments (CPIA). Bank staff knowledgeable on the country rates the country high, moderate or low on several questions in four categories; (i) economic management; (ii) structural policies; (iii) policies for social inclusion/equity; and (iv) public sector

172 Interim Guidelines for Poverty Reduction Support Credits - official use only * IDA/SecM2001-0251/3, May 24, 2001 
management and institutions. Calculations keys such as population, GDP, and the results of the CPIA determine the yearly IDA allocation to the country. Depending on the allocation and what is agreed in the CAS, the portfolio can include nutrition or not.

Whether nutrition is included as a separate credit or as part of another credit, for example health, education, agriculture/rural development or in some case under social funds, depends on the country priorities as listed in the CAS, the ongoing country dialogue and the country team discussions. 


\section{Annex II: Additional tables and graphs}

Table 1: Countries for which aggregate governance indicators and underweight malnutrition data is avallable $(n=82)$

\begin{tabular}{llll}
\hline Africa & Atrica & Asila & Latin America \\
\hline Angola & Madagascar & Afghanistan & Argentina \\
Benin & Mali & Bangladesh & Bolivia \\
Botswana & Malawi & Bhutan & Brazil \\
Burkina Faso & Mauritania & Cambodia & Chile \\
Burundi & Mauritius & China & Colombia \\
Cameroon & Mozambique & India & Costa Rica \\
CAR & Niger & Indonesia & Dominican Rep. \\
Chad & Nigeria & Iran & Ecuador \\
Comoros & Rwanda & Korea, North & El Salvador \\
Cote d'lwoire & Sao Tome \& & Lao PDR & Guatemala \\
& Principe & Malaysia & Guyana \\
DRC & Senegal & Maldives & Haiti \\
Djibouti & Seychelles & Mongolia & Honduras \\
Eritrea & Sierra Leone & Myanmar & Jamaica \\
Ethiopia & Somalia & Nepal & Mexico \\
Gabon & South Africa & Pakistan & Nicaragua \\
Gambia, The & Swaziland & Philippines & Panama \\
Ghana & Tanzania & Sri Lanka & Peru \\
Guinea & Togo & Thailand & Uruguay \\
Guinea-Bissau & Uganda & Vietnam & Venezuela \\
Kenya & Zambia & & \\
Lesotho & Zimbabwe & &
\end{tabular}


Table 2: Six categorles of goods and services and preferred delivery mechanism

\begin{tabular}{|c|c|c|c|c|}
\hline Variables & \multicolumn{2}{|c|}{ High Contestability } & \multicolumn{2}{|c|}{ Low Contestabillty. } \\
\hline $\begin{array}{l}\text { High } \\
\text { Mealsurability }\end{array}$ & $\begin{array}{l}\text { Type I: Private } \\
\text { - Iron supplem } \\
\text { - Vitamin A su } \\
\text { - Infrastructure } \\
\text { - Infrastructure } \\
\text { vehicles, build } \\
\text { - Food distribu } \\
\text { - Iodine fortifie } \\
\text { - Iron fortified } \\
\text { - Vitamin A for }\end{array}$ & $\begin{array}{l}\text { ector } \\
\text { tation } \\
\text { lementation } \\
\text { equipment, } \\
\text { a. } \\
\text { in } \\
\text { salt } \\
\text { eat flour } \\
\text { ed sugar }\end{array}$ & $\begin{array}{l}\text { Type ll: Publio } \\
\text { sector partner } \\
\text { (only when ve } \\
\text { specified inve } \\
\text { needed) } \\
\text { - Multi-vitamin } \\
\text { fortification of } \\
\text { - Advanced ho } \\
\text { equipment to } \\
\text { liposuction } \\
\text { - Start up ind } \\
\text { weaning- food } \\
\text { specialized fo }\end{array}$ & $\begin{array}{l}\text { nd Private } \\
\text { ip } \\
\text { highly } \\
\text { nents are } \\
\text { nd mineral } \\
\text { staple food } \\
\text { ital } \\
\text { rform } \\
\text { ries for } \\
\text { and other } \\
\text { s }\end{array}$ \\
\hline $\begin{array}{l}\text { Low } \\
\text { Measurability }\end{array}$ & $\begin{array}{l}\text { Non-into } \\
\text { asymmetric } \\
\text { Type IllA: } \\
\text { Public sector } \\
\text { - Monitoring \& } \\
\text { evaluation } \\
\text { - Policy } \\
\text { anallysis \& } \\
\text { development } \\
\text { - Pesearch }\end{array}$ & $\begin{array}{l}\text { Info } \\
\text { Asymmetric } \\
\text { Type IIIB: } \\
\text { Civil Society } \\
\text { - Growth } \\
\text { promotion } \text { IEC }^{73} \\
\text { nutrition } \\
\text { education at } \\
\text { community } \\
\text { level } \\
\text { - Nutrition } \\
\text { training at } \\
\text { community } \\
\text { level }\end{array}$ & $\begin{array}{l}\text { Non-info } \\
\text { Asymmetric } \\
\text { Type IVA: } \\
\text { Public Sector } \\
\text { - Policy } \\
\text { decision } \\
\text { making } \\
\text { - National } \\
\text { plan } \\
\text { development } \\
\text { - Criteria } \\
\text { development }\end{array}$ & $\begin{array}{l}\text { Info- } \\
\text { Asymmetric } \\
\text { Type IVB: } \\
\text { Public sector } \\
\text { (Common } \\
\text { pool } \\
\text { resources } \\
\text { only) } \\
\text { - Information } \\
\text { campaigns }\end{array}$ \\
\hline
\end{tabular}

Source: Rokx 2000

${ }^{173} \mathrm{IEC}=$ Information, Education and Communication 
Table 3: Aggregate Indicators (Kaufmann) and Underweight Malnutrition Rates

\begin{tabular}{|c|c|c|c|c|c|c|c|c|}
\hline Country & VAO4 & VA96 & PSO 4 & PS96 & GE04 & GE96 & ROOO4 & RQ96 \\
\hline Afghanistan & -1.35 & -1.53 & -2.03 & -1.82 & -1.24 & & -2.05 & \\
\hline Angola & -1.02 & -1.42 & -0.95 & -2.17 & -1.14 & -1.13 & -1.40 & -1.60 \\
\hline Argentina & 0.49 & 0.60 & -0.24 & 0.47 & -0.33 & 0.45 & -0.81 & 0.82 \\
\hline Bangladesh & -0.69 & -0.33 & -1.24 & -0.53 & -0.72 & -0.67 & -1.15 & -0.54 \\
\hline Benin & 0.30 & 0.75 & -0.37 & 1.20 & -0.39 & 0.01 & -0.49 & 0.16 \\
\hline Bhitan & -1.18 & -1.37 & 0.84 & 1.00 & -0.14 & 0.33 & 0.00 & 0.08 \\
\hline Bolivia & -0.01 & 0.10 & -0.65 & .0 .23 & -0.63 & -0.44 & 0.05 & 0.82 \\
\hline Botswana & 0.73 & 0.74 & 0.70 & 0.87 & 0.83 & 0.33 & 0.96 & 0.69 \\
\hline Brazil & 0.34 & 0.23 & -0.13 & -0.17 & 0.02 & -0.16 & 0.19 & 0.21 \\
\hline $\begin{array}{l}\text { Burkina } \\
\text { Faso }\end{array}$ & -0.38 & -0.46 & -0.32 & -0.28 & -0.52 & -0.76 & -0.26 & -0.27 \\
\hline Buruindi & -1.13 & -1.28 & -2.04 & -1.75 & -1.24 & -0.98 & -1.35 & -1.31 \\
\hline Cambodia & -0.89 & -0.68 & -0.60 & -1.15 & -0.87 & -0.58 & -0.25 & -0.29 \\
\hline Cameroon & -1.18 & -1.05 & -0.90 & -0.98 & -0.64 & -1.04 & -0.71 & -0.82 \\
\hline CAR & -1.20 & -0.17 & -1.43 & -0.01 & -1.65 & -0.82 & -1.28 & -0.29 \\
\hline Chad & -1.09 & -0.76 & -1.20 & -0.68 & -1.29 & -0.58 & -0.84 & 0.01 \\
\hline Chile & 1.09 & 0.93 & 0.89 & 0.75 & 1.27 & 1.20 & 1.62 & 1.52 \\
\hline China & -1.54 & -1.29 & -0.07 & 0.12 & 0.11 & 0.18 & -0.45 & -0.06 \\
\hline Colombia & -0.47 & -0.07 & -1.69 & -1.25 & -0.18 & 0.07 & -0.12 & 0.49 \\
\hline Comoros & -0.14 & -0.11 & -0.13 & & -1.45 & -0.63 & -1.06 & -0.72 \\
\hline Costa Rica & 1.11 & 1.37 & 0.98 & 0.89 & 0.49 & 0.16 & 0.67 & 0.68 \\
\hline $\begin{array}{l}\text { Cote } \\
\text { d'lvoire }\end{array}$ & -1.46 & -0.19 & $-2,28$ & 0.32 & -1.30 & -0.11 & -0.83 & -0.15 \\
\hline Djibouti & -0.85 & -0.77 & -0.44 & & -0.76 & -1.11 & -0.76 & 0.01 \\
\hline $\begin{array}{l}\text { Dominican } \\
\text { Republic }\end{array}$ & 0.27 & 0.02 & -0.01 & -0.20 & -0.46 & -0.29 & -0.28 & 0.14 \\
\hline DAC & -1.64 & -1.23 & -2.27 & -1.73 & -1.41 & -2.07 & -1.80 & -2.38 \\
\hline Ecuador & -0.19 & 0.06 & -0.83 & -0.61 & -0.85 & -0.65 & -0.60 & -0.05 \\
\hline El Salvador & 0.26 & -0.22 & -0.23 & -0.09 & -0.22 & -0.38 & 0.56 & 0.73 \\
\hline Eritrea & -1.96 & -1.10 & -0.14 & 0.46 & -1.05 & -0.43 & -1.29 & -0.14 \\
\hline Ethiopia & -1.11 & -0.61 & -0.98 & -0.61 & -0.96 & -0.41 & .1 .19 & -0.72 \\
\hline Gaboni & -0.71 & -0.54 & -0.01 & -0.15 & -0.53 & -0.99 & -0.46 & -0.51 \\
\hline Gambia & -0.59 & -1.34 & 0.38 & 0.20 & -0.49 & -0.10 & -0.15 & -1.28 \\
\hline Ghana & 0.39 & -0.35 & -0.10 & 0.06 & -0.17 & -0.07 & -0.28 & -0.14 \\
\hline Guatemala & -0.39 & -0.64 & -0.85 & -1.14 & -0.87 & -0.56 & -0.07 & 0.03 \\
\hline Guinea & -1.12 & -1.13 & .0 .91 & -1.33 & -0.93 & -1.21 & -0.94 & 0.01 \\
\hline Guinea- & & & & & & & & \\
\hline & -0.62 & -0.55 & -0.53 & -0.57 & -1.25 & -0.87 & -0.86 & -0.06 \\
\hline Guyana & 0.62 & 0.90 & -0.53 & 0.10 & -0.20 & -0.28 & -0.14 & 0.22 \\
\hline Haiti & -1.50 & -0.46 & -1.87 & -0.21 & -1.90 & -1.42 & -1.11 & -1.23 \\
\hline Honduras & -0.02 & -0.36 & -0.69 & -0.40 & -0.68 & -0.98 & -0.33 & -0.29 \\
\hline lndia & 0.27 & 0.28 & -0.81 & -0.77 & -0.04 & -0.14 & -0.59 & -0.09 \\
\hline Indonesia & -0.44 & -1.15 & $-1,38$ & -0.45 & -0.36 & 0.18 & -0.42 & 0.27 \\
\hline Iran & -1.36 & -1.08 & -0.91 & -0.37 & -0.66 & -0.30 & -1.33 & -1.62 \\
\hline Jamaica & 0.54 & 0.55 & -0.28 & 0.64 & 0.13 & -0.41 & 0.15 & 0.54 \\
\hline
\end{tabular}

Source: Kaufmann et al (2005); WHO Global Data-base (2005) 
Table 3: Aggregate Indicators (Kaufmann) and Underweight Malnutrition Rates - continued

\begin{tabular}{|c|c|c|c|c|c|c|c|c|}
\hline Counity & VA04 & VA96. & PS04 & PS96 & GE04 & GE96 & RQ04 & RQ96 \\
\hline Kenya & -0.34 & -0.48 & -0.96 & -0.38 & -0.81 & -0.60 & -0.43 & -0.48 \\
\hline Kored, North & -205 & -1.84 & 0.67 & -1.20 & -1.68 & -1.30 & -2.05 & -2.43 \\
\hline Lao PDR & -1.55 & -1.09 & -0.76 & 1.20 & -1.02 & -0.04 & -1.24 & -1.17 \\
\hline Lesotho & 0.28 & 0.02 & 0.27 & 1.00 & -0.33 & 0.17 & -0.26 & -0.71 \\
\hline Madagascar & 0.07 & 0.26 & -0.02 & 0.23 & -0.43 & -0.64 & 0.10 & -0.07 \\
\hline Malawi & -0.50 & -0.43 & -0.33 & 0.10 & -0.81 & -0.69 & .0 .57 & -0.43 \\
\hline Mataysia & $-0,36$ & -0.05 & 0.38 & 0.95 & 0.99 & 1.07 & 0.44 & 0.86 \\
\hline Maldivas & -1.07 & -0.98 & 0.82 & & 0.47 & 0.06 & 0.00 & 0.23 \\
\hline Mali & 0.35 & 0.30 & 0.07 & 0.64 & -0.29 & -0.85 & -0.26 & 0.16 \\
\hline Mauritania & -1.16 & -0.84 & 0.26 & 0.73 & 0.22 & 0.25 & 0.04 & -0.65 \\
\hline Mauritius & 0.94 & 0.87 & 0.91 & 1.18 & 0.60 & 0.70 & 0.33 & 0.17 \\
\hline Mexico & 0.36 & -0.23 & -0.13 & -0.36 & -0.02 & -0.12 & 0.55 & 0.59 \\
\hline Mongolla & 0.45 & 0.38 & 0.48 & 0.80 & -0.46 & -0.27 & 0.18 & -0.57 \\
\hline Mozambique & -0.13 & -0.20 & -0.15 & -0.34 & -0.39 & -0.72 & -0.29 & -0.98 \\
\hline Myanmar & -2.19 & -1.73 & -1.21 & -1.09 & -1.57 & -0.99 & -2.34 & -1.12 \\
\hline Nepal & -1.00 & 0.14 & -1.74 & -0.35 & -0.90 & -0.318 & -0.60 & -0.22 \\
\hline Nicaragua & 0.06 & -0.22 & -0.15 & -0.66 & -0.71 & -0.46 & -0.15 & -0.21 \\
\hline Niger & -0.12 & -0.41 & -0.56 & -10.10 & -0.87 & -0.82 & -0.63 & -0.84 \\
\hline Nigeria & .0 .65 & -1.49 & -1.78 & -1.56 & -1.02 & -1.22 & -1.26 & -0.97 \\
\hline Pakistan & -1.31 & -0.98 & -1.59 & -1.21 & 0.57 & $=0.40$ & -1.03 & -0.57 \\
\hline Panama & 0.54 & 0.33 & 0.29 & 0.36 & 0.01 & -0.55 & 0.22 & 0.65 \\
\hline Perui & -0.04 & -0.73 & -0.68 & -0.90 & -0.58 & -0.18 & 0.17 & 0.65 \\
\hline Philipplines & 0.02 & 0.17 & -1.01 & -0.12 & -0.23 & 0.19 & -0.06 & 0.45 \\
\hline Rwanda & -1.09 & -1.43 & -0.92 & -1.22 & -0.56 & -1.26 & -0.42 & -1.09 \\
\hline $\begin{array}{l}\text { Sao-Tome \& } \\
\text { P. }\end{array}$ & 0.55 & 0.88 & 0.08 & & -0.89 & -0.55 & -0.47 & -0.36 \\
\hline Senegal & 0.19 & -0.17 & -0.21 & -0.67 & -0.13 & -0.40 & -0.31 & -0.45 \\
\hline Seychelles & -0.04 & 0.10 & 0.84 & .. & -0.31 & -0.58 & -1.21 & -1.17 \\
\hline $\begin{array}{l}\text { Sierra- } \\
\text { Leone }\end{array}$ & -0.49 & -1.37 & -0.61 & -2.25 & -1.32 & -0.24 & -1.02 & .0 .45 \\
\hline Somialia & -1.58 & -1.91 & -2.39 & -2.14 & -2.32 & -2.19 & -2.63 & -2.91 \\
\hline South-Africa & 0.816 & 0.68 & -0.24 & -0.97 & 0.74 & 0.33 & 0.44 & 0.27 \\
\hline Sri Lanka & -0.16 & -0.21 & -1.06 & -1.73 & -0.27 & .0 .30 & 0.21 & 0.34 \\
\hline Swazilland & -1.45 & -1.28 & 0.23 & 0.19 & -0.60 & -0.45 & -0.36 & 0.02 \\
\hline Tanzania & -0.35 & 0.77 & .0 .38 & 0.02 & -0.37 & -11.18 & -0.55 & -0.52 \\
\hline Thaillaind & 0.24 & 0.01 & -0.15 & 0.20 & 0.38 & 0.47 & -0.01 & 0.49 \\
\hline Togo & -1.22 & -1.07 & -0.55 & -0.56 & -1.31 & -0.66 & -0.77 & 0.24 \\
\hline Uganda & -0.64 & -0.63 & -1.27 & -1.19 & -0.43 & -0.37 & 0.07 & 0.10 \\
\hline Uruguay & 1,00 & 0.78 & 0.49 & 0.85 & 0.52 & 0.61 & 0.30 & 0.97 \\
\hline Venezuela & -0.46 & 0.06 & -4.10 & -0.61 & -0.96 & -0.72 & -1.24 & -0.08 \\
\hline Vietniam & -1.54 & -1.31 & 0.16 & 0.40 & -0.31 & -0.10 & -0.57 & -0.56 \\
\hline Zambia & -0.36 & -0.16 & -0.16 & -0.37 & -0.84 & -0.86 & .0 .49 & 0.27 \\
\hline Zimbabwe & -1.48 & -0.30 & -1.86 & -0.11 & -1.20 & -0.26 & -2.15 & -0.87 \\
\hline
\end{tabular}

Source: Kaufmann ef al (2005); WHO Global Data-base (2005) 
Table 3: Aggregate Indicators (Kaufmann) and Underweight Malnutrition Rates - continued

\begin{tabular}{|c|c|c|c|c|c|c|}
\hline Country & RLO4 & RL96 & $\mathrm{CCO} 4$ & CC96 & $\begin{array}{l}\text { W/A } \\
\text { (most } \\
\text { recent } \\
\text { data) }\end{array}$ & $\begin{array}{l}\text { W/A } \\
\text { change }\end{array}$ \\
\hline Afghanistan & -1.81 & -1.19 & -1.33 & & 49 & \\
\hline Angola & -1.33 & -1.44 & -1.12 & -1.00 & 31 & \\
\hline Argentina & -0.71 & 0.28 & -0.44 & -0.12 & 5 & \\
\hline Bangladesh & -0.86 & -0.68 & -11.09 & -0.47 & 52 & -2.67 \\
\hline Benin & -0.47 & -0.01 & -0.34 & $\ldots$ & 23 & -1.20 \\
\hline Bhutan & 0.27 & -1.19 & 0.69 & & 19 & \\
\hline Bolivia & -0.55 & -0.66 & -0.78 & -0.87 & 8 & \\
\hline Botswana & 0.73 & 0.80 & 0.86 & 0.40 & 13 & \\
\hline Brazil & -0.21 & -0.26 & -0.15 & -0.11 & 6 & \\
\hline Burkina Faso & -0.62 & -0.75 & -0.35 & -0.31 & 34 & 1.0 \\
\hline Burundi & -1.50 & -0.19 & -1.16 & ... & 45 & \\
\hline Cambodia & -0.98 & -0.91 & -0.97 & -0.94 & 45 & \\
\hline Cameroon & -1.00 & -1.18 & -0.78 & -1.10 & 22 & \\
\hline CAR & -1.44 & -0.19 & -1.36 & $\ldots$ & 23 & \\
\hline Chad & -1.15 & -0.19 & -1.14 & .. & 28 & -3.67 \\
\hline Chile & 1.16 & 1.26 & 1.44 & 1.28 & 1 & \\
\hline China & -0.47 & -0.45 & -0.51 & -0.01 & 10 & \\
\hline Calombia & -0.70 & -0.46 & -0.16 & -0.43 & 7 & \\
\hline Comoras & -1.04 &.. & -1.14 & $\ldots$ & 25 & \\
\hline Costa Rica & 0.57 & 0.64 & 0.78 & 0.76 & 5 & \\
\hline Cote d"ivoire & -1.42 & -0.69 & -1.01 & 0.41 & 21 & \\
\hline Djibouti & -0.61 &. & -0.94 &.. & 18 & \\
\hline $\begin{array}{l}\text { Dominican } \\
\text { Republic }\end{array}$ & -0.54 & -0.52 & -0.50 & -0.33 & 5 & \\
\hline DRC & -1.74 & -1.82 & -1.31 & -1.98 & 34 & \\
\hline Ecuador & -0.71 & -0.39 & -0.75 & -0.75 & 14 & \\
\hline El Salvador & -0.34 & -0.48 & -0.39 & -0.75 & 12 & \\
\hline Eritrea & -0.78 & -0.19 & -0.64 & & 40 & \\
\hline Ethiopia & -1.00 & -0.27 & -0.85 & -0.98 & 47 & \\
\hline Gabon & -0.51 & -0.31 & -0.58 & -1.24 & 12 & \\
\hline Gambia & -0.32 & 0.25 & -0.61 & 0.37 & 17 & -2.25 \\
\hline Ghana & 0.16 & -0.12 & -0.17 & $-0 . \overline{47}$ & 25 & $\times 0.75$ \\
\hline Guatemala & -0.96 & -0.64 & -0.74 & -0.96 & 24 & \\
\hline Guinea & -1.09 & -1.08 & -0.81 & 0.37 & 33 & \\
\hline $\begin{array}{l}\text { Guinea- } \\
\text { Bissau }\end{array}$ & -1.26 & -1.59 & -0.71 & -0.98 & 25 & \\
\hline $\begin{array}{l}\text { Bissau } \\
\text { Guyana }\end{array}$ & -0.48 & 0.01 & -0.35 & -0.31 & 12 & \\
\hline Haitî & -1.66 & -1.23 & -1.49 & -0.98 & 17 & \\
\hline Honduras & -0.61 & -0.85 & -0.71 & -0.97 & 17 & \\
\hline India & -0.09 & -0.01 & -0.31 & -0.31 & 47 & \\
\hline Indonesia & -0.91 & -0.36 & -0.90 & -0.47 & 25 & -1.80 \\
\hline Iran & -0.83 & -0.77 & -0.59 & -0.83 & 11 & \\
\hline Jamaica & -0.32 & -0.21 & -0.52 & -0.33 & 4 & \\
\hline
\end{tabular}


Annex 11 : Additional tables and graphs

Table 3: Aggregate Indicators (Kaufmann) and Underweight Malnutrition Plates - continued

\begin{tabular}{|c|c|c|c|c|c|c|}
\hline country & BLO4 & RL96 & $\mathrm{Cc04}$ & cc96 & $\begin{array}{l}\text { W/A } \\
\text { (most } \\
\text { recent } \\
\text { dalta) }\end{array}$ & $\begin{array}{l}\text { W/A } \\
\text { annual } \\
\text { change }\end{array}$ \\
\hline Kenya & -0.98 & -0.77 & -0.89 & -1.05 & 22 & -0.40 \\
\hline Korea, North & -1.15 & -1.04 & -1.46 & -0.31 & 28 & \\
\hline Lao PDA & -1.27 & -1.36 & -1.15 & -0.94 & 40 & \\
\hline Lesolho & -0.03 & -0.31 & -0.05 & & 18 & 0.50 \\
\hline Madargascar & 0.30 & -0.85 & .0 .15 & 0.37 & 40 & -1.30 \\
\hline Malawi & -0.29 & -0.20 & -0.83 & -0.99 & 25 & -1.25 \\
\hline Malaysila & 0.52 & 0.85 & 0.29 & 0.51 & 20 & \\
\hline Maldives & -0.57 & & 0.12 & & 45 & \\
\hline Mall & .0 .34 & -0.77 & -0.52 & -0.31 & 33 & -1.40 \\
\hline Mauritania & -0.62 & -0.61 & 0.02 & & 32 & 3.0 \\
\hline Mauritlus & 0.84 & 0.71 & 0.33 & 0.48 & 15 & \\
\hline Mexico & -0.26 & -0.12 & -0.27 & -0.34 & 8 & \\
\hline Mongolia & 0.18 & 0.48 & -0.51 & 0.37 & 13 & \\
\hline Mozambicue & -0.60 & .1 .24 & -0.79 & -0.52 & 26 & \\
\hline Myanmar & -1.62 & -1.32 & -1.49 & -1.17 & 28 & \\
\hline Nepal & -0.82 & -0.36 & -0.61 & -0.28 & 48 & 0.20 \\
\hline Nicanagua & -0.65 & -0.68 & -0.34 & -0.115 & 10 & \\
\hline Niger & -0.92 & -1.25 & -0.87 & -0.31 & 41 & $-5.00^{*}$ \\
\hline Nigeria & -1.44 & -1.20 & -1.11 & -1.20 & 31 & \\
\hline Pakistan & -0.78 & -0.44 & -0.87 & -0.98 & 38 & \\
\hline Panama & 0.04 & 0.26 & -0.06 & -0.50 & 7 & \\
\hline Perul & $-0,63$ & -0.35 & -0.35 & -0.10 & 7 & \\
\hline Philippines & -0.62 & -0.11 & -0.55 & -0.40 & 32 & \\
\hline Fwanda & 0.90 & -0.19 & -0.36 & $\ldots$ & 24 & -0.75 \\
\hline $\begin{array}{l}\text { Sao-Tome \& } \\
\text { P. }\end{array}$ & -0.55 & & -0.66 & & 16 & \\
\hline Senegal & -0.20 & -0.17 & -0.40 & -0.39 & 23 & -0.71 \\
\hline Seychelles & -0.17 & & 0.01 & & 6 & \\
\hline $\begin{array}{l}\text { Sierra- } \\
\text { Leone }\end{array}$ & -1.10 & -1.02 & -0.88 & -1.66 & 27 & \\
\hline Somatia & -2.31 & -1.69 & -1.58 & -1.66 & 26 & \\
\hline South-Africa & 0.32 & 0.35 & 0.48 & 0.63 & 9 & \\
\hline SriLanka & -0.03 & 0.29 & -0.16 & -0.23 & 33 & 0.00 \\
\hline Swaziland & -0.95 & 0.40 & -0.95 & & 10 & \\
\hline Tanzania & -0.49 & .0 .70 & -0.57 & -1.03 & 29 & -0.67 \\
\hline Thailland & -0.05 & 0.49 & -0.25 & .0 .32 & 18 & \\
\hline Togo & -1.01 & -1.23 & -0.92 & -0.98 & 25 & \\
\hline Uganda & -0.79 & -0.88 & -0.71 & -0.52 & 23 & -0.60 \\
\hline Uruguay & 0.42 & 0.53 & 0.50 & 0.45 & 5 & \\
\hline Venezuela & -1.10 & $-0,66$ & -0.94 & -0.72 & 4 & \\
\hline Vietmem & -0.59 & -0.50 & -0.74 & -0.64 & 34 & -3.00 \\
\hline Zambia & -0.54 & .0 .35 & -0.74 & -0.98 & 25 & 1.00 \\
\hline Zimbabwe & -1.53 & .0 .24 & -1.01 & -0.12 & 13 & \\
\hline
\end{tabular}

Source: Kaufmann et al (2005); WHO Global Data-base (2005)

* = seasonal bias in data 


\section{Annex III. The Millennium Development Goals, Targets, and Indicators}

\section{List of goals and targets}

Goal 1. Eradicate extreme poverty and hunger

Target 1. Halve, between 1990 and 2015 the proportion of people whose income is less than one dollar a day.

1. Proportion of population below $\$ 1$ per day

2. Poverty gap ratio (incidence $x$ depth of poverty)

3. Share of poorest quintile in national consumption

Target 2. Halve, between 1990 and 2015 , the proportion of people who suffer from hunger:

4. Prevalence of underweight children (under five years of age)

5. Proportion of population below minimum level of dietary energy

consumption

Goal 2. Achileve universal primary education

Target 3 Ensure that, by 2015 , children everywhere, boys and girls alike, will be able to complete a full course of primary schooling:

6. Net enrolment ratio in primary education

7. Proportion of pupils starting grade 1 who reach grade 5

8. Illiteracy rate of 15-24-year-olds

Goal 3. Promote gender equality and empower women

Target 4. Eliminate gender disparity in primary and secondary education, preferably by 2005 , and to all levels of education no later than 2015 .

9. Ratio of girls to boys in primary, secondary and tertiary education

10. Ratio of literate females to males of 15-to-24-year-olds

11. Ratio of women to men in wage employment in the non-agricultural sector

12. Proportion of seats held by women in national parliament

Goal 4. Reduce child mortality

Target 5 Reduce by two thirds, between 1990 and 2015 , the under-five mortality rate

13. Under-five mortality rate

14. Infant mortality ratie

15. Proportion of 1-year-old children immunized against measles

Goall 5. Improve maternal health

Target 6 . Reduce by three quarters, between 1990 and 2015, the maternal mortality ratio.

16. Maternal mortality ratio

17. Proportion of births attended by skilled health personnel

Goal 6. Combat HIV/AIDS, malarla and other diseases

Target 7 . Have halted by 2015 and begun to reverse the spread of HIV/AIDS

18. HIV prevalence among 15-to-24-year-old pregnant women

19. Contraceptive prevalence rate

20. Number of children orphaned by HIV/AIDS

Target 8 . Have halted by 2015 and begun to reverse the incidence of malaria and other major diseases.

21. Prevalence and death rates associated with malaria

22. Proportion of population in malaria risk areas using effective malaria

prevention and treatment measures.

23. Incidence of tuberculosis (per 100,000 people) 
24. Proportion of fuberculosis cases detected and cured under directly obsenved treatment short course

\section{Goal 7. Ensure environmental sustainabillty}

Target 9 Integrate the princlples of sustainable development into gountry policies and programs and reverse the losses of environmental rescurces.

25. Proportion of land area covered by forest

26. Land area protected to maintain biological diversity

27. GDP per unit of energy use (as proxy for energy efficiency)

28. Carbon dioxide emissions (per capita)

Target 10 thalve by 2015 the proportion of people without sustainable access to safe drinking water.

29. Proportion of population with sustainable access to an improved water source

Targe 11. By 2020 to have achieved a significant improvement in the fives of at least 100 million slum dwellers.

30. Proportion of people with access to improved sanitation

31. Proportion of people with access to secure tenure (urban/rural)

\section{Goal 8. Develop a Globall Partnership for Development}

Target 12 . Develop further an open, rule-based, predietable, non-cliscriminatory trading and financial system

Target 13. Address the special needs of the least developed countries

Target 14 Address the special needs of landlacked countries and small island doveloping States.

Target 15 Deal comprehensively with the debt problems of developing countries through national and international measures in order to make debt sustainable in the long term:

Indicators for targets $12-15$

Official development assistance

32. Net ODA as percentage of OECD/DAC donors gross mational product

(targets of $0.7 \%$ in total and $0.15 \%$ for LDCs)

33. Proportion of ODA to basic social services (basic education, primary health care, mutrition, saie water and sanitation)

34. Proportion of ODA that is untied.

35. Proportion af ODA for environment in small istand developing stats

36. Proportion of ODA for transport sector in landlocked countries.

Market access

37. Proportion of exports (by value and excluding arms) admitted free of duties and quotas

38. Average tariffs and quotas on agricultural products and textiles and clothing

39. Domestic and export agricultural subsidies in OECD countries

40. Proportion of ODA provided to help build trade capacity

Debt sustainability

41. Proportion of official bilateral HIPC debt cancelled

42. Debt service as a percentage of exports of goods and services

43. Proportion of ODA provided as debt relief

44. Number of countries reaching HIPC decision and completion points

Target 16 , In cooperation with developing countries, develop and implement strategles for decent and productive work for youth

45. Unemployment rate of 15 to 24 year olds

Target 17 In cooperation with pharmaceutical companies, provide access to affordable essential drugs in developing countries 
Annex III: Millennium Development Goals, Targets and Indicators

46. Proportion of population with access to affordable essential drugs on a sustainable bases

Target 18 . In cooperation with the private sector, make available the benefits of new technologies, especially information and communications.

47. Telephone lines per 1,000 people

48. Personal computers per 1,000 people

Source:World Bank 2001 
Before joining the World Bank in 1996, Claudia Rokx lived and worked in the Dominican Republic where she managed a nutrition education NGO. She obtained a degree in nutrition and dietetics in Nijmegen in the Netherlands and a mastersdegree in public administration at the Open University in the Netherlands. In 2001 she started the PhD work on this dissertation with the University of Maastricht in the Netherlands.

She is currently lead health specialist for Indonesia at the World Bank. While writing this book she was senior nutrition specialist at the World Bank and responsible for the nutrition portfolio in Africa. She assisted the governments of Madagascar and Senegal in the design of the ongoing large scale nutrition programs and led the policy dialogue on nutrition in Ghana, Mauritania and the Gambia. She also led the development of the nutrition strategy for the Africa and the Eastern European and Central Asia regions for the World Bank and has authored and co-authored papers on institutional economics and nutrition and progress on the nutrition MDG. She has presented work on community-based nutrition and the World Bank at a number of international congresses and most recently in Argentina. DC.

She is married, has two sons, and lives in Washington 